MPR Reference No.: 6091-480

MATHEMATICA

Policy Research, Inc.

\title{
Kauffman Firm Survey (KFS) Third Follow Up Methodology Report
}

\section{Final Report}

July 1, 2009

\author{
David DesRoches \\ Frank Potter \\ Betsy Santos \\ Zhanyun Zhao
}

Submitted to:

Ewing Marion Kauffman Foundation 4801 Rockhill Road

Kansas City, MO 64110

Project Officer:

E.J. Reedy
Submitted by:

Mathematica Policy Research, Inc.

P.O. Box 2393

Princeton, NJ 08543-2393

Telephone: (609) 799-3535

Facsimile: (609) 799-0005

Project Director:

David DesRoches 
Electronic copy available at: http://ssrn.com/abstract=1428953 


\section{CONTENTS}

Chapter

Page

A. EXECUTIVE SUMMARY

\section{1}

B. THE KAUFFMAN FIRM SURVEY: QUESTIONNAIRE DESIGN

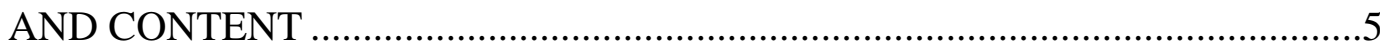

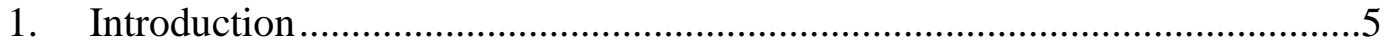

2. Third Follow-Up Questionnaire Design ..................................................6

C. SAMPLING DESIGN ........................................................................... 10

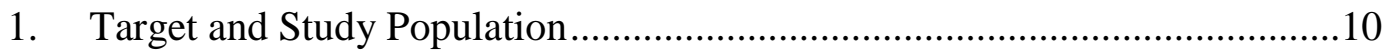

2. Sample Stratification......................................................................... 11

D. DATA COLLECTION PREPARATION .....................................................13

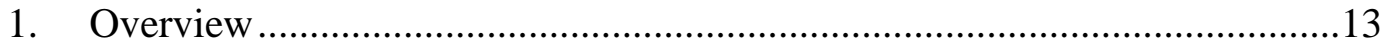

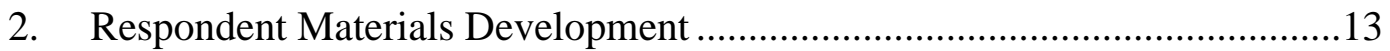

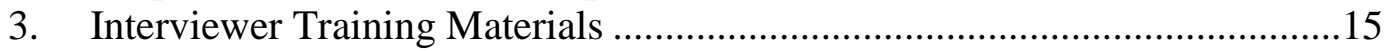

4. Survey Operations Center Staff Training...............................................16

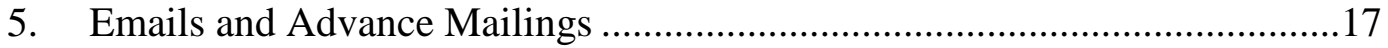

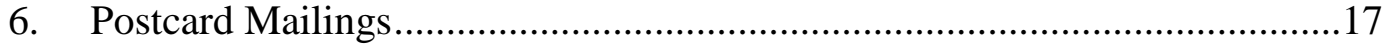

7. Response Protocols to Panel Member Inquiries ........................................18

8. Respondent Incentives ....................................................................... 19

E. DATA COLLECTION .............................................................................20

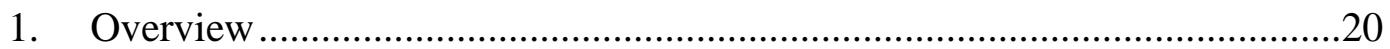

2. Timing of Sample Releases.....................................................................22

3. Schedule of Contacts to Panel Members …..................................................23

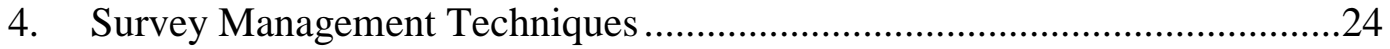

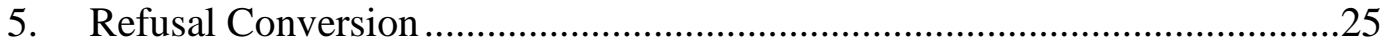

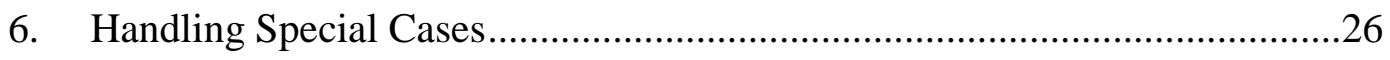

a. Owner-Name Cases....................................................................26

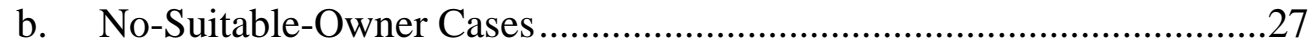

c. Web Partial Cases .............................................................................27

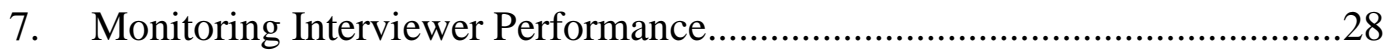

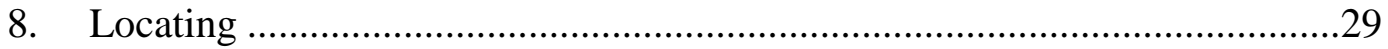

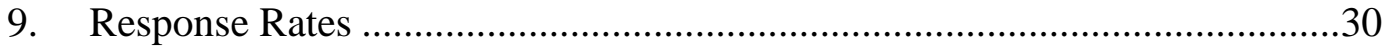

iii 


\section{CONTENTS (continued)}

E. (continued)

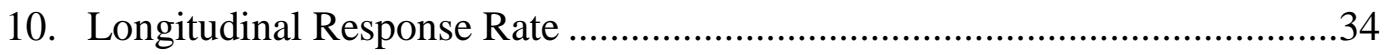

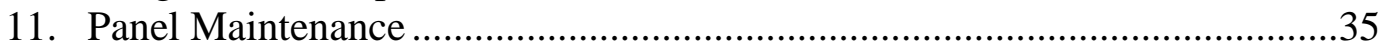

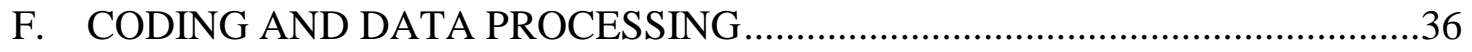

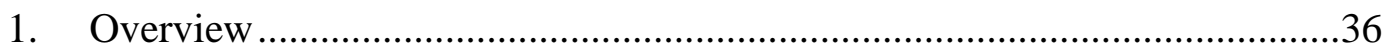

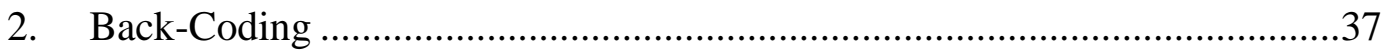

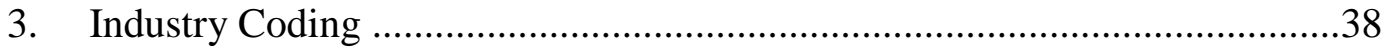

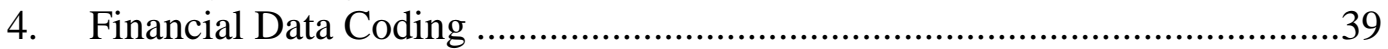

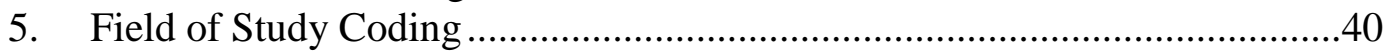

6. Quality Assurance Procedures for Coding ...............................................40

7. Data Cleaning and Frequency Review..................................................4

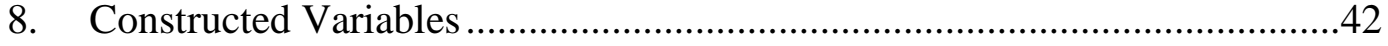

a. Financial Measures with Three Levels of Data .................................42

b. Financial Variables with Two Levels of Data ...................................43

c. Variables Summing Financial Measures...........................................43

d. Intellectual Property Measures........................................................44

9. Preparation of Codebook and Data Documentation ...................................44

10. Preparation of Public Use Data File........................................................45

G. WEIGHTING AND NONRESPONSE ADJUSTMENTS ..............................45

1. Third Follow-Up Response Analysis Summary .......................................45

2. Longitudinal Response Analysis Summary ..........................................50

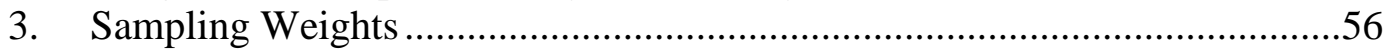

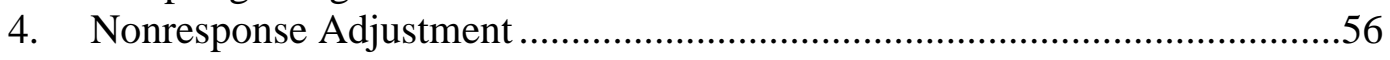

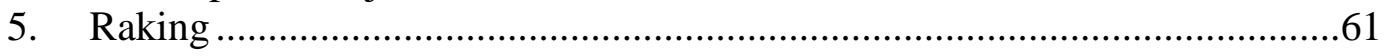

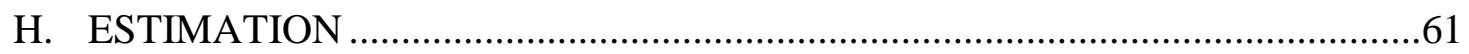

1. Point Estimation..............................................................................61

2. Variance and Interval Estimation........................................................62

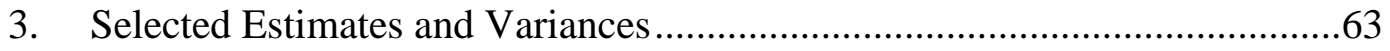

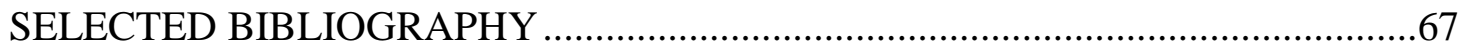


CONTENTS (continued)

APPENDIX A: KFS THIRD FOLLOW-UP QUESTIONNAIRE PROPOSED CHANGES

APPENDIX B: KAUFFMAN FIRM SURVEY THIRD FOLLOW-UP QUESTIONNAIRE

APPENDIX C: RESPONDENT MATERIALS

APPENDIX D: KAUFFMAN FIRM SURVEY THIRD FOLLOW-UP ANNOTATED QUESTIONNAIRE

APPENDIX E: DATA DOCUMENTATION MEMO 



\section{LIST OF TABLES}

$\begin{array}{lll}\text { Table Page } & \text { Pan }\end{array}$

1 KFS MILESTONES

2 ESTIMATED COUNT AND SAMPLE FOR THE THIRD FOLLOW-UP SURVEY FROM THE D\&B DATABASE: BUSINESSES THAT HAD A 2004 START DATE AND COMPLETED THE BASELINE SURVEY

3 KFS THIRD FOLLOW-UP RELEASES .27

4 WEIGHTED AND UNWEIGHTED AAPOR RESPONSE RATES FOR THE THIRD FOLLOW-UP SURVEY ACROSS TECHNOLOGY SAMPLING STRATA A .38

5 WEIGHTED AND UNWEIGHTED AAPOR RESPONSE RATES FOR THE THIRD FOLLOW-UP SURVEY ACROSS THE RESPONSE STATUS FOR FIRST AND SECOND FOLLOW-UP SURVEYS A

6 WEIGHTED AND UNWEIGHTED LONGITUDINAL RESPONSE RATESFOR THE THIRD FOLLOW-UP SURVEY ACROSS TECHNOLOGY SAMPLING STRATA A

7 WEIGHTED LOCATION AND RESPONSE RATES FOR THE THIRD FOLLOW-UP SURVEY RELATIVE TO THE BASELINE SURVEY AMONG BUSINESSES IN THE KAUFFMAN FIRM SURVEY .51

8 WEIGHTED LOCATION AND RESPONSE RATES FOR THE THIRD FOLLOW-UP SURVEY RELATIVE TO THE BASELINE SURVEY AMONG BUSINESSES IN THE KAUFFMAN FIRM SURVEY: HIGH-TECHNOLOGY

9 WEIGHTED LOCATION AND RESPONSE RATES FOR THE THIRD FOLLOW-UP SURVEY RELATIVE TO THE BASELINE SURVEY AMONG BUSINESSES IN THE KAUFFMAN FIRM SURVEY: MEDIUM-TECHNOLOGY

10 WEIGHTED LOCATION AND RESPONSE RATES FOR THE THIRD FOLLOW-UP SURVEY RELATIVE TO THE BASELINE SURVEY AMONG BUSINESSES IN THE KAUFFMAN FIRM SURVEY: NON-TECHNOLOGY 


\section{LIST OF TABLES (continued)}

Table

Page

11 WEIGHTED LONGITUDINAL RESPONSE RATES FOR THE FIRST, SECOND AND THIRD FOLLOW-UP SURVEYS RELATIVE TO THE BASELINE SURVEY AMONG BUSINESSES IN THE KAUFFMAN FIRM SURVEY

12 WEIGHTED LONGITUDINAL RESPONSE RATES FOR THE FIRST, SECOND AND THIRD FOLLOW-UP SURVEYS RELATIVE TO THE BASELINE SURVEY AMONG BUSINESSES IN THE KAUFFMAN FIRM SURVEY: HIGH-TECHNOLOGY. .58

13 WEIGHTED LONGITUDINAL RESPONSE RATES FOR THE FIRST AND SECOND FOLLOW-UP SURVEYS RELATIVE TO THE BASELINE SURVEY AMONG BUSINESSES IN THE KAUFFMAN FIRM SURVEY: MEDIUM-TECHNOLOGY

14 WEIGHTED LONGITUDINAL RESPONSE RATES FOR THE FIRST AND SECOND FOLLOW-UP SURVEYS RELATIVE TO THE BASELINE SURVEY AMONG BUSINESSES IN THE KAUFFMAN FIRM SURVEY: NON-TECHNOLOGY

15 DESCRIPTIVE STATISTICS OF INITIAL SAMPLING WEIGHT FOR THE THIRD FOLLOW-UP SURVEY

16 SUMMARY OF NONRESPONSE MODELS FOR THE THIRD FOLLOW-UP SURVEY WEIGHTS.

17 SUMMARY OF NONRESPONSE MODELS FOR THE LONGITUDINAL WEIGHTS FOR THE FIRST, SECOND, AND THIRD

FOLLOW-UP SURVEYS

18 VARIANCE ESTIMATION FOR SOME BUSINESS AND OWNER CHARACTERISTICS 


\section{A. EXECUTIVE SUMMARY}

Although entrepreneurship is crucial to a capitalist economy, little information is available about U.S. businesses in their first years of operation. As part of an effort to gather more data on new businesses in the United States, the Ewing Marion Kauffman Foundation sponsored the Kauffman Firm Survey (KFS), a panel study of businesses founded in 2004 and tracked over their first years of operation. The KFS collects data about the nature of new business formation; the characteristics of the strategy, offerings, and employment patterns; the nature of the financial and organizational arrangements of these businesses; and the characteristics of those who own and operate them. With the completion of the Third Follow-Up, the KFS has collected this information from the panel of diverse businesses over four years, providing a unique look at business dynamics over this formative period.

Summary of KFS Sample Design. MPR created the panel by using a list frame sample of new businesses selected from the Dun \& Bradstreet Corporation (D\&B) database. In 2005, we received from $\mathrm{D} \& \mathrm{~B}$ two sampling frames containing a total of roughly 250,000 businesses started in 2004. From these lists, we selected a Baseline Survey sample (conducted starting in 2005 and completed in 2006), which we screened for eligibility and recruited into the study. In response to the Foundation's interest in understanding the dynamics of high-technology and woman-owned businesses, the sample design for the KFS oversampled high-technology businesses (based on industry designation), and kept business ownership by gender consistent across all sample strata. Rather than a sample of new business founders, the unit of analysis for the KFS design is the sampled business, so that if the same business changed ownership from one reporting period to another, it would remain in the sample.

Questionnaire Design. Prior to the Baseline Survey, MPR conducted extensive questionnaire design, which is documented in the KFS Baseline Methodology Report 
(DesRoches et al. 2007). The design issues included establishing consistent definitions of what constituted the start of a new business, as well as testing the most efficient methods for collecting data from sampled businesses. The Baseline questionnaire contained a core set of questions that were repeated in future follow-ups.

The core questions repeated for the follow-up surveys focused on business characteristics, strategy and innovation, business structure and benefits, financing, and demographics of the owner-operators, which enabled us to track changes to how businesses obtain operating funds and perform over the first few years of operations. In contrast to the previous follow-up surveys conducted in 2006 and 2007, which included few changes to the questionnaire, the Foundation sought to add to the Third Follow-Up questionnaire new modules of questions that could enhance the usefulness of the data. A request for proposals that sought new areas of inquiry was issued in late 2007 to researchers studying entrepreneurship and innovation. These proposals were evaluated by the Foundation and MPR, and ultimately four sets of questions were added to the Third Follow-Up questionnaire.

Because sample attrition is a consistent challenge, we sought during the Third Follow-Up to shorten and refine the questionnaire so as to minimize respondent burden. This included having panel members simply confirm certain information gathered during previous rounds (rather than collect it again) and collecting new data only if the situation of the business had changed. Another strategy collected demographic information only from new owner-operators or from owner-operators for whom we did not already have it.

Third Follow-Up Survey Data Collection. Since the Baseline Survey had established eligibility for all the businesses in the panel, the only eligibility criterion for the 4,295 included in the Third Follow-Up was whether the business was still in operation. Specifically, the remaining businesses were those that completed the Baseline Survey $(4,928)$, minus those 
identified as permanently out of business during the First and Second Follow-Ups (633). Businesses identified as temporarily out of business in the previous follow-ups were included in the Third Follow-Up sample in case they had resumed operations since the previous interview.

As in previous rounds, panel members were contacted initially by email and invited to complete the KFS web survey. Those businesses without email addresses, or those who did not respond to the initial message, were sent an invitation through U.S. mail. As in prior waves, respondents were offered a post-paid $\$ 50$ incentive for completing the Third Follow-Up. Among the remaining eligible businesses, 2,915 interviews were completed, which resulted in a weighted response rate of 83 percent. As in the two previous follow-up surveys, most interviews were completed on the web (65 percent), the rest (35 percent) through computer-assisted telephone interviewing (CATI).

Data Processing and File Production. To ensure the highest-quality data possible, we used rigorous coding, data cleaning, and MPR's quality assurance (QA) methods when processing data collected during the Third Follow-Up. MPR staff performed the following steps to ensure that we delivered a clean data file:

- Examined the open-ended responses and, where possible, "back-coded" (moved responses placed in "other-specify" fields into fields that matched one of the prelisted response categories for the question).

- Coded the open-ended responses to the question on "primary industry of the business," using the North American Industry Classification System (NAICS) taxonomy.

- Coded the open-ended responses to a new question on respondents' field of study using the Classification of Instructional Programs (CIP) taxonomy.

- Reviewed answers to financial questions for consistency and corrected any obvious instances of double-counting of equity or debt amounts.

- Added constructed variables to the data set to facilitate analysis.

- Produced documentation to accompany the data file, including (1) a copy of the questionnaire, with related variable names listed next to the questions; and (2) a 
memo listing the data source for variables not found in the questionnaire and describing the constructed variables.

- Combined the Third Follow-Up data set with the data collected during the three previous rounds to create longitudinal files for both public and restricted use.

Weighting and Nonresponse Adjustments. MPR statisticians adjusted the set of sampling weights and nonresponse adjustments developed during the Baseline Survey and refined after the First and Second Follow-Ups. These weights were then applied to the businesses in the Third Follow-Up panel. As a result of oversampling businesses in high-technology industries, a weighting factor (the inverse of the probability of selection) was required so that estimates collected during the data collection would reflect the true population based on the full D\&B frame. The nonresponse adjustments to the weights were applied to account for those businesses that could not be contacted or interviewed. Using logistic propensity modeling and chi-squared automatic interaction detector (CHAID) analysis, MPR statisticians developed these adjustments for the final set of sampling weights. The final weights and adjustments were added to the longitudinal data file. 


\section{B. THE KAUFFMAN FIRM SURVEY: QUESTIONNAIRE DESIGN AND CONTENT \\ 1. Introduction}

The KFS is a unique research program dedicated to advancing understanding of the early years of new-business development. This goal has broad implications for the U.S. economy, since entrepreneurship plays a major role in the economic growth of the country, and accurate information about the development and sustainability of new businesses is essential to the design of public and private programs to encourage their creation. The KFS is also special because of the design and implementation obstacles that were overcome to produce these data. Accurate information about new businesses is not easy to obtain, and few previous surveys collected data on the dynamics of business development, since longitudinal surveys of new businesses often experienced serious sample attrition. Obtaining cooperation from owners of new businesses also made this type of survey difficult to implement, which resulted in low response rates. Such surveys have faced the added complexity of defining exactly what constitutes a new business and precisely when its operations begin, concepts that lend themselves to subjectivity if they are not carefully defined. To address these related informational and methodological challenges, and as part of its commitment to advancing entrepreneurship and studying the creation and development of new businesses, the Foundation contracted with MPR to conduct the KFS. Table 1 provides the key milestones of the project. Further information on the design and initial rounds of KFS data collection are available in the KFS Baseline methodology report (DesRoches et al. 2007), the First Follow-Up methodology report (DesRoches et al. 2008), and the Second Follow-Up methodology report (DesRoches et al. 2008). 
TABLE 1

KFS MILESTONES

\begin{tabular}{ll}
\hline Date & \\
\hline March 2004 & Project awarded to MPR \\
June 2004 & $\begin{array}{l}\text { Principal investigator designated } \\
\text { Received first D\&B database file }\end{array}$ \\
August 2004 & Pilot Test 1A—initial screening criteria \\
& Pilot Test 1B-additional screening criteria \\
& In-person developmental interviews \\
& Meeting in Washington, DC, to review sample design and \\
& questionnaire development status \\
& Questionnaire Review I-Draft of eligibility screening and \\
financial section of questionnaire sent to technical advisors & Questionnaire Review II-Complete draft questionnaire prepared \\
to send to technical advisors & Pilot Test 2-Sample test; full questionnaire test; 400 completed \\
interviews & Received second D\&B database file \\
January-March 2005 & KFS Baseline data collection; 4,928 completed interviews \\
November 2005 & KFS First Follow-Up data collection; 3,998 completed interviews \\
July 2005-July 2006 & KFS Second Follow-Up data collection; 3,390 completed \\
June 2006-January 2007 & interviews \\
May-December 2007 & KFS Third Follow-Up data collection; 2,915 completed interviews \\
June-December 2008 & \\
\hline &
\end{tabular}

\section{Third Follow-Up Questionnaire Design}

As part of its initial KFS questionnaire design, MPR developed a core set of questions to be asked annually of sampled businesses. Consequently, only minor adjustments were made to the First and Second Follow-Up questionnaires. Prior to the Third Follow-Up Survey, however, the Foundation issued a request for proposals to users of the KFS data and researchers in the entrepreneurship and innovation fields for modules of questions that could complement and 
enhance the KFS data. Four sets of questions were submitted to the Foundation, and MPR evaluated these potential additions using several criteria: (1) the relevance and appropriateness of the topic area for the KFS panel, (2) the extent to which adding these questions would create excessive respondent burden, and (3) issues involved in administering the questions as submitted. This evaluation of the submitted questions is included as Appendix A. Ultimately, several new questions were included in the Third Follow-Up Survey, and these are described (along with the core KFS questions) below.

Questionnaire development for the Third Follow-Up Survey began in December 2007, and in March 2008 we pretested the new survey content on a convenience sample of 6 businesses. Questionnaire development was completed in April 2008. The final questionnaire consisted of seven sections, each of which is described below.

Section A: Introduction. This section introduced the study, the sponsor, and MPR as the organization conducting the study. It also verified that the correct business was reached and was still in operation. Section A also ensured that the respondent for the business (most often the respondent during the Second Follow-Up Survey) was an owner and operator of the business. Because the financial questions were quite detailed, it was important to identify a person sufficiently knowledgeable about the finances to provide accurate information. Therefore, this part of the questionnaire identified a current owner who was also involved in the day-to-day operations. However, since the respondent for the business could change from one survey round to the next, a mechanism for designating a new respondent was included in the section. Finally, the business address was confirmed. If respondents reported that the business had ceased operations, we asked the reason for the closing, whether the business had filed for bankruptcy, and in what calendar year the business closed. 
Section B: Eligibility Screening. As with the previous follow-ups, there was no Section B, since business eligibility was established during the Baseline Survey.

Section C: Business Characteristics. The respondent was asked to confirm the legal status and primary industry description, which were pre-filled from previous rounds. If either was incorrect or had changed since the last interview, the respondent was asked for updated information. Other data collected in this section included the names of other owner-operators and the number of both full- and part-time employees. This section also asked about the type of location from which the business operates, reasons for any changes in location since the last interview, whether the business had opened another location, the number of locations the business operated in, and in what month and year the business opened any additional location.

Section D: Strategy and Innovation. This section included questions about whether the business offered a product or a service and whether the respondent believed that the business had a competitive advantage. A new series of questions, added in the Third Follow-Up, explored the competitive advantage the business had in terms of any teaming arrangements or intellectual property. Respondents were also asked whether the business owned or licensed any intellectual property, such as patents, copyrights, or trademarks, as well as whether they "licensed in" any intellectual property. Respondents were asked a series of questions about sales, such as whether the business had any sales during 2007 and what the percentage distribution was of such sales to individuals, government, and other businesses. New questions asked about the proximity of most customers to the business, the presence and percentage of international sales, and the presence and percentage of internet sales in calendar year 2007.

Section E: Business Organization and Human Resource Benefits. This section included questions about the number of employees who performed various functions within the business 
and the types of benefits offered. The questions about benefits for full- and part-time employees were asked separately.

Section F: Business Finances. The business finances section was the focus of the questionnaire. Topics included:

- Equity investment by owner-operators into the business in 2007

- Total equity investment by owner-operators over the life of the business

- Withdrawals of cash from the business by owner-operators in 2007

- Percentage of ownership by each owner, for multiple-owner businesses

- Sources and amount of debt financing by the business and its owners

- Amount of revenue, if any, the business received in 2007

- Total expenses incurred by the business in 2007

- Total expenses spent on salary and wages

- Profit or loss during 2007

- Types of assets and liabilities and their estimated value

In addition to these core financial questions, new questions were added, including:

- Applications for new or renewed loans or lines of credit in 2007

- Approval or denial of credit applications, and the reason for the most recent denial

- Whether applications for needed capital were not filed due to fear of denial

- Amount of research and development expenses in 2007

Section G: Work Behaviors and Demographics of Owner(s). This section collected demographic and other information on the owner-operators. Respondents were asked whether they were paid employees and how many hours they worked in an average week. They were also asked how many years of experience they had in the industry of the new business and whether they had started other new businesses. The rest of this section collected basic demographic characteristics on the owner-operators, such as age, gender, race, education level, and 
U.S. citizenship. For multiple-owner businesses, respondents were asked these questions about themselves and then about each of the other owner-operators. Added to Section G was a new question that collected the field of study for the respondent's highest degree.

Finally, contact information was updated for future follow-up surveys. This included the name, address, phone number, and email address of someone to contact if we were unable to reach the business for the next follow-up. It also asked for an email address of the respondent and a website for the business. The name and address of the person to whom the incentive check would be sent was also recorded. At the conclusion of the interview, the respondent was thanked and told that the incentive check would be sent in two or three weeks. The final Third Follow-Up Survey questionnaire is in Appendix B.

\section{SAMPLING DESIGN}

\section{Target and Study Population}

For the Baseline Survey, the target population was all new businesses started in calendar year 2004 in the United States (including the District of Columbia). The baseline target population includes any new, independent business that was created by a single person or a team of people, or was the purchase of an existing business or a franchise, and excludes any branch or subsidiary owned by an existing or inherited business. As discussed in the Baseline Survey methodology report, the study population was further defined by the source of the sampling frame: the D\&B database, which we chose because it is among the largest commercial lists available and offers information on linkages among establishments within enterprises (or businesses). In the Baseline Survey methodology report (DesRoches et al. 2007), we also discussed the screening process in the Baseline Survey to identify businesses that "started" in 2004. 
For the Third Follow-Up Survey, the target population was the same as for the First and Second Follow-Up: all new businesses that (1) started in year 2004, and (2) met the survey eligibility criteria. The study population (as described above) was a subset of the target population in that the businesses had to have been listed in the D\&B database with a start date of 2004. The Third Follow-Up Survey sample included all businesses that met the survey criteria and completed the Baseline Survey. In the Baseline Survey, the businesses that were refusals or unlocatable were possibly in operation after the initial year and are therefore part of our target population. The nonresponse adjustment procedures used on the weights for the Baseline Survey sample compensated for these refusals. Therefore, the Third Follow-Up Survey sample includes only eligible businesses from which we obtained complete data in the Baseline Survey, and this was the same sample we used in the First and Second Follow-Up. Specifically, businesses that did not respond to the First or Second Follow-Up Surveys were thus still included in the sample. Businesses that were identified as permanently out of business in the First or Second Follow-Up Surveys were also treated as out of business in the Third Follow-Up. The only difference between the Third and the previous Follow-Up Surveys is that businesses that were temporarily out of business in the First or Second Follow Up Surveys were given another chance in the Third Follow-Up Survey to complete the interview, though nearly 60 percent of them turned out to be permanently or temporarily out of business as well.

\section{Sample Stratification}

For the Baseline Survey, the D\&B database was our source file for the sampling frame. We partitioned the file into six sampling strata defined by three industrial technology categories 
(based on industry designation ${ }^{1}$ ) and gender of the owner or CEO of the business (based on the data element in the D\&B database and additional information; see DesRoches et al (2007) for details). In Table 2, we provide the estimated population count and sample count of businesses that met the survey eligibility criteria for each stratum.

TABLE 2

\section{ESTIMATED COUNT AND SAMPLE FOR THE THIRD FOLLOW-UP SURVEY FROM THE D\&B DATABASE: BUSINESSES THAT HAD A 2004 START DATE AND COMPLETED THE BASELINE SURVEY}

\begin{tabular}{lccc}
\hline $\begin{array}{l}\text { Technology } \\
\text { Sampling Strata }\end{array}$ & $\begin{array}{c}\text { Woman-Ownership } \\
\text { Sampling Strata }\end{array}$ & $\begin{array}{c}\text { Estimated Number of New } \\
\text { Businesses in 2004 }\end{array}$ & $\begin{array}{c}\text { Sample for Third } \\
\text { Follow-Up Survey }^{\mathrm{b}}\end{array}$ \\
\hline Total & & $\mathbf{7 3 , 2 7 8}$ & $\mathbf{4 , 9 2 8}$ \\
\hline High-technology & Yes & 1,313 & 705 \\
& No & 190 & 103 \\
Medium-technology & & 1,123 & 602 \\
& Yes & 9,675 & 1,329 \\
No & 2,026 & 271 \\
& & 7,649 & 1,058 \\
& Yes & 62,290 & 2,894 \\
& No & 14,366 & 513 \\
\hline
\end{tabular}

${ }^{a}$ The estimated number of businesses is the weighted count of eligible responding businesses having a start date of 2004 and meeting the new-business-screening criteria (see DesRoches et al. 2007).

${ }^{\mathrm{b}}$ The sample count for the Third Follow-Up Survey included businesses that were determined to be permanently out of business, temporarily out of business, or refusals in the First or Second Follow-Up. Attempts were made to contact the refusals and the temporarily out of business from the prior follow-up surveys, but not the permanently out of business.

${ }^{1}$ The technology categories are based on the designation identified by the businesses' Standard Industry Classification (SIC) code, developed in the early 1990s by researchers from Bureau of Labor Statistics. For details, see Paul Hadlock et al. "High Technology Employment: Another View." Monthly Labor Review, July 1991, pp. 2630. 


\section{DATA COLLECTION PREPARATION}

\section{Overview}

Preparation for the Third Follow-Up data collection generally followed the procedures used for the two previous follow-ups. In an effort to minimize KFS panel attrition, data collection materials, training manuals, and interviewer training continued to stress retention. Most of the Third Follow-Up panel members had completed the Second Follow-Up Survey (3,390 of 4,295, or 79 percent). Of the 903 who had not responded at the Second Follow-Up, 451 had not completed either of the first two follow-up surveys. We anticipated greater difficulties completing these cases given the length of time since last contact. Even though most panel members were likely to remember the study, we expected a somewhat lower response rate due to panel fatigue and the fact that a fifth of the businesses had not responded to one or both of the previous follow-ups. The data collection plan, as in previous rounds, started with an email alerting panel members to the web survey. Additional contacts included email reminders, an advance letter mailing, and postcards, followed by CATI for those not completing the web survey.

\section{Respondent Materials Development}

The goal for the Third Follow-Up Survey was to retain as many as possible of the 4,295 businesses remaining in the KFS panel. Our focus was to remind the panel members of their previous participation, repeat the information about the $\$ 50$ incentive and the promise of strict confidentiality, stress the importance of the longitudinal nature of the study, and urge continued participation. We emphasized that their previous participation meant that the selection process was over and that we could not replace their business with another.

Another point of emphasis in the materials sent to panel members in previous rounds was the "Kauffman Firm Survey" title, which was included in all materials sent to respondents and 
served as the first part of the email subject line. It had also been printed on all respondent gifts provided with the panel maintenance packets in the previous rounds. Our goal was to continue to "brand" the Kauffman Firm Survey name to increase recognition among panel members.

In keeping with MPR's QA policies, draft survey materials for the Third Follow-Up Survey were reviewed by a senior MPR staff member outside the project. After comments from the reviewer were incorporated, the materials were sent to MPR's editing department. Project staff finalized the edited versions before the survey director approved them for use in data collection.

The survey materials included:

- Email Message. We had collected email addresses at the end of each of the previous surveys, and we had email addresses for 83 percent of Third Follow-Up panel members. The initial survey contact was an email message to panel members who had provided an email address.

The email message reminded them of their previous participation, informed them that we could not replace their business with another, and explained why we were doing the fourth year of the study. This message included their unique web login and password, as well as an easy "click-through" (pre-filled login and password) to the website to participate in the study. This procedure greatly reduced respondent errors during login and facilitated completion of the questionnaire. The email message also provided contact information for MPR staff in case of questions.

- Reminder Email. This was sent as a brief reminder to panel members who had not completed the web survey one week after the initial email message. This message also included the same web login and password information and "click-through" to the website as the initial email message.

- Advance Letter. The advance letter was the first contact with Third Follow-Up panel members who had not provided an email address in any of the previous rounds. It was similar to the email message, but provided additional information about the study, asked for cooperation, and provided web login information. And like the email message, it provided contact information for MPR staff.

- Frequently Asked Questions (FAQs). This one-page document provided answers to some questions panel members were likely to have about the survey, MPR, and the Foundation. This was also included with the advance letter.

- Reminder Postcard. The postcard was sent as a reminder to panel members who had not completed the web survey one week after the advance letter mailing. It listed the website URL and encouraged respondents to $\log$ on and complete the survey. 
Because of confidentiality concerns, the postcard omitted the login and password, but it did include the project helpline to call for this information.

- Refusal Letter. This letter was sent to respondents who had refused to participate in the survey after being contacted by telephone, or who had refused through email or a call-in. It was the first effort at refusal conversion.

Copies of these data collection materials are in Appendix C.

\section{Interviewer Training Materials}

Modifying the Second Follow-Up materials as needed, project staff developed a set of training materials for the Third Follow-Up. These materials focused on issues we expected to encounter during the Third Follow-Up, such as how to designate a new respondent for the business if the Second Follow-Up respondent was no longer there or was unavailable during the data collection period, or if the business had not responded to one or more of the previous follow-ups. As noted in Section B, the instrument was designed to encourage the Second FollowUp respondent to answer in the Third Follow-Up, assuming the person was still an owner and operator of the business. For businesses not responding to the Second Follow-Up, or in cases where that respondent was no longer with the business, previous respondents or others in the business who could complete the interview were prioritized as follows:

- First Follow-Up respondent

- Baseline Survey respondent

- Any owner-operators present with the business at Baseline

- Any new owner-operators identified during the First Follow-Up interview

- Any new owner-operators identified during the Second Follow-Up interview

- Any new owner-operators identified during the Third Follow-Up interview

Interviewers were trained to follow this priority if the Second Follow-Up respondent was not available or the business was a nonrespondent to that round. The training materials were updated 
using the experiences from previous rounds to reflect the slight differences in the survey instrument.

The telephone interviewer training manual contained information about the following topics:

- The background of the study

- Eligibility criteria for respondents

- The importance of confidentiality

- The procedures for contacting panel members

- Procedures on scheduling appointments and requesting new letters or emails

- Dealing with privacy managers and cell phones

- Building effective engagement and rapport with panel members

- Refusal avoidance and conversion

- Strategies for handling "gatekeepers"

- Question-by-question review of the entire survey instrument

\section{Survey Operations Center Staff Training}

The telephone interviewing staff included both those who had worked on previous rounds of the KFS and those new to the project. All interviewers attended the full KFS training session regardless of their prior experience on the project. The training was conducted over 12 hours, in two 4-hour "classroom" segments and 4 hours of "hands-on" practice with the CATI survey. Emphasis was placed on the importance of the initial contact, introducing the study effectively, and moving directly into the interview. The hands-on practice consisted of paired "mock" interviews, where one trainee played the role of respondent and the other played the interviewer. To ensure that each pair of interviewers had the same experiences, project staff developed detailed mock scripts for the "respondents" based on experiences from previous rounds of data collection. Part of this practice involved "engagement scenarios," in which pairs of interviewers 
alternated between the respondent and the interviewer roles, but this time the focus was on overcoming objections and answering the questions that panel members were most likely to ask.

\section{Emails and Advance Mailings}

As noted in Section 2 above, the first contact made with 83 percent of the Second FollowUp sample was the email message. For those without email addresses (and for those whose email bounced back), the first notice of the survey was the advance letter.

Both the advance letter, printed on MPR's letterhead, and the initial email briefly introduced the study, reminded the business owner of the previous rounds, and asked for participation in the Third Follow-Up. They also supplied the project's toll-free number, website URL, email address, and contact information to offer panel members the option of contacting MPR if they had further questions or if they preferred to call in to complete the survey or make an appointment to do so. Before each mailing was delivered to the post office, MPR inspected 10 percent of the packets for consistency and accuracy.

\section{Postcard Mailings}

One week after the advance mailing, a reminder postcard was sent to each sampled business that had not yet completed the web questionnaire. The postcard included the name of the owner and the name and address of the business. An overview of the study, the website URL, and MPR contact information were also provided, and panel members were encouraged to contact MPR if they had lost or forgotten their password or login ID. The postcard labels were generated through MPR's Sample Management System (SMS). Before being mailed, postcards were also inspected for consistency with U.S. postal standards. 


\section{Response Protocols to Panel Member Inquiries}

Prompt and efficient handling of inquiries from panel members helps establish rapport and thus increases the chances that they will complete the survey. As in previous rounds of the KFS, panel members in the Third Follow-Up could contact MPR through several avenues:

- Toll-free telephone number

- KFS email

- Project staff telephone numbers

The toll-free number was monitored by MPR's trained "help desk" staff during business hours. A panel member could call in to complete the questionnaire on the telephone or make an appointment to have an interviewer call back and administer it. Another important function of the toll-free number was to provide the login ID and password to panel members who wanted to complete the web survey but had misplaced that information. Help desk staff were trained to identify each caller through a look-up file to make sure the person was indeed an owner of the sampled business. The survey director's phone number was also provided in case help desk staff could not answer all the questions a panel member posed.

Some panel members and gatekeepers who were called requested that an email message be sent with information explaining the survey and how to participate. The email that was sent in response to such requests was the same one used in the initial email and the reminder email. It included the panel member's password, login ID, and URL for the web survey.

Some panel members also emailed with questions about the study, explanations about their businesses, or refusals. In the period after email invitations had been sent to panel members, MPR staff monitored the KFS project mailbox seven days a week in order to respond to questions promptly. Responses were usually emailed within 24 hours of initial receipt of a panel 
member's email. When a panel member refused through email, staff would attempt a refusal conversion by addressing the stated reason, such as the amount of time the questionnaire would take to complete, and explaining the importance of the study.

\section{Respondent Incentives}

We offered panel members $\$ 50$ to complete the Third Follow-Up (whether on the web or through CATI), the same amount as in the previous rounds. The incentive was offered not as a payment for the panel members' time but rather as a "token of appreciation" for participation. We made this distinction because if the money was presented as compensation for their time, some owners might think the payment insufficient and refuse to participate. Instead, the incentive was presented as an honorarium, or a way of recognizing the owner's contribution to the success of the study.

KFS incentive checks were mailed weekly to ensure that respondents received them promptly. Payments returned to MPR without forwarding information were sent to MPR locating specialists for address updating. Each check was then reissued and sent to the new business location. If a check was returned with forwarding information, the panel member information was updated in the MPR SMS, and the check was reissued.

During the Third Follow-Up data collection, a few panel members indicated that they did not recall having received their $\$ 50$ payment for participation in one of the previous rounds. In all these cases, we determined that MPR had indeed sent the check to the respondent, although most had not been cashed. In these instances MPR staff would call or email back that the check had been sent but had not been cashed. We would then verify the address and send a new check. Some panel members wanted to receive their check from the previous round before they completed the Third Follow-Up Survey. MPR staff made sure that these panel members were contacted to complete the Third Follow-Up within a week of being sent the replacement check. 


\section{E. DATA COLLECTION}

\section{Overview}

Data collection on the Third Follow-Up Survey closely mirrored that of the Second FollowUp. Overall, the study continued to be successful in retaining panel businesses, achieving a response rate of 83 percent (weighted). We were also successful in slightly increasing the percentage of respondents who completed the web survey (65 percent in the Third Follow-Up compared to 63 and 59 percent in the Second and First Follow-Ups, respectively). Figure 1 illustrates the data collection process for the Third Follow-Up. 
FIGURE 1

\section{KAUFFMAN FIRM SURVEY THIRD FOLLOW-UP DATA COLLECTION PROCESS}

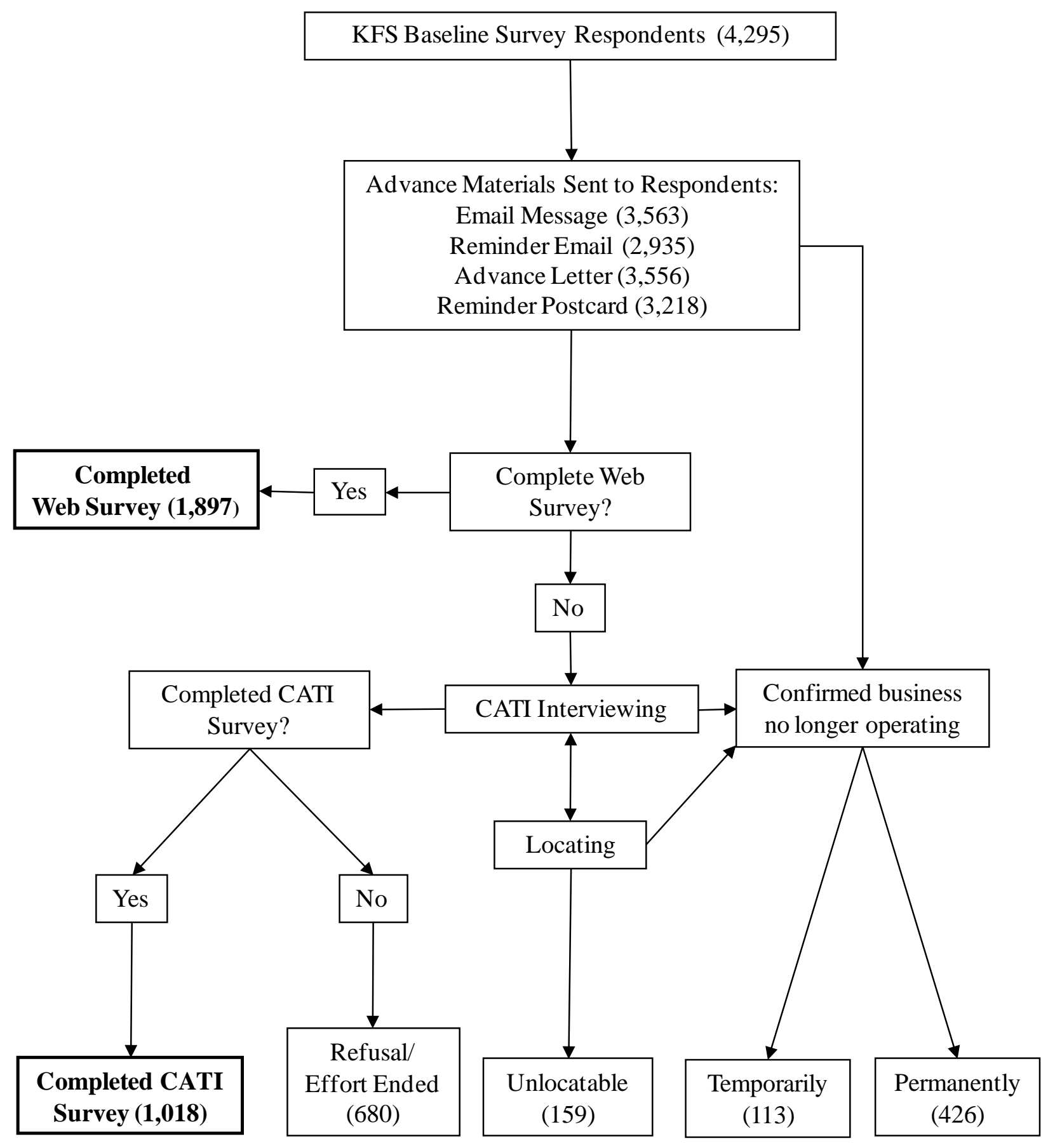




\section{Timing of Sample Releases}

Data collection began on June 24, 2008, and concluded on December 23, 2008. There were three separate batches of Third Follow-Up sample (dates and sample sizes are in Table 3). Each batch or "release" began with an email message to panel members.

Although the web and CATI instruments were thoroughly tested before data collection began, the first sample release was deliberately small to permit a live test of the instrument and the systems involved in recording completes and refusals and in generating mailings.

\section{TABLE 3}

\section{KFS THIRD FOLLOW-UP RELEASES}

\begin{tabular}{lcc}
\hline Sample Release & Release Date & Sample Size \\
\hline 1 & $6 / 24 / 2008$ & 177 \\
2 & $7 / 9 / 2008$ & 1,821 \\
3 & & 2,297 \\
\hline Total & & $\mathbf{4 , 2 9 5}$ \\
\hline
\end{tabular}

The initial email message displayed the subject line "Kauffman Firm Survey-Round 3." The reminder email had the same text as the initial email. For all but the first release, the emails were sent out over two days to prevent triggering various spam filters. This also spread out the web response to avoid overloading the server and preventing some panel members from being able to $\log$ in. Of the advance emails, 14 percent (492) bounced back as undeliverable. Project staff examined email bouncebacks for obvious misspellings or other problems, corrected 106 and re-sent the email messages to the updated address. As in the previous rounds, MPR project staff conducted daily testing of the KFS website just before sending batches of emails.

In addition to bouncebacks from emails, some of the U.S. Postal Service addresses to which the advance mailing was sent were not accurate, and the materials were returned. When the returned mail included an updated address, this was recorded in the MPR SMS, and the materials 
were re-sent. When there was notification of "no such address," the existing address was recorded as inaccurate to prevent any re-mails, and that panel member case was sent to locating staff to search for the new address.

\section{Schedule of Contacts to Panel Members}

As mentioned above, 83 percent of business owners received their first contact about the Third Follow-Up through an email message. One week later, the advance letter was sent to all businesses that had not completed the web questionnaire. For the businesses that had not provided an email address, or whose email address had changed or expired, this was the first contact about the Third Follow-Up Survey. One week following the advance letter, we sent a reminder postcard. A week after this reminder, CATI operations began. We spaced these initial contacts as we did so that panel members would have time to log on to the web and complete the survey before CATI follow-up began, thus minimizing CATI costs. About 23 percent of panel members had completed by web before CATI operations began, which was less than during the Second Follow-Up (31 percent).

During CATI follow-up, MPR's call scheduler program provided the panel member contact information needed by interviewers to make telephone contact. This scheduler assures that callbacks are conducted at the appropriate time, and that telephone attempts that do not result in contact, such as answering machines and "no answers," are recontacted on different days of the week, at different times of the day and evening, and on weekends. An answering machine message tailored specifically to the KFS was also left at periodic intervals. These intervals were designed to avoid irritating the panel member, and they also gave the panel member time to respond to the message before the next call. Cases with wrong numbers, and those with a series of no contacts, were sent to locating for updating. Along with setting scheduler parameters, 
sending emails on request, and following other procedures, a variety of additional steps helped make CATI more efficient.

\section{Survey Management Techniques}

Survey management is designed to make CATI as efficient as possible by scheduling, monitoring, and evaluating the survey procedures. One of the most important aspects of efficient interviewing is properly matching the available sample and interviewer hours, so that panel members are called shortly after they receive the advance materials. To this end, project staff coordinated training schedules and sample releases with interviewer schedules. This coordination helped to ensure that interviewer hours were highest when new sample was released, so that the initial telephone contact with the panel members took place at the most opportune time. Project staff conducted weekly reviews of interviewer productivity, cooperation rates, calls per hour, and monitoring reports.

Although we achieved a high response rate in the Third Follow-Up, many businesses either were still reluctant to participate or put off completing the questionnaire. As in most surveys, the final 10 percent of completes took considerably more resources than the first 90 percent. As the Third Follow-Up Survey was coming to an end, the remaining nonresponding panel members had been provided multiple opportunities to respond. They had been contacted, and interviewers had made their best attempts to complete the interview with them. To maximize the response rate, KFS project staff implemented the following steps for nonrespondents:

- Sending a series of email messages indicating that the study was coming to an end and that their time for participation was limited. This email also stressed that we had already received responses from a sizable percentage of panel members.

- Sending an additional letter to pending cases, emphasizing that the project needed their participation, reminding them of the $\$ 50$ incentive and their previous participation, and asking them to complete the questionnaire. The envelope also contained a $\$ 5$ bill as a pre-incentive. 
- Adjusting interviewer schedules to ensure that cases in the Pacific Time zone received sufficient call coverage.

- Developing a special answering machine message to replace the initial one, indicating that the study was ending and that this was the last opportunity to participate.

After these efforts were made, data collection on the Third Follow-Up Survey ended on December 23, 2008.

\section{Refusal Conversion}

Because the Third Follow-Up Survey was the fourth annual survey, KFS respondents usually remembered the previous surveys and required little persuasion. Nonetheless, there were some refusals, which necessitated a refusal conversion effort.

Attempts to convert refusals help ensure that those completing the survey are representative of all sample members. Without refusal conversion, results could be skewed toward people who like to do surveys or who are interested in the particular topic. Such sample members may answer the questions differently from people who initially refuse to participate in a research study. To obtain as representative a sample as possible, we used refusal conversion techniques to persuade and convert panel members who initially refused.

First, all refusal cases were put on hold for 14 days, during which a refusal letter was sent, acknowledging the refusal but emphasizing the unique nature of the study and the importance of participation. The survey website URL was provided in the letter, along with the panel member's password and login ID. After the waiting period, if the panel member had not completed the survey on the web, interviewers trained in refusal conversion techniques called the business. Refusal conversion training was conducted for KFS interviewers who had demonstrated the ability to build rapport and had higher-than-average cooperation rates. 
Project staff reviewed refusals periodically, especially the few adamant first refusals, to determine whether they should be finalized without a conversion attempt. These reviews were conducted by the survey director, who used her judgment to strike a balance between avoiding calling people who were vehemently opposed to another call and giving business owners a chance to change their minds.

When businesses refused again after the conversion attempt, project staff examined the cases and put them into three different categories: (1) cases that might be converted by additional attempts, (2) cases that should be finalized for the Third Follow-Up but could be tried again during the Fourth Follow-Up, and (3) cases that should be finalized and not contacted again. Of the 4,295 cases in the Third Follow-Up, 352 initially refused, of which 46 (13 percent) were converted and completed the questionnaire.

\section{Handling Special Cases}

Several other types of cases that required special handling and review are described below. These were assigned to interviewers with special training on how to resolve them.

\section{a. Owner-Name Cases}

After the Second Follow-Up Survey, there were 25 panel members who did not provide a full first and last name for one or more owner-operators. Being able to track individual owners through the early years of the business allows us to learn about the makeup of the ownership team that runs the business, and is an important analytical focus of the KFS. Therefore, cases that had owners without full first and last names were separated out and designated as "CATI-only." We did not want these cases completed on the web, because we would not be certain we could properly identify all owner-operators involved with the business. For example, in some of these cases, respondents had used initials or other identifiers, such as "Owner 2," but we needed a first 
and last name. If the respondent insisted on such a designation, we needed assurance that the person identified as "Owner 2" in previous rounds was the same as "Owner 2" in the Third Follow-Up. This process would also ensure that the proper demographic questions were asked.

These cases received a special letter that provided MPR contact information should they have any questions about the study or concerns about confidentiality. The letter also informed them that a professional telephone interviewer would be calling them shortly. Specially trained interviewers called to conduct the interview and try to obtain the complete names of all owners.

\section{b. No-Suitable-Owner Cases}

A limited number of panel members (15) had no identifiable owner-operator in the Third Follow-Up because the business was wholly owned either by silent partners or by owners those who hired a manager to run the business. In these instances, the CATI supervisor reviewed the cases and referred them to the survey director, who would decide whether or not the interview should be completed with a manager.

\section{c. Web Partial Cases}

Web partials were cases in which the panel member logged on to the questionnaire on the web, completed one or more questions, and then logged off before finishing. Panel members partially completing the questionnaire were contacted by highly experienced interviewers who proceeded as follows:

1. Examined the case before calling, to learn at what point in the questionnaire the panel member had broken off. This enables the interviewer (1) to tell the panel member how much longer the interview will take to complete, and (2) to get to the first unanswered question quickly if the member agrees to complete the questionnaire.

2. Called the panel member, acknowledging that he or she did partially complete the study. Interviewers are trained to emphasize the business's previous participation and the $\$ 50$ incentive, and to offer to have the panel member complete the survey over the phone. Interviewers informed the panel member how much time it will take to 
complete the questionnaire and assured the member of the confidentiality of the survey data.

3. Emphasized to anyone other than the panel member answering the phone that the panel member has already completed part of the questionnaire.

4. Included concise and complete notes for cases in which the panel member was contacted but did not complete the questionnaire.

In addition to these groups of cases, there were rare occasions such as when the web server went off-line for maintenance. After these occurrences, the project mailbox received email messages from panel members who had tried unsuccessfully to log on to the web to participate in the survey. Project staff responded quickly to these messages, apologized to the panel members affected, and let them know when the problem had been solved so they could log on to complete the interview.

\section{Monitoring Interviewer Performance}

Monitoring interviewer performance helps improve data quality and also provides an opportunity to improve interviewer techniques on panel member engagement and refusal avoidance. The monitoring process also helps identify unanticipated issues and provides support for interviewers who have questions about individual questionnaire items.

MPR emphasizes the importance of the monitoring process, and the MPR monitoring software allows the monitors to enter evaluations of interviewer performance into the system easily, where it is stored for retrieval by supervisors and project staff. So that they fully understood the project requirements, all Third Follow-Up Survey monitors attended the interviewer training. At the beginning of the data collection, project staff closely monitored interviewers to evaluate the performance of the questionnaire and to provide feedback on the performance of individual interviewers. Afterward, 10 percent of the interviewers' work was monitored. 
Monitoring consisted of listening carefully as the interviewer engaged the panel member or gatekeeper, while also observing the interviewer's CATI screen to check for accurate coding and correct computer logic. After the monitors observed the interviewer and prepared evaluations, they would meet with the interviewer to review the case, point out interviewer strengths, and suggest improvements.

Monitoring reports were generated weekly and included such data as the number and type of mistakes each interviewer was making and the number of positive comments made by the monitor. Because of the generally high experience level of the interviewers and the high cooperation rates, monitors reported few problems with the interviewers or with the survey instrument.

An interviewer debriefing was conducted toward the end of the data collection period. Interviewers reported that the success of the Third Follow-Up was due to (1) the fact that respondents were familiar with and interested in KFS, (2) the incentive, and (3) prompt followup by project staff on missing checks from previous surveys. They also mentioned that the best refusal conversion technique was to emphasize that the interviewer would conduct the interview at a brisk pace out of respect for the owner's busy schedule.

As another step to ensure quality, data were reviewed at two benchmarks-after the first 50 interviews and again after about 250 had been completed. Project staff reviewed the data to examine skip patterns, "other-specify" fields, and other items for accuracy.

\section{Locating}

Cases that require locating may be systematically different from those that do not. Some new businesses will never become fully established, and others will move or change phone numbers, sometimes because they are home-based and the business owner moves. To ignore businesses that have moved or changed contact information runs the risk of excluding businesses 
that differ from those that are easier to contact. For the Third Follow-Up, a substantial locating effort was made to find each listed business that could not be contacted using the information collected during the previous rounds. To update the existing contact information about sampled businesses or principals, the KFS locators used zip key, directory assistance, Lexis-Nexis, Accurint, and other web searches. Through a systematic use of these resources, locators could sometimes determine whether a business was still operating and would find updated contact information. If cases were confirmed as still being in business, they were returned to interviewing for additional attempts. A supervisor would examine a case without any new leads to determine what further action, if any, should be taken. Cases for which there was no good contact information were ultimately coded as unlocatable.

The MPR SMS was the clearinghouse for information about locating attempts, as well as all email and mail contacts attempted with panel members. Each email, letter, and postcard that was sent to panel members was recorded, as were new addresses, phone numbers, and owner names. Information gathered by telephone interviewers was also recorded in the SMS. For performance evaluation, the SMS also has management tools that allow locating supervisors to measure the effectiveness of individual locators. Finally, the SMS allows supervisors to review cases that had multiple contact attempts and, when no further locating action is warranted, to finalize them as "unlocatable."

During the Third Follow-Up Survey, 743 cases (17 percent of the total sample) required some degree of locating efforts. Of these, 159 were finalized as unlocatable, which means that 79 percent of all cases sent to locating were found.

\section{Response Rates}

Response rates are often used as measures of the "potential" for nonresponse bias and of the quality and the validity of survey data. In general, unweighted response rates measure the 
proportion of the sample that resulted in usable information for analysis. Weighted response rates represent an estimate of the proportion of the survey population for which usable information is available. The weighted response rate is also considered to be a measure of the potential for nonresponse bias. Because we oversampled businesses in the high-tech sampling stratum, the weighted response rates may differ from the unweighted ones. To compute the response rate for the Third Follow-Up Survey, we used a standard algorithm recommended by the American Association for Public Opinion Research (AAPOR). ${ }^{2}$ In this computation, the unweighted response rate is the count of the number of completed interviews among eligible businesses divided by the estimated total count of eligible businesses (the weighted response rate is comparable with weighted counts used instead of the unweighted counts). For the KFS, we provide these response rates using two definitions of eligibility:

1. Businesses that met the survey criteria, started in 2004 and (for the unweighted response rate) completed the Baseline Survey, and are in operation at the time of data collection.

2. Businesses that met the survey criteria, started in 2004 and (for the unweighted response rate) completed the Baseline Survey, and are in operation at the time of data collection, plus businesses that were not operating at the time of data collection. ${ }^{3}$

The two definitions differ only in that the second includes businesses that were not in operation at the time of the survey.

\footnotetext{
2 The response rate definitions recommended by AAPOR are available at [www.aapor.org/uploads/ standarddefs_4.pdf].

${ }^{3}$ For a weighted response rate, the numerator and dominator are population-level estimates, and the weighted response rate is a measure of the potential for nonresponse bias in survey-based estimates, because it measures the proportion of the population that provided data. For the unweighted response rate, the numerator and dominator are sample-level counts and therefore need the restriction of "completed the Baseline Survey." The unweighted response rate is essentially an operational measure of data collection success, rather than a measure of the quality of the survey or the survey estimates.
} 
Using the AAPOR response rate algorithm (specifically, AAPOR's Rate \#3), we assumed that all businesses with unknown eligibility (under either definition) would be eligible at the same rate as businesses for which we obtained sufficient information to define eligibility. The AAPOR response rate under the first eligibility definition is:

$$
R R_{1}=\frac{\text { Completes }}{\text { Completes }+ \text { Elig. Non-completes }+ \text { Unknown Elig. } \times \text { Est. Elig. rate }}
$$

Where estimated eligibility rate is defined as:

$$
\text { Est. Elig. rate }=\frac{\text { Completes }+ \text { Elig. } \text { Non-completes }}{\text { Completes }+ \text { Elig. Non-completes }+ \text { Ineligibles }}
$$

Businesses that had unknown eligibility either were unlocatable or were located but did not respond. Ineligible businesses were those that were non-operational at the time of the survey. The eligible non-completes were eligible for the Third Follow-Up but refused to participate (such as a "break-off"). Because eligibility was determined as part of the interview and there were no break-offs, the number of eligible non-completes was zero.

Under the second eligibility definition, the AAPOR response rate is computed:

$$
R R_{2}=\frac{\text { Completes }+ \text { Non-operational Businesses }}{\text { Completes }+ \text { Non-operational Businesses }+ \text { Elig. Non-completes }+ \text { Unknown Elig. } \times \text { Est. Elig. rate }}
$$

Where estimated eligibility rate is defined as:

$$
\text { Est. Elig. rate }=\frac{\text { Completes }+ \text { Non }- \text { operational Businesses }+ \text { Elig. Non-completes }}{\text { Completes }+ \text { Non }- \text { operational Businesses }+ \text { Elig. Non-completes }+ \text { Ineligibles }}
$$

Once again, the difference between the two response rates, $R R_{1}$ and $R R_{2}$, is that in $R R_{2}$ the businesses that are not in operation at the time of the survey were classified as eligible. 
Of the 4,928 panel members from the Baseline Survey, we completed interviews with 2,915 eligible businesses and identified 1,174 that were no longer in business. ${ }^{4}$ The other 839 cases had unknown eligibility (refusals or unlocatables). Because there were no eligible non-completes, the two equations are algebraically the same. The overall unweighted AAPOR response rate is computed as 83.0 percent; under the second definition, it is also 83.0 percent.

When the sampling weights are incorporated, the weighted AAPOR response rate is 82.5 percent under both eligibility definitions. Table 4 shows the unweighted/weighted response rates across the three technology sampling strata under both definitions.

TABLE 4

WEIGHTED AND UNWEIGHTED AAPOR RESPONSE RATES FOR THE THIRD FOLLOW-UP SURVEY ACROSS TECHNOLOGY SAMPLING STRATA ${ }^{\mathrm{a}}$

\begin{tabular}{lccccc}
\hline $\begin{array}{l}\text { Technology } \\
\text { Sampling Strata }\end{array}$ & $\begin{array}{c}\text { Completes } \\
\text { (Count) }\end{array}$ & $\begin{array}{c}\text { Out of } \\
\text { Business } \\
\text { (Count) }\end{array}$ & $\begin{array}{c}\text { Unknown } \\
\text { Eligibility } \\
\text { (Count) }\end{array}$ & $\begin{array}{c}\text { Unweighted AAPOR } \\
\text { Response Rate } \\
\text { (Percentage) }\end{array}$ & $\begin{array}{c}\text { Weighted AAPOR } \\
\text { Response Rate } \\
\text { (Percentage) }\end{array}$ \\
\hline Total & $\mathbf{2 , 9 1 5}$ & $\mathbf{1 , 1 7 4}$ & $\mathbf{8 3 9}$ & $\mathbf{8 3 . 0}$ & $\mathbf{8 2 . 5}$ \\
\hline $\begin{array}{l}\text { High- } \\
\text { technology }\end{array}$ & 434 & 145 & 126 & 82.1 & 82.0 \\
$\begin{array}{l}\text { Medium- } \\
\text { technology }\end{array}$ & 831 & 292 & 206 & 84.5 & 84.2 \\
Non-technology & 1,650 & 737 & 507 & 82.5 & 82.3 \\
\hline
\end{tabular}

${ }^{a}$ As noted in the text, response rates $R R_{1}$ and $R R_{2}$ were equal because there were no businesses classified as eligible noncompletes.

In the Third Follow-Up, we were able to convert some nonrespondents in the First and/or Second Follow-Up into completes. However, most nonrespondents in the First and/or Second Follow-Up were still nonrespondents in the Third Follow-Up. Table 5 shows the unweighted/ weighted response rates in the Third Follow-Up Survey across response levels in the First and

\footnotetext{
${ }^{4}$ Among 1,174 businesses that were out of business, 635 had already been identified in the First or Second Follow-Up Survey as permanently out of business.
} 
TABLE 5

WEIGHTED AND UNWEIGHTED AAPOR RESPONSE RATES FOR THE THIRD FOLLOW-UP SURVEY ACROSS THE RESPONSE STATUS FOR FIRST AND SECOND FOLLOW-UP SURVEYS ${ }^{a}$

\begin{tabular}{lccccc}
\hline $\begin{array}{l}\text { Response to Follow- } \\
\text { Up Surveys }\end{array}$ & $\begin{array}{c}\text { Completes } \\
\text { (Count) }\end{array}$ & $\begin{array}{c}\text { Out of } \\
\text { Business } \\
\text { (Count) }\end{array}$ & $\begin{array}{c}\text { Unknown } \\
\text { Eligibility } \\
\text { (Count) }\end{array}$ & $\begin{array}{c}\text { Unweighted AAPOR } \\
\text { Response Rate } \\
\text { (Percentage) }\end{array}$ & $\begin{array}{c}\text { Weighted AAPOR } \\
\text { Response Rate } \\
\text { (Percentage) }\end{array}$ \\
\hline Total & $\mathbf{2 , 9 1 5}$ & $\mathbf{1 , 1 7 4}$ & $\mathbf{8 3 9}$ & $\mathbf{8 3 . 0}$ & $\mathbf{8 2 . 5}$ \\
\hline $\begin{array}{l}\text { Respondents to First } \\
\text { and Second Follow- }\end{array}$ & 2,702 & 943 & 332 & 91.7 & 91.1 \\
$\begin{array}{l}\text { Up } \\
\text { Respondents to First } \\
\text { or Second Follow- }\end{array}$ & 166 & 162 & 251 & 56.6 & \\
$\begin{array}{l}\text { Up } \\
\text { Non-respondents to }\end{array}$ & & & & & 58.2 \\
$\begin{array}{l}\text { First and Second } \\
\text { Follow-Up }\end{array}$ & 47 & 69 & 256 & 31.2 & 31.2 \\
\hline
\end{tabular}

${ }^{a}$ As noted in the text, response rates $R R_{1}$ and $R R_{2}$ were equal because there were no businesses classified as eligible noncompletes.

Second Follow-Up. Businesses that responded in neither the First nor the Second Follow-Up achieved a 31.2 percent (unweighted) and 31.2 percent (weighted) response rate in the Third Follow-Up; businesses that responded only to one of the first two Follow-Up Surveys achieved a 56.6 percent (unweighted) and 58.2 percent (weighted) response rate in the Third Follow-Up; businesses that were First and Second Follow-Up respondents achieved a 91.7 percent (unweighted) and 91.1 percent (weighted) response rate in the Third Follow-Up. Clearly businesses that did not respond in the previous rounds were much less likely to respond in the next. We expect that in the next rounds, it is even less likely that they will respond if they did not respond in multiple consecutive rounds. In any longitudinal survey, the serial nonrespondents are the most difficult group from which to obtain completed responses.

\section{Longitudinal Response Rate}

Because of the longitudinal design of the KFS, we also report the longitudinal response rates. A longitudinal respondent is defined as a business that responded to the First, Second, and 
Third Follow-Up Surveys. The longitudinal response rate is the count (or weighted count) of respondents in the First, Second, and Third Follow-Up Surveys as a proportion of the count (or weighted count) of eligible businesses at the time of the Baseline Survey. As was the case for the response rates for the cross-sectional Third Follow-Up Survey, the longitudinal response rates are the same under the two eligibility definitions. Table 6 gives the longitudinal response rates under the two eligibility definitions.

TABLE 6

WEIGHTED AND UNWEIGHTED LONGITUDINAL RESPONSE RATES FOR THE THIRD FOLLOW-UP SURVEY ACROSS TECHNOLOGY SAMPLING STRATA ${ }^{\mathrm{a}}$

\begin{tabular}{|c|c|c|c|}
\hline Technology Sampling Strata & Respondents & $\begin{array}{l}\text { Unweighted Response } \\
\text { Rate (Percentage) }\end{array}$ & $\begin{array}{c}\text { Weighted Response } \\
\text { Rate } \\
\text { (Percentage) }\end{array}$ \\
\hline Total & 3,646 & $\mathbf{7 4 . 0}$ & 73.2 \\
\hline High-technology & 521 & 73.9 & 73.8 \\
\hline Medium-technology & 1,018 & 76.6 & 76.2 \\
\hline Non-technology & 2,107 & 72.8 & 72.7 \\
\hline
\end{tabular}

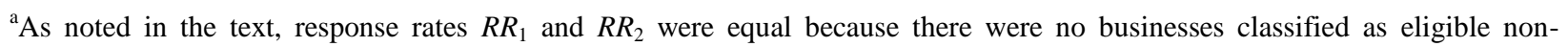
completes.

\section{Panel Maintenance}

The strength and the uniqueness of the KFS data are the longitudinal information they provide for analysis. To minimize panel attrition between surveys, we made a significant effort to express appreciation to panel members through both an incentive and a "post survey" mailing. The $\$ 50$ incentive was one way both to thank respondents for participation in each survey and to encourage participation in future follow-ups. The "panel maintenance packet" was another technique. For the Third Follow-Up, this packet consisted of a letter of appreciation and a 2009 calendar with the study name and contact information printed on it. The letter thanked 
respondents for completing the survey and reminded them of the interview in the upcoming year. It also contained contact information for MPR's survey director. So that it would not be discarded or ignored as just another piece of junk mail, the panel maintenance packet was designed to appear attractive and important: the envelope carried a first-class stamp instead of the bulk rate imprint common to mass mailings.

For the Third Follow-Up, 2,915 panel maintenance packets were sent in January 2009. As with previous surveys, these generated some returned packets, some of which contained updated addresses. Those addresses were recorded and the packets re-mailed.

Another procedure for reducing panel attrition was to deal promptly with respondent requests, especially when dealing with incentives provided to respondents. During the Third Follow-Up, if respondents called in to say they had not received their $\$ 50$ incentive, MPR staff would check through the MPR respondent payment system to see whether a check had been mailed and, if yes, whether it had been cashed. Often checks were sent but not cashed, so staff would verify the address information. Any missing address information, usually a suite or apartment number, was obtained and entered into the SMS, and the checks were reissued. This updated contact information was collected and stored for use on future follow-up surveys.

\section{F. CODING AND DATA PROCESSING}

\section{Overview}

As with other Third Follow-Up operations, the coding and data processing were aided by the processes created in earlier rounds. The previous programs and procedures were used during the Third Follow-Up, and many needed little or no updating. High-quality coding and dataprocessing procedures help to provide the highest-quality data file for analysis. 


\section{Back-Coding}

Seventeen questions in the Third Follow-Up Survey contained open-ended responses, with all but one having an "other-specify" alternative if respondents did not think their answers fit into one of the existing categories. Each of these verbatim responses entered by the CATI interviewer or, on the web survey, by the respondent was reviewed for possible back-coding. Back-coding - the process of determining whether the answer actually fits into one of the existing categories - reduces the percentage of responses in the "other" category, providing a higher level of specificity and data quality. Sometimes respondents do not hear all the answer categories during a telephone interview, do not read them carefully on a web survey, or interpret a category incorrectly. Although some responses could not be back-coded, many could. Qualified and experienced coding staff performed the back-coding of the "other-specify" responses to these questions:

- A10 (Reason for being out of business)

- C1z2 (Form of legal status of business)

- C8 (Primary location where business operates)

- C9 (Reason for change in location)

- E1h (Key responsibilities of employees)

- E2a.1 (Employee benefits provided to full-time employees)

- E2b.1 (Employee benefits provided to part-time employees)

- F3g (Sources of equity)

- F7f (Sources of respondent debt)

- F9f (Sources of other owner debt)

- F11k (Sources of debt of the business)

- F28g (Other business owner property)

- F28h (Other assets) 
- F30c (Other liabilities)

- G6 (Race)

Since these questions had been used in previous rounds, the back-coding in the Third Follow-Up used the results from back-coding of the previous rounds as a guide, thus maintaining consistency.

\section{Industry Coding}

Question C1b (principal activity of the business) is used to determine the North American Industry Classification System (NAICS) code. $^{5}$ The Third Follow-Up asked respondents to confirm the industry description for their business, which had been obtained during previous survey rounds. If the respondent disagreed with the primary industry description, the web questionnaire (or telephone interviewer) asked for an updated description. Coders then reviewed these verbatim descriptions and identified the most appropriate NAICS code. MPR used coders with substantial experience in industry and, specifically, NAICS coding, and they were instructed to leave the six-digit code from the Second Follow-Up if they could not code to a sixdigit NAICS based on the description collected during the Third Follow-Up.

As in the previous rounds, the next step was to ensure that the NAICS descriptions for the updated NAICS code were entered into the case records. This required obtaining the listing of NAICS codes and associated descriptions, matching them to the cases with updated NAICS codes, and data the matching description into the data file for that business. This revised description was put into place for use on the Fourth Follow-Up Survey.

\footnotetext{
${ }^{5}$ The NAICS system, developed by the U.S. Census Bureau, is the standard establishment classification for all federal surveys, replacing the Standard Industry Classification codes. See [www.census.gov/epcd/www/naics.html] for more information on NAICS.
} 


\section{Financial Data Coding}

Financial data back-coding presented a number of challenges during the Third Follow-Up. Not all owners of new businesses have a clear understanding of financial accounting, asset categories, or even the difference between debt and equity. While the numbers of cases with this problem decreased in the Third Follow-Up, some complex cases that required review by project staff still existed.

Because the questions in the business finances section included dollar values, back-coding these also required adding the amount of the back-coded question to the appropriate response category. For example, if a respondent indicated in the "other-specify" for equity investment that "Dad" had invested $\$ 10,000$ in the business, the $\$ 10,000$ would have to be added to any amount already entered into the section that recorded amounts invested by "parents, in-laws, or children of owners of the business." Many of the financial back-codes were obvious after review by the survey director. In addition, the programs developed during the previous rounds of coding were used to correct these problems. The programs moved the back-coded responses from the "otherspecify" field into the correct response category and added the related dollar amount into the

proper field. This allowed the response and the corresponding amount to be back-coded to the appropriate category.

Responses to some other questions were somewhat more complex. For example, many respondents did not make a clear distinction between the two "other asset" categories in Question F28, and these had to be adjusted as well. "Any other business property" (F28g) was designed to record tangible assets, while the "any other assets" category (F28h) was designed to record intangible assets such as patents, trademarks, and copyrights, as well as financial assets such as long-term bonds. 
Some of the "other-specify" fields required extensive review and case-by-case recoding. In some cases, account balances had to be moved from debt to equity and vice versa. When the intended response was not clear, responses were kept as reported, but when it was clear that the respondent had put account information in the incorrect response category, appropriate adjustments were made to the data for that case.

\section{Field of Study Coding}

As discussed previously, we collected field-of-study information about respondents' highest postsecondary degree in the Third Follow-Up (Question G9a and Question G9b). MPR coded the verbatim responses using the Classification of Instructional Programs (CIP) taxonomy. ${ }^{6}$ MPR coders reviewed each verbatim and, using a database of CIP codes, assigned the most appropriate six-digit code, which is the most specific level of CIP code. MPR assigned coders who had substantial experience in coding field of study on other MPR studies.

\section{Quality Assurance Procedures for Coding}

Quality Assurance (QA) is included in all MPR's survey operations and was also used throughout the KFS coding process. The coding supervisor reviewed all work completed by coders and made corrections before sending the results to the survey and project directors, who reviewed all coded cases. We included comments on any cases that were changed during the QA review, so that the coders would have feedback for future rounds. These were primarily reminders about procedures for handling responses that could not be back-coded. As mentioned above, QA checks were also made between the Third Follow-Up codes and those of previous rounds to ensure consistency across rounds. One of these checks was the owner number: because

\footnotetext{
${ }^{6}$ See [http://nces.ed.gov/pubs2002/cip2000/index.asp] for more information on CIP.
} 
each owner-operator is identified by a unique ID number, project staff ensured that the same number was assigned to that owner in the Third Follow-Up.

MPR programmers tested all back-coding programs on a test data set for accuracy prior to adding the updated codes from the live data into the file. Both the programming and the project staff examined the adjusted data set to make sure that all changes were made accurately and that each step of the process was documented. Both were checked to ensure that the new descriptions were accurate. Additional checks were performed to ensure that back-coded financial items and their associated amounts had been properly transferred.

Project staff also looked for common "other-specify" answers to any question, to determine whether sufficient responses existed to form a new response category in the Third Follow-Up. If a response to an "other-specify" category appeared in at least 3 percent of the cases, the addition of a new response category would be considered. As in previous surveys, however, no Third Follow-Up question had an "other-specify" response that reached this threshold.

\section{Data Cleaning and Frequency Review}

To ensure data quality across all rounds of the KFS, the Third Follow-Up used the same set of specifications developed to machine-edit the data in previous rounds. These computer edit specifications began by checking the skip patterns and consistency checks in the CATI questionnaire, which were then expanded at each round to cover other data consistency issues identified.

After these cleaning specifications were finalized, they were programmed into SAS and applied to the original, unedited data. After these processes were completed, a set of frequency distributions was generated and then reviewed by project staff for quality control to ensure that the cleaning statements were implemented properly and to check for any other data inconsistencies. 
During the initial review of the frequencies, inconsistent data values were noted for revision. Inconsistent values usually came from web cases since, to avoid increasing respondent frustration that can result in not completing the questionnaire, the web program had fewer builtin data checks than the CATI program. The frequency review also served as a final check that "other-specify" responses were back-coded properly, with any additional responses that could be back-coded noted so that they could be corrected. After the initial review, we compiled a list of values to be edited, and these were implemented through SAS. To ensure that all inconsistent values were corrected, we produced a second set of frequency distributions after cleaning.

Once the Third Follow-Up data file was finalized (all cleaning was completed and reviewed) and the constructed variables were added (discussed in the next section), the Third Follow-Up data were added to the KFS longitudinal file. Third Follow-Up variables were given a "_3" suffix to distinguish them from variables from earlier data collection rounds. This combined file went through a final quality control review to ensure that the process of combining the two files did not create any unexpected errors or complications. The longitudinal file was provided to the KFS data enclave for restricted use by approved researchers.

\section{Constructed Variables}

For the Third Follow-Up data, we produced a set of constructed variables using the procedures created in the previous rounds. These variables consolidated data reporting in questions with different levels of specificity in order to facilitate analysis of these data. Below is a review of the different categories of constructed variables.

\section{a. Financial Measures with Three Levels of Data}

When asked about different sources of business financing, such as equity or debt, respondents were first asked whether these sources were used (an "indicator" question). 
Respondents reporting that the business had used one of these types of financing were then asked for an exact dollar amount for the reference period. Respondents unable or unwilling to provide an exact dollar amount (either through a "don't know" or "refused" response in CATI or by not answering a response field on the web) were provided a set of ranges and asked to select the appropriate one. The goal of constructing variables for these financial measures was to combine these values into one variable that would inform researchers about both the incidence of usage and the amounts used or acquired during the reference period. Respondents answering "no" to the indicator question were given a " 0 " in the constructed variable. For exact-value responses, the value associated with the range the value fell into was placed in the new constructed variable. For example, if a respondent indicated that the business had a year-end personal credit card balance of $\$ 20,000$ (question F8b), the value " 6 " was placed in the constructed variable, indicating the range $\$ 10,001$ to $\$ 25,000$. For respondents who gave a range response to the question, these values were placed in the constructed variable as is.

\section{b. Financial Variables with Two Levels of Data}

We also created constructed variables for measures that did not include an indicator variable, such as total expenses (F17) and total wage expenses (F18). For these constructed variables, we used the process as described above to translate exact values into ranges.

\section{c. Variables Summing Financial Measures}

The KFS instrument asked about equity and debt in terms of specific sources, such as from owner-operators, family members, banks, and other organizations. By summing all discrete sources falling into a particular category, we created a set of constructed variables that provided subtotals of equity and debt provided by owner-operators and non-owner-operators, as well as a total from all sources. 


\section{d. Intellectual Property Measures}

The KFS questions on patents, copyrights, and trademarks asked an indicator question for each type, and businesses that reported having these types of properties were asked how many they had. The constructed variables were created to provide both the incidence and the quantities of these items by entering a " 0 " for cases reporting no patents, copyrights, or trademarks, and for those reporting them, the number of the specific type was entered into the constructed variable.

Once the constructed variables were created and reviewed for quality control, the clean data file was provided to MPR statisticians so that the survey weights and nonresponse adjustment variables could be added.

\section{Preparation of Codebook and Data Documentation}

The main codebook for the Third Follow-Up Survey is the questionnaire, which was annotated to include the variable names in the data file next to the appropriate questions from which the variables were derived. An annotated questionnaire was created for use with the restricted-use longitudinal data file, which is in Appendix D. A full list of the variables constructed for the Third Follow-Up data file, as well as more about their construction, is in the data documentation memo in Appendix E. This memo provides information about variables not derived directly from the questionnaire, including:

- Sampling variables, such as those used in the technology and gender strata

- Weighting variables for each round of the KFS, such as nonresponse and poststratification adjustments, as well as the longitudinal weight variable

- Survey management variables, such as the unique ID number given to cases, final dispositions, and number of contacts made to businesses

- D\&B-derived variables, such as industry codes and other descriptive measures provided with the D\&B file

- Constructed variables, as discussed in Section F.8 


\section{Preparation of Public Use Data File}

In addition to the restricted-use data file we provided to the KFS data enclave, MPR produced a file for public use, available on the Foundation website [www.kauffman.org/kfs/ request_download.cfm]. To create this file, we used several strategies to ensure that respondent confidentiality was not compromised. These included removing geographic variables (with the exception of “census region"), exact value variables for financial questions, and all "otherspecify" variables. We reviewed the remaining variables file for values or cells containing small numbers of respondents, and "top-coded" those values into a summary statistic. QA on the public use data file was conducted by MPR staff with extensive experience in producing such files for federal agencies. Once approved, copies of the file were produced in SAS, SPSS, and STATA and provided to the Foundation, along with an annotated questionnaire and data documentation memo specifically designed for use with the public use data file.

\section{G. WEIGHTING AND NONRESPONSE ADJUSTMENTS}

\section{Third Follow-Up Response Analysis Summary}

For the purpose of nonresponse analysis in the Third Follow-Up alone, we classified the 4,928 panel members into two categories: located and unlocated. The located cases were further classified into "completes" and "nonrespondents." Completes included businesses (1) for which we obtained either a web survey questionnaire or a CATI interview, or (2) that were classified as ineligible (ceased operations). Using information from the Baseline Survey, we located nearly the entire sample in the Third Follow-Up - the overall location rate (the weighted percentage of eligible businesses in the Baseline Survey that were located in the Third Follow-Up) is 96.5 percent. The weighted location and response rates relative to the Baseline Survey for the full sample are given in Table 7 and by technology stratum in tables 8 to 10 . 
TABLE 7

WEIGHTED LOCATION AND RESPONSE RATES FOR THE THIRD FOLLOW-UP SURVEY RELATIVE TO THE BASELINE SURVEY AMONG BUSINESSES IN THE KAUFFMAN FIRM SURVEY

\begin{tabular}{|c|c|c|c|c|c|c|}
\hline & $\begin{array}{c}\text { Sample } \\
\text { Count }\end{array}$ & Located & $\begin{array}{l}\text { Weighted } \\
\text { Percentage } \\
\text { Located }\end{array}$ & Complete $^{\mathrm{a}}$ & $\begin{array}{c}\text { Weighted } \\
\text { Percentage } \\
\text { Complete/Located }\end{array}$ & $\begin{array}{c}\text { Weighted } \\
\text { Response } \\
\text { Rate }\end{array}$ \\
\hline All & 4,928 & 4,769 & 96.5 & 4,089 & 85.5 & 82.5 \\
\hline \multicolumn{7}{|l|}{ Technology Sampling Strata } \\
\hline High-technology & 705 & 692 & 97.9 & 579 & 83.8 & 82.0 \\
\hline Medium-technology & 1,329 & 1,286 & 96.7 & 1,123 & 87.1 & 84.2 \\
\hline Non-technology & 2,894 & 2,791 & 96.5 & 2,387 & 85.3 & 82.3 \\
\hline \multicolumn{7}{|l|}{ Sole Proprietorship } \\
\hline Yes & 1,635 & 1,560 & 95.5 & 1,387 & 88.4 & 84.4 \\
\hline No & 3,293 & 3,209 & 97.1 & 2,702 & 83.9 & 81.5 \\
\hline \multicolumn{7}{|l|}{ Number of Employees } \\
\hline 0 & 2,838 & 2,744 & 96.3 & 2,400 & 87.0 & 83.8 \\
\hline At least 1 & 2,090 & 2,025 & 96.9 & 1,689 & 83.4 & 80.8 \\
\hline \multicolumn{7}{|l|}{ Primary Location of the Business } \\
\hline Residence & 2,483 & 2,414 & 97.0 & 2,137 & 88.1 & 85.4 \\
\hline Others & 2,445 & 2,355 & 96.1 & 1,952 & 83.0 & 79.8 \\
\hline \multicolumn{7}{|l|}{ Total Revenue } \\
\hline 0 & 1,704 & 1,627 & 95.0 & 1,369 & 83.7 & 79.6 \\
\hline$\$ 1$ to $\$ 25,000$ & 1,321 & 1,289 & 97.8 & 1,157 & 88.7 & 86.7 \\
\hline$\$ 25,001$ or more & 1,903 & 1,833 & 97.0 & 1,563 & 84.8 & 82.2 \\
\hline \multicolumn{7}{|l|}{ Total Debt } \\
\hline 0 & 2,231 & 2,149 & 95.9 & 1,852 & 86.1 & 82.6 \\
\hline Positive & 2,697 & 2,620 & 97.0 & 2,237 & 85.0 & 82.5 \\
\hline \multicolumn{7}{|l|}{ Age of the Responding Owner } \\
\hline 34 or younger & 864 & 815 & 94.7 & 689 & 84.2 & 79.8 \\
\hline 35 to 44 & 1,618 & 1,564 & 96.3 & 1,312 & 83.8 & 80.7 \\
\hline 45 to 54 & 1,447 & 1,415 & 97.5 & 1,212 & 85.9 & 83.7 \\
\hline 55 or older & 999 & 975 & 97.2 & 876 & 89.1 & 86.7 \\
\hline \multicolumn{7}{|l|}{$\begin{array}{l}\text { Responding Owner's Years of } \\
\text { Experience }\end{array}$} \\
\hline 0 to 10 & 2,577 & 2,484 & 96.2 & 2,145 & 86.3 & 83.0 \\
\hline 11 to 20 & 1,305 & 1,267 & 97.0 & 1,061 & 83.5 & 81.0 \\
\hline 21 or more & 1,046 & 1,018 & 96.9 & 883 & 85.8 & 83.2 \\
\hline \multicolumn{7}{|l|}{ Responding Owner's Education } \\
\hline Associate's degree or lower & 2,395 & 2,287 & 95.1 & 1,944 & 84.9 & 80.7 \\
\hline Bachelor's degree or higher & 2,533 & 2,482 & 98.1 & 2,145 & 86.1 & 84.5 \\
\hline
\end{tabular}

${ }^{\mathrm{a} C}$ Completed cases include businesses with complete data for applicable questions. These include Third Follow-Up completes and ineligible businesses (businesses that were not operational). 
TABLE 8

WEIGHTED LOCATION AND RESPONSE RATES FOR THE THIRD FOLLOW-UP SURVEY RELATIVE TO THE BASELINE SURVEY AMONG BUSINESSES IN THE KAUFFMAN FIRM SURVEY: HIGH-TECHNOLOGY

\begin{tabular}{|c|c|c|c|c|c|c|}
\hline & $\begin{array}{l}\text { Sample } \\
\text { Count }\end{array}$ & Located & $\begin{array}{l}\text { Weighted } \\
\text { Percentage } \\
\text { Located }\end{array}$ & Completes $^{\mathrm{a}}$ & $\begin{array}{l}\text { Weighted Percentage } \\
\text { Complete/Located }\end{array}$ & $\begin{array}{c}\text { Weighted } \\
\text { Response Rate }\end{array}$ \\
\hline All & 705 & 692 & 97.9 & 579 & 83.8 & 82.0 \\
\hline \multicolumn{7}{|l|}{ Sole Proprietorship } \\
\hline Yes & 153 & 147 & 95.5 & 131 & 90.2 & 86.2 \\
\hline No & 552 & 545 & 98.7 & 448 & 81.9 & 80.8 \\
\hline \multicolumn{7}{|l|}{ Have Competitive Advantage } \\
\hline Yes & 478 & 470 & 98.2 & 393 & 84.0 & 82.4 \\
\hline No & 227 & 222 & 97.5 & 186 & 83.3 & 81.2 \\
\hline \multicolumn{7}{|l|}{ Number of Owners } \\
\hline 1 & 331 & 324 & 97.6 & 280 & 87.0 & 84.9 \\
\hline 2 or higher & 374 & 368 & 98.3 & 299 & 80.8 & 79.4 \\
\hline \multicolumn{7}{|l|}{ Total Assets } \\
\hline$\$ 0$ to $\$ 10,000$ & 223 & 216 & 96.4 & 191 & 88.8 & 85.6 \\
\hline$\$ 10,001$ to $\$ 100,000$ & 259 & 256 & 98.8 & 223 & 87.2 & 86.2 \\
\hline$\$ 100,001$ or more & 223 & 220 & 98.5 & 165 & 74.7 & 73.6 \\
\hline \multicolumn{7}{|l|}{ Total Revenue } \\
\hline$\$ 0$ & 253 & 246 & 96.9 & 201 & 82.0 & 79.4 \\
\hline$\$ 1$ to $\$ 100,000$ & 239 & 236 & 98.7 & 213 & 90.2 & 89.0 \\
\hline$\$ 100,001$ or more & 213 & 210 & 98.5 & 165 & 78.6 & 77.4 \\
\hline \multicolumn{7}{|l|}{ Age of the Responding Owner } \\
\hline 34 or younger & 78 & 75 & 96.0 & 59 & 78.6 & 75.5 \\
\hline 35 to 44 & 216 & 211 & 97.5 & 177 & 83.8 & 81.7 \\
\hline 45 to 54 & 248 & 245 & 98.6 & 200 & 81.7 & 80.5 \\
\hline 55 or older & 163 & 161 & 98.5 & 143 & 89.3 & 87.9 \\
\hline \multicolumn{7}{|l|}{$\begin{array}{l}\text { Responding Owner's Years of } \\
\text { Experience }\end{array}$} \\
\hline 0 to 10 & 314 & 308 & 97.9 & 261 & 85.1 & 83.3 \\
\hline 11 to 20 & 202 & 198 & 97.8 & 161 & 80.9 & 79.1 \\
\hline 21 or more & 189 & 186 & 98.2 & 157 & 84.6 & 83.1 \\
\hline \multicolumn{7}{|l|}{ Responding Owner's Education } \\
\hline Associate's degree or lower & 346 & 342 & 98.6 & 284 & 83.3 & 82.1 \\
\hline Bachelor's degree or higher & 359 & 350 & 97.3 & 295 & 84.2 & 81.9 \\
\hline
\end{tabular}

${ }^{a}$ Completed cases include businesses with complete data for applicable questions. These include Third Follow-Up completes and ineligible businesses (businesses that were not operational). 
TABLE 9

WEIGHTED LOCATION AND RESPONSE RATES FOR THE THIRD FOLLOW-UP SURVEY RELATIVE TO THE BASELINE SURVEY AMONG BUSINESSES IN THE KAUFFMAN FIRM SURVEY:

MEDIUM-TECHNOLOGY

\begin{tabular}{|c|c|c|c|c|c|c|}
\hline & Sample Count & Located & $\begin{array}{l}\text { Weighted } \\
\text { Percentage } \\
\text { Located }\end{array}$ & Completes $^{\mathrm{a}}$ & $\begin{array}{c}\text { Weighted } \\
\text { Percentage } \\
\text { Complete/ } \\
\text { Located }\end{array}$ & $\begin{array}{c}\text { Weighted } \\
\text { Response } \\
\text { Rate }\end{array}$ \\
\hline All & 1,329 & 1,286 & 96.7 & 1,123 & 87.1 & 84.2 \\
\hline \multicolumn{7}{|l|}{ Sole Proprietorship } \\
\hline Yes & 426 & 405 & 95.0 & 364 & 89.7 & 85.2 \\
\hline No & 903 & 881 & 97.5 & 759 & 85.9 & 83.8 \\
\hline \multicolumn{7}{|l|}{ Number of Employees } \\
\hline 0 & 828 & 802 & 96.9 & 720 & 89.7 & 86.9 \\
\hline At least 1 & 501 & 484 & 96.5 & 403 & 82.9 & 79.9 \\
\hline \multicolumn{7}{|l|}{ Have Competitive Advantage } \\
\hline Yes & 905 & 879 & 97.1 & 762 & 86.4 & 83.8 \\
\hline No & 424 & 407 & 95.9 & 361 & 88.6 & 85.0 \\
\hline \multicolumn{7}{|l|}{ Primary Location of the Business } \\
\hline Residence & 873 & 853 & 97.7 & 765 & 89.5 & 87.5 \\
\hline Others & 456 & 433 & 94.9 & 358 & 82.4 & 78.2 \\
\hline \multicolumn{7}{|l|}{ Total Assets } \\
\hline$\$ 0$ to $\$ 3,000$ & 420 & 406 & 96.7 & 358 & 87.8 & 84.9 \\
\hline$\$ 3,001$ to $\$ 25,000$ & 488 & 473 & 96.9 & 431 & 90.9 & 88.1 \\
\hline$\$ 25,001$ or more & 421 & 407 & 96.5 & 334 & 82.1 & 79.2 \\
\hline \multicolumn{7}{|l|}{ Total Revenue } \\
\hline$\$ 0$ & 433 & 416 & 96.0 & 360 & 86.2 & 82.7 \\
\hline$\$ 1$ to $\$ 25,000$ & 412 & 400 & 97.0 & 366 & 91.3 & 88.6 \\
\hline$\$ 25,001$ or more & 484 & 470 & 97.1 & 397 & 84.3 & 81.9 \\
\hline \multicolumn{7}{|l|}{ Age of the Responding Owner } \\
\hline 34 or younger & 233 & 215 & 92.4 & 189 & 87.3 & 80.7 \\
\hline 35 to 44 & 428 & 414 & 96.6 & 347 & 83.8 & 81.0 \\
\hline 45 to 54 & 378 & 373 & 98.6 & 322 & 85.8 & 84.6 \\
\hline 55 or older & 290 & 284 & 97.8 & 265 & 93.3 & 91.2 \\
\hline \multicolumn{7}{|l|}{ Responding Owner's } \\
\hline \multicolumn{7}{|l|}{ Years of Experience } \\
\hline 0 to 10 & 556 & 535 & 96.3 & 466 & 86.9 & 83.7 \\
\hline 11 to 20 & 436 & 421 & 96.5 & 359 & 85.1 & 82.2 \\
\hline 21 or more & 337 & 330 & 97.8 & 298 & 89.8 & 87.7 \\
\hline \multicolumn{7}{|l|}{ Responding Owner's Education } \\
\hline Associate's degree or lower & 423 & 399 & 94.2 & 347 & 86.8 & 81.8 \\
\hline Bachelor's degree or higher & 906 & 887 & 97.9 & 776 & 87.2 & 85.3 \\
\hline
\end{tabular}

${ }^{a}$ Completed cases include businesses with complete data for applicable questions. These include Third Follow-Up completes and ineligible businesses (businesses that were not operational). 
TABLE 10

WEIGHTED LOCATION AND RESPONSE RATES FOR THE THIRD FOLLOW-UP SURVEY RELATIVE TO THE BASELINE SURVEY AMONG BUSINESSES IN THE KAUFFMAN FIRM SURVEY: NON-TECHNOLOGY

\begin{tabular}{|c|c|c|c|c|c|c|}
\hline & $\begin{array}{c}\text { Sample } \\
\text { Count }\end{array}$ & Located & $\begin{array}{l}\text { Weighted } \\
\text { Percentage } \\
\text { Located }\end{array}$ & Completes $^{\mathrm{a}}$ & $\begin{array}{l}\text { Weighted } \\
\text { Percentage } \\
\text { Complete/ } \\
\text { Located }\end{array}$ & $\begin{array}{c}\text { Weighted } \\
\text { Response } \\
\text { Rate }\end{array}$ \\
\hline All & 2,894 & 2,791 & 96.5 & 2,387 & 85.3 & 82.3 \\
\hline \multicolumn{7}{|l|}{ Sole Proprietorship } \\
\hline Yes & 1,056 & 1,008 & 95.6 & 892 & 88.2 & 84.3 \\
\hline No & 1,838 & 1,783 & 97.0 & 1,495 & 83.6 & 81.1 \\
\hline \multicolumn{7}{|l|}{ Number of Owners } \\
\hline 1 & 1,754 & 1,682 & 95.9 & 1,453 & 86.2 & 82.6 \\
\hline 2 or more & 1,140 & 1,109 & 97.3 & 934 & 84.0 & 81.7 \\
\hline \multicolumn{7}{|l|}{ Total Revenue } \\
\hline$\$ 0$ & 1,018 & 965 & 94.9 & 808 & 83.4 & 79.1 \\
\hline$\$ 1$ to $\$ 25,000$ & 780 & 762 & 97.9 & 674 & 88.2 & 86.3 \\
\hline$\$ 25,001$ or more & 1,096 & 1,064 & 97.0 & 905 & 84.9 & 82.3 \\
\hline \multicolumn{7}{|l|}{ Total Debt } \\
\hline 0 & 1,205 & 1,152 & 95.7 & 994 & 86.0 & 82.3 \\
\hline Positive & 1,689 & 1,639 & 97.1 & 1,393 & 84.8 & 82.3 \\
\hline \multicolumn{7}{|l|}{ Age of the Responding Owner } \\
\hline 34 or younger & 553 & 525 & 95.0 & 441 & 83.9 & 79.7 \\
\hline 35 to 44 & 974 & 939 & 96.3 & 788 & 83.8 & 80.6 \\
\hline 45 to 54 & 821 & 797 & 97.3 & 690 & 86.0 & 83.7 \\
\hline 55 or older & 546 & 530 & 97.1 & 468 & 88.4 & 85.8 \\
\hline \multicolumn{7}{|c|}{ Responding Owner's Years of Experience } \\
\hline 0 to 6 & 1,300 & 1,252 & 96.3 & 1,092 & 87.0 & 83.8 \\
\hline 7 to 15 & 756 & 730 & 96.5 & 604 & 82.8 & 79.9 \\
\hline 16 or more & 838 & 809 & 96.6 & 691 & 84.9 & 82.0 \\
\hline \multicolumn{7}{|l|}{ Gender of the Responding Owner } \\
\hline Female & 843 & 816 & 96.8 & 701 & 85.9 & 83.1 \\
\hline Male & 2,051 & 1,975 & 96.3 & 1,686 & 85.0 & 81.9 \\
\hline \multicolumn{7}{|l|}{ Responding Owner's Education } \\
\hline Associate's degree or lower & 1,626 & 1,546 & 95.1 & 1,313 & 84.8 & 80.6 \\
\hline Bachelor's degree or higher & 1,268 & 1,245 & 98.2 & 1,074 & 85.9 & 84.4 \\
\hline
\end{tabular}

${ }^{a}$ Completed cases include businesses with complete data for applicable questions. These include Third Follow-Up completes and ineligible businesses (primarily businesses that were not operational). 
In general, businesses in the medium-technology sampling strata responded at a slightly higher rate than did businesses in the high-technology and non-technology sampling strata. Because businesses in the non-technology sampling stratum account for the majority of the study population ( 85 percent), the overall location and response rates will generally reflect the pattern of the businesses in the non-technology stratum. In addition to the technology sampling strata, we analyzed the response patterns by gender, age category, education, experience in the industry of the responding owner, legal status, physical location (residence or not), and number of employees, as well as by financial information (total debt, total revenue, etc.). All these characteristics are from data collected in the Baseline Survey. ${ }^{7}$

Generally speaking, the age of the responding owner was positively correlated with response to the Third Follow-Up Survey. However, among businesses in the high-technology stratum, those whose owners were between 45 and 54 years old had a response rate slightly lower than businesses whose owners were between 35 and 44 . Businesses whose responding owner had at least a bachelor's degree responded at a higher rate in both medium-technology and nontechnology strata, but at a slightly lower rate among businesses in the high-technology sampling stratum. Sole proprietorships responded at a higher rate across all strata. Overall, businesses whose revenues were between $\$ 1$ and $\$ 25,000$ had a higher response rate than others.

\section{Longitudinal Response Analysis Summary}

For the purpose of longitudinal nonresponse analysis in the First, Second and Third FollowUp surveys, we classified the 4,928 panel members into two categories: completes and

\footnotetext{
${ }^{7}$ For consistency with tables from the previous rounds of surveys, the characteristics shown in the response rate tables (tables 8-15) are from the data collected in the Baseline survey. In the nonresponse adjustments, the characteristics used as covariates in the SAS models are from data collected in the Baseline, First Follow-Up, and Second Follow-Up survey to take into account the dynamic features of the survey.
} 
nonrespondents. Completes included businesses (1) for which we obtained either a web survey questionnaire or a telephone interview in all three rounds, or (2) that were classified as ineligible (ceased operations) in all three rounds, or (3) that completed an interview in the First Follow-Up and then was classified as out of business in the Second and Third Follow-Up, or (4) that completed an interview in the First and Second Follow-Up and then was classified as out of business in the Third Follow-Up. The weighted response rates for the full sample are given in Table 11 and by technology stratum in Tables 12 to 14 .

In general, businesses in the medium-technology and high-technology sampling strata responded at a higher rate than did non-technology businesses. Again, because businesses in the non-technology sampling stratum account for the majority of the study population (85 percent), the overall location and response rates will generally reflect the pattern of the businesses in the non-technology stratum. As we did for the nonresponse analysis for the Third Follow-Up Survey alone, we analyzed the response patterns by gender, age category, education, experience in the industry of the responding owner, legal status, physical location (residence or not), and number of employees, as well as by financial information (total debt, total revenue, etc.). All these characteristics are from data collected in the Baseline Survey. ${ }^{8}$

For the longitudinal response, the age of the responding owner was positively correlated with response across all three strata. Businesses whose responding owner had at least a bachelor's degree responded at a higher rate across all technology strata, though the differential was slightly smaller among businesses in the high-technology sampling stratum than in the other two strata. Sole proprietorships responded at a higher rate across all technology strata. In

\footnotetext{
${ }^{8}$ To be consistent with tables from the previous rounds of surveys, the characteristics shown in the response rate tables (Table 8-15) are from the data collected in the Baseline survey. In the nonresponse adjustments, the characteristics used as covariates in the SAS models are from data collected in the Baseline, First Follow-Up, and Second Follow-Up survey to take into account the dynamic features of the survey.
} 
TABLE 11

WEIGHTED LONGITUDINAL RESPONSE RATES FOR THE FIRST, SECOND AND THIRD FOLLOW-UP SURVEYS RELATIVE TO THE BASELINE SURVEY AMONG BUSINESSES IN THE KAUFFMAN FIRM SURVEY

\begin{tabular}{|c|c|c|c|}
\hline & Sample Count & Completes $^{\mathrm{a}}$ & Weighted Response Rate \\
\hline All & 4,928 & 3,646 & 73.2 \\
\hline \multicolumn{4}{|l|}{ Technology Sampling Strata } \\
\hline High-technology & 705 & 521 & 73.8 \\
\hline Medium-technology & 1,329 & 1,018 & 76.2 \\
\hline Non-technology & 2,894 & 2,107 & 72.7 \\
\hline \multicolumn{4}{|l|}{ Sole Proprietorship } \\
\hline Yes & 1,635 & 1,250 & 75.8 \\
\hline No & 3,293 & 2,396 & 71.7 \\
\hline \multicolumn{4}{|l|}{ Number of Employees } \\
\hline 0 & 2,838 & 2,155 & 74.8 \\
\hline At least 1 & 2,090 & 1,491 & 70.9 \\
\hline \multicolumn{4}{|l|}{ Primary Location of the Business } \\
\hline Residence & 2,483 & 1,936 & 76.5 \\
\hline Others & 2,445 & 1,710 & 69.9 \\
\hline \multicolumn{4}{|l|}{ Total Revenue } \\
\hline 0 & 1,704 & 1,210 & 69.4 \\
\hline$\$ 1$ to $\$ 25,000$ & 1,321 & 1,060 & 79.4 \\
\hline$\$ 25,001$ or more & 1,903 & 1,376 & 72.1 \\
\hline \multicolumn{4}{|l|}{ Total Debt } \\
\hline 0 & 2,231 & 1,669 & 74.3 \\
\hline Positive & 2,697 & 1,977 & 72.3 \\
\hline \multicolumn{4}{|l|}{ Age of the Responding Owner } \\
\hline 34 or younger & 864 & 584 & 67.2 \\
\hline 35 to 44 & 1,618 & 1,154 & 71.0 \\
\hline 45 to 54 & 1,447 & 1,102 & 75.6 \\
\hline 55 or older & 999 & 806 & 79.3 \\
\hline \multicolumn{4}{|c|}{ Responding Owner's Years of Experience } \\
\hline 0 to 10 & 2,577 & 1,877 & 72.4 \\
\hline 11 to 20 & 1,305 & 947 & 72.2 \\
\hline 21 or more & 1,046 & 822 & 76.7 \\
\hline \multicolumn{4}{|l|}{ Responding Owner's Education } \\
\hline Associate's degree or lower & 2,395 & 1,689 & 70.1 \\
\hline Bachelor's degree or higher & 2,533 & 1,957 & 76.6 \\
\hline
\end{tabular}

${ }^{\text {a } C o m p l e t e d ~ c a s e s ~ i n c l u d e ~ b u s i n e s s e s ~ w i t h ~ c o m p l e t e ~ d a t a ~ f o r ~ a p p l i c a b l e ~ q u e s t i o n s . ~ T h e s e ~ i n c l u d e d ~ b u s i n e s s e s ~(1) ~ f o r ~ w h i c h ~ w e ~}$ obtained either a web survey questionnaire or a telephone interview in all three rounds, or (2) that were classified as ineligible (ceased operations) in all three rounds, or (3) that completed an interview in the First Follow-Up and then was classified as out of business in the Second and Third Follow-Up, or (4) that completed an interview in the First and Second Follow-Up and then was classified as out of business in the Third Follow-Up. 
TABLE 12

WEIGHTED LONGITUDINAL RESPONSE RATES FOR THE FIRST, SECOND AND THIRD FOLLOW-UP SURVEYS RELATIVE TO THE BASELINE SURVEY AMONG BUSINESSES IN THE KAUFFMAN FIRM SURVEY: HIGH-TECHNOLOGY

\begin{tabular}{|c|c|c|c|}
\hline & Sample Count & Completes $^{\mathrm{a}}$ & Weighted Response Rate \\
\hline All & 705 & 521 & 73.8 \\
\hline \multicolumn{4}{|l|}{ Sole Proprietorship } \\
\hline Yes & 153 & 120 & 78.3 \\
\hline No & 552 & 401 & 72.5 \\
\hline \multicolumn{4}{|l|}{ Have Competitive Advantage } \\
\hline Yes & 478 & 350 & 73.5 \\
\hline No & 227 & 171 & 74.5 \\
\hline \multicolumn{4}{|l|}{ Number of Owners } \\
\hline 1 & 331 & 257 & 77.7 \\
\hline 2 or higher & 374 & 264 & 70.3 \\
\hline \multicolumn{4}{|l|}{ Total Assets } \\
\hline$\$ 0$ to $\$ 10,000$ & 223 & 170 & 76.1 \\
\hline$\$ 10,001$ to $\$ 100,000$ & 259 & 206 & 79.7 \\
\hline$\$ 100,001$ or more & 223 & 145 & 64.7 \\
\hline \multicolumn{4}{|l|}{ Total Revenue } \\
\hline$\$ 0$ & 253 & 188 & 74.6 \\
\hline$\$ 1$ to $\$ 100,000$ & 239 & 187 & 77.9 \\
\hline$\$ 100,001$ or more & 213 & 146 & 68.3 \\
\hline \multicolumn{4}{|l|}{ Age of the Responding Owner } \\
\hline 34 or younger & 78 & 51 & 65.0 \\
\hline 35 to 44 & 216 & 155 & 71.6 \\
\hline 45 to 54 & 248 & 183 & 74.0 \\
\hline 55 or older & 163 & 132 & 80.8 \\
\hline \multicolumn{4}{|c|}{ Responding Owner's Years of Experience } \\
\hline 0 to 10 & 314 & 232 & 73.9 \\
\hline 11 to 20 & 202 & 142 & 69.9 \\
\hline 21 or more & 189 & 147 & 77.9 \\
\hline \multicolumn{4}{|l|}{ Responding Owner's Education } \\
\hline Associate's degree or lower & 346 & 248 & 71.5 \\
\hline Bachelor's degree or higher & 359 & 273 & 76.1 \\
\hline
\end{tabular}

${ }^{a}$ Completed cases include businesses with complete data for applicable questions. These included businesses (1) for which we obtained either a web survey questionnaire or a telephone interview in all three rounds, or (2) that were classified as ineligible (ceased operations) in all three rounds, or (3) that completed an interview in the First Follow-Up and then was classified as out of business in the Second and Third Follow-Up, or (4) that completed an interview in the First and Second Follow-Up and then was classified as out of business in the Third Follow-Up. 
TABLE 13

WEIGHTED LONGITUDINAL RESPONSE RATES FOR THE FIRST AND SECOND FOLLOW-UP SURVEYS RELATIVE TO THE BASELINE SURVEY AMONG BUSINESSES IN THE KAUFFMAN FIRM SURVEY: MEDIUM-TECHNOLOGY

\begin{tabular}{|c|c|c|c|}
\hline & Sample Count & Completes $^{\mathrm{a}}$ & Weighted Response Rate \\
\hline All & 1,329 & 1,018 & 76.2 \\
\hline \multicolumn{4}{|l|}{ Sole Proprietorship } \\
\hline Yes & 426 & 330 & 77.0 \\
\hline No & 903 & 688 & 76.0 \\
\hline \multicolumn{4}{|l|}{ Number of Employees } \\
\hline 0 & 828 & 653 & 78.6 \\
\hline At least 1 & 501 & 365 & 72.4 \\
\hline \multicolumn{4}{|l|}{ Have Competitive Advantage } \\
\hline Yes & 905 & 689 & 75.8 \\
\hline No & 424 & 329 & 77.2 \\
\hline \multicolumn{4}{|l|}{ Primary Location of the Business } \\
\hline Residence & 873 & 706 & 80.7 \\
\hline Others & 456 & 312 & 68.1 \\
\hline \multicolumn{4}{|l|}{ Total Assets } \\
\hline$\$ 0$ to $\$ 3,000$ & 420 & 320 & 75.9 \\
\hline$\$ 3,001$ to $\$ 25,000$ & 488 & 405 & 82.8 \\
\hline$\$ 25,001$ or more & 421 & 293 & 69.2 \\
\hline \multicolumn{4}{|l|}{ Total Revenue } \\
\hline$\$ 0$ & 433 & 322 & 74.0 \\
\hline$\$ 1$ to $\$ 25,000$ & 412 & 339 & 82.2 \\
\hline$\$ 25,001$ or more & 484 & 357 & 73.3 \\
\hline \multicolumn{4}{|l|}{ Age of the Responding Owner } \\
\hline 34 or younger & 233 & 163 & 69.7 \\
\hline 35 to 44 & 428 & 308 & 71.9 \\
\hline 45 to 54 & 378 & 298 & 78.2 \\
\hline 55 or older & 290 & 249 & 85.4 \\
\hline \multicolumn{4}{|c|}{ Responding Owner's Years of Experience } \\
\hline 0 to 10 & 556 & 411 & 73.9 \\
\hline 11 to 20 & 436 & 325 & 74.3 \\
\hline 21 or more & 337 & 282 & 82.8 \\
\hline \multicolumn{4}{|l|}{ Responding Owner's Education } \\
\hline Associate's degree or lower & 423 & 303 & 71.5 \\
\hline Bachelor's degree or higher & 906 & 715 & 78.4 \\
\hline
\end{tabular}

${ }^{\text {a } C o m p l e t e d ~ c a s e s ~ i n c l u d e ~ b u s i n e s s e s ~ w i t h ~ c o m p l e t e ~ d a t a ~ f o r ~ a p p l i c a b l e ~ q u e s t i o n s . ~ T h e s e ~ i n c l u d e d ~ b u s i n e s s e s ~(1) ~ f o r ~ w h i c h ~ w e ~}$ obtained either a web survey questionnaire or a telephone interview in all three rounds, or (2) that were classified as ineligible (ceased operations) in all three rounds, or (3) that completed an interview in the First Follow-Up and then was classified as out of business in the Second and Third Follow-Up, or (4) that completed an interview in the First and Second Follow-Up and then was classified as out of business in the Third Follow-Up. 
TABLE 14

WEIGHTED LONGITUDINAL RESPONSE RATES FOR THE FIRST AND SECOND FOLLOW-UP SURVEYS

RELATIVE TO THE BASELINE SURVEY AMONG BUSINESSES IN THE KAUFFMAN FIRM SURVEY: NON-TECHNOLOGY

\begin{tabular}{|c|c|c|c|}
\hline & Sample Count & Completes $^{\mathrm{a}}$ & Weighted Response Rate \\
\hline All & 2,894 & 2,107 & 72.7 \\
\hline \multicolumn{4}{|l|}{ Sole Proprietorship } \\
\hline Yes & 1,056 & 800 & 75.7 \\
\hline No & 1,838 & 1,307 & 70.9 \\
\hline \multicolumn{4}{|l|}{ Number of Owners } \\
\hline 1 & 1,754 & 1,294 & 73.7 \\
\hline 2 or more & 1,140 & 813 & 71.1 \\
\hline \multicolumn{4}{|l|}{ Total Revenue } \\
\hline$\$ 0$ & 1,018 & 700 & 68.7 \\
\hline$\$ 1$ to $\$ 25,000$ & 780 & 616 & 78.9 \\
\hline$\$ 25,001$ or more & 1,096 & 791 & 72.0 \\
\hline \multicolumn{4}{|l|}{ Total Debt } \\
\hline 0 & 1,205 & 891 & 73.8 \\
\hline Positive & 1,689 & 1,216 & 71.8 \\
\hline \multicolumn{4}{|l|}{ Age of the Responding Owner } \\
\hline 34 or younger & 553 & 370 & 66.9 \\
\hline 35 to 44 & 974 & 691 & 70.8 \\
\hline 45 to 54 & 821 & 621 & 75.2 \\
\hline 55 or older & 546 & 425 & 78.1 \\
\hline \multicolumn{4}{|c|}{ Responding Owner's Years of Experience } \\
\hline 0 to 6 & 1,300 & 945 & 72.6 \\
\hline 7 to 15 & 756 & 535 & 70.8 \\
\hline 16 or more & 838 & 627 & 74.5 \\
\hline \multicolumn{4}{|l|}{ Gender of the Responding Owner } \\
\hline Female & 843 & 625 & 74.3 \\
\hline Male & 2,051 & 1,482 & 71.9 \\
\hline \multicolumn{4}{|l|}{ Responding Owner's Education } \\
\hline Associate's degree or lower & 1,626 & 1,138 & 69.9 \\
\hline Bachelor's degree or higher & 1,268 & 969 & 76.1 \\
\hline
\end{tabular}

${ }^{\mathrm{a}}$ Completed cases include businesses with complete data for applicable questions. These included businesses (1) for which we obtained either a web survey questionnaire or a telephone interview in all three rounds, or (2) that were classified as ineligible (ceased operations) in all three rounds, or (3) that completed an interview in the First Follow-Up and then was classified as out of business in the Second and Third Follow-Up, or (4) that completed an interview in the First and Second Follow-Up and then was classified as out of business in the Third Follow-Up. 
medium-technology and non-technology strata, businesses whose revenues were between $\$ 1$ and $\$ 25,000$ had a higher response rate than others, and the differential was smaller for businesses in the medium-technology sampling stratum than in the non-technology stratum. In the hightechnology stratum, businesses having no revenue had the highest response rate, and businesses with higher revenue (over $\$ 100,000)$ had the lowest.

\section{Sampling Weights}

The initial sampling weight for the Third Follow-Up Survey is defined as the final analysis weight from the Baseline Survey, that is, the weight that includes the nonresponse adjustment and the post-stratification/raking adjustment. Table 15 shows the descriptive statistics of the initial sampling weight.

TABLE 15

DESCRIPTIVE STATISTICS OF INITIAL SAMPLING WEIGHT FOR THE THIRD FOLLOW-UP SURVEY

\begin{tabular}{lccccc}
\hline & Minimum & Maximum & Mean & Median & \multicolumn{2}{c}{ Std Deviation } \\
\cline { 2 - 6 } All & 1.17 & 46.98 & 14.87 & 17.69 & 8.69 \\
\hline High-technology & 1.17 & 3.42 & 1.86 & 1.84 & 0.34 \\
Medium-technology & 4.39 & 12.39 & 7.28 & 7.29 & 1.03 \\
Non-technology & 13.50 & 46.98 & 21.52 & 20.93 & 4.01 \\
\hline
\end{tabular}

\section{Nonresponse Adjustment}

In essentially all surveys, the sampling weights have to be adjusted to compensate for the panel members who cannot be located or who refuse to respond. The general approach was discussed in detail in DesRoches et al. (2007). For the Third Follow-Up Survey, we applied a similar strategy: we used weighted logistic propensity modeling separately for each technology stratum. Because of the high rate of locating the businesses, we incorporated both the location and the response status of sampled businesses into the modeling. That is, we used three response 
propensity logistic models (one for each technology sampling stratum). The two levels in the binary response for this model were "a located respondent" versus "nonrespondent or not located." For the KFS, a sample member was classified as a respondent if the sample member completed the questionnaire (that is, was an eligible respondent) or was determined to be ineligible (that is, was out of business). We used the inverse of the propensity score as the response adjustment factor. The response-adjusted weight for each sample case is the product of the initial weight and the response adjustment factor. Finally, we computed a raking factor in each technology stratum to ensure that the marginal sums of the weights were the same before and after nonresponse adjustment.

We developed the models using data from the responses to the Baseline Survey and the First and Second Follow-Up within the sampling technology groups. We evaluated the data as main effects and also investigated interactions among these variables. To identify candidate variables to be used as main effects and interactions among these variables for the modeling, we first ran a CHAID analysis in SPSS to find possible significant predictors and combinations of them. To further refine the candidate variables and interaction terms, we then processed, through forward and backward stepwise regression (using the SAS logistic procedure with weights normalized to the sample size), the variables and interactions we had identified with CHAID. After identifying a smaller pool of main effects and interactions for potential inclusion in the final model, we evaluated a series of models to determine the final parsimonious model. Because the SAS logistic procedure does not incorporate the sampling design, the final selection of the covariates was accomplished with the logistic regression procedure in SUDAAN using various measures of goodness of fit and predictive ability. ${ }^{9}$ For selecting variables or interactions in a model, we

\footnotetext{
${ }^{9}$ Research Triangle Institute. SUDAAN Language Manual, Release 9.0. Research Triangle Park, NC: Research Triangle Institute, 2004.
} 
included variables or interactions that have a statistical significance level (alpha level) of 0.30 or lower (instead of the standard 0.05). We used a higher significance level because the purpose of the model was to improve the estimation of the propensity score, not to identify statistically significant factors related to response. In addition, the information sometimes reflected proxy variables for some underlying variable that was both unknown and unmeasured. The variables used as main effects and the interactions in the response model are summarized in Table 16. The value for the R-squared statistic ranged from 0.08 to 0.11 for the various final models, and the Hosmer-Lemeshow statistics ranged from 0.21 to 0.97 . These values are similar to those observed for other response propensity modeling efforts using logistic regression with designbased sampling weights.

We used essentially the same approach to construct the longitudinal weights. The two levels in the binary response for this model were "longitudinal respondent" versus "longitudinal nonrespondent." For the purpose of longitudinal weighting, a sample member was classified as a respondent if any of the following apply:

- Completed the interview in all three rounds (that is, was an eligible respondent)

- Was determined to be ineligible in all three rounds (that is, was out of business)

- Completed the questionnaire in the First Follow-Up and then was out of business for the Second and Third Follow-Up

- Completed an interview in the First and Second Follow-Up and then was classified as out of business in the Third Follow-Up

The variables used as main effects and the interactions in the longitudinal response model are summarized in Table 17. The value for the R-squared statistic ranged from 0.08 to 0.15 for the various models, and the Hosmer-Lemeshow statistics ranged from 0.54 to 0.96 . These values are similar to those observed for other response propensity modeling efforts using logistic regression with design-based sampling weights. 
TABLE 16

SUMMARY OF NONRESPONSE MODELS FOR THE THIRD FOLLOW-UP SURVEY WEIGHTS

\begin{tabular}{|c|c|c|c|c|}
\hline Variable & Level & High-tech & Medium-tech & Non-tech \\
\hline Responding owner's age & 4 & Main & Main, Interaction & Interaction \\
\hline Responding owner's experience & 3 & Main & & Interaction \\
\hline Responding owner's education & 2 & & Main, Interaction & Interaction \\
\hline Responding owner's race & 2 & & Main & Main, Interaction \\
\hline Responding owner's full-time/part-time & 2 & Interaction & Main & Interaction \\
\hline Total assets & 3 & Interaction & Main, Interaction & Main \\
\hline Total revenue & 3 & Interaction & Main, Interaction & Interaction \\
\hline Total debt & 2 & & Main, Interaction & Interaction \\
\hline Total expense & 3 & & Interaction & Main, Interaction \\
\hline Total equity & 3 & & Main, Interaction & Main, Interaction \\
\hline Total liability & 2 & & Main & \\
\hline Legal status & 2 & & Main & Main \\
\hline Primary location & 2 & Main, Interaction & Main, Interaction & Interaction \\
\hline Number of owners & 2 & Interaction & Main & \\
\hline Number of employees & 2 & & Interaction & Main \\
\hline Having sales & 2 & Main & Interaction & Main, Interaction \\
\hline Providing services & 2 & Main, Interaction & & \\
\hline Providing products & 2 & & Main, Interaction & Interaction \\
\hline Major industry & 2 & & & Interaction \\
\hline Intellectual property & 2 & Main, Interaction & Main, Interaction & \\
\hline R\&D expenditure & 2 & Main & Main & \\
\hline Competitive advantage & 2 & Interaction & & Main, Interaction \\
\hline Full R-squared & & 0.114 & 0.124 & 0.084 \\
\hline Reduced R-squared & & 0.075 & 0.109 & 0.080 \\
\hline Hosmer-Lemeshow statistics & & 0.971 & 0.208 & 0.560 \\
\hline Percentage concordant & & 68.3 & 74.3 & 70.1 \\
\hline Percentage discordant & & 31.0 & 25.3 & 29.4 \\
\hline Percentage tied & & 0.7 & 0.4 & 0.5 \\
\hline
\end{tabular}


TABLE 17

SUMMARY OF NONRESPONSE MODELS FOR THE LONGITUDINAL WEIGHTS FOR THE FIRST, SECOND, AND THIRD FOLLOW-UP SURVEYS

\begin{tabular}{|c|c|c|c|c|}
\hline Variable & Level & High-tech & Medium-tech & Non-tech \\
\hline Responding owner's age & 4 & Main, Interaction & Main, Interaction & Interaction \\
\hline Responding owner's experience & 3 & Main, Interaction & Interaction & Main, Interaction \\
\hline Responding owner's gender & 2 & & Main, Interaction & \\
\hline Responding owner's education & 2 & Interaction & Interaction & Main, Interaction \\
\hline Responding owner's race & 2 & & Main, Interaction & Main, Interaction \\
\hline Responding owner's full-time/part-time & 2 & Interaction & Interaction & \\
\hline Total assets & 3 & Main, Interaction & Main, Interaction & \\
\hline Total revenue & 3 & Interaction & Main, Interaction & Interaction \\
\hline Total debt & 2 & & Main, Interaction & Interaction \\
\hline Total expense & 3 & & & Main, Interaction \\
\hline Total equity & 3 & Interaction & Main, Interaction & Main, Interaction \\
\hline Total liability & 2 & & & Interaction \\
\hline Legal status & 2 & & Main, Interaction & Main \\
\hline Primary location & 2 & Interaction & Main, Interaction & Main \\
\hline Number of employees & 2 & & Main, Interaction & \\
\hline Number of owners & 2 & & & Interaction \\
\hline Having sales & 2 & Main & Interaction & Main, Interaction \\
\hline Providing services & 2 & Interaction & & Main \\
\hline Major industry & 2 & & & Main \\
\hline Intellectual property & 2 & & & Interaction \\
\hline$R \& D$ expenditure & 2 & Main & Interaction & Main \\
\hline Competitive advantage & 2 & Main, Interaction & & Main \\
\hline Full R-squared & & 0.176 & 0.150 & 0.099 \\
\hline Reduced R-squared & & 0.146 & 0.121 & 0.083 \\
\hline Hosmer-Lemeshow statistics & & 0.803 & 0.960 & 0.544 \\
\hline Percentage concordant & & 74.3 & 73.3 & 67.2 \\
\hline Percentage discordant & & 25.3 & 26.4 & 32.4 \\
\hline Percentage tied & & 0.4 & 0.4 & 0.5 \\
\hline
\end{tabular}




\section{Raking}

In the final step of weighting, we applied a raking method. Raking is an iteration method and is essentially a post-stratification on a set of variables when only their marginal population distributions are known. In the previous rounds, we applied a single-level post-stratification within the three technology groups to make the sum of weights the same before and after nonresponse adjustments. In the Third Follow-Up Survey, to achieve better precision, we used raking adjustments within the six sampling strata defined by the technology group and woman ownership indicator. The set of variables for which we controlled for marginal totals include the four-level census division, the two-level MSA indicator, and the two-level industry (service industry or not). Collapsing might be needed within each individual variable to make sure there were enough cases within each cell. The raking adjustment factor ranged between 0.95 and 1.06 for the Third Follow-Up weights, and between 0.90 and 1.08 for the longitudinal weights.

\section{H. ESTIMATION}

\section{Point Estimation}

The KFS uses a simple stratified sampling design. As described in DesRoches et al. (2007), the businesses in the high-technology sampling stratum were oversampled substantially (actually all were included in the sample). We also oversampled the medium-technology businesses relative to the non-technology ones. The sampling weights take this oversampling into account to remove the potential bias in the estimates relative to unweighted estimates. Moreover, as shown in Section G, the response rate differed by factors like legal status, ownership, and age and education of the owner. The nonresponse adjustments described in Section G were designed to minimize potential nonresponse bias in the estimates. We strongly recommend the use of the nonresponse-adjusted weights for all estimates using the KFS data. 


\section{Variance and Interval Estimation}

Variance estimates calculated from KFS data must incorporate the sample design features to obtain the correct (approximately unbiased) estimates. Most procedures in standard statistical packages such as SAS, STATA, and SPSS are not appropriate for the proposed design, because the assumptions in these software packages or procedures are for independent, identically distributed observations or for simple random sampling with replacement. ${ }^{10}$ Although the simple random sample variance may approximate the true sampling variance for some surveys, it is likely to underestimate substantially the sampling variance with the KFS design.

The sampling variance is a measure of the variation of an estimator attributable to having sampled a portion of the full population of interest using a specific probability-based sampling design. The sampling variance is a measure of the variation of the estimate of a population parameter (for example, a population mean or proportion) over repeated samples, whereas the classic "population" variance is a measure of the variation among the observations in the population. The population variance is different from the sampling variance in the sense that the population variance is a constant, independent of any sampling issues, while the sampling variance becomes smaller as the sample size increases. The sampling variance is zero when the full population is observed, as in a census.

For the KFS, the sampling variance estimate is a function of the sampling design and the population parameter being estimated. Called the design-based sampling variance, it assumes the use of fully adjusted sampling weights, which are derived from the sampling design, with adjustments to compensate for nonresponse among the businesses and additional adjustments to align the sampling totals to external totals, as previously described. We developed a single fully

\footnotetext{
${ }^{10}$ STATA and SAS software packages now contain procedures that account for the sampling design and can be used for estimation of the sampling variances.
} 
adjusted sampling weight and information on analysis parameters (that is, analysis stratification) necessary for the estimation of the sampling variance for a statistic using the Taylor series linearization approach. The fully adjusted sampling weight and the analysis parameters can be used in survey data analysis procedures in SUDAAN or in certain procedures in STATA, SAS, and SPSS to compute design-unbiased variance estimates. These variance estimates can be used to make interval estimates. For example, for a proportion $(p)$ of businesses (or owners) with certain characteristics, the 90 percent confidence interval is

$$
[p-1.645 \times(\operatorname{std} \text { err. }(p)), p+1.645 \times(\operatorname{std} \text { err. }(p))]
$$

To identify sampling levels or stages, the SUDAAN software requires specifying the survey design and STRATA variables. This is the stratum variable we used when drawing the sample (that is, the six-level variable defined by technology group and woman-owned status).

\section{Selected Estimates and Variances}

The point and variance estimation procedures are straightforward, and we provide example estimates at the business level and the owner level here. These estimates are for the following variables (the question number and response categories are in parentheses).

Business level:

- Percentage of businesses that are sole proprietorships $(\mathrm{C} 1 \mathrm{z} 2=1)$

- Percentage of businesses that are partnerships $(\mathrm{C} 1 \mathrm{z} 2=5,6)$

- Percentage of businesses whose primary location is a residence such as a home or garage $(\mathrm{C} 8=1)$

- Percentage of businesses that have any patents, copyrights, or trademarks (any D3 = 1)

- Percentage of businesses that have R\&D expenditures $(\mathrm{F} 19=1)$

Owner level:

- Percentage of responding owners who are 25-44 (G4 = 2, 3) 
- Percentage of responding owners with higher than bachelor's degree (G9 = 7, 8, 9, 10)

- Percentage of responding owners who work full-time $(\mathrm{G} 1 \mathrm{~b} 1=3,4,5,6)$

- Percentage of responding owners who are women $(\mathrm{G} 10=2)$

Table 18 shows these estimates and their standard errors (the square root of the variance). 
TABLE 18

VARIANCE ESTIMATION FOR SOME BUSINESS AND OWNER CHARACTERISTICS

\begin{tabular}{|c|c|c|c|c|}
\hline & High-tech & $\begin{array}{c}\text { Sample } \\
\text { Size }\end{array}$ & Estimate & $\begin{array}{c}\text { Standard } \\
\text { Error }\end{array}$ \\
\hline \multirow[t]{4}{*}{ Percentage of businesses that are sole proprietorships } & All & 2,915 & 33.7 & 1.03 \\
\hline & High-tech & 434 & 19.2 & 1.95 \\
\hline & Medium-tech & 831 & 26.2 & 1.54 \\
\hline & Non-tech & 1,650 & 35.3 & 1.19 \\
\hline \multirow[t]{4}{*}{ Percentage of businesses that are partnerships } & All & 2,915 & 4.8 & 0.48 \\
\hline & High-tech & 434 & 1.2 & 0.49 \\
\hline & Medium-tech & 831 & 2.6 & 0.58 \\
\hline & Non-tech & 1,650 & 5.2 & 0.57 \\
\hline \multirow[t]{4}{*}{$\begin{array}{l}\text { Percentage of businesses that have any patents, copyrights, or } \\
\text { trademarks }\end{array}$} & All & 2,903 & 20.1 & 0.87 \\
\hline & High-tech & 433 & 33.8 & 2.35 \\
\hline & Medium-tech & 825 & 26.0 & 1.60 \\
\hline & Non-tech & 1,645 & 18.8 & 1.00 \\
\hline \multirow[t]{4}{*}{ Percentage of businesses that have $R \& D$ expenditures } & All & 2,906 & 15.0 & 0.78 \\
\hline & High-tech & 433 & 35.7 & 2.37 \\
\hline & Medium-tech & 829 & 18.1 & 1.42 \\
\hline & Non-tech & 1,644 & 14.0 & 0.90 \\
\hline \multirow{4}{*}{$\begin{array}{l}\text { Percentage of businesses whose primary location is a residence, such } \\
\text { as a home or garage }\end{array}$} & All & 2,762 & 48.8 & 1.12 \\
\hline & High-tech & 417 & 33.1 & 2.34 \\
\hline & Medium-tech & 787 & 61.5 & 1.81 \\
\hline & Non-tech & 1,558 & 47.0 & 1.30 \\
\hline \multirow[t]{4}{*}{ Percentage of responding owners who are 25 to 44} & All & 2,834 & 49.3 & 1.11 \\
\hline & High-tech & 420 & 38.3 & 2.41 \\
\hline & Medium-tech & 814 & 45.8 & 1.80 \\
\hline & Non-tech & 1,600 & 50.2 & 1.29 \\
\hline \multirow[t]{4}{*}{$\begin{array}{l}\text { Percentage of responding owners with higher than a bachelor's } \\
\text { degree }\end{array}$} & All & 2,821 & 50.0 & 1.10 \\
\hline & High-tech & 417 & 51.3 & 2.51 \\
\hline & Medium-tech & 812 & 72.5 & 1.63 \\
\hline & Non-tech & 1,592 & 46.1 & 1.29 \\
\hline \multirow[t]{4}{*}{ Percentage of responding owners who work full-time } & All & 2,831 & 64.2 & 1.06 \\
\hline & High-tech & 420 & 75.4 & 2.15 \\
\hline & Medium-tech & 813 & 61.1 & 1.73 \\
\hline & Non-tech & 1,598 & 64.5 & 1.22 \\
\hline \multirow[t]{4}{*}{ Percentage of responding owners who are women } & All & 2,834 & 29.9 & 0.80 \\
\hline & High-tech & 420 & 16.4 & 1.38 \\
\hline & Medium-tech & 814 & 22.1 & 0.99 \\
\hline & Non-tech & 1,600 & 31.5 & 0.94 \\
\hline
\end{tabular}





\section{SELECTED BIBLIOGRAPHY}

Ballou, Janice, Frank Potter, and David DesRoches. "Kauffman Firm Survey Design Report." Report submitted to the Ewing Marion Kauffman Foundation. Princeton, NJ: Mathematica Policy Research, Inc., December 10, 2004.

Ballou, Janice, Tom Barton, David DesRoches, Frank Potter, E.J. Reedy, Alicia Robb, Scott Shane and Zhanyun Zhao. "The Kauffman Firm Survey: Results from the Baseline and First Follow-Up Surveys.” Available at SSRN: http://ssrn.com/abstract=1098173, March 2008.

Ballou, Janice, Zhanyun Zhao, Frank Potter, and David DesRoches. "Meeting the Challenges of Designing the Kauffman Firm Survey (KFS): Sampling Frame, Definitions, Questionnaire Development, and Respondent Burden." Proceedings of the International Conference on Establishment Surveys, Montreal, June 2007.

DesRoches, David, Janice Ballou, Frank Potter, Betsy Santos, and Zhanyun Zhao. "Kauffman Firm Survey Second Follow Up Methodology Report." Final report submitted to the Ewing Marion Kauffman Foundation. Princeton, NJ: Mathematica Policy Research, Inc. Available at SSRN: http://papers.ssrn.com/sol3/papers.cfm?abstract_id=1284474 October 7, 2008.

DesRoches, David, Tom Barton, Jaceey Sebastian, Betsy Santos, Frank Potter, and Janice Ballou. "Kauffman Firm Survey Baseline Methodology Report." Final report submitted to the Ewing Marion Kauffman Foundation. Princeton, NJ: Mathematica Policy Research, Inc. Available at SSRN: http://papers.ssrn.com/sol3/papers.cfm?abstract_id=1024045, August 7, 2007.

DesRoches, David, Tom Barton, Janice Ballou, Frank Potter, Zhanyun Zhao, Betsy Santos, and Jaceey Sebastian. "Kauffman Firm Survey First Follow Up Methodology Report." Final report submitted to the Ewing Marion Kauffman Foundation. Princeton, NJ: Mathematica Policy Research, Inc. Available at SSRN:

http://papers.ssrn.com/sol3/papers.cfm?abstract_id=1116766 April 8, 2008.

Potter, Frank, Zhanyun Zhao, David DesRoches, and Janice Ballou. "Response Rates and Response Patterns Among New Employers: Results from the Kauffman Firm Survey." Proceedings of the American Statistical Association Survey Methods Section, August 2006. 

APPENDIX A

KFS THIRD FOLLOW-UP QUESTIONNAIRE PROPOSED CHANGES 

FROM: David DesRoches

DATE: $2 / 4 / 2008$

KFS - 110

SUBJECT: Comments on proposed question additions to Kauffman Firm Survey questionnaire

\section{INTRODUCTION}

The Kauffman Firm Survey (KFS) plans a Third Follow-Up Survey in 2008. As part of the Kauffman Foundation's outreach to data users, a request for proposals was issued in October 2007 for new questions to be added to the KFS questionnaire. Four sets of questions were submitted, totaling 34 questions. Given the length of the Second Follow-Up Survey questionnaire (33 minutes on average by telephone), it will be necessary to prioritize the proposed questions so as to limit the increase in respondent burden and any corresponding reduction in the survey response rate. In evaluating the suggested questions, MPR considered their relevance to the KFS panel, the likely effect of adding the question on respondent burden and, and the potential issues involved in administering the question. This memo details the questions submitted, along with comments from MPR staff on the KFS project team.

\section{PROPOSED QUESTIONS FROM THE NATIONAL SCIENCE FOUNDATION}

\section{A. Follow-up to C8 (Business Location)}

C8a. Next, I'm going to ask you whether you chose this location to be close to several types of organizations. The first one is [READ FIRST ITEM]. Did you chose this location to be close to [or in] a [REPEAT FIRST ITEM]. The next one is [READ NEXT ITEM]? [As necessary:] Did you chose this location to be close to [or in] a [REPEAT ITEM].

\begin{tabular}{|l|c|c|c|c|}
\hline & Yes & No & $\begin{array}{c}\text { Don't } \\
\text { know }\end{array}$ & Refused \\
\hline Science or research park & & & & \\
\hline Business incubator center & & & & \\
\hline Technology corridor & & & & \\
\hline University or college & & & & \\
\hline
\end{tabular}


MEMO TO: E. J. Reedy

FROM: David DesRoches

DATE: $\quad 2 / 4 / 2008$

PAGE: 2

Read descriptions as needed:

Science parks, also called research parks, are real estate developments designed to promote technology development. Many science parks are affiliated with universities or government agencies.

Business incubator centers are facilities to help startup companies grow through the use of business services and other shared resources. Business incubators can be located in science and research parks.

Technology corridors are loosely-defined geographic areas with clusters of technologyoriented companies. They are typically located near a population center or a major highway or airport.

Universities and colleges include branch campuses, research centers, and any other location of an academic institution.

\section{MPR comments:}

1. This question is most appropriate for businesses that are primarily operated from a nonresidential setting. We are concerned that the proximity of home-based businesses to these types of locations will not be meaningful for analysis, and we recommend that home-based businesses be skipped over this question.

2. We are somewhat concerned that businesses may be chosen to locate near a "university or college" for reasons that have nothing to do with innovation, especially among KFS non-tech businesses. We would recommend looking at the data collected at a question like this be used in conjunction with data on primary industry. As an alternative, this question could only be asked of high-tech and medium-tech businesses.

3. In addition to the question on primary location asked in the Baseline Survey, the followup surveys have also included questions about the reason for changes in primary location and the number of locations the business has. We recommend that if this question is added to the KFS, that it be placed after the question about the reason for changes in the primary location (currently question C9), and before the question about additional locations (currently question C10).

4. In terms of the question wording, we would recommend an opening statement that is clearly tied to the primary location, and expanding the description of the list, since some of the items on the list are not organizations per se. An example is:

"Now, focusing on your current primary location of [READ C8 RESPONSE], I'm going to ask you whether you chose this location to be close to several types of several types of organizations or areas." 
MEMO TO:

FROM:

DATE:

E. J. Reedy

PAGE:

David DesRoches

$2 / 4 / 2008$

\section{B. Follow-up to D2 (Competitive advantage)}

(If respondent answers "YES" in D2.)

D2a. I'm going to ask you about several items that could have contributed to your company's competitive advantage both in calendar year 2007 and in 2004 when you started your company. For each one I read, please tell me if it is a major reason, a minor reason, or not a reason for your competitive advantage in 2007. After that, I will ask you if this is something about your company that was the same or different in 2004. If an item does not seem to apply to you, you can say that it is not a reason. The first one is [READ FIRST ITEM].

[As necessary:] Would you say that is a is a major reason, a minor reason, or not a reason for your competitive advantage in 2007? Is that the same situation or different from 2004? If "different," ask: In 2004 was it a major reason, a minor reason, or not a reason for your company's competitive advantage.

The next item is [READ NEXT ITEM]. [As necessary:] Would you say that is a major reason, a minor reason, or not a reason for your competitive advantage in 2007? Is that the same situation or different from 2004? If "different," ask: In 2004 was that a major reason, a minor reason, or not a reason for your company's competitive advantage?

\begin{tabular}{|l|l|l|l|l|l|l|l|l|}
\hline & \multicolumn{2}{|c|}{2007} & & & & \\
\hline & $\begin{array}{c}\text { Major } \\
\text { reason }\end{array}$ & $\begin{array}{c}\text { Minor } \\
\text { reason }\end{array}$ & $\begin{array}{c}\text { Not a } \\
\text { reason }\end{array}$ & $\begin{array}{c}\text { Major } \\
\text { reason }\end{array}$ & $\begin{array}{c}\text { Minor } \\
\text { reason }\end{array}$ & $\begin{array}{c}\text { Not a } \\
\text { reason }\end{array}$ & $\begin{array}{c}\text { Don't } \\
\text { know }\end{array}$ & Refused \\
\hline $\begin{array}{l}\text { Teaming up with a college or } \\
\text { university }\end{array}$ & & & & & & & & \\
\hline $\begin{array}{l}\text { Teaming up with a government } \\
\text { laboratory or government_research } \\
\text { center }\end{array}$ & & & & & & & & \\
\hline Teaming up with another company & & & & & & & & \\
\hline $\begin{array}{l}\text { A patent, such as one awarded to } \\
\text { your company, one that you applied } \\
\text { for, or one that you licensed }\end{array}$ & & & & & & & & \\
\hline $\begin{array}{l}\text { The science and technology of your } \\
\text { products or services }\end{array}$ & & & & & & & & \\
\hline
\end{tabular}

\section{MPR comments:}

1. The first sentence assumes that the competitive advantage was static between 2004 and 2007 (meaning the business had an advantage at both points in time), which is not necessarily true and may confuse respondents. The KFS has consistently taken the approach of reducing respondent recall problems by concentrating on the previous calendar year during each survey round. For this reason, we strongly recommend asking this set of questions of calendar year 2007 only. 
MEMO TO: E. J. Reedy

FROM: David DesRoches

DATE: $\quad 2 / 4 / 2008$

PAGE: $\quad 4$

2. Given that these questions are likely to be most relevant to high-tech businesses, we recommend screening questions so that non-tech businesses do not have to answer the entire list. For example, the following two questions could be asked of all respondents reporting a competitive advantage at D2:

a. Is the competitive advantage you have related in any way to teaming up with a college or university, a government research center, or another company?

b. Is the competitive advantage that you have related in any way to patents you own, have applied for, or licensed, or to unpatented science and technology that you own?

If "No" to both questions, they would skip the grid, and if "Yes" to both, they would answer the whole set of questions. If "Yes" to one and "No" to the other, they would only be asked the questions related the "Yes" answer. We believe this would strike a balance between gathering useful information and increasing respondent burden.

\section{Follow-up to F19 (Research and Development spending)}

\section{IF BUSINESS REPORTED “0” spending at F19, GO TO F20.}

F19a. Could you please estimate how much your company spent on R\&D in 2007 including salaries, wages, and benefits?

$\$$

[if volunteered:] None

Don't know

Refused

IF DON'T KNOW OR REFUSED, PROBE: You don't have to give me an exact figure; your best estimate will do.

\section{MPR comments:}

1. Prior to the Baseline Survey, we piloted questions on the total amount the business spent on $\mathrm{R} \& \mathrm{D}$, but the question was dropped from the Baseline Survey due to the difficulty of respondent being able to provide an accurate figure. This may be less of a problem with more established businesses and asking this only of those who reported some spending.

2. We assume this question is trying to capture a total expenditure figure for $R \& D$, not just salaries, wages, and benefits. If so, we should include other expenses that should be included (such as materials, equipment, space, etc.) or risk having some respondents include only the items mentioned in the current question. 
MEMO TO: E. J. Reedy

FROM: David DesRoches

DATE: $\quad 2 / 4 / 2008$

PAGE: $\quad 5$

3. For Don't Know, Refused, or Blank responses, we recommend using the standard KFS ranges used for other financial questions in the survey.

F19b. Of your R\&D spending in 2007 [As necessary: READ TOTAL AMOUNT], could you please estimate the percent of the total, if any, that was used for projects that have a biotechnology application?

percent

[if volunteered:] None

Don't know

Refused

IF DON'T KNOW OR REFUSED, PROBE: You don't have to give me an exact figure; your best estimate will do.

[As needed:] Biotechnology is the use of science and engineering for the study of living organisms.

F19c. Of your R\&D spending in 2007 [As necessary: READ TOTAL AMOUNT], could you please estimate the percent of the total, if any, that was used for projects that use materials synthesis and processing?

percent

[if volunteered:] None

Don't know

Refused

IF DON'T KNOW OR REFUSED, PROBE: You don't have to give me an exact figure; your best estimate will do.

IF RESPONDENT ASKS WHETHER TO INCLUDE WHAT THEY ALREADY REPORTED IN F19b, THE ANSWER IS "YES."

[As needed:] Materials synthesis and processing is the use of science and engineering to form and manipulate new materials. 
MEMO TO: E. J. Reedy

FROM: David DesRoches

DATE: $\quad 2 / 4 / 2008$

PAGE: $\quad 6$

F19d. Of your R\&D spending in 2007 [As necessary: READ TOTAL AMOUNT], could you please estimate the percent of the total, if any, that was used for software projects.

percent

[if volunteered:] None

Don't know

Refused

IF DON'T KNOW OR REFUSED, PROBE: You don't have to give me an exact figure; your best estimate will do.

IF RESPONDENT ASKS WHETHER TO INCLUDE WHAT THEY ALREADY REPORTED IN F19b OR F19c, THE ANSWER IS “YES.”

[As needed:] Software is the programs, applications, routines, and so forth, for computers, excluding those used exclusively for company operations.

\section{MPR comment:}

1. The question and optional probe at F19d should be more explicit about including software developed for products and services, and excluding software for internal use only.

2. We should consider a screening question that asks if any of the R\&D was for biotechnology, materials, or software, in turn. If the answer is "Yes" to one or more than one, we could follow up with questions about each of those. This would reduce respondent burden.

F19e. Of your R\&D spending in 2007 [As necessary: READ TOTAL AMOUNT], did you obtain any of that though a federal government research program such as the Small Business Innovation Research program — SBIR, the Advanced Technology Program — ATP, or any another federal research program?

Yes

No

Don't know

Refused

IF F19e is No, Don't know, OR Refused, GO TO F20. 
MEMO TO: E. J. Reedy

FROM: David DesRoches

DATE: $\quad 2 / 4 / 2008$

PAGE: $\quad 7$

F19e1. Could you give me the names of the federal government research programs that helped you?

Small Business Innovation Research (SBIR) program

Advanced Technology Program (ATP)

Other (Specify answers)

\section{MPR comment:}

1. It is not clear whether the list of programs at F19e1 is read to the respondent or not. We recommend that each item in the list be read with a "Yes/No" option for response.

2. Prior to the Baseline Survey, we piloted questions on participation of businesses in SBIR, HUBZone, and 8(a) business development certification. These question was dropped from the Baseline Survey due to the low level of participation reported by respondents. We are concerned that incidence will not have increased appreciably among KFS businesses, so that the questions may not produce sufficient businesses participating in these programs for analysis..

D. Follow-up to F20 (Purchase of new or used machinery or equipment)

IF BUSINESS REPORTED “0” PURCHASES AT F20, GO TO F21.

F20a. Could you please estimate how much your company spent on these purchases?

$\$$

[if volunteered:] None

Don't know

Refused

IF DON'T KNOW OR REFUSED, PROBE: You don't have to give me an exact figure; your best estimate will do.

\section{MPR comments:}

1. Prior to the Baseline Survey, we piloted questions on the total amount the business spent on new or used machinery or equipment, but the question was dropped from the Baseline Survey due to the difficulty of respondent being able to provide an accurate figure. This may be less of a problem with more established businesses and only asking this of those who reported some spending.

2. For Don't Know, Refused, or Blank responses, we recommend using the standard KFS ranges used for other financial questions in the survey. 
MEMO TO: E. J. Reedy

FROM: David DesRoches

DATE: $\quad 2 / 4 / 2008$

PAGE: $\quad 8$

\section{E. Follow-up to G9 (Highest level of education)}

IF EDUCATION IS 01 TO 05, GO TO G10.

IF EDUCATION IS 08, GO TO G9b.

G9a. What was the primary field of study for that degree?

IF EDUCATION IS 06, 07, 09, 10, GO TO G10.

G9b. What was the primary field of study for [your/the OWNER'S] bachelor's degree?

\section{MPR comments:}

1. During the development of the KFS questionnaire, we were sensitive to the need to include demographic questions that one owner-operator (as respondent) could answer accurately for all other owner-operators in the business. The result of this effort has been very low item nonresponse among the demographic questions. We feel these questions will have above average item nonresponse due to some owner-operators not knowing the field of study for other owner-operators.

2. For the follow-up surveys, we have been asking the education question about owneroperators only if they were new to the business (and we therefore needed to ask the entire demographic battery), or if we were unable to collect this information during previous rounds of the survey (due to refusal). These follow-up questions would require the education question to be asked of all owner-operators during the Third Follow-Up.

3. Adding these questions will also increase the amount of coding effort required for the survey. We estimate that over 2,500 text string verbatim responses will be collected through the addition of these questions. We would need to know the most appropriate taxonomy to code these verbatim to (CIP, SESTAT), and the level of specificity required. 
MEMO TO: E. J. Reedy

FROM: $\quad$ David DesRoches

DATE: $\quad 2 / 4 / 2008$

PAGE: $\quad 9$

\section{PROPOSED QUESTIONS FROM DR. CHARLES BRAYMAN (KANSAS STATE UNIVERSITY)}

\section{QUESTION 1:}

A domestic business is a business based in the United States. A foreign business is a business based in foreign country. The primary competitors of [NAME BUSINESS] in calendar year 2007 were:

DOMESTIC BUSINESSES

FOREIGN BUSINESSES

BOTH FOREIGN AND DOMESTIC BUSINESSES

DON'T KNOW

REFUSED

QUESTION DELIVERY: Computer-Assisted Telephone and Web-based Survey QUESTION TESTED: No

PROPOSED LOCATION IN SURVEY: After Question D3 or Globalization Module SPECIFIC POPULATION: All Respondents

\section{MPR comment:}

1. This question, if added to the KFS, would probably be best placed after D2, which asks about competitive advantage.

\section{QUESTION 2:}

What percentage of the sales of [NAME BUSINESS] was to foreign parties in calendar year 2007 ?

[_______ $]$ PERCENTAGE

\section{DON'T KNOW}

REFUSED

QUESTION DELIVERY: Computer-Assisted Telephone and Web-based Survey QUESTION TESTED: No

PROPOSED LOCATION IN SURVEY: After Question D7 or Globalization Module

SPECIFIC POPULATION: Respondents with YES for D6 
MEMO TO: E. J. Reedy

FROM: David DesRoches

DATE: $\quad 2 / 4 / 2008$

PAGE: $\quad 10$

\section{MPR comments:}

1. The current question refers to foreign "parties," which may be a confusing term for respondents. We suggest using the same terms used in question D7 and identifying those as being outside the U.S. For example, the question could be revised to:

"Some businesses make sales to individuals, businesses, or governments outside the United States. In calendar year 2007, what percentage of [NAME BUSINESS]'s sales were to individuals, businesses, or governments located outside the United States?"

2. We expect the percentage of businesses in the KFS sample that export will be fairly low. Another approach to this question is to employ a screening question to determine if any of the business' sales were of an export nature, and ask the percentage question only of those who indicate the business had export sales.

\section{QUESTION 3:}

Which of the following have prevented or restricted foreign sales?

(RESPONDENT MAY CHOOSE MORE THAN ONE) LIMITED KNOWLEDGE OF FOREIGN MARKET CONDITIONS COST OF ESTABLISHING A FOREIGN MARKET UNITED STATES EXPORT RESTRICTIONS TARIFFS, QUOTAS, AND OTHER REGULATIONS OF FOREIGN COUNTRIES DON'T KNOW REFUSED

QUESTION DELIVERY: Computer-Assisted Telephone and Web-based Survey QUESTION TESTED: No PROPOSED LOCATION IN SURVEY: After Proposed Question 2 SPECIFIC POPULATION: Respondents with YES for D6

\section{MPR comments:}

1. For this question, it will be important to establish that businesses reporting no foreign sales actually attempted to make such sales. Those respondents whose businesses never considered foreign markets will have a hard time answering this question. A screener question would identify those businesses who reported no foreign sales but had tried to make them. The proposed question could then be asked of this group.

2. The use of the word "restricted" suggests that those businesses with limited foreign sales could be asked this question. We would suggest limiting the question to only those businesses that tried and failed to establish foreign sales, since defining a benchmark 
MEMO TO: E. J. Reedy

FROM: David DesRoches

DATE: $\quad 2 / 4 / 2008$

PAGE: $\quad 11$

percentage as limited seems arbitrary (for example, businesses may be satisfied or at capacity making a small percentage of sales to foreign parties).

3. We would suggest an "Other-Specify" response option be added to the question.

\section{QUESTION 4:}

Which type of party did [NAME BUSINESS] license out [ITEMS ANSWERED YES IN D4] in calendar year 2007?

$\begin{array}{lll}\text { PATENTS } & \text { COPYRIGHTS } & \text { TRADEMARKS } \\ \text { DOMESTIC } & \text { DOMESTIC } & \text { DOMESTIC } \\ \text { FOREIGN } & \text { FOREIGN } & \text { FOREIGN } \\ \text { BOTH } & \text { BOTH } & \text { BOTH } \\ \text { DON'T KNOW } & \text { DON'T KNOW } & \text { DON'T KNOW } \\ \text { REFUSED } & \text { REFUSED } & \text { REFUSED }\end{array}$

QUESTION DELIVERY: Computer-Assisted Telephone and Web-based Survey QUESTION TESTED: No

PROPOSED LOCATION IN SURVEY: After Question D4 or Globalization Module

SPECIFIC POPULATION: Respondents with YES for any part of D4

\section{QUESTION 5:}

Which type of party did [NAME BUSINESS] license in [ITEMS ANSWERED YES IN D5] in calendar year 2007 ?

PATENTS
DOMESTIC
FOREIGN
BOTH
DON'T KNOW
REFUSED

COPYRIGHTS
DOMESTIC
FOREIGN
BOTH
DON'T KNOW
REFUSED

\author{
TRADEMARKS \\ DOMESTIC \\ FOREIGN \\ BOTH \\ DON'T KNOW \\ REFUSED
}

QUESTION DELIVERY: Computer-Assisted Telephone and Web-based Survey QUESTION TESTED: No

PROPOSED LOCATION IN SURVEY: After Question D5 or Globalization Module SPECIFIC POPULATION: Respondents with YES for any part of D5

RATIONALE AND BACKGROUND: 
MEMO TO: E. J. Reedy

FROM: $\quad$ David DesRoches

DATE: $\quad 2 / 4 / 2008$

PAGE: $\quad 12$

\section{MPR comment:}

1. We suggest rewording these questions so they use similar terminology to that suggested above at Question 2. Although these questions are unlikely to increase respondent burden for most respondents since few will qualify to be asked them, the small portion of the sample answering them are likely to be the most valuable in terms of growth potential. We are concerned about increasing respondent burden among this group.

\section{QUESTION 6:}

Did [NAME BUSINESS] purchase equipment or materials from foreign parties during calendar year 2007 ?

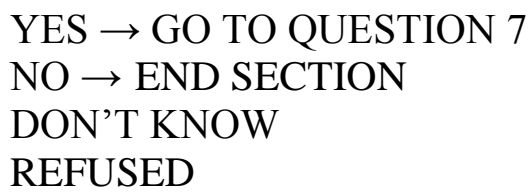

QUESTION DELIVERY: Computer-Assisted Telephone and Web-based Survey QUESTION TESTED: No PROPOSED LOCATION IN SURVEY: After Question F17 or Globalization Module SPECIFIC POPULATION: All Respondents

\section{MPR comment:}

1. For this question it will be important to distinguish between importing equipment or materials from outside the U.S. versus purchasing goods from a foreign company located in the U.S. Rather than use the phrase "foreign parties," we recommend asking whether they purchased equipment or materials from outside the U.S.

\section{QUESTION 7:}

Which of the following contributed to the decision to purchase equipment or materials from foreign sources during calendar year 2007?

FOREIGN SOURCES HAD A LOWER PRICE

GOOD NOT PRODUCED BY SOURCES IN THE UNITED STATES

DON'T KNOW

REFUSED

QUESTION DELIVERY: Computer-Assisted Telephone and Web-based Survey QUESTION TESTED: No 
MEMO TO: E. J. Reedy

FROM: David DesRoches

DATE: $\quad 2 / 4 / 2008$

PAGE: $\quad 13$

PROPOSED LOCATION IN SURVEY: After Proposed Question 6 or Globalization Module

SPECIFIC POPULATION: Respondents with YES for Proposed Question 6

\section{MPR comments:}

1. We assume that respondents can select multiple responses to this question.

2. We recommend including a "foreign sources had higher quality" response option.

3. We recommend including an "Other-Specify" response option.

\section{PROPOSED QUESTIONS FROM DR. ALICIA ROBB (UNIVERSITY OF CALIFORNIA - SANTA CRUZ)}

These would be placed after F14.

READ: This next section is about recent applications for credit. I want you to include renewals of, and new applications for, lines of credit and other types of loans. Do not include applications for credit cards, loans from owners, or trade credit with suppliers. Also, do not include applications that were withdrawn or that are still pending.

How many times in the last three years did the firm apply for new loans?

NUMBER:

$\mathrm{DK} / \mathrm{RF}$

\section{MPR comments:}

1. Prior to the KFS Baseline Survey, we piloted similar questions on applications for financing and denials. These were removed from the Baseline Survey questionnaire after review of the pilot data, with the reasoning that denial of applications represented very different outcomes according to industry, which affected the usefulness of the data collected.

2. The use of a three-year time frame would differ from all other time references in the questionnaire. The KFS has consistently taken the approach of reducing respondent recall problems by concentrating on the previous calendar year during each survey round. For this reason, we recommend asking this set of questions of calendar year 2007 only. Also, is the current question asking about three calendar years, or three years from the date of the Third Follow-Up interview?

3. We are assuming that respondents reporting zero credit applications will skip out the rest of these questions. 
MEMO TO: E. J. Reedy

FROM: David DesRoches

DATE: $\quad 2 / 4 / 2008$

PAGE: $\quad 14$

Were these loan applications always approved, always denied, or sometimes approved and sometimes denied?

ALWAYS APPROVED .....................................................

ALWAYS DENIED …....................................................

SOMETIMES APPROVED/SOMETIMES DENIED .............3

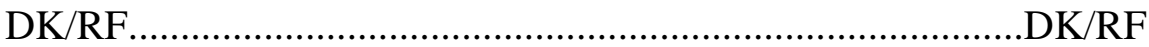

IF ANY DENIALS: (Otherwise skip to last 2 questions)

For your most recent denial, what official reasons did the funder give for denying the firm's application?

Do you think there were any other reasons that the application was turned down?

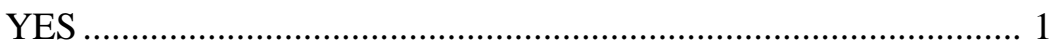

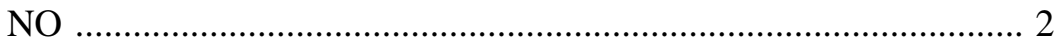

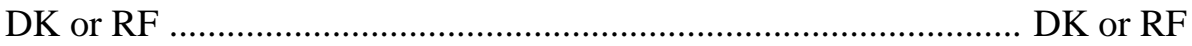

What were they?

During the last three years, were there times when [FIRM] needed credit, but did not apply because it thought the application would be turned down?

IF R ASKS ABOUT CANCELlED APPLICATIONS, SAY: Include applications that were withdrawn because the firm suspected it would be turned down.

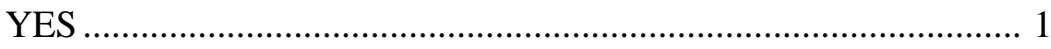

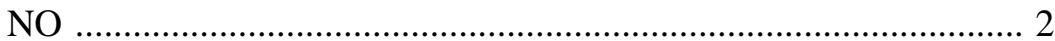

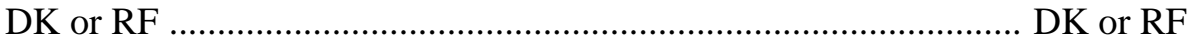

Why did you think the firm would have been turned down? 
MEMO TO:

FROM:

DATE:

E. J. Reedy

PAGE:

David DesRoches

$2 / 4 / 2008$

15

\section{CODEFRAME FOR}

I* Terms of loan sought */

11 = Insufficient collateral or no guarantee available $47=$ Tax Lien, Judgments $98=$ Not ascertainable

$12=$ Loan too large (personal or business lawsuits) $. \mathrm{D}=$ Don't know

$13=$ Loan too small $/ *$ Miscellaneous $* /$. R=Refuse

$14=$ Size of loan (small vs. large n.a.) $51=$ Inability to audit account $. S=$ Legitimate skip

/* Type of loan */ 52 = Insufficient time to process application

21 = Loan would overconcentrate inst. Portfolio 53 = Inadequate documentation provided.

$22=$ Institution doesn't like to make loans of this type $54=$ Federal rules or regulations make loan difficult or impossible

/* General reasons */ $56=$ Economy, slow or weak economy

$30=$ Credit history, not otherwise specified $/ *$ Institutional error or prejudice*/

$31=$ Business credit history $61=$ Institution made a mistake

$32=$ Personal credit history $62=$ Informational problem, fact blown out of proportion

$33=$ Poor balance sheet, financial situation $63=$ Arbitrariness

(included embezzlement, fraud, theft) $64=$ Personality conflict

$34=$ Firm would fail institution's formula or guidelines $65=$ Prejudice on racial/ethnic basis

(included owner too young, lack of business plan) $66=$ Prejudice against women

$35=$ Ability to renew/repay questionable $69=$ Prejudice or discrimination (not-specified or other)

$36=$ Firm not in business long enough $/ *$ Other reasons to anticipate turndown $* /$

(included young management) $71=$ Experience with previous loan applications

/* Characteristics of firm */ $72=$ Banks don't loan to (small) business

$41=$ Firm too small for institution, too few assets (includes self-employed or no employees)

42 = Large amount of outstanding loans, overextended $/ *$ Problem responses */

$43=$ Firm too highly leveraged, too little equity $94=$ Same as previous

$45=$ Firm in declining or risky industry $95=$ No particular reason

$46=$ Bad fit between institution and firm 97=Other

\section{MPR comments:}

1. We are concerned that respondents will not recall specifically the "official" reasons the funder provided in the first question, especially if the most recent denial was some time ago.

2. For the second question, we would clearly be collecting the respondent's perceptions or expectations of why they were denied. The KFS has tried to avoid including perception questions, since the respondent may vary from one survey round to another-making comparison across rounds less meaningful.

3. The code frame provided would not be able to be displayed for the web survey, which would mean collecting verbatim responses for these two questions and coding them after collection. This will increase the amount of coding effort required for the survey.

In terms of getting access to credit, how do you think 2007 compared with $2005 \& 2006 ?$

More Difficult 1

Less Difficult. .2

The Same 3

DK or RF . DK or RF 
MEMO TO: E. J. Reedy

FROM: David DesRoches

DATE: $\quad 2 / 4 / 2008$

PAGE: $\quad 16$

\section{MPR comment:}

1. This is another perception question (see above). Also, because the time frame for the first question is three years, we cannot be sure that the business sought credit during both 2007 and 2005-2006.

Did your business experience any negative effects from the subprime lending market meltdown (crisis)?

YES $\mathrm{NO}$

\section{MPR comment:}

1. This is another perception question (see above).

\section{PROPOSED QUESTIONS FROM DRS. PURI AND ROBINSON (DUKE UNIVERSITY)}

We propose adding two questions to the end of Section D that would branch off an affirmative response to Question D7.b. If the respondent firm answers "Yes" to D7.b, we would ask:

D8: Do you have other business relationships with any of these firms?

Yes No

D9: (If D8==Yes) What type of business relationships are these? (check all that apply)

Strategic Alliance

Joint Venture

Co-Marketing Agreement

Co-Distribution Agreement

R\&D Alliance

Subsidiary

\section{MPR comment:}

1. We would suggest defining the "relationships" referred to in the question by including examples such as "joint ventures or distribution agreements." 
MEMO TO: E. J. Reedy

FROM: David DesRoches

DATE: $\quad 2 / 4 / 2008$

PAGE: $\quad 17$

We also propose a series of questions to appear immediately after Question F.6 in the business finances section. If Question F.3D is answered "Yes", then we would branch to the following questions after F.6:

New F7: Do you have any other business relationships with this firm?

Yes No

New F8: (If F8==Yes) What type of business relationships are these? (check all that apply)

Strategic Alliance

Joint Venture

Co-Marketing Agreement

Co-Distribution Agreement

R\&D Alliance

Subsidiary

\section{MPR comments:}

1. We would suggest defining the "relationships" referred to in the question by including examples such as "joint ventures or distribution agreements."

2. The proposal references asking these questions of all listed owners at F6 "in a Likert format." Is the intent here that one respondent for the business be asked whether each of the owners (owner-operators and non-operating equity holders in the business) have a relationship with the business(es) referred to in F.3d? If so, we feel this would be problematic, since nonoperating owners in F.3 can represent multiple individuals such as spouses, family members, and angels. Our recommendation would be to concentrate on the relationships between the sampled business and the business(es) that own a share of the sampled business (at F.3d) only. 

APPENDIX B

KAUFFMAN FIRM SURVEY THIRD FOLLOW-UP QUESTIONNAIRE 

MPR Reference No.: 6091-410

MATHEMATICA

Policy Research, Inc.

\section{Kauffman Firm Survey}

Third Follow-Up

Final Questionnaire

May 15, 2008 



\section{A. INTRODUCTION}

INTRO: Hello, my name is . I'm calling on behalf of the Kauffman Foundation.

May I speak with (OWNER NAME/the owner or CEO of [NAME BUSINESS])?

OWNER NAME = Second Follow-Up Respondent for Section A.

\begin{tabular}{|c|c|}
\hline OWNER NAME —BAD TIME/CALL BACK ................. $02 \rightarrow$ & GO TO A2a \\
\hline 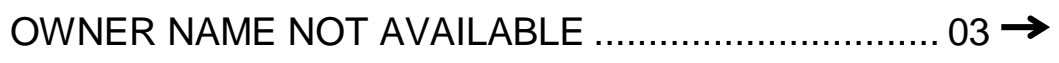 & GO TO Inform \\
\hline OWNER NAME NO LONGER WITH BUSINESS.......... $04 \rightarrow$ & $\begin{array}{l}\text { GO TO A1a } \\
\text { [then } A 4 w e b \\
\text { if } A 1 a=1 \text { ] }\end{array}$ \\
\hline USINESS NO LONGER IN OPERATION .................. $05 \rightarrow$ & GO TO A10 \\
\hline d & T \\
\hline
\end{tabular}

A1a. Your business has been participating in the Kauffman Firm Survey. Last year we asked you some questions about [NAME BUSINESS]'s operations in 2006. Now we'd like to ask about calendar year 2007.

We'd like to confirm that the name of the business is [NAME BUSINESS] and that [NAME BUSINESS] is still operating.

[NAME BUSINESS] IS THE CURRENT NAME

AND [NAME BUSINESS] IS STILL OPERATING......... 01

THE BUSINESS NAME IS INCORRECT .................. $02 \rightarrow$ GO TO A2Web

[NAME BUSINESS] IS OUT OF BUSINESS ............... $03 \rightarrow$ GO TO A10

A1b. We'd like to confirm that you are [OWNER NAME] and you are you are still an owner of [NAME BUSINESS]?

[OWNER NAME] IS THE RESPONDENT AND IS

STILL AN OWNER OF [NAME BUSINESS]....

[OWNER NAME] IS THE RESPONDENT AND IS

STILL AN OWNER OF [NAME BUSINESS], BUT

CORRECT [OWNER NAME]'S NAME.

02 $\rightarrow$ GO TO A4aWeb

RESPONDENT IS NOT [OWNER NAME].

03 $\rightarrow$ GO TO A4Webz

THE RESPONDENT [OWNER NAME] IS NO

LONGER AN OWNER OF [NAME BUSINESS] 07 $\rightarrow$ GO TO A5a Box 
A1c. We'd like to confirm that the title of your position is [TITLE]? Is that correct?

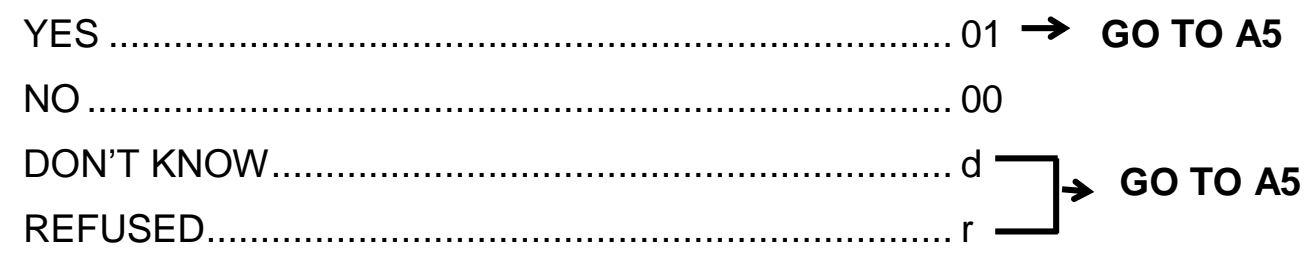

A1d. What is your job title?

INTERVIEWER: ENTER JOB TITLE.

UPDATE TITLE

\section{GO TO A5}

A2a. I'm sorry. When would be a better time to reach (you/[OWNER])?

INTERVIEWER: ENTER CALLBACK DATE AND TIME.

READ: Is this the best number to reach you?

INTERVIEWER: UPDATE CONTACT INFORMATION AS NEEDED.

Thank you very much. Good-bye.

\section{THANK AND TERMINATE}

A2Web. What is the correct business name?

INTERVIEWER: TYPE IN BUSINESS NAME.

A3Web. Is this a corrected spelling, a name change but the same business, or a different business?

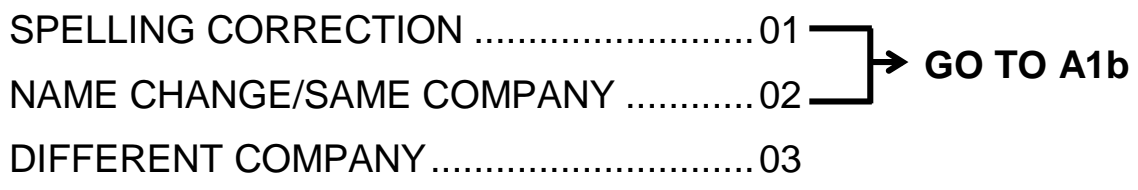


A3Webz. We are trying to find out what happened to [NAME BUSINESS]. Is [NAME BUSINESS] still in operation?

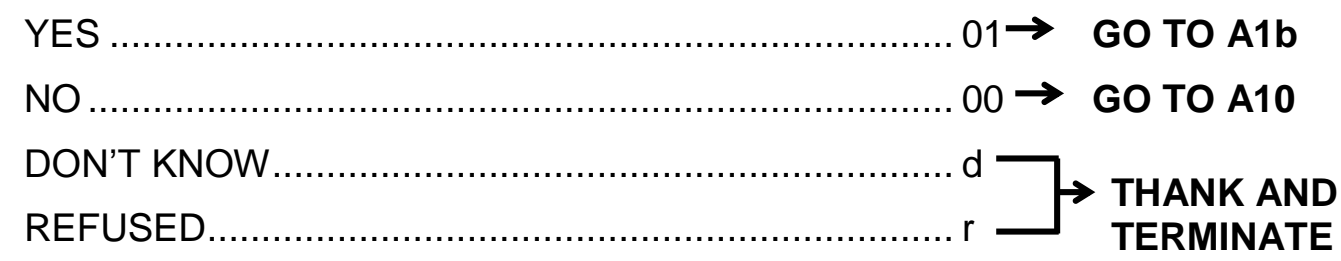

A4Webz Is [OWNER NAME] still an owner and actively involved in running [NAME BUSINESS]?

IF NEEDED: By actively involved, we mean providing regular assistance or advice with day-to-day operations of the business rather than providing only money or occasional operating assistance.

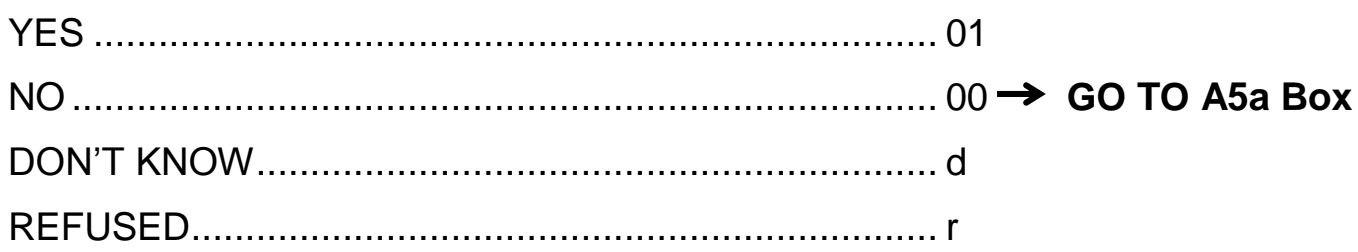

A4Webz1 Would [OWNER NAME] be available to do the study at another time?

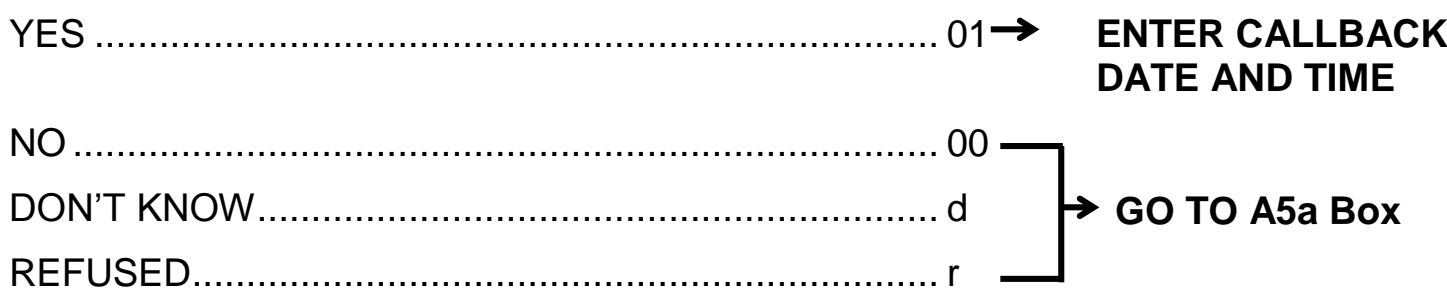

A4aWeb What is the correct spelling of your name?

NAME:

A5. Are you still actively involved in running [NAME BUSINESS]? By actively involved in running the business, we mean providing regular assistance or advice with day-to-day operations of the business rather than providing only money or occasional operating assistance.

YES $01 \rightarrow \quad$ GO TO A4

NO 00

DON'T KNOW.

REFUSED. 


\section{A5a BOX: \\ IF MORE THAN ONE OWNER-OPERATOR- FOUNDER FROM SECOND FOLLOW-UP, ASK A5a. ELSE, ASK A4Web.}

A5a. During the last interview with your business, we recorded other owners of [NAME BUSINESS]. Please tell me the person who is an owner of the business, is actively involved in running [NAME BUSINESS], and will answer this study.

By actively involved in running the business, we mean providing regular assistance or advice with day-to-day operations of the business rather than providing only money or occasional operating assistance.

READ THE OWNER NAMES BELOW. SELECT ONLY ONE.

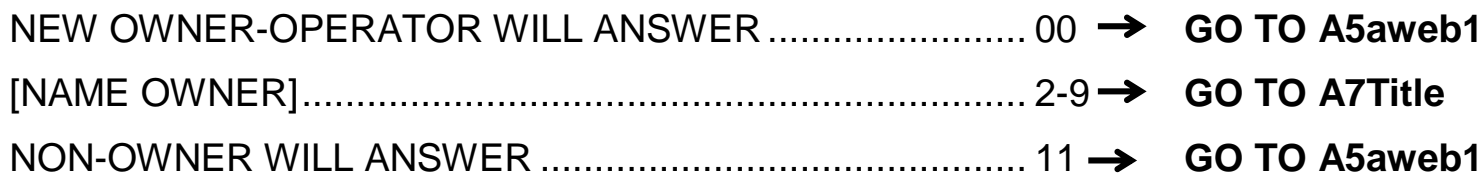

INTERVIEWER: CODE 11 ONLY WITH SUPERVISOR PERMISSION AND WRITE NOTE DOCUMENTING CIRCUMSTANCES

A4Web Who is currently an (OWNER/CEO) of [NAME BUSINESS]?

NAME:

A4Webz2 Are you (OWNER/CEO)?

YES 01

NO $00 \rightarrow$ GO TO Inform

A5new. And are you actively involved in running [NAME BUSINESS]? By actively involved in running the business, we mean providing regular assistance or advice with day-to-day operations of the business rather than providing only money or occasional operating assistance.

YES 01 $\rightarrow$ GO TO A4new

NO 00 
A7. Is there another owner of [NAME BUSINESS] who is actively involved in running [NAME BUSINESS], and can answer questions about the business?

PROBE: By actively involved in running the business, we mean providing regular assistance or advice with day-to-day operations of the business rather than providing only money or occasional operating assistance.

YES 01

NO $00 \rightarrow$ GO TO Stop5

A5aWeb1 Who is another owner of [NAME BUSINESS] who is actively involved in running [NAME BUSINESS], and can answer questions about the business?

ENTER FIRST NAME

ENTER LAST NAME

ENTER JOB TITLE

A4Webz2 Are you (OWNER/CEO)?

YES $01 \rightarrow$ GO TO A4new

NO 00

Inform. Do you know a good time and date I can call to contact (OWNER/CEO)?

INTERVIEWER: ENTER CALLBACK DATE AND TIME.

THANK AND TERMINATE

Stop5. Thank you for your time.

THANK AND TERMINATE

A7Title. What is [OWNER NAME]'s title?

A4Webz2 Are you (OWNER NAME)?

YES $01 \rightarrow$ GO TO A4new

NO $00 \rightarrow$ GO TO Inform 
A4. You participated last year in the Kauffman Firm Survey. At that time, we asked some questions about [NAME BUSINESS] operations in 2006. Now we'd like to ask about the year 2007. Again, your answers will be completely confidential, and you will once again receive a $\$ 50$ payment as a token of our appreciation.

\section{GO TO A8}

A4new. Your business participated last year in the Kauffman Firm Study. At that time, we asked some questions about [NAME BUSINESS]'s operation in 2006. Now we'd like to ask about the year 2007. Again, your answers will be kept confidential, and you will receive a $\$ 50$ payment as a token of our appreciation.

A8. l'd like to confirm your business' mailing address. Is [NAME BUSINESS]'s mailing address (ADDRESS, CITY, STATE, ZIP)?

WEB: Our records indicate that the mailing address for [NAME BUSINESS] is (ADDRESS, CITY, STATE, ZIP). Is this correct?

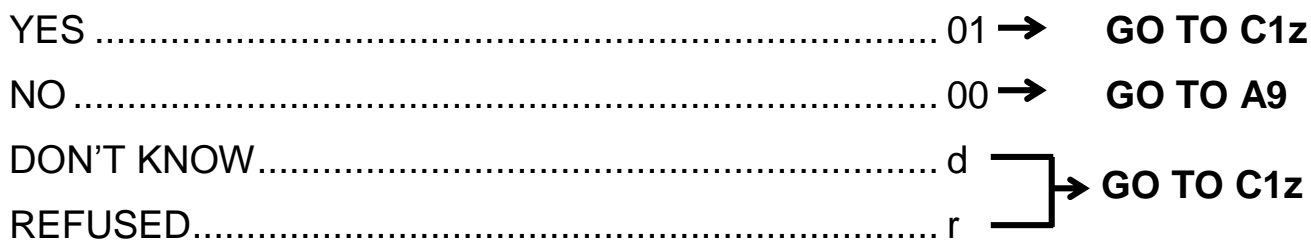

A9. What is [NAME BUSINESS]'s correct mailing address?

\section{INTERVIEWER: UPDATE MAILING ADDRESS INFORMATION.}

ADDRESS:

CITY:

STATE:

ZIP:

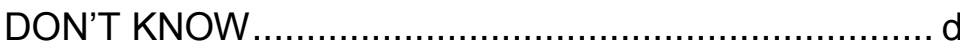

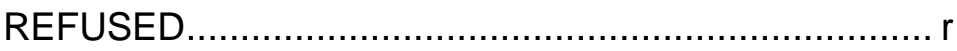

\section{GO TO C12}


A10. What is the main reason [NAME BUSINESS] is out of business?

\begin{tabular}{|c|c|}
\hline 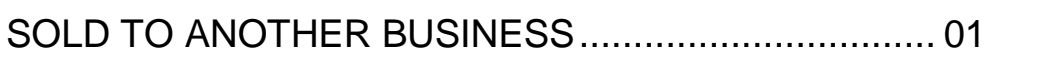 & \\
\hline MERGED WITH ANOTHER BUSINESS ........................ 02 & \\
\hline TEMPORARILY STOPPED OPERATIONS .................... 03 & \\
\hline PERMANENTLY STOPPED OPERATIONS ..................... 04 & A11 \\
\hline OTHER (SPECIFY)... & \\
\hline
\end{tabular}

DON'T KNOW ...........................................................

REFUSED.............................................................

\section{THANK AND TERMINATE}

A11. In what calendar year did [NAME BUSINESS] close?

YEAR | 2 | 0 | $0 \mid$

DON'T KNOW ............................................................

REFUSED ...............................................

A11a. Did [NAME BUSINESS] file for bankruptcy?

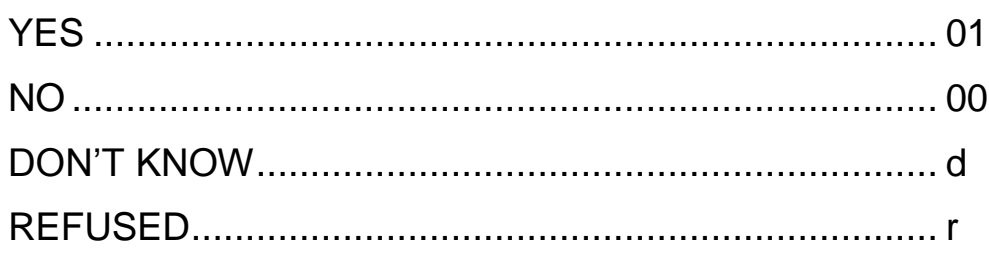

THANK AND TERMINATE 


\section{NO SECTION B}

Prepared by Mathematica Policy Research, Inc. 


\section{BUSINESS CHARACTERISTICS}

All of the following questions I'm going to ask are about [NAME BUSINESS]. Some of the questions will ask to confirm information about your business which you provided to us previously. As we go through the interview, please tell me if any of the information about your business is incorrect and needs to be updated.

C1z. Our records show that [NAME BUSINESS] had a legal status of

[tOWNERshipModel]. As of December 31, 2007, is that still the legal status of [NAME BUSINESS]?

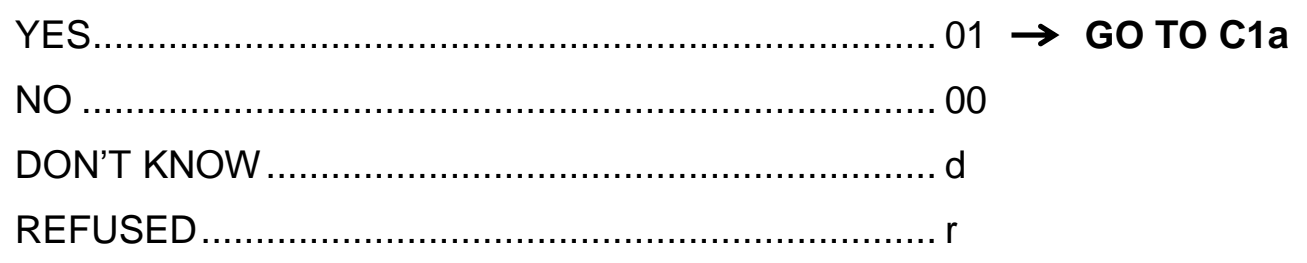


C1z2. I'm going to read you a list of some different forms of legal status a business can have. As of December 31, 2007, which form of legal status did [NAME BUSINESS] have? Was it a...

\section{READ LIST AND READ DESCRIPTIONS AS NEEDED:}

Sole Proprietorship: A type of business ownership in which a business is owned and managed by one individual and no subchapter S-corporation or C-corporation has been established.

Limited Liability Company: A cross between a corporation and a partnership, and offering some of the benefits of both. Similar to S corporations, income produced by a limited liability company flows through to owners (known as "members") who pay their own taxes as individuals. Unlike S-corporations, however, limited liability companies are not subject to as many government restrictions.

Subchapter S-Corporation: Corporations in which all profits and losses are passed through to shareholders, just as they are passed through to partners in a partnership.

C-Corporation: Legal entities separate from their owners that may engage in business, make contracts, own property, pay taxes, and sue and be sued by others.

General Partnership: An association of two or more people who co-own a business for the purpose of making a profit and no subchapter S-corporation or C-corporation has been established.

Limited Partnership: A partnership in which one or more partners are general partners who manage the business and others are limited partners who invest in the business but forego any right to manage the company.

Sole Proprietorship, ......................................... 01

Limited Liability Company, ...................................... 02

Subchapter S-Corporation, ..................................... 03

C-Corporation, ................................................. 04

General Partnership, ........................................ 05

Limited Partnership, or .......................................... 06

Something else? (SPECIFY) ................................. 07

DON'T KNOW ................................................. d

REFUSED .......................................................... 
C1a. Our records indicate the principal activity of the business was [D\&B NAICS CODE DESCRIPTION]. Was that still the principal activity of the business as of December $31,2007 ?$

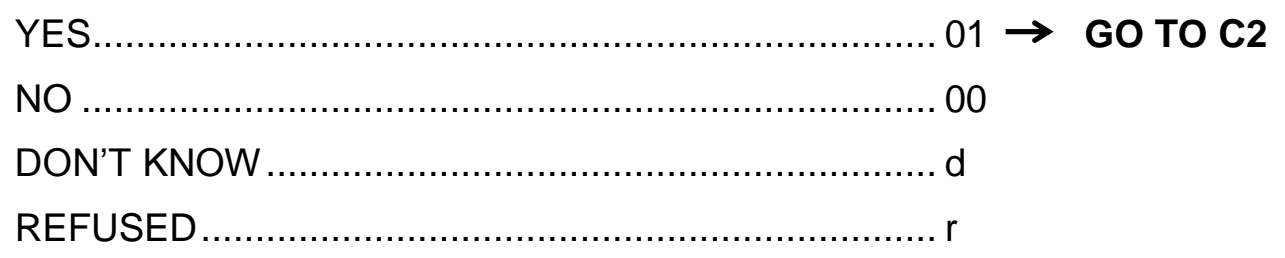

C1b. As of December 31, 2007, what was the principal activity of the business?

IF SOLE PROPRIETORSHIP IN [tOWNERshipModel] [or C1z2], GO TO C5.

C2. As of December 31, 2007, how many individuals or entities owned [NAME BUSINESS]? Please include all individuals or entities who owned shares in the business.

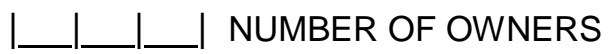

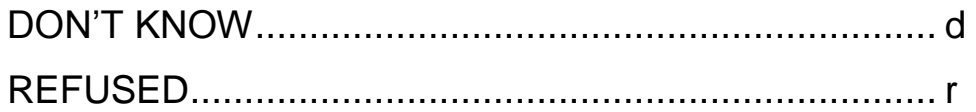

C3. Of the [NUMBER OF OWNERS FROM C2] owners as of December 31, 2007, how many owners actively helped to run [NAME BUSINESS]? By helped to run the business we mean that they provided regular assistance or advice with day-to-day operations of the business, rather than providing only money or occasional operating assistance.

\section{|_____ NUMBER OF OWNER/OPERATORS}

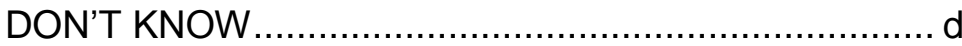

REFUSED ........................................................ $\mathrm{r}$ 


\section{IF ONE OWNER/OPERATOR REPORTED AT C3, GO TO C5. IF MORE THAN ONE}

OWNER/OPERATOR REPORTED AT C3, ASK:

\section{C4. FOR EACH SECOND FOLLOW-UP OWNER/OPERATOR WHO IS NOT THE RESPONDENT, ASK:}

Was [OWNER NAME] still an owner who actively helped run [NAME BUSINESS]—as of December 31, 2007?

YES

$\mathrm{NO}$

YES BUT THE NAME IS MISSPELLED 02

DON'T KNOW d

REFUSED. $r$

FOR ALL MISSPELLED NAMES, ASK:

How do you spell (your/his/her) name?

\section{INTERVIEWER: ENTER NAME}

THEN ASK:

How many other people, not previously listed, were owners actively helping to run [NAME BUSINESS] as of December 31, 2007.

\section{INTERVIEWER: PREVIOUSLY LISTED PEOPLE ARE STATED BELOW. NUMBER OF OWNERS STATED IN C3: [FILL FROM C3]}

I want to record with you the first and last names of these owners. These are the people who joined the business between the last time we talked to you and December 31, 2007. I'm going to be asking some questions about each of the owners who actively helped run [NAME BUSINESS]. Can you tell me the first and last name of the other owner(s) of $A B C$ Business?

INTERVIEWER: $\quad$ ENTER FIRST AND LAST NAMES. 
C4Confirm. I have listed:

FIRST NAME

LAST NAME

OWNER A (RESPONDENT)

OWNER B

OWNER C

OWNER D

Are there any other owner-operators as of December 31, 2007 of [NAME BUSINESS] that I have not mentioned?

\title{
INTERVIEWER: CONFIRM SPELLING OF NAMES. TO CORRECT NAMES, ARROW BACK TO TABLE.
}

\author{
ADD ANOTHER NAME OR \\ CORRECT A MISSPELLING ................................... 01

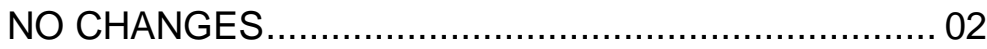

\section{NOTE: UP TO 10 OWNER/OPERATOR/FOUNDERS WILL BE INCLUDED.}

C5. Not counting owner(s), on December 31, 2007, how many people worked for [NAME BUSINESS]? Please include all full- and part-time employees, but exclude contract workers who work for the business either full- or part-time but are not on the business' official payroll.
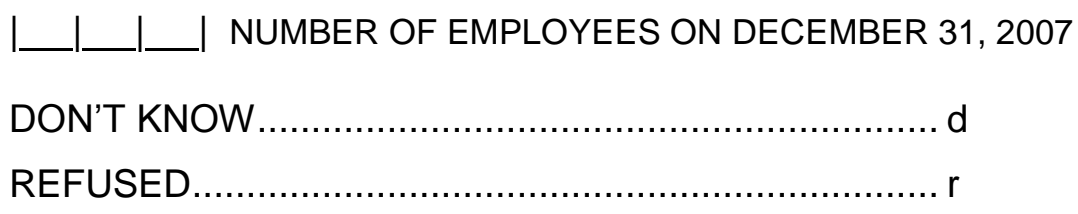

C5b. Was this change an increase, a decrease, or no change in the number of people who worked for [NAME BUSINESS] on December 31, 2007 compared to December 31, $2006 ?$

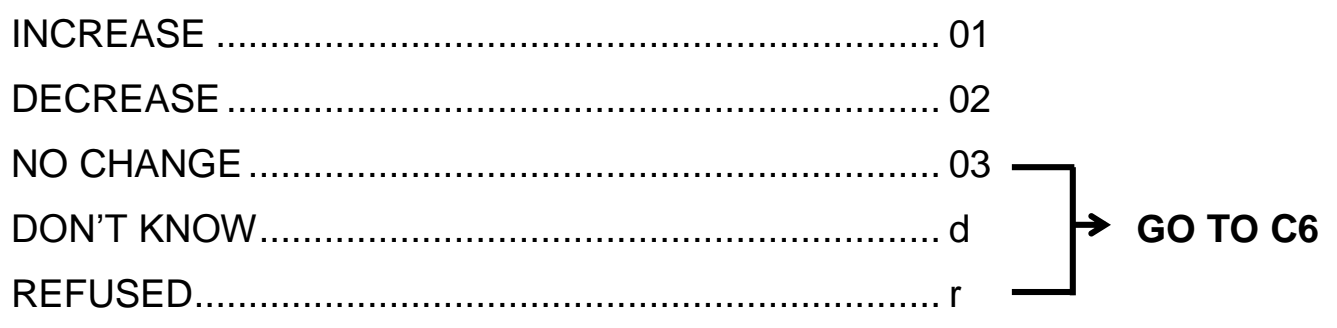


C5c. And what was the (increase/decrease) in the number of people who worked for [NAME BUSINESS] on December 31, 2007 compared to December 31, 2006? Your best estimate is fine.

L_____ CHANGE IN NUMBER OF EMPLOYEES

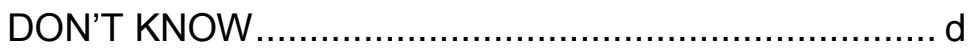

REFUSED ..........................................................

IF BUSINESS REPORTED “0” EMPLOYEES AT C5, GO TO C8z.

C6. And of those [NUMBER FROM C5], how many were full-time?

(IF NEEDED: Full-time is considered 35 hours or more per week)

|____ NUMBER OF DECEMBER 31, 2007 FULL-TIME EMPLOYEES

DON'T KNOW ................................................... d

REFUSED............................................................

C7. And how many were part-time? (IF NEEDED: Part-time is considered less than 35 hours per week)

|_l___ NUMBER OF DECEMBER 31, 2007 PART-TIME EMPLOYEES

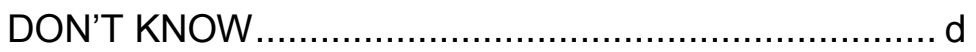

REFUSED..........................................................

C8z. Our records show that the primary location where [NAME BUSINESS] operates is [tPrimaryLocation]. Is that correct?

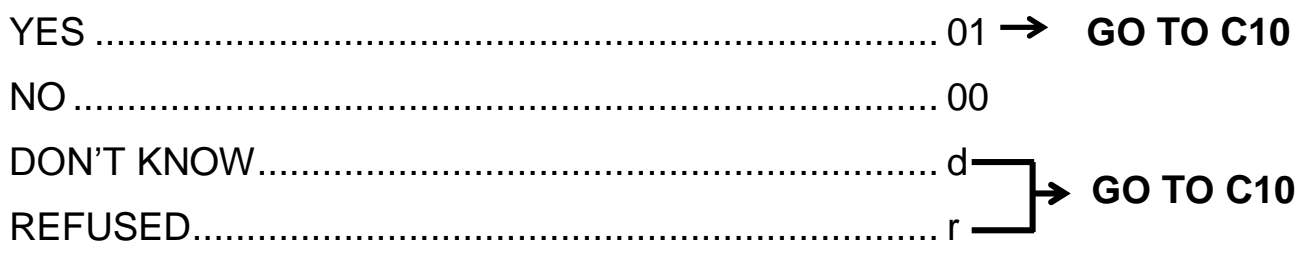


C8. How would you describe the primary location where [NAME BUSINESS] operates? Is it ...

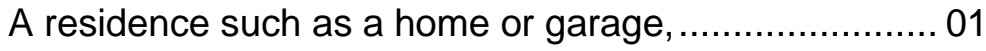

A rented or leased space, ........................................ 02

Space the business purchased, .............................. 03

A site where a client is located, or ............................... 04

Some other location? (SPECIFY) ............................ 05

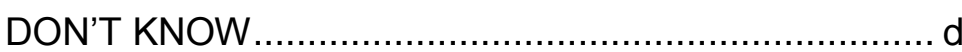

REFUSED.............................................................

C9. What was the main reason for the change of location?

Previous location too expensive ..................................... 01

Needed more space due to growth of business ............ 02

Moved closer to customers ........................................... 03

Moved business and residence to new location ............ 04

OTHER (SPECIFY) .................................................. 05

DON'T KNOW ........................................................

REFUSED.......................................................

C10. As of December 31, 2007, did [NAME BUSINESS] operate in more than one location?

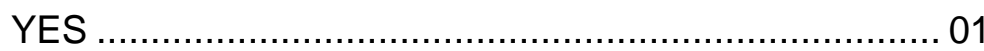

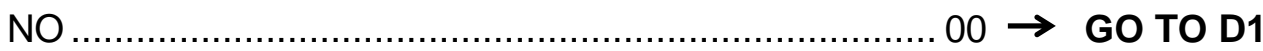

C11. And as of December 31, 2007, how many locations did [NAME BUSINESS] operate in? |_____ NUMBER OF LOCATIONS AS OF DECEMBER 31, 2007

C11a. In what month and year did you open your second location? Month Year $\mid 2$ 


\section{STRATEGY AND INNOVATION}

D1. Does [NAME BUSINESS] provide (READ ITEM)?
a. A service
b. A product

YES

\begin{tabular}{l|ll} 
NO & T \\
\hline
\end{tabular}
DON'T
KNOW REFUSED

$0100 \quad d \quad r$
$\begin{array}{llll}0 & 00 & d & r\end{array}$

D2. Businesses often have to compete with other businesses. A competitive advantage is something unique or distinctive a business provides that gives it an advantage compared to competitors. In calendar year 2007, did [NAME BUSINESS] have a competitive advantage over its competitors?

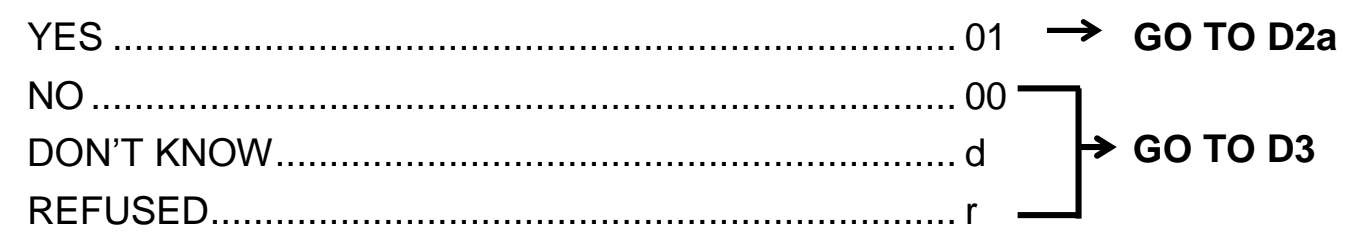


D2a. Was the competitive advantage [NAME BUSINESS] had in calendar year 2007 related in any way to [ITEM]?

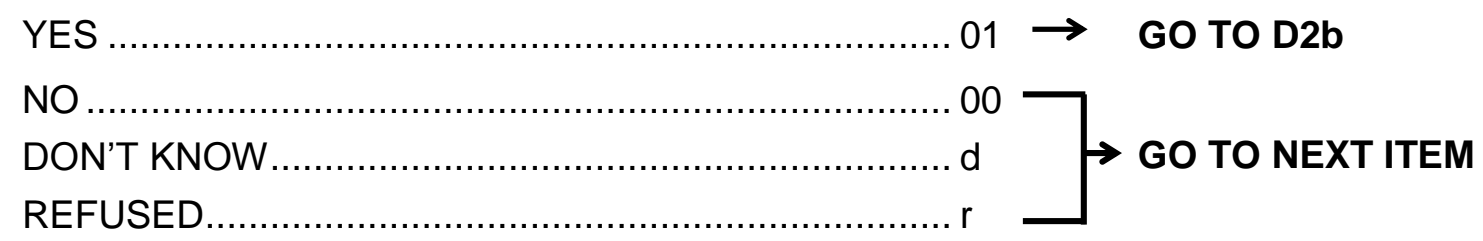

D2b. Do you consider this to have given [NAME BUSINESS] a major or a minor competitive advantage in calendar year 2007?

REPEAT D2a-D2b FOR EACH ITEM.

\section{ITEMS}

a. teaming up with a college or university?

b. teaming up with another company?

c. teaming up with a government lab or research center?

\begin{tabular}{|c|c|c|c|}
\hline D2a. & \multicolumn{2}{|c|}{$\begin{array}{l}\text { Reason For } \\
\text { Competitive } \\
\text { Advantage }\end{array}$} \\
\hline YES & NO & $\begin{array}{l}\text { DON'T } \\
\text { KNOW }\end{array}$ & REFUSED \\
\hline
\end{tabular}

$0100 \quad d \quad$ IF

\section{D2b. Strength of reason for Competitive Advantage}

\begin{tabular}{|c|c|c|c|}
\hline MAJOR & MINOR & DON'T & \\
REASON & REASON & KNOW & REFUSED \\
\hline
\end{tabular}

IF YES $\rightarrow 01$

00

d

r

IF d

r r

$x^{2}$

$\begin{array}{lllll}01 & 00 & d & r & \text { YES } \rightarrow\end{array}$

IF

$0100 \quad d$

00

d

d $r$

d. patents that [NAME BUSINESS] owns, has applied for, or licensed?..

$01 \quad 00 \quad d$

r

$r \quad$ IF

\section{YS}

$r \quad$ IF

\begin{abstract}
IF
\end{abstract}
00 
D3. Whether assigned by an owner or obtained in some other way, does [NAME BUSINESS] have any of the following? (READ LIST)

FOR EACH "YES," ASK: How many (READ ITEM) does [NAME BUSINESS] have?

\section{INTERVIEWERS IF NEEDED:}

Patent: A patent is a right given by the government to preclude others from making and selling an invention for 20 years from the date of application in return for disclosure of how the invention operates.

Copyright: The legal right granted to authors, composers, artists and publishers to protect their thoughts and ideas for exclusive publication, reproduction, sale and distribution of their works.

Trademark: Words, names, symbols or devices, or any combination of these used to identify the goods of a business and to distinguish these goods from the goods of others.

\begin{tabular}{|c|c|c|c|c|c|}
\hline & YES & NO & $\begin{array}{l}\text { DON'T } \\
\text { KNOW }\end{array}$ & REFUSED & $\begin{array}{c}\text { NUMBER } \\
\text { BUSINESS HAS }\end{array}$ \\
\hline a. Patents .................. & 01 & 00 & $d$ & r & $1 \ldots 1$ \\
\hline b. Copyrights ............... & 01 & 00 & $d$ & r & I_L \\
\hline c. Trademarks ............ & 01 & 00 & $d$ & r & \\
\hline
\end{tabular}

D4. "Licensing out" is licensing patents, copyrights, or trademarks owned by the business to other parties under a licensing agreement. In calendar year 2007, did [NAME BUSINESS] license out any (READ ITEM)?

a. Patents

b. Copyrights

c. Trademarks

\begin{tabular}{|c|c|c|}
\hline YES & NO & $\begin{array}{l}\text { DON'T } \\
\text { KNOW }\end{array}$ \\
\hline
\end{tabular}

d

d

d
REFUSED r r r

D5. "Licensing in" is acquiring the right to use intellectual property such as patents, copyrights, or trademarks created by someone outside the business through a licensing agreement. In calendar year 2007, did [NAME BUSINESS] license in any (READ ITEM)?

a. Patents

\begin{tabular}{|l|l|l|l|}
\hline YES & NO & $\begin{array}{l}\text { DON'T } \\
\text { KNOW }\end{array}$ & REFUSED \\
\hline
\end{tabular}

b. Copyrights

00 d $r$

c. Trademarks

01

00

d

$r$

01

00

d r 
D6. Did [NAME BUSINESS] have any customers or sales in calendar year 2007?

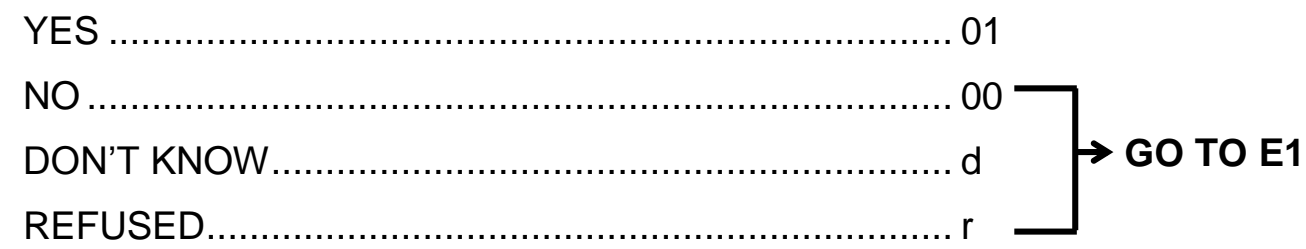

D7. l'd like to learn more about the type of customers that [NAME BUSINESS] had during calendar year 2007. I am going to ask you to estimate the percent of the business' sales that were made to individuals, businesses, and government agencies. The total should equal $100 \%$.

a. During calendar year 2007, what percentage of the business' sales were to private individuals?

L_____ PERCENTAGE

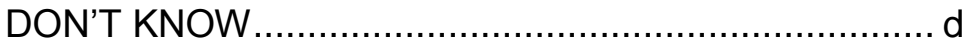

REFUSED ............................................................. r

b. What percentage of the business' sales were to other businesses?

[IF NEEDED: Please include sales to for-profit and not-for-profit business.]

l_____ PERCENTAGE

DON'T KNOW ...................................................... d

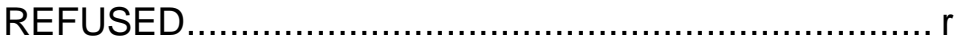

c. What percentage of the business' sales were to government agencies?

I_____ PERCENTAGE

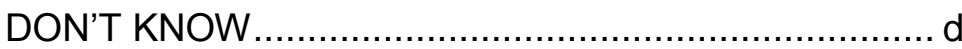

REFUSED............................................................ 
D8. Now, I will read you a list of customer locations. When I am done reading, please select only one answer choice for your response. During calendar year 2007, where were most of [NAME BUSINESS]'s customers located? Would you say . . .

In neighborhoods local to the business, ............................ 01

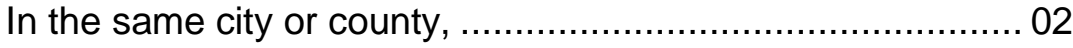

In the same region, such as in nearby counties

or states, 03

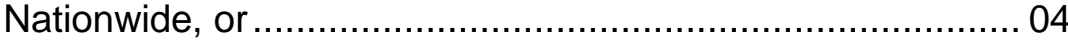

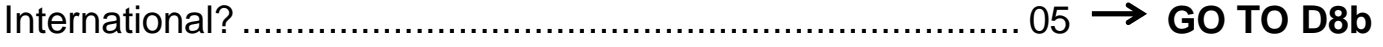

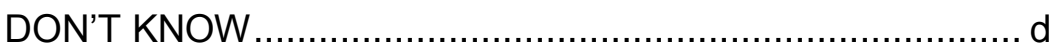

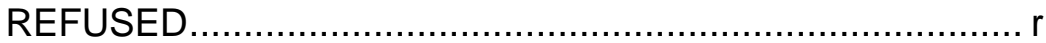

D8a. During calendar year 2007, were any of [NAME BUSINESS]'s sales made to individuals, businesses, or governments outside the United States?

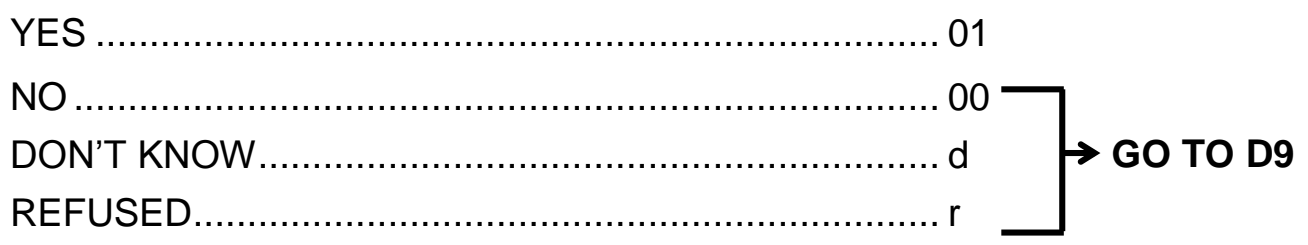

D8b. What percent of [NAME BUSINESS]'s total sales were to individuals, businesses, or governments outside of the United States? Would you say ...

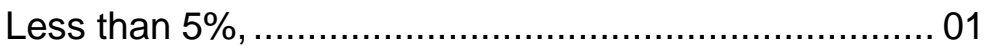

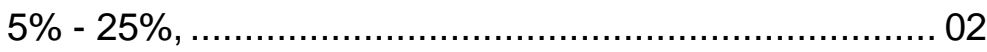

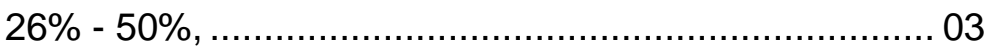

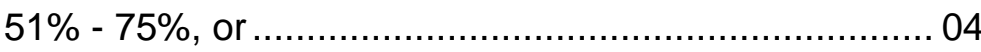

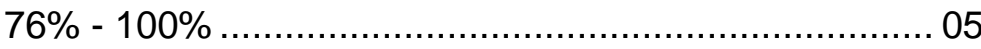

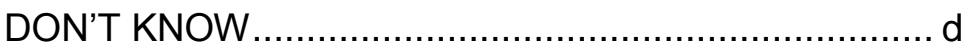

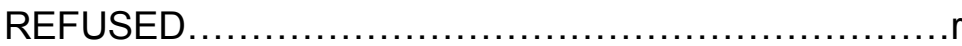

D9. During calendar year 2007, were any of [NAME BUSINESS]'s sales made to customers through the internet, such as through the business' website or an online retailer site?

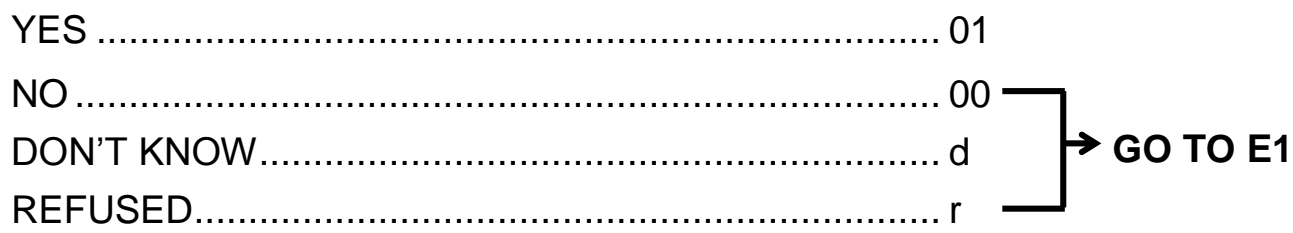


D9a. What percent of [NAME BUSINESS]'s total sales were sales made to customers through the internet? Would you say ...

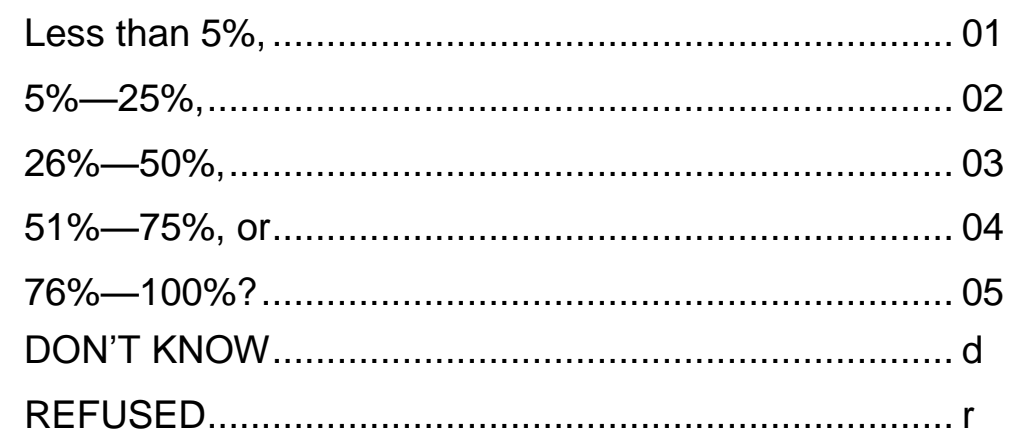




\section{E. BUSINESS ORGANIZATION AND HR BENEFITS}

\section{IF ONE OWNER REPORTED AT C2 AND BUSINESS REPORTED “0” EMPLOYEES AT C5, GO TO F1.}

Next, l'd like to ask about how [NAME BUSINESS] is organized and about the benefits that are offered to employees.

E1. On December 31, 2007, how many employees or owners, if any, did [NAME BUSINESS] have who were primarily responsible for (READ ITEM)? Please include only full- and part-time employees, but not contract workers who work for the business but are not on the business' official payroll.

\begin{tabular}{|c|c|c|}
\hline $\begin{array}{c}\text { NUMBER } \\
\text { EMPLOYEES OR } \\
\text { OWNERS }\end{array}$ & $\begin{array}{c}\text { DON'T } \\
\text { KNOW }\end{array}$ & REFUSED \\
\hline
\end{tabular}

a. Human resources such as employee benefits, recruitment, or hiring

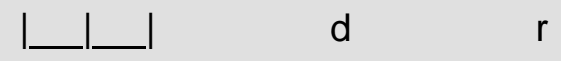

b. Sales or Marketing such as sales, market research, customer analysis, or promotional activities

c. Executive administration functions such as strategic planning, competitive analysis, shareholder relations, or general management ....

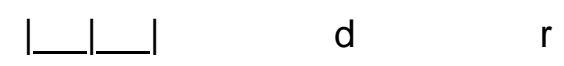

d. Research and development on new products or services

e. Production or manufacturing such as producing materials or products, production planning, production control, quality control, or storage.

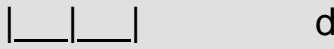

d $\quad r$

f. General administration such as office management, responding to maintenance requests, purchase supplies, or training employees in office procedures.

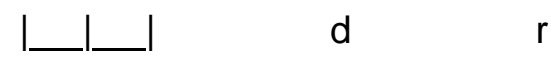

g. Financial administration such as accounting procedures, budgeting, financial analysis, or investment activities

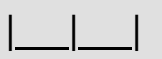

d $r$

h. Does [NAME BUSINESS] have employees with any other key responsibilities? (SPECIFY)

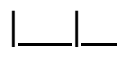

d $r$ 
E2a. As of December 31, 2007, did [NAME BUSINESS] offer full-time employees or owners (READ ITEM):

\begin{tabular}{|c|c|c|c|c|}
\hline & YES & NO & $\begin{array}{l}\text { DON'T } \\
\text { KNOW } \\
\end{array}$ & REFUSED \\
\hline $\begin{array}{l}\text { a. A health insurance plan either through the } \\
\text { business or an association }\end{array}$ & 01 & 00 & d & $\mathrm{r}$ \\
\hline $\begin{array}{l}\text { b. A retirement plan such as profit sharing, pension, } \\
\text { including } 401 \mathrm{~K} \text {, annuity, Keogh, etc. }\end{array}$ & 01 & 00 & d & $\mathrm{r}$ \\
\hline c. Stock options or other stock ownership...................... & 01 & 00 & d & $\mathrm{r}$ \\
\hline d. A bonus plan. & 01 & 00 & $d$ & r \\
\hline 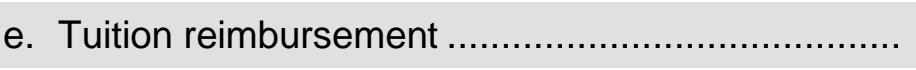 & 01 & 00 & $d$ & r \\
\hline f. Paid vacation & 01 & 00 & $d$ & r \\
\hline g. Paid sick days & 01 & 00 & d & $\mathrm{r}$ \\
\hline h. Alternative work schedules such as flex time or & 01 & 00 & d & $\mathrm{r}$ \\
\hline 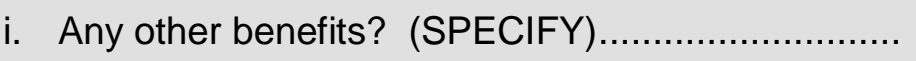 & 01 & 00 & d & $\mathrm{r}$ \\
\hline
\end{tabular}

IF ZERO PART-TIME EMPLOYEES AT C7, GO TO F1.

E2b. As of December 31, 2007, did [NAME BUSINESS] offer part-time employees (READ ITEM):
a. A health insurance plan either through the business or an association
b. A retirement plan such as profit sharing, pension, including $401 \mathrm{~K}$, annuity, Keogh, etc.

$0100 \quad d \quad r$
c. Stock options or other stock ownership.
d. A bonus plan.

$01 \quad 00$
e. Tuition reimbursement
01

00
$01 \quad 00$
f. Paid vacation
01
00
g. Paid sick days. $01 \quad 00$
h. Alternative work schedules such as flex time or job sharing 01
00

$\begin{array}{ll}d & r \\ d & r \\ d & r \\ d & r \\ d & r \\ d & r\end{array}$
i. Any other benefits? (SPECIFY)

$\begin{array}{ll}01 & 00 \\ 01 & 00\end{array}$

$\begin{array}{ll}d & r \\ d & r\end{array}$

\begin{tabular}{|l|l|l|l|}
\hline YES & NO & $\begin{array}{c}\text { DON'T } \\
\text { KNOW }\end{array}$ & REFUSED \\
\hline
\end{tabular}




\section{F. BUSINESS FINANCES}

F1. Now l'd like to ask about [NAME BUSINESS]'s financing. Businesses can get money from the savings or investments of the owner(s), money from spouses, family or other individuals, from companies, borrowing in an owner's name, venture funds, or by borrowing in the name of the business. Some of the funds must be paid back and other funds represent an equity stake or share of the business. We will ask some questions about what happened during calendar year 2007, some questions about what has happened since the business began, and other questions about balances as of December 31, 2007.

F1a. First, in calendar year 2007, did [you/OWNER B-J] put any of your own money into [NAME BUSINESS] in return for an ownership share of the business? Please do not include any money borrowed from others or from credit cards.

IF NEEDED: This would include all additional money invested by [you/OWNER B-J] in the business during calendar year 2007.

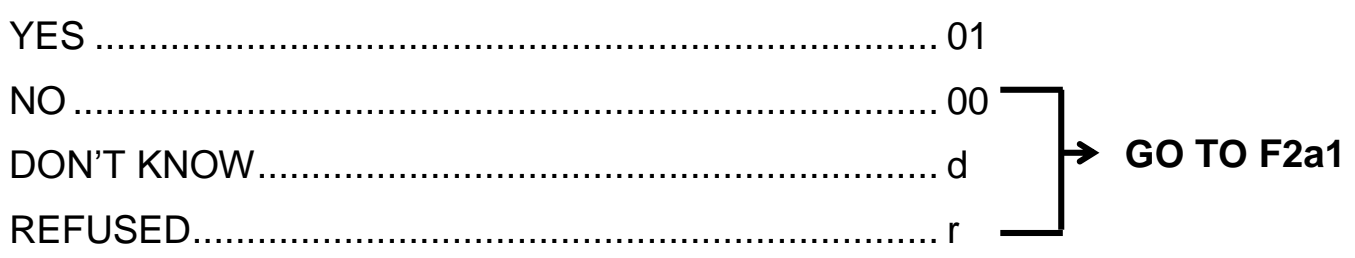


F2a. IF YES: How much of [your/her/his] own money did [you/she/he] put into the business during calendar year 2007?

IF NEEDED: Your best estimate is fine.

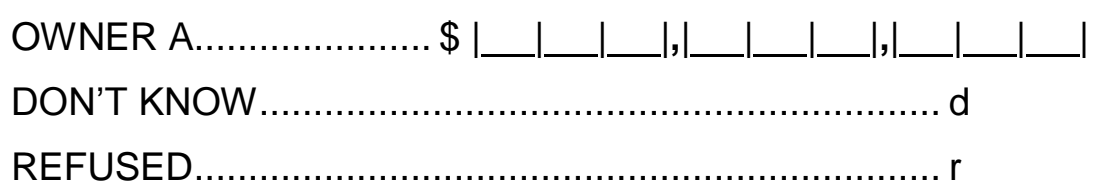

IF DON'T KNOW OR REFUSED, PROBE WITH RANGES: Would you say it was ...

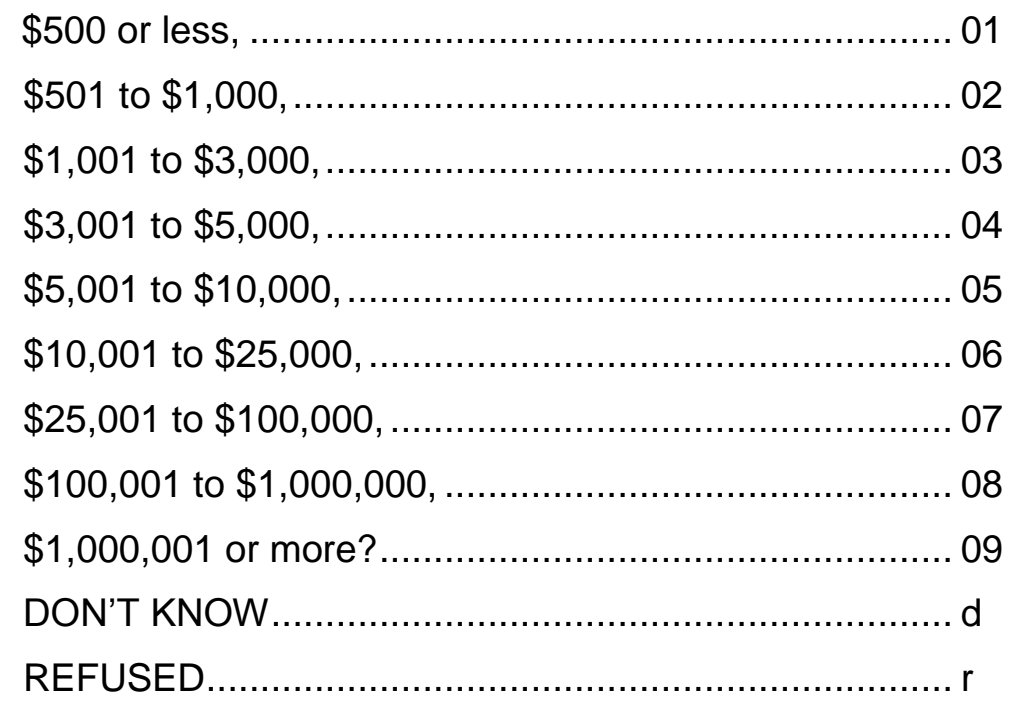


F2a1. Counting all years, how much of [your/OWNER B-J]'s own money did [you/she/he] put into [NAME BUSINESS] as of December 31, 2007?

IF NEEDED: This includes all money [you/she/he] invested in the business as of December 31, 2007.

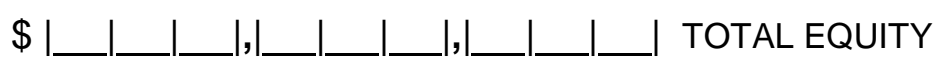

DON'T KNOW ................................................... $\mathrm{d}$

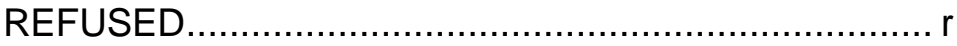

PROBE: IF DON'T KNOW OR REFUSED, PROBE WITH RANGES:

Would you say it was...

$\$ 500$ or less, ............................................................ 01

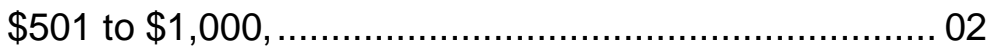

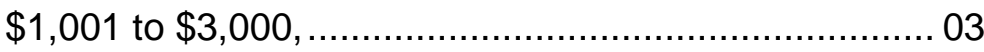

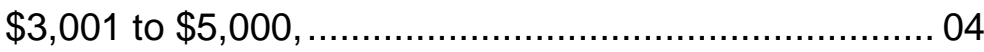

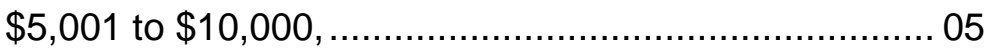

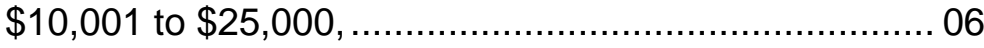

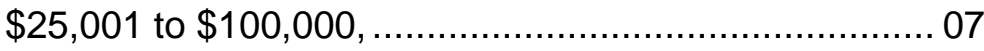

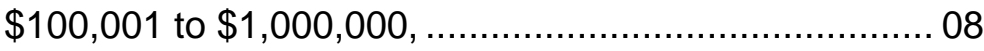

$\$ 1,000,001$ or more?

DON'T KNOW ......................................................

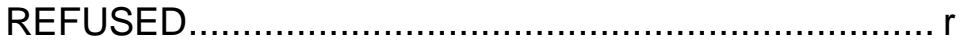

\section{IF F2a IS GREATER THAN F2a1:}

I may have made a mistake. The amount invested in 2007 is greater than the amount invested in all years combined. Is there an error?

F2b. What percentage of the business did [you/OWNER B-J] own on December 31, 2007?

I_____ PERCENTAGE OF BUSINESS

DON'T KNOW

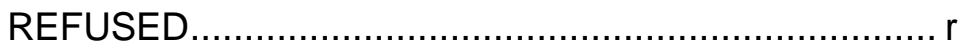

IF MORE THAN ONE OWNER/OPERATOR AT C4, ASK F1a-F2b FOR EACH

OWNER/OPERATOR. OTHERWISE, GO TO F3.

IF SOLE PROPRIETORSHIP AT QUESTION C1z OR C1z2, GO TO F6a. 
F3. Equity investment is money received in return for some portion of ownership, and it is another way to fund business expenses. During calendar year 2007, did the business obtain equity financing from any of the following sources?

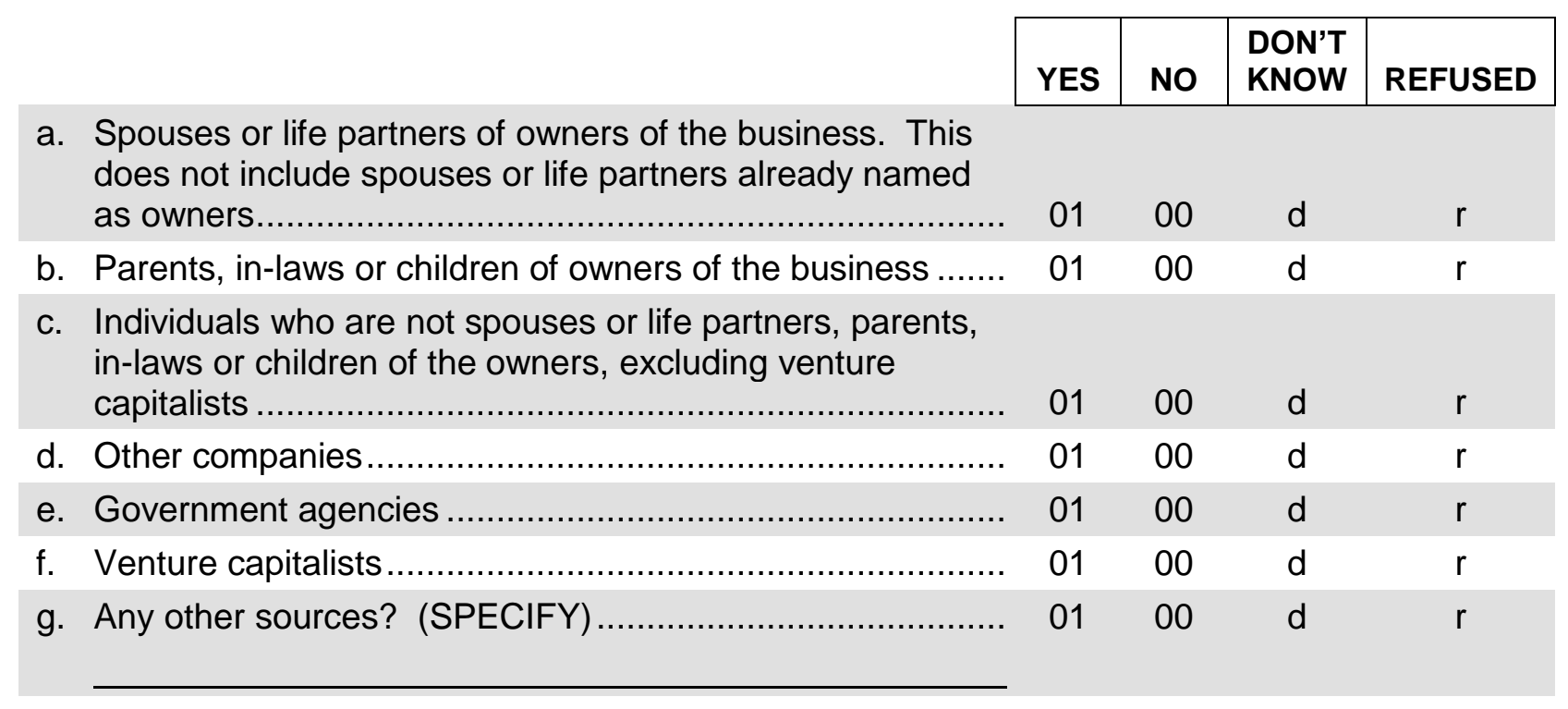

F4. FOR EACH EQUITY FINANCING OPTION REPORTED AS "YES” ABOVE, ASK:

In calendar year 2007, how much money did [NAME BUSINESS] receive from [EQUITY OPTION]?

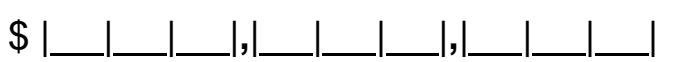

DON'T KNOW

REFUSED.
CALENDAR YEAR 2007 AMOUNT FROM EQUITY OPTION

IF DON'T KNOW OR REFUSED, PROBE WITH RANGES: Would you say it was ...

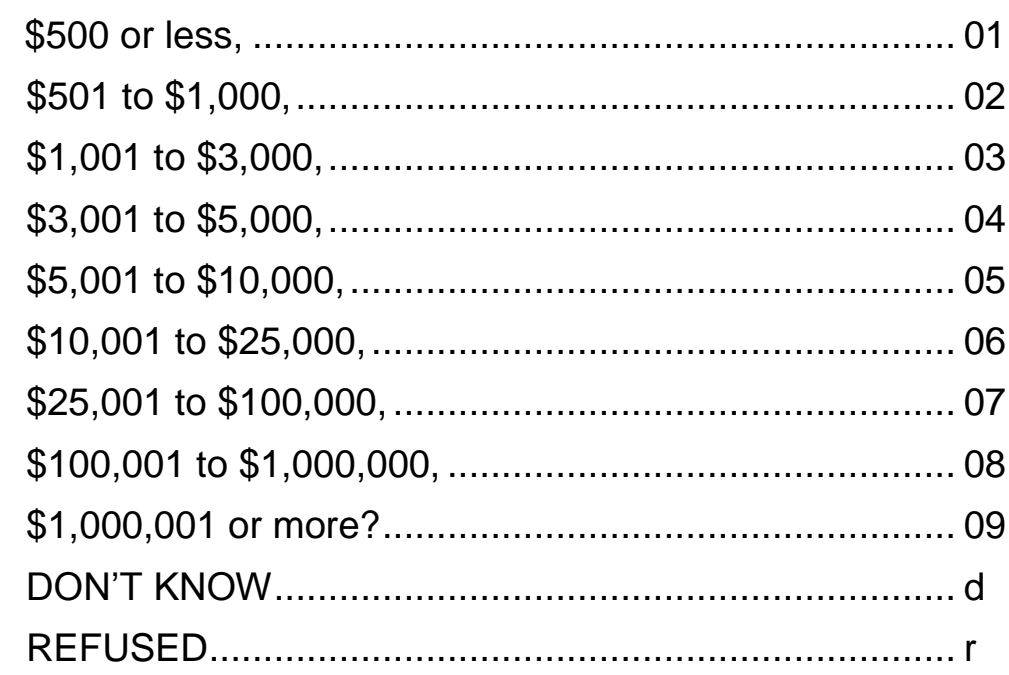


F4a. Counting all years, how much did [EQUITY OPTION] put into [NAME BUSINESS] as of December 31, 2007?

PROBE: This includes all money invested by [EQUITY OPTION] in all years.

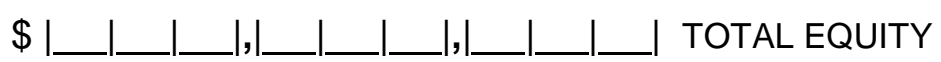

DON'T KNOW........................................................

REFUSED.........................................................

PROBE: IF DON'T KNOW OR REFUSED, PROBE WITH RANGES: Would you say it was...

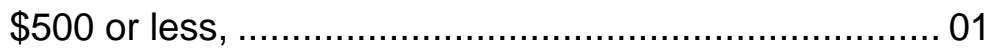

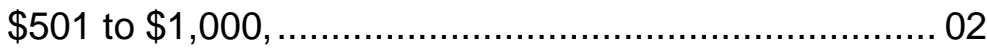

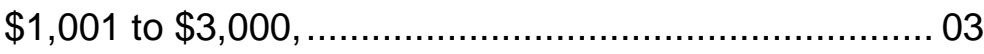

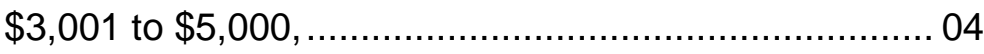

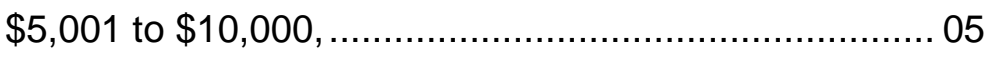

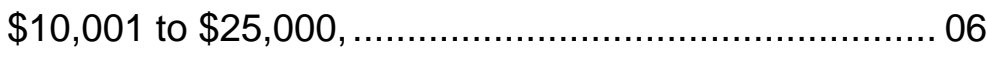

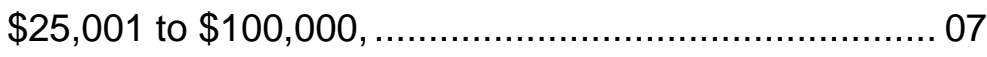

$\$ 100,001$ to $\$ 1,000,000, \ldots \ldots \ldots \ldots \ldots \ldots \ldots \ldots \ldots \ldots \ldots \ldots \ldots \ldots \ldots \ldots . . .08$

$\$ 1,000,001$ or more? ................................................... 09

DON'T KNOW..........................................................

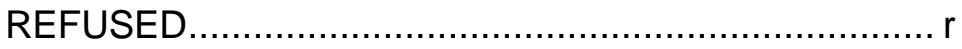

\section{IF F4 IS GREATER THAN F4a:}

I may have made a mistake. The amount invested in 2007 is greater than the amount invested in all years combined. Is there an error?

F5. FOR EACH EQUITY FINANCING OPTION REPORTED AS "YES" ABOVE, ASK: What was the total percentage of the business owned by the [EQUITY OPTION] who invested money in the business as of December 31, 2007?

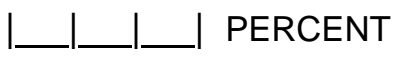

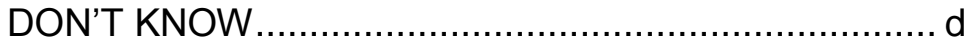

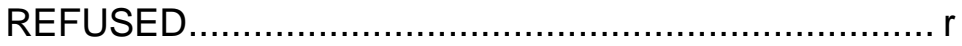




\section{INTERVIEWER CHECK BOX: CHECK ANSWER FROM F2b AND F5 FOR TOTAL PERCENTAGE OF BUSINESS ACCOUNTED FOR.}

IF TOTAL PERCENTAGE EQUALS 100\%, GO TO F6a

IF TOTAL EQUALS LESS OR MORE THAN 100\%

F6. So far, you've given me the following information on who owns [NAME BUSINESS]: [LIST EQUITY INVESTORS FROM F2b AND F5]. Can we review this list?

\section{REVIEW LIST OF OWNERS AND PERCENTAGES WITH RESPONDENT. MAKE CHANGES AS NEEDED, ADDING NEW OWNERS AND/OR PERCENTAGES AS NECESSARY.}

DON'T KNOW

d

REFUSED. $r$

F6a. Have you (or other owners) withdrawn money from the business for personal use in calendar year 2007?

INTERVIEWER IF NEEDED: This does not include owner salaries.

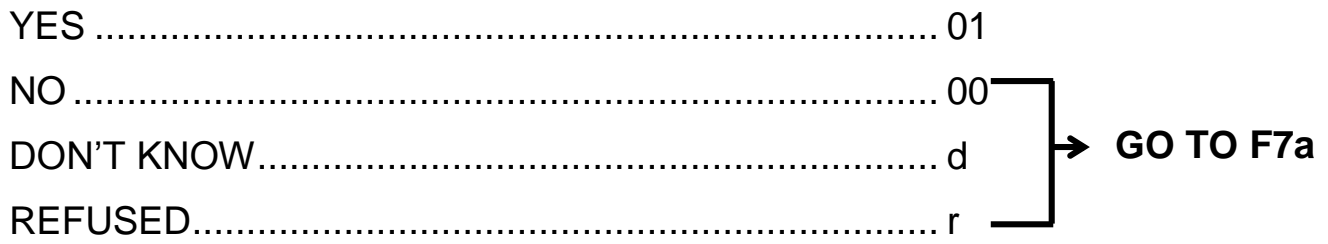


F6b. IF YES: Thinking of calendar year 2007, how much money, if any, did you and other owners withdraw from the business for personal use? This includes any dividends paid.

\$ l_____ا______________ TOTAL DRAWINGS CALENDAR YEAR 2007

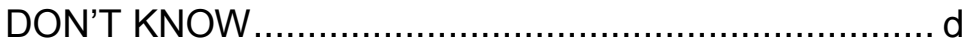

REFUSED ......................................................

IF DON'T KNOW OR REFUSED, PROBE WITH RANGES: Would you say it was . . .

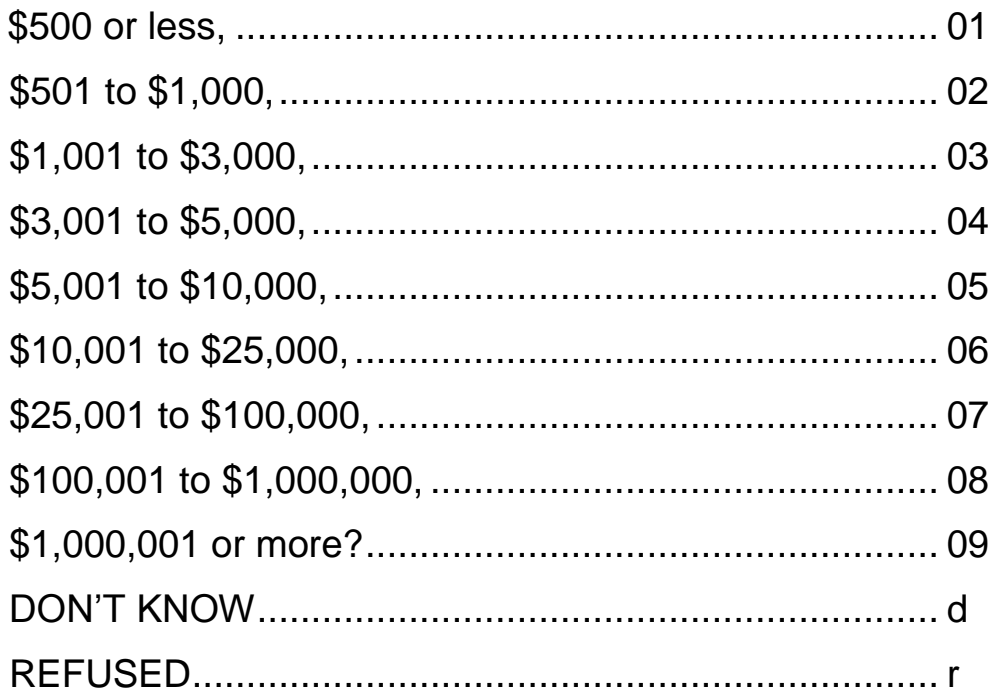


F7a. Another way to finance a business is debt financing. Debt is money borrowed that has to be paid back with or without interest.

We will be talking about categories of debt based on who is responsible for paying it back. For each category, l'll ask you about several sources of debt business owners or businesses can use to fund operations. We want to make sure that any businessrelated debt is reported in the right category, and is reported only once. I will identify each category and remind you when I change categories. Here is the first category.

I'm going to ask you about some different types of debt financing you may have borrowed in your name on behalf of [NAME BUSINESS]. For each, please tell me if you used this type at any time during calendar year 2007. Did you use [NAME FINANCING OPTION FROM LIST]?

F7b. IN BELOW LIST, FOR EACH DEBT FINANCING OPTION BUSINESS REPORTED, ASK: How many [NAME DEBT FINANCING OPTION] did you use to finance the operation of the business during calendar year 2007 ?

\begin{tabular}{|c|c|c|c|c|}
\hline YES & NO & $\begin{array}{c}\text { DON'T } \\
\text { KNOW }\end{array}$ & REFUSED & $\begin{array}{c}\text { NUMBER } \\
\text { USED }\end{array}$ \\
\hline
\end{tabular}

a. Personal credit cards for businessrelated purposes

$01 \quad 00 \quad d$

d $\quad r$

b. Personal loans from a bank or other financial institution, such as a mortgage or home equity loan used for the business $01 \quad 00$

c. Business or corporate credit cards issued in your name. 0

$00 \quad \mathrm{~d}$

d $\quad r$

d. Personal loans from any family or friends.

$00 \quad d$

d $\quad r$

e. Personal loans from any other individuals not associated with the management of the business 01

f. Any other sources? (SPECIFY) 01 $00 \quad d$ d

$00 \quad d \quad r$


F8a. IF ANSWERED "YES" TO F7a ITEMS a, c, ASK: As of December 31, 2007, what was the maximum credit line on the [NAME DEBT FINANCING OPTION]?

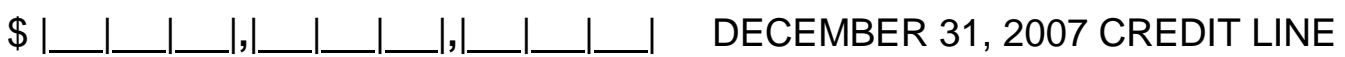

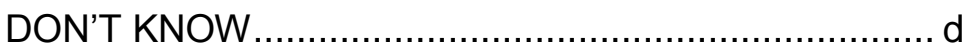

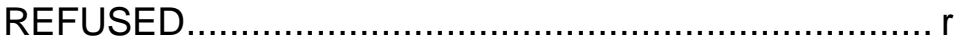

IF DON'T KNOW OR REFUSED, PROBE WITH RANGES: Would you say it was . .

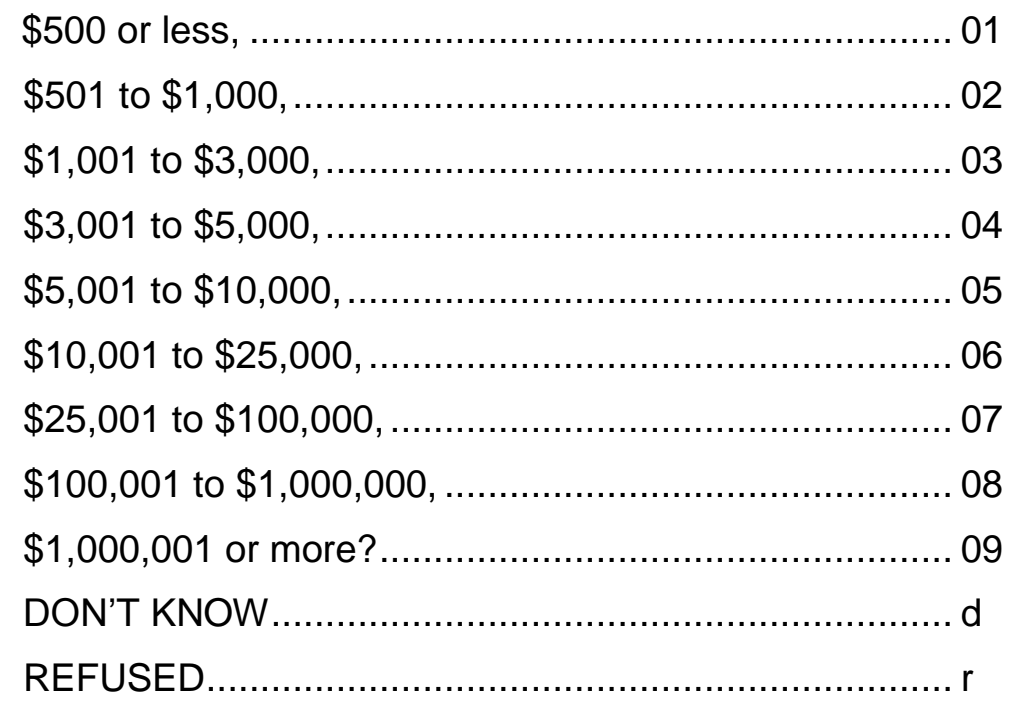


F8b. IF ANSWERED "YES" TO F7a ITEMS a, c, ASK: As of December 31, 2007, what was the outstanding balance on the [NAME DEBT FINANCING OPTION]?

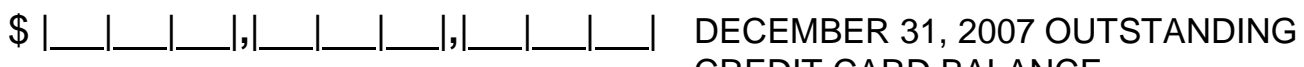
CREDIT CARD BALANCE

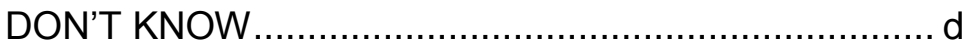

REFUSED.........................................................

IF DON'T KNOW OR REFUSED, PROBE WITH RANGES: Would you say it was . .

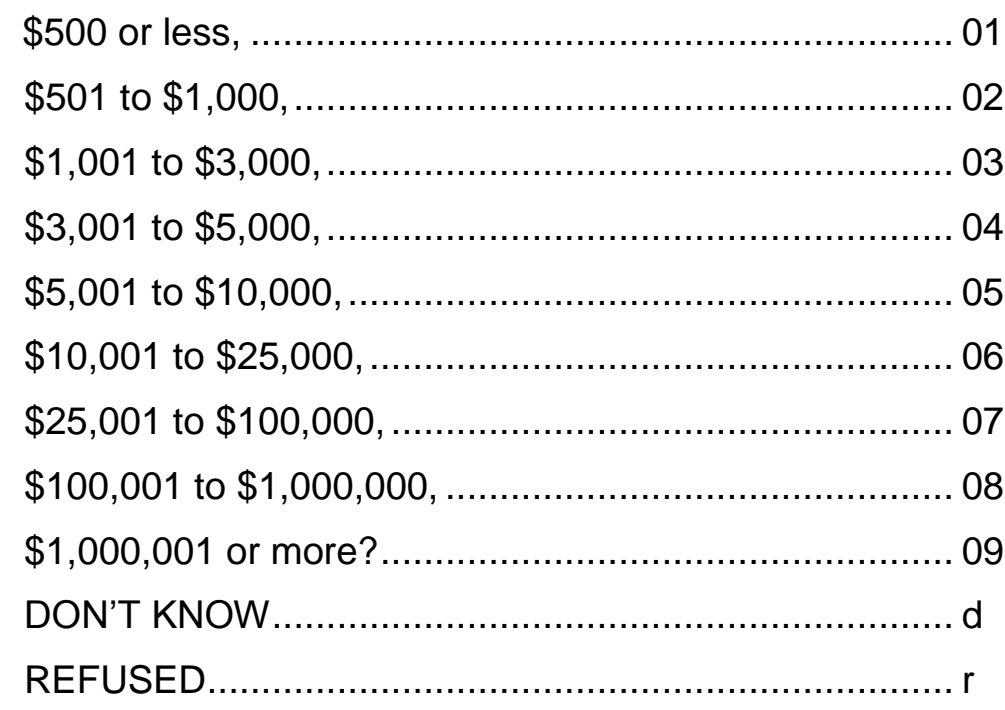

\section{IF F8b IS GREATER THAN F8a:}

Perhaps I made a mistake. The amount I recorded as the balance outstanding is greater than the amount reported as the maximum credit limit. 
F8c. IF ANSWERED “YES” TO F7a ITEMS b, d, e, f, ASK: In calendar year 2007, how much was obtained from the [NAME DEBT FINANCING OPTION]?

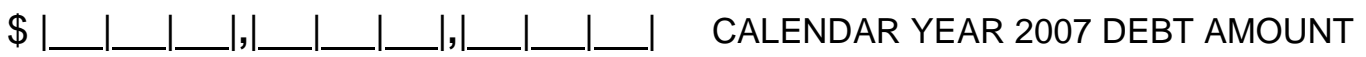

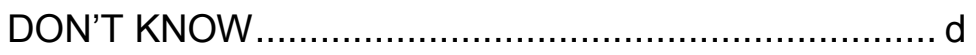

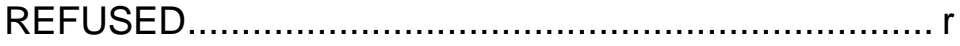

IF DON'T KNOW OR REFUSED, PROBE WITH RANGES: Would you say it was . . .

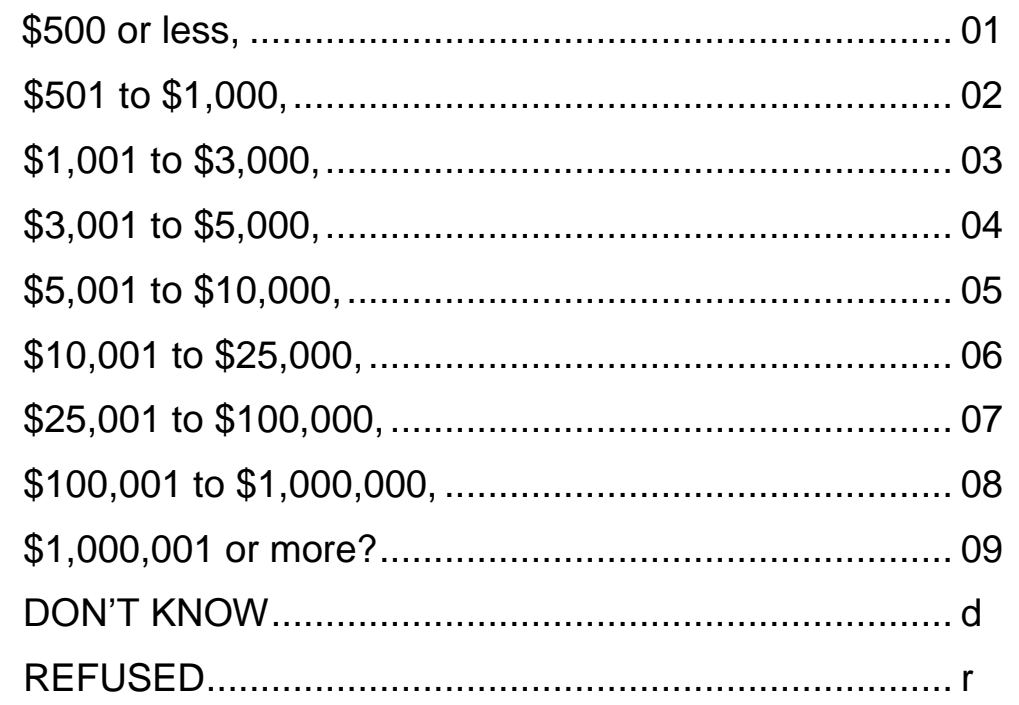


F8d. IF ANSWERED “YES” TO F7a ITEMS b, c, e, f, ASK: As of December 31, 2007, what was the estimated amount of the [NAME DEBT FINANCING OPTION] owed by you on behalf of [NAME BUSINESS]?

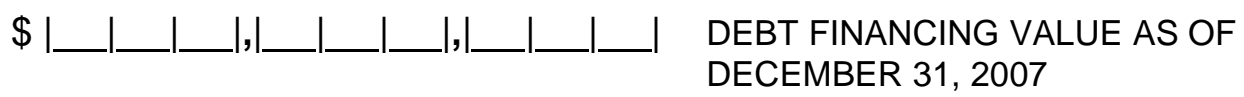

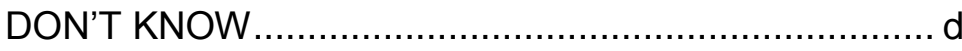

REFUSED ..........................................................

IF DON'T KNOW OR REFUSED, PROBE WITH RANGES: Would you say it was . .

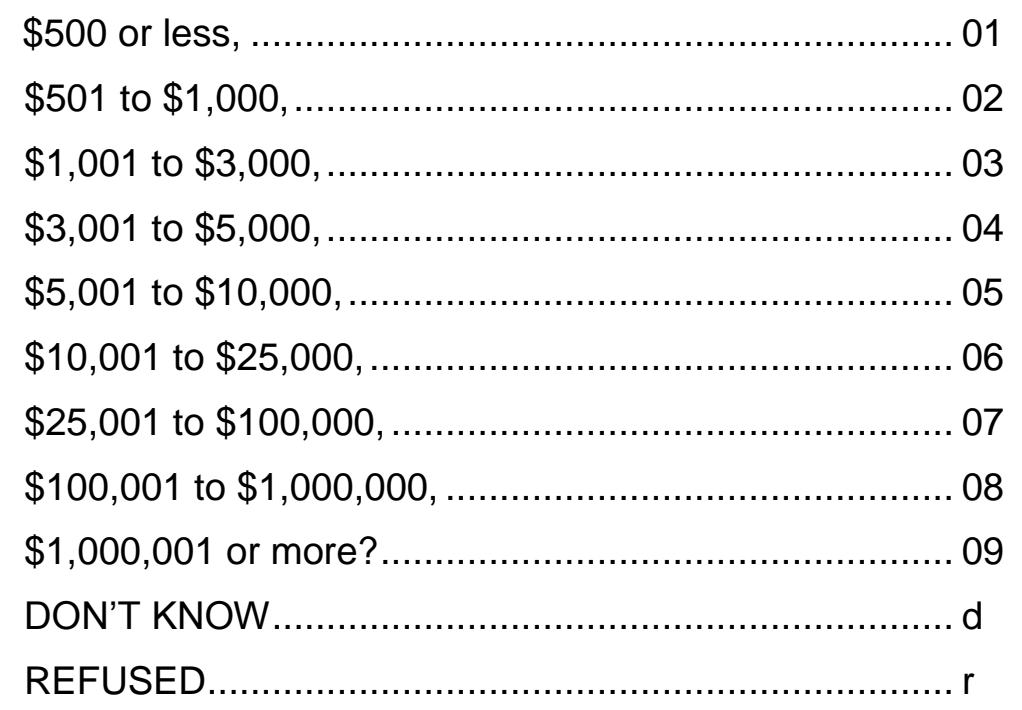




\section{IF MORE THAN ONE OWNER/OPERATOR AT C4, ASK F9a. OTHERWISE, GO TO}

F11a.

F9a. Here is the next debt category. I'm going to ask you about some different types of debt financing that other owners may have borrowed on behalf of [NAME BUSINESS]. This debt does not include amounts already reported in the previous section about your debt. For each, please tell me if other owners used this type at any time during calendar year 2007. Did other owners use [NAME DEBT FINANCING OPTION FROM LIST]?

F9b. IN BELOW LIST, FOR EACH DEBT FINANCING OPTION BUSINESS REPORTED, ASK: How many [NAME DEBT FINANCING OPTION] did other owners use to finance the operation of the business during calendar year 2007?

\begin{tabular}{|l|l|l|l|c|}
\hline YES & NO & $\begin{array}{c}\text { DON'T } \\
\text { KNOW }\end{array}$ & REFUSED & $\begin{array}{c}\text { NUMBER } \\
\text { USED }\end{array}$ \\
\hline
\end{tabular}

a. Personal credit cards for business-related purposes

$0100 \quad d$

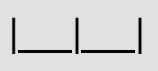

b. Personal loans from a bank or other financial institution, such as a mortgage or home equity loan used for the business

c. Business or corporate credit cards issued in the other owner's name(s). $0100 \quad d$

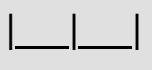

d. Personal loans from any family or friends.

$0100 \quad d$

e. Personal loans from any other individuals not associated with the management of the business.

f. Any other sources? (SPECIFY)

$0100 \quad d$

$01 \quad 00$ d

1

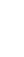
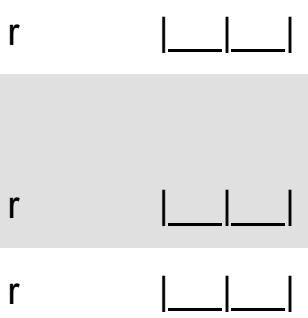
F10a. IF ANSWERED "YES" TO F9a ITEMS a, c, ASK: As of December 31, 2007, what was the maximum credit line on the [NAME DEBT FINANCING OPTION] of (one of) the other owner(s)?

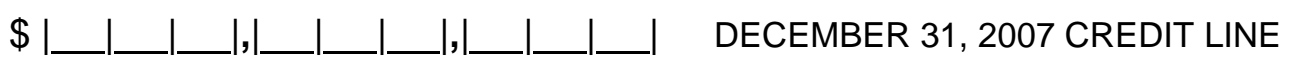

DON'T KNOW ....................................................

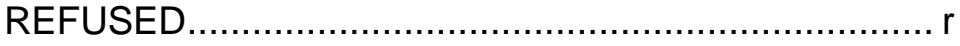

IF DON'T KNOW OR REFUSED, PROBE WITH RANGES: Would you say it was . .

\begin{tabular}{|c|c|}
\hline$\$ 501$ to $\$ 1,000, \ldots .$. &. .02 \\
\hline$\$ 1,001$ to $\$ 3,000, \ldots \ldots \ldots$ & $\ldots 03$ \\
\hline$\$ 3,001$ to $\$ 5,000, \ldots \ldots$. & $\ldots 04$ \\
\hline$\$ 5,001$ to $\$ 10,000, \ldots$ & $\ldots 05$ \\
\hline$\$ 10,001$ to $\$ 25,000, \ldots$ & $\ldots .06$ \\
\hline$\$ 25,001$ to $\$ 100,000$, . & $\ldots .07$ \\
\hline$\$ 100,001$ to $\$ 1,000,000$, & $\ldots 08$ \\
\hline$\$ 1,000,001$ or more? $\ldots$. & $\ldots 09$ \\
\hline DON'T KNOW............ & $\ldots d$ \\
\hline REFUSED.... & $\ldots . . r$ \\
\hline
\end{tabular}


F10b. IF ANSWERED "YES" TO F9a ITEMS a, c, ASK: As of December 31, 2007, what was the outstanding balance on the [NAME DEBT FINANCING OPTION] used by (one of) the other owner(s)?

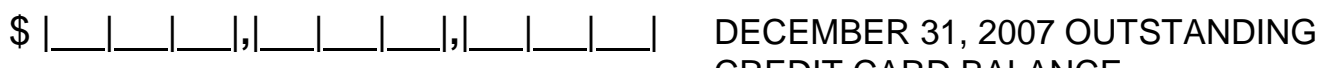
CREDIT CARD BALANCE

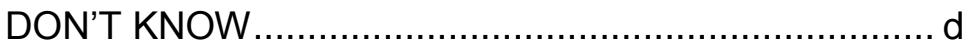

REFUSED ..........................................................

IF DON'T KNOW OR REFUSED, PROBE WITH RANGES: Would you say it was . .

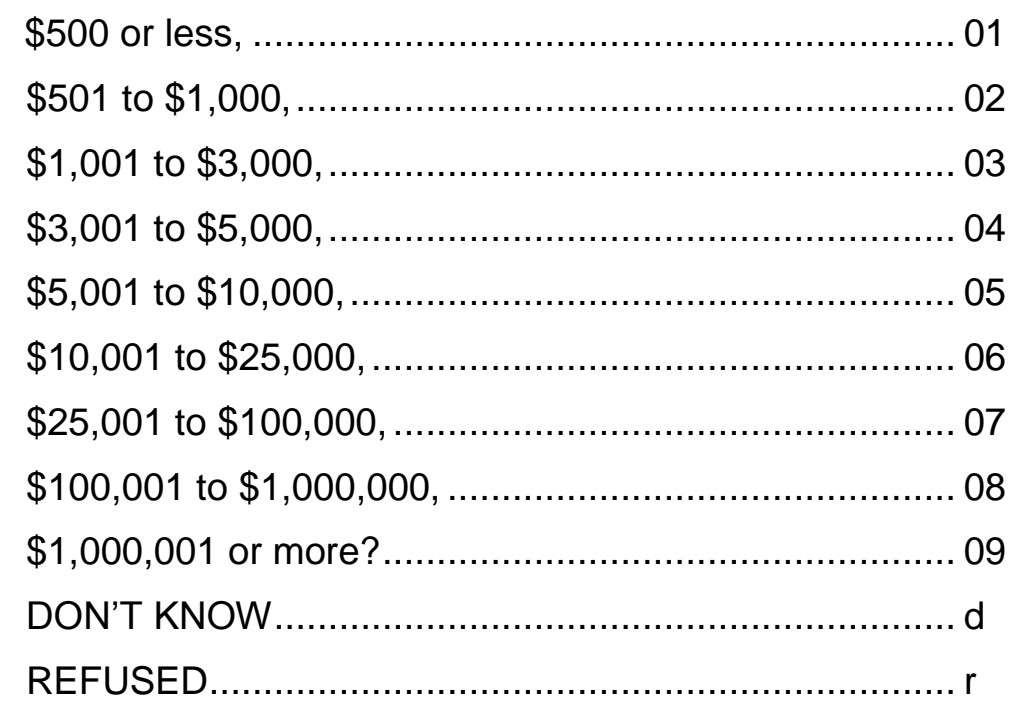

\section{IF F10b IS GREATER THAN F10a:}

Perhaps I made a mistake. The amount I recorded as the balance outstanding is greater than the amount reported as the maximum credit limit. 
F10c. IF ANSWERED "YES" TO F9a, ITEMS b, d, e, f, ASK: In calendar year 2007, how much was obtained from the [NAME DEBT FINANCING OPTION] other owners used?

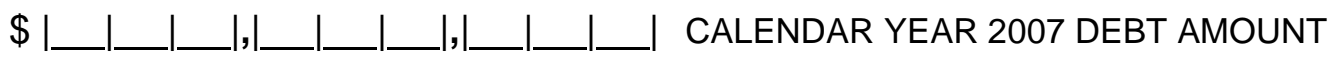

DON'T KNOW

REFUSED.......................................................

IF DON'T KNOW OR REFUSED, PROBE WITH RANGES: Would you say it was ...

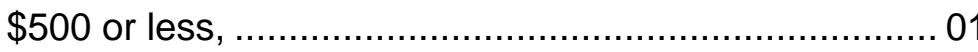

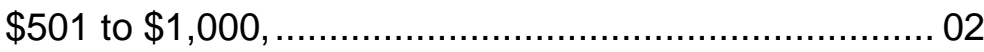

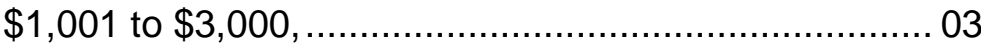

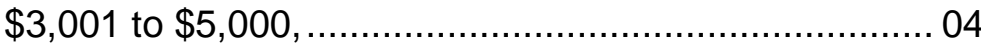

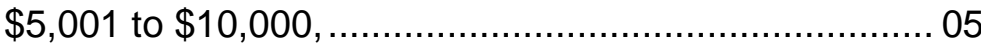

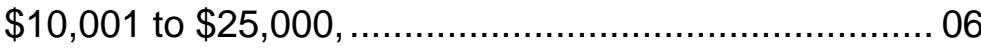

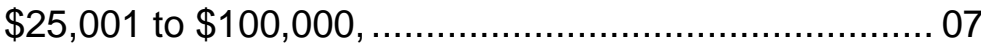

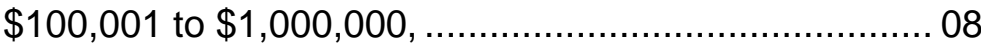

$\$ 1,000,001$ or more?

DON'T KNOW ........................................................

REFUSED 
F10d. IF ANSWERED “YES” TO F9a ITEMS b, d, e, f, ASK: As of December 31, 2007, what was the estimated amount of the [NAME DEBT FINANCING OPTION] owed by other owners on behalf of [NAME BUSINESS]?

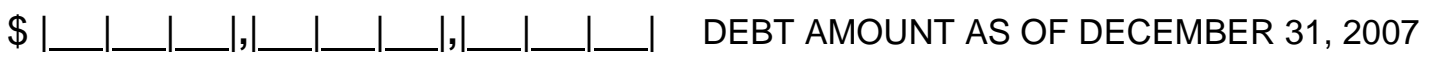

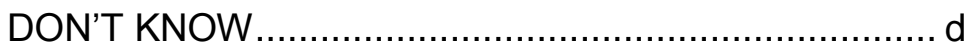

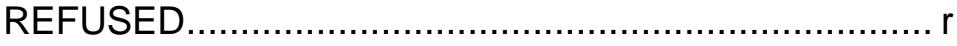

IF DON'T KNOW OR REFUSED, PROBE WITH RANGES: Would you say it was . .

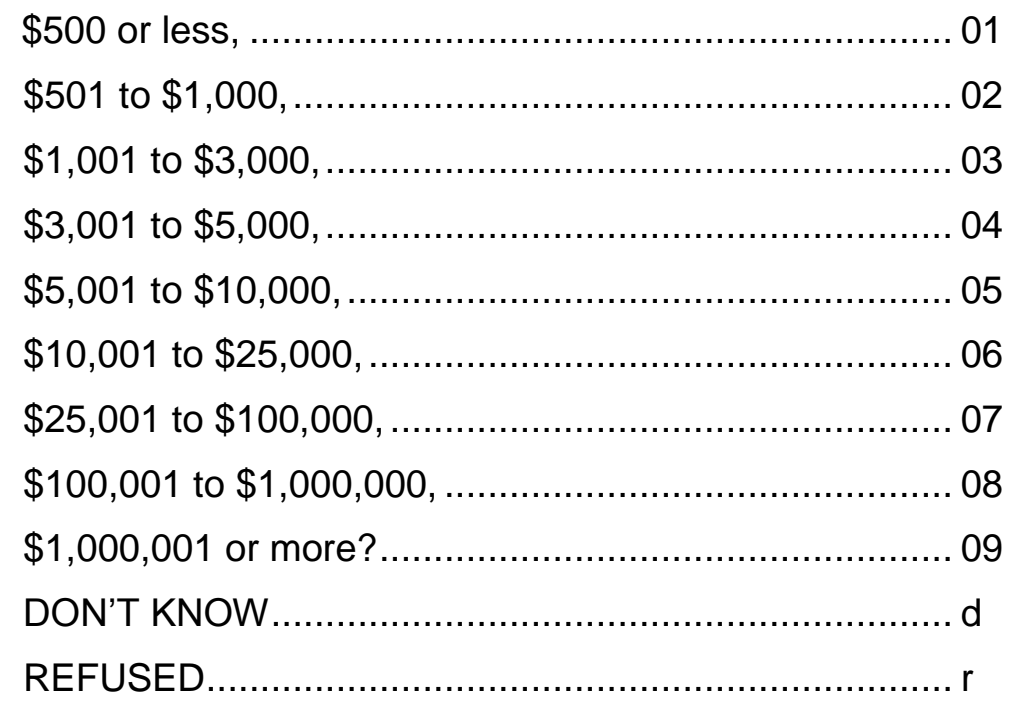


F11a. We are once again switching to another debt category. Now l'm going to ask you about some different types of debt financing that may have been obtained in the name of the business during calendar year 2007. This debt does not include amounts already reported in the previous sections about your debt or the debt of other owners. During calendar year 2007, did [NAME BUSINESS] use [NAME DEBT FINANCING OPTION FROM LIST]?

F11b. IN BELOW LIST, FOR EACH DEBT FINANCING OPTION BUSINESS REPORTED, ASK: How many [NAME DEBT FINANCING OPTION] did the business use to finance the operation or the business during calendar year 2007 ?

\begin{tabular}{|c|c|c|c|c|c|c|}
\hline & & YES & NO & $\begin{array}{l}\text { DON'T } \\
\text { KNOW }\end{array}$ & REFUSED & $\begin{array}{c}\text { NUMBER } \\
\text { USED }\end{array}$ \\
\hline a. & $\begin{array}{l}\text { Business or corporate credit cards issued in the } \\
\text { name of the business }\end{array}$ & 01 & 00 & $d$ & $r$ & - \\
\hline b. & Business loans from a commercial bank ............. & 01 & 00 & $d$ & $r$ & I_ \\
\hline c. & $\begin{array}{l}\text { Business line of credit (READ IF NEEDED: a } \\
\text { business line of credit is when a business has } \\
\text { an agreement with a bank or other financial } \\
\text { institution to borrow up to a certain amount of } \\
\text { funds) }\end{array}$ & 01 & 00 & $d$ & $r$ & \\
\hline d. & $\begin{array}{l}\text { Business loans from a non-bank financial } \\
\text { institution } \ldots \ldots \ldots \ldots \ldots \ldots \ldots \ldots \ldots \ldots \ldots \ldots \ldots \ldots \ldots \ldots \ldots \ldots \ldots \ldots \ldots \ldots \ldots \ldots \ldots \ldots \ldots \ldots \ldots\end{array}$ & 01 & 00 & $d$ & $r$ & \\
\hline e. & $\begin{array}{l}\text { Business loans from any family or friends of the } \\
\text { owners }\end{array}$ & 01 & 00 & $d$ & $r$ & \\
\hline f. & 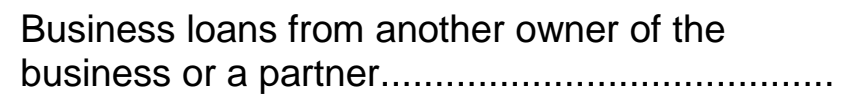 & 01 & 00 & $d$ & $r$ & \\
\hline g. & 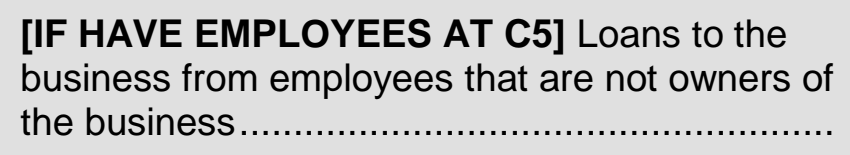 & 01 & 00 & $d$ & $r$ & \\
\hline h. & Loans from government agencies ......................... & 01 & 00 & $d$ & r & I \\
\hline i. & Loans from other businesses ................................ & 01 & 00 & d & r & I_工 \\
\hline j. & 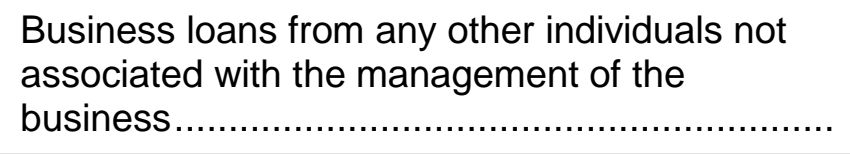 & 01 & 00 & $d$ & r & | \\
\hline $\mathrm{k}$. & Any other sources? (SPECIFY) $\ldots \ldots \ldots \ldots \ldots \ldots \ldots \ldots \ldots \ldots \ldots \ldots \ldots \ldots$ & 01 & 00 & $d$ & r & $1 \ldots 1$ \\
\hline
\end{tabular}


F12a. IF ANSWERED "YES" TO F11a ITEMS a, c, ASK: As of December 31, 2007, what was the maximum credit line on the [NAME DEBT FINANCING OPTION]?

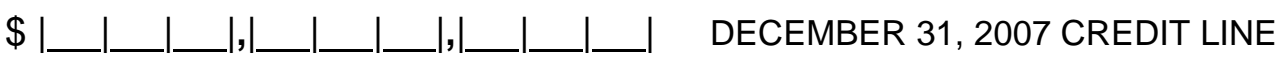

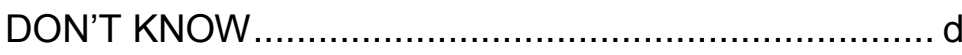

REFUSED ............................................................ $\mathrm{r}$

IF DON'T KNOW OR REFUSED, PROBE WITH RANGES: Would you say it was . .

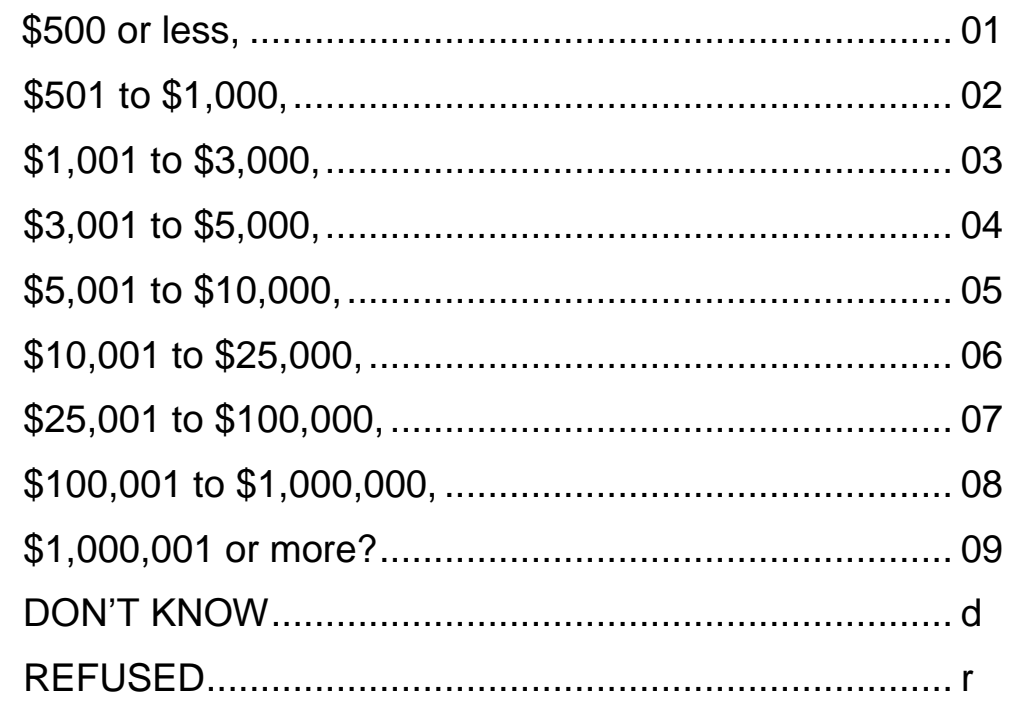


F12b. IF ANSWERED "YES" TO F11a ITEMS a, c, ASK: As of December 31, 2007, what was the outstanding balance on the [NAME DEBT FINANCING OPTION]?

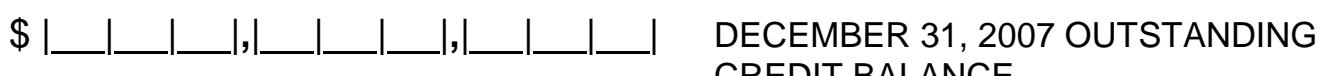
CREDIT BALANCE

DON'T KNOW .....................................................

REFUSED.......................................................

IF DON'T KNOW OR REFUSED, PROBE WITH RANGES: Would you say it was ...

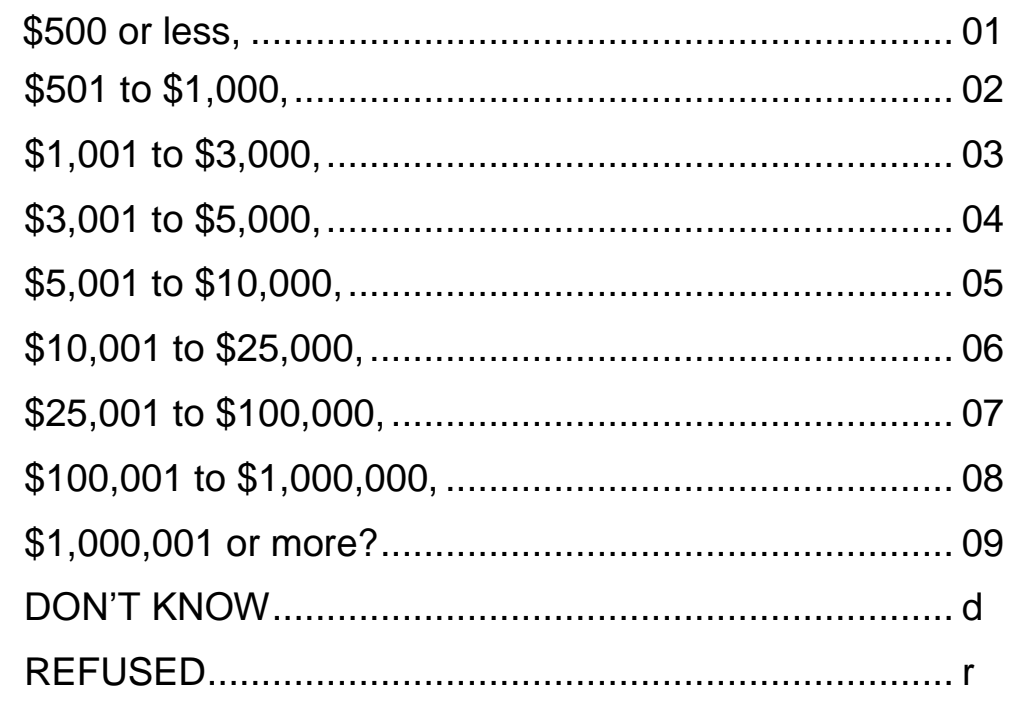

\section{IF F12a IS LESS THAN F12b:}

Perhaps I made a mistake. The amount I recorded as the balance outstanding is greater than the amount reported as the maximum credit limit. 
F12c. IF ANSWERED "YES" TO F11a ITEMS b, d-k, ASK: In calendar year 2007, how much was the amount obtained from [NAME DEBT FINANCING OPTION] used by [NAME BUSINESS]?

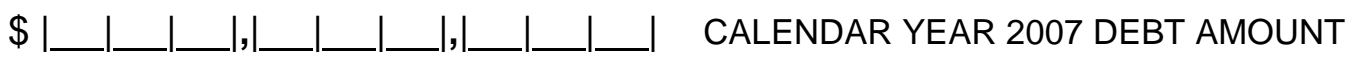

DON'T KNOW......................................................

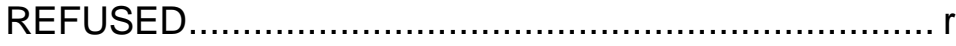

IF DON'T KNOW OR REFUSED, PROBE WITH RANGES: Would you say it was . .

\begin{tabular}{|c|c|}
\hline$\$ 501$ to $\$ 1,000, \ldots .$. &. .02 \\
\hline$\$ 1,001$ to $\$ 3,000, \ldots \ldots \ldots$ & $\ldots 03$ \\
\hline$\$ 3,001$ to $\$ 5,000, \ldots \ldots$. & $\ldots 04$ \\
\hline$\$ 5,001$ to $\$ 10,000, \ldots$ & $\ldots 05$ \\
\hline$\$ 10,001$ to $\$ 25,000, \ldots$ & $\ldots .06$ \\
\hline$\$ 25,001$ to $\$ 100,000$, . & $\ldots .07$ \\
\hline$\$ 100,001$ to $\$ 1,000,000$, & $\ldots 08$ \\
\hline$\$ 1,000,001$ or more? $\ldots$. & $\ldots 09$ \\
\hline DON'T KNOW............ & $\ldots d$ \\
\hline REFUSED.... & $\ldots . . r$ \\
\hline
\end{tabular}


F12d. IF ANSWERED "YES” TO F11a ITEMS b, d-k, ASK: As of December 31, 2007, what was the estimated amount of the [NAME DEBT FINANCING OPTION] owed by [NAME BUSINESS]?

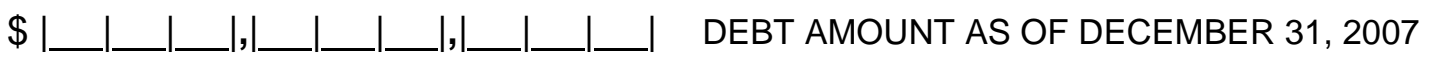

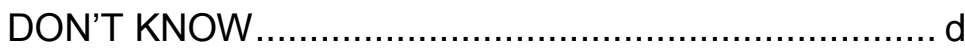

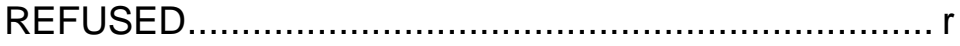

IF DON'T KNOW OR REFUSED, PROBE WITH RANGES: Would you say it was . .

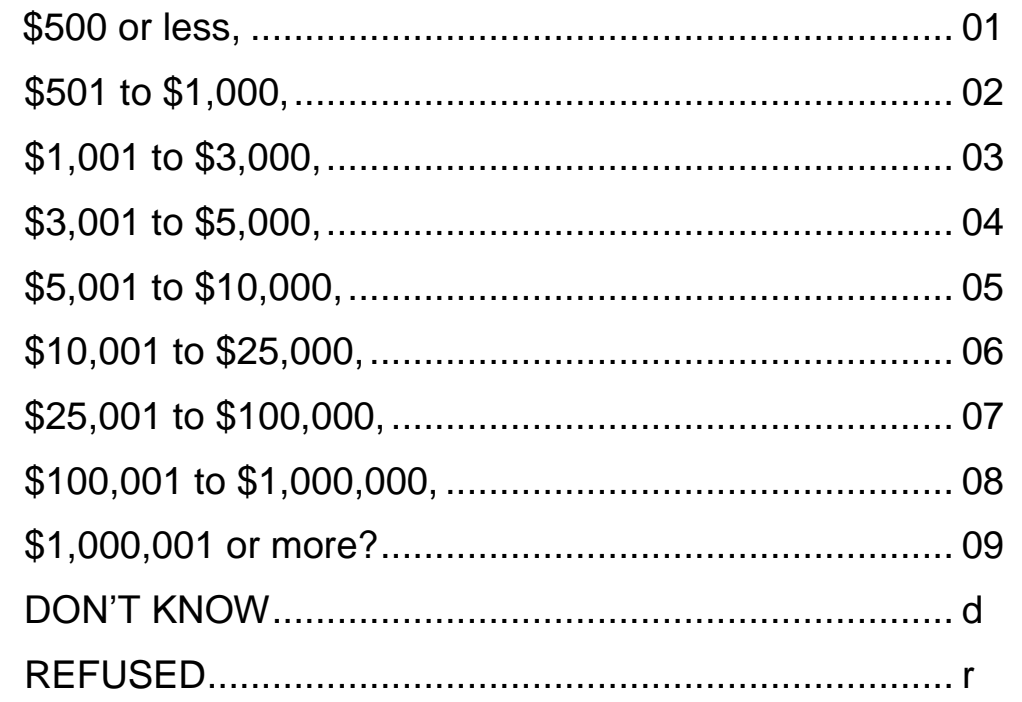

F13. Trade financing is where a business has an arrangement with a supplier to make purchases on account. In calendar year 2007, did [NAME BUSINESS] make any purchases through trade financing?

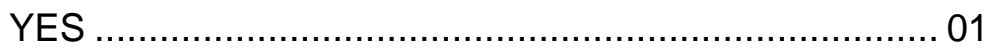

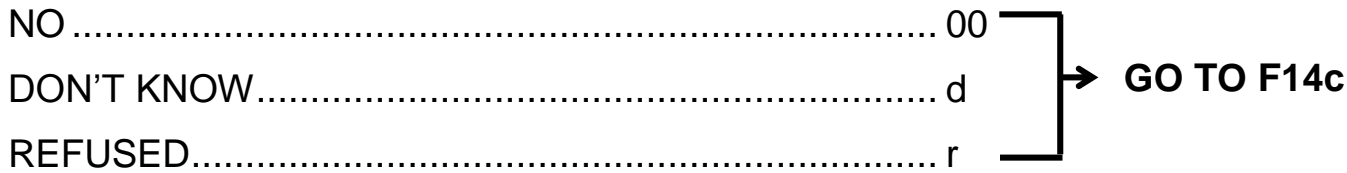


F14a. In calendar year 2007, what was the amount of purchases made through trade financing?

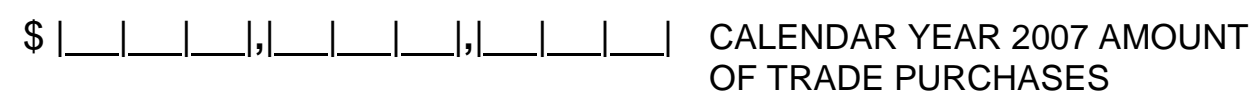

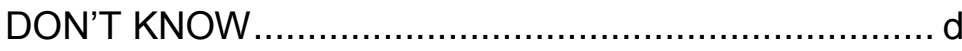

REFUSED............................................................

F14b. IF DON'T KNOW OR REFUSED, PROBE WITH RANGES: Would you say it was ...

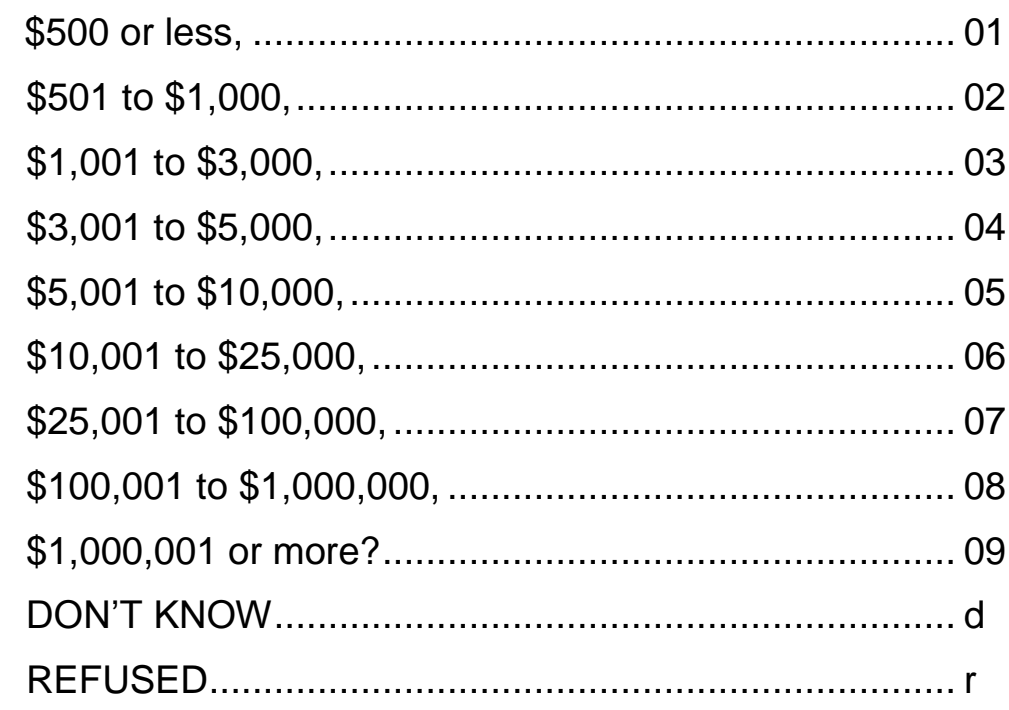

F14c. This next section is about applications for credit [NAME BUSINESS] made in calendar year 2007. In responding to these questions, include new as well as renewal applications for lines of credit and other types of loans. Do not include applications for credit cards, loans from owners, trade credit with suppliers, or loan applications that were withdrawn or are still pending.

F14d. Did [NAME BUSINESS] make any applications for new or renewed loans or lines of credit in calendar year 2007?

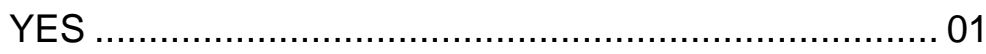

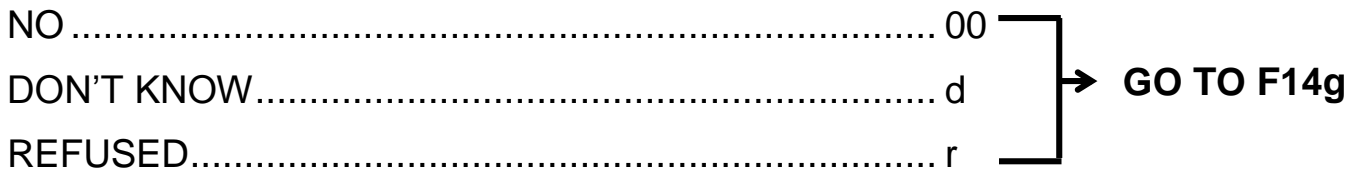


F14e. Were these applications always approved, sometimes approved and sometimes denied, or always denied?

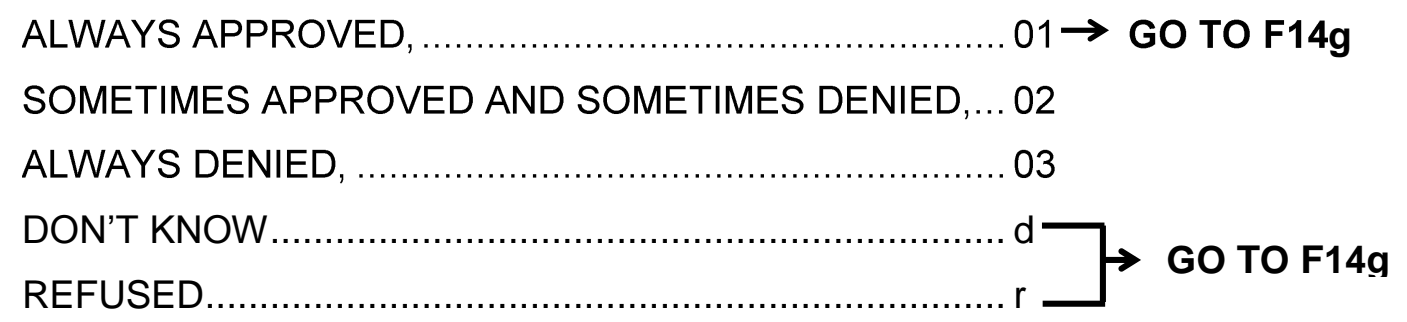

F14f. Consider the most recent time [NAME BUSINESS]'s credit application was denied. Officially, was the application denied because of . . .

\begin{tabular}{|c|c|c|c|c|}
\hline & YES & NO & $\begin{array}{l}\text { DON'T } \\
\text { KNOW }\end{array}$ & REFUSED \\
\hline 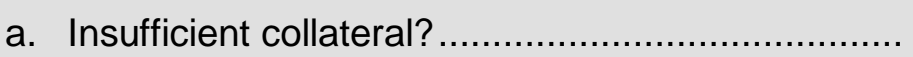 & 01 & 00 & $d$ & r \\
\hline b. The loan requested was too large? ....................... & 01 & 00 & $d$ & r \\
\hline c. Inadequate documentation provided? & 01 & 00 & $d$ & r \\
\hline 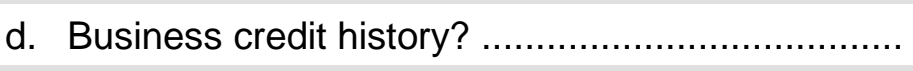 & 01 & 00 & d & r \\
\hline e. Personal credit history? .......................... & 01 & 00 & $d$ & r \\
\hline f. Not being in business long enough? ..................... & 01 & 00 & $d$ & r \\
\hline 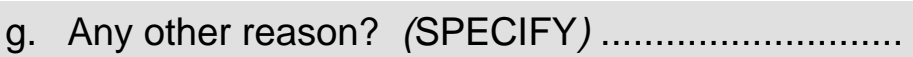 & 01 & 00 & $d$ & r \\
\hline
\end{tabular}

F14g. During calendar year 2007, was there any time when [NAME BUSINESS] needed credit, but did not apply because you or others associated with [NAME BUSINESS] thought the application would be denied?

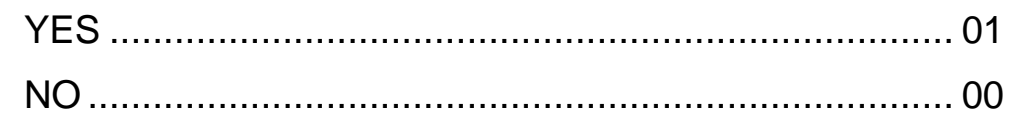

DON'T KNOW ....................................................... d

REFUSED....................................................... 
F15. In calendar year 2007, did [NAME BUSINESS] receive any revenue (money), from the sales of goods, services, or intellectual property? [IF SOLE PROPRIETORSHIP, ADD: This would be gross receipts reported on a Schedule $\mathrm{C}$ or $\mathrm{C}-\mathrm{EZ}$ with your personal income tax return.]

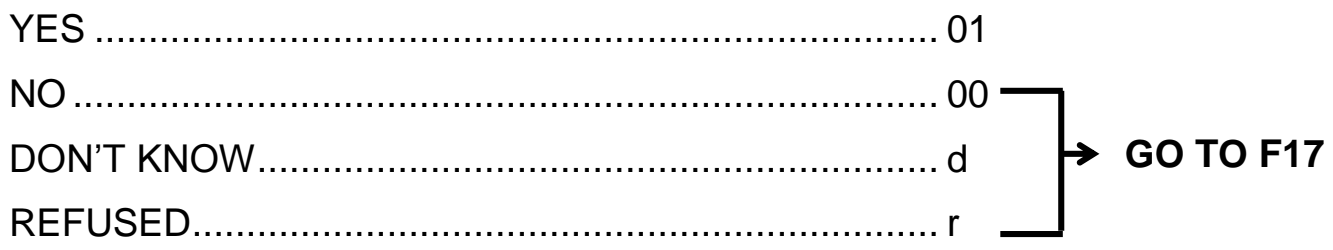

IF F15 = 01 AND D6 = 00:

I may have made a mistake. Earlier in the interview, I recorded that [NAME BUSINESS] did not have any customers or sales in calendar year 2007. Is there an error?

F16. What was [NAME BUSINESS]'s total revenue for calendar year 2007? [IF SOLE PROPRIETORSHIP, ADD: This would be gross receipts reported on a Schedule $C$ or C-EZ with your personal income tax return.]

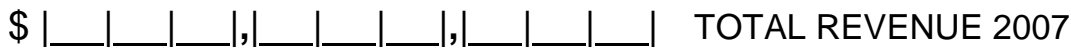

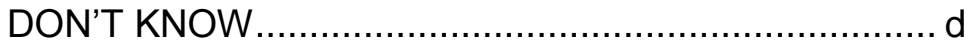

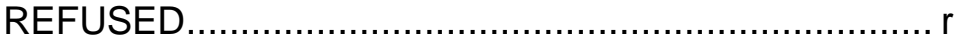

IF DON'T KNOW OR REFUSED, PROBE WITH RANGES: Would you say it was . .

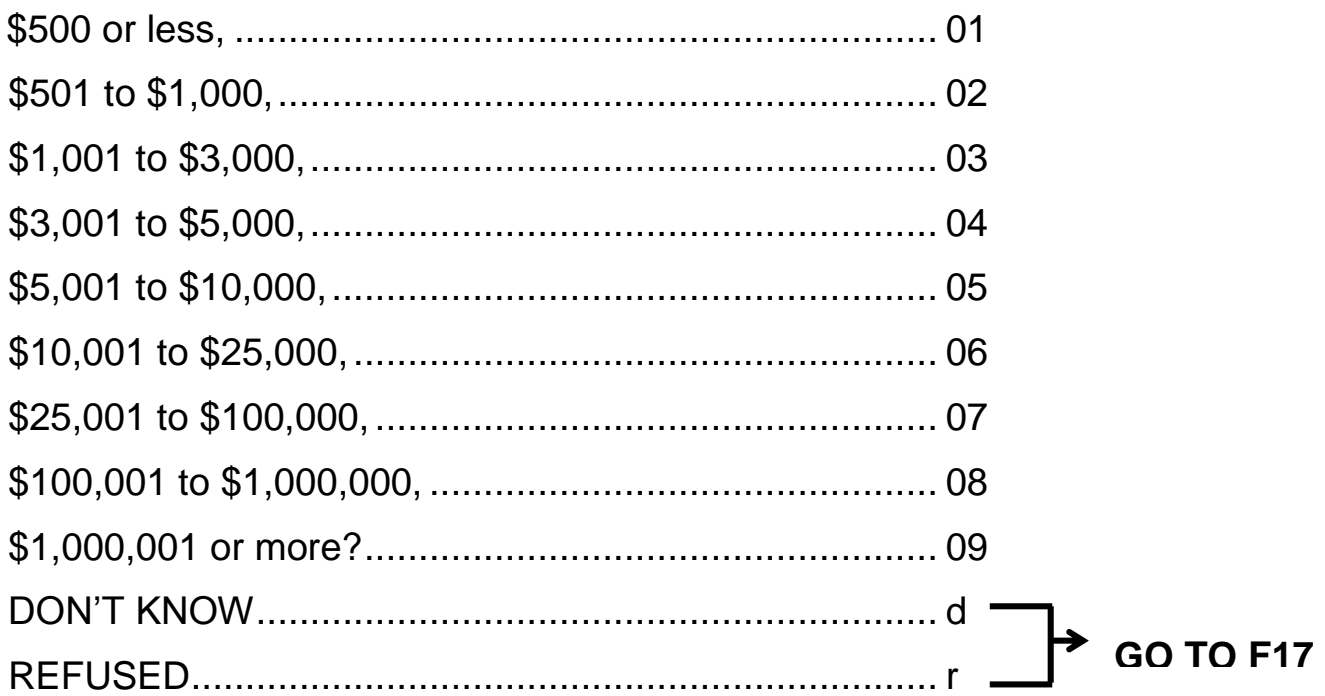


F16b. Was this an increase, a decrease, or no change in the amount of revenue for [NAME BUSINESS] in calendar year 2007 compared to $2006 ?$

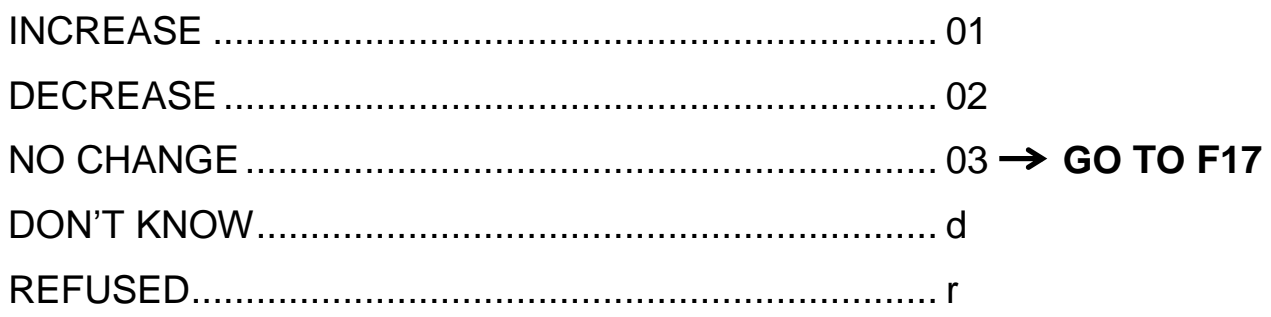

F16c. And what was the percentage change in revenue in calendar year 2007 compared 2006? Your best estimate is fine.

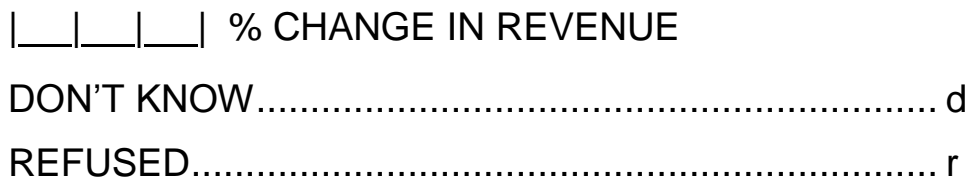

F17. Now l'm going to ask about the expenses the business paid. Expenses are the costs paid for the operation of the business, including wages, salaries, interest on loans, capital leases, materials, etc. How much, if any, did [NAME BUSINESS] pay in expenses during calendar year 2007 ?

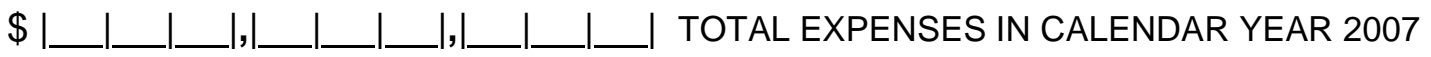

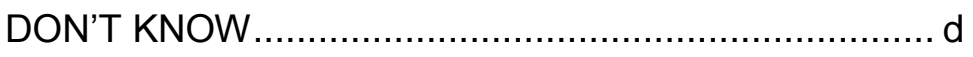

REFUSED......................................................

IF DON'T KNOW OR REFUSED, PROBE WITH RANGES: Would you say it was ...
$\$ 500$ or less, 01

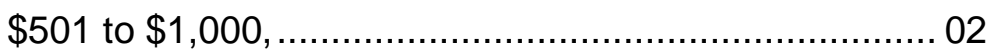

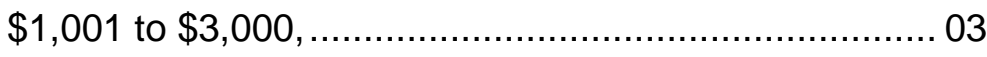

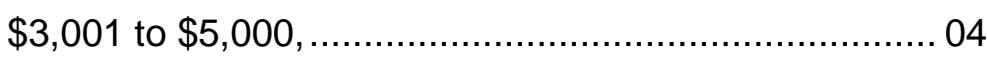

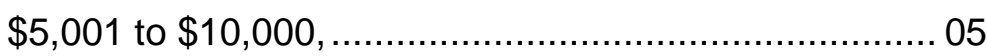

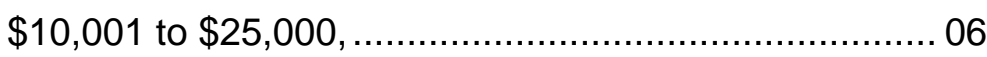

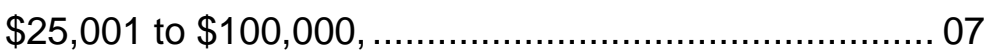

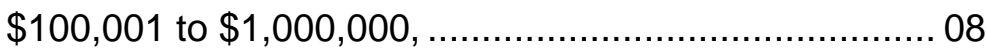
$\$ 1,000,001$ or more? ............................................ 09
DON'T KNOW .................................................. d
REFUSED. 
F17b. Was this an increase, a decrease, or no change in total expenses for [NAME BUSINESS] in calendar year 2007 compared to $2006 ?$

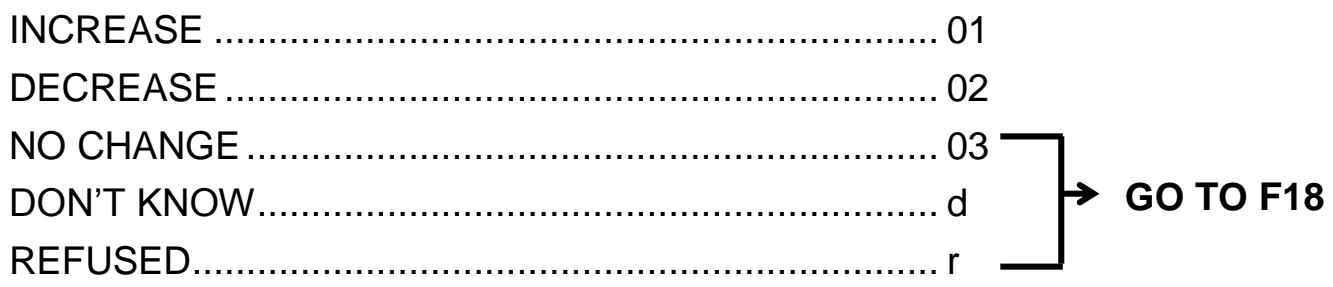

F17c. And what was the percentage change in total expenses in calendar year 2007 compared 2006? Your best estimate is fine.

L_____ $\%$ CHANGE IN EXPENSES

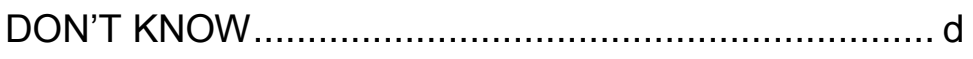

REFUSED...........................................................

F18. IF BUSINESS REPORTED “0” EMPLOYEES AT C5, GO TO F19.

How much, if any, did [NAME BUSINESS] pay in wages, salaries, and benefits to full-and part-time employees in calendar year 2007? Please do not include wages, salaries, and benefits to contract workers who work for the business but are not on the business' official payroll.

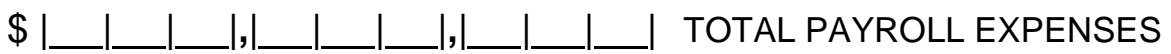
IN CALENDAR YEAR 2007

DON'T KNOW.........................................................

REFUSED........................................................ $\mathrm{r}$

IF DON'T KNOW OR REFUSED, PROBE WITH RANGES: Would you say it was ...

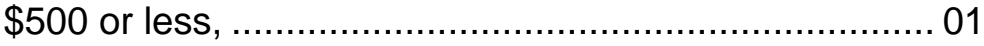

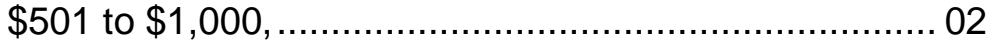

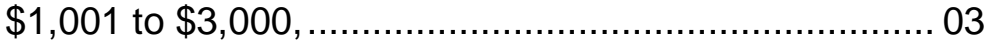

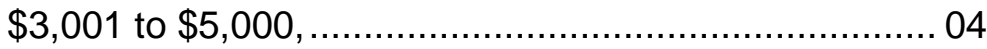

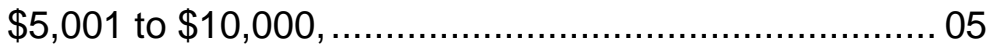

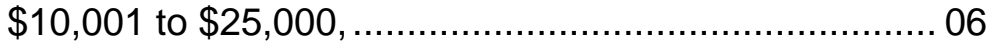

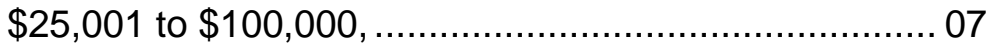

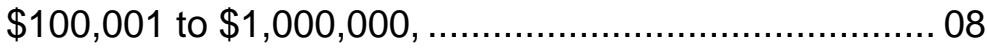

$\$ 1,000,001$ or more?................................................ 09

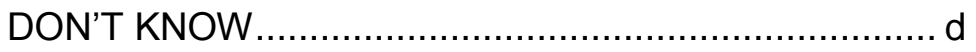

REFUSED ........................................................... $\mathrm{r}$ 


\section{IF F18 > F17:}

I may have made a mistake. I recorded that the business' wage expenses for 2007 were greater than its total expenses. Is there an error?

F19. Did [NAME BUSINESS] spend any money on research and development of new products and services during calendar year 2007 ?

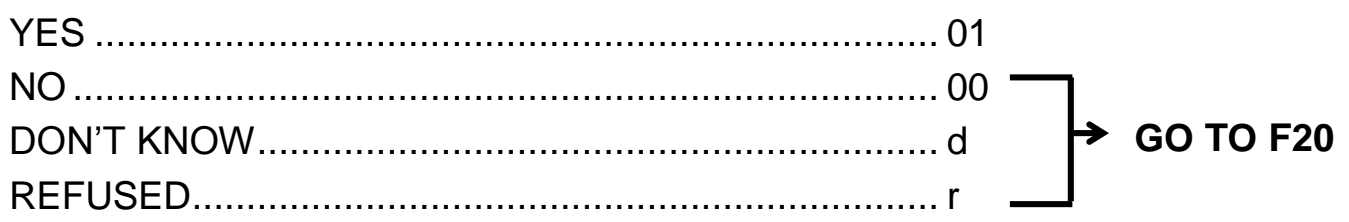

F19a. Please estimate [NAME BUSINESS]'s total research and development expenses for calendar year 2007, including materials, equipment, space, salaries, wages, benefits, and consulting fees?

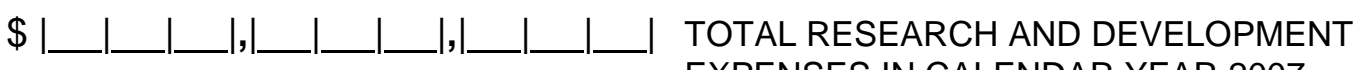
EXPENSES IN CALENDAR YEAR 2007

DON'T KNOW..........................................................

REFUSED.......................................................

IF DON'T KNOW OR REFUSED, PROBE WITH RANGES: Would you say it was ...

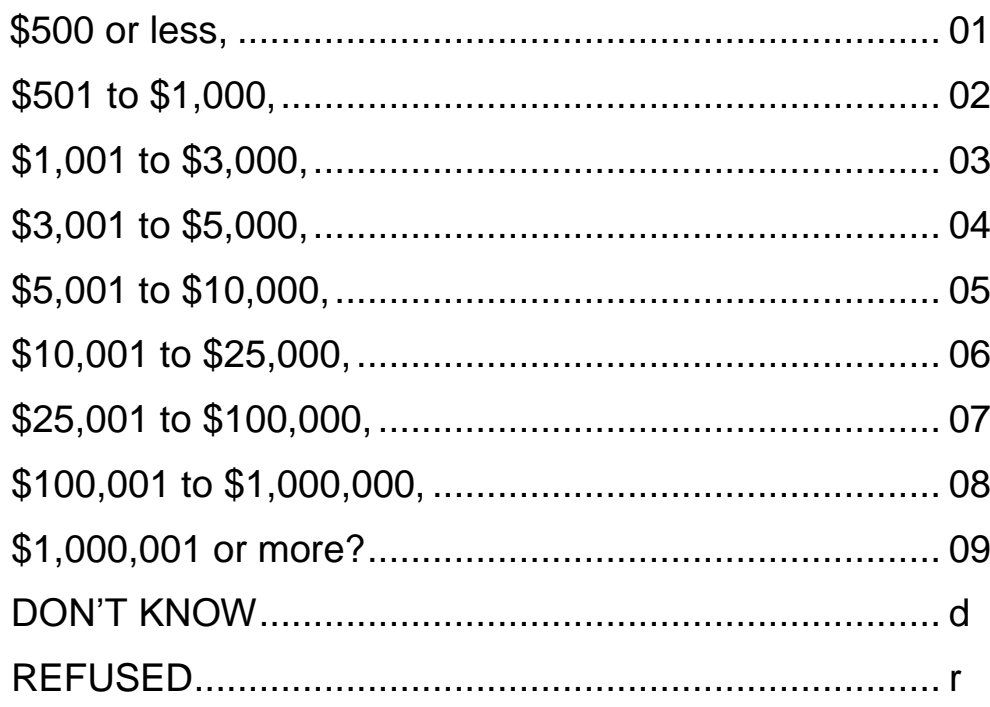

\section{IF F19a > F17:}

I may have made a mistake. I recorded that the business' research and development expenses for 2007 were greater than its total expenses. Is there an error? 
F20. Did [NAME BUSINESS] spend any money on the purchase of new or used machinery or equipment during calendar year 2007?

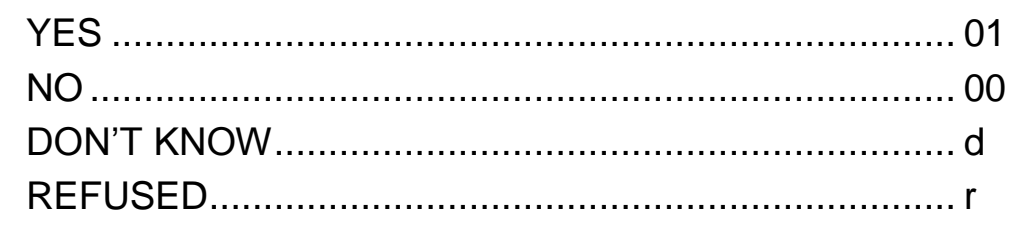

F21. Did [NAME BUSINESS] spend any money on rental or lease payments for buildings or other structures during calendar year 2007?

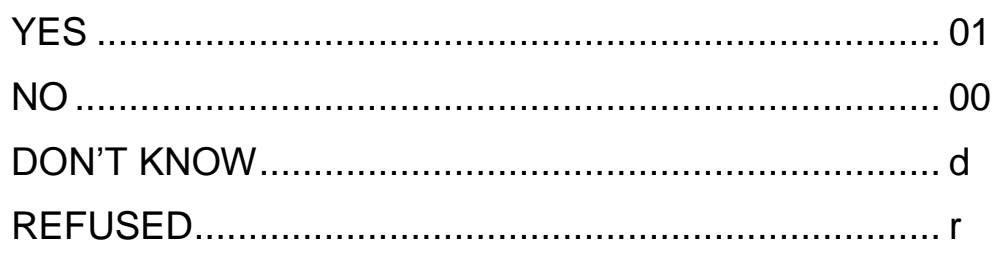

F22. Did [NAME BUSINESS] spend any money on rental or lease payments for machinery or equipment during calendar year 2007?

YES NO

F23. Profit is the business' income after all expenses and taxes have been deducted. What was [NAME BUSINESS]'s total profit or loss for calendar year 2007?

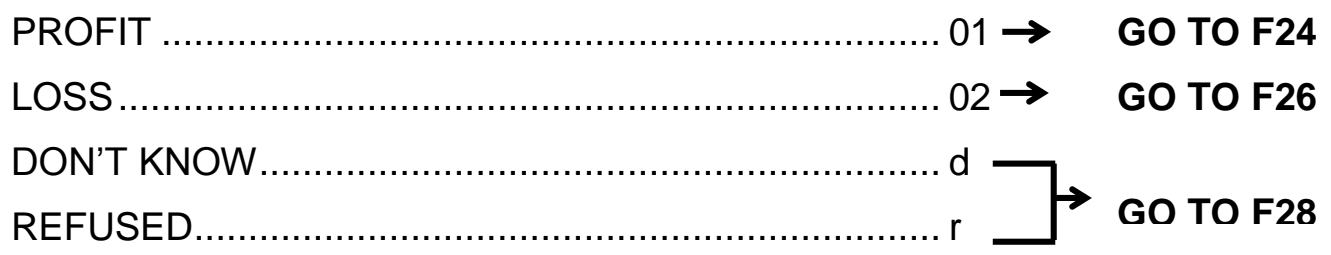

IF F23 = 01 AND F15 = 00:

I may have made a mistake. Earlier in the interview, I recorded that [NAME BUSINESS] did not have any revenue in calendar year 2007. Is there an error?

F24. ENTER PROFIT AMOUNT

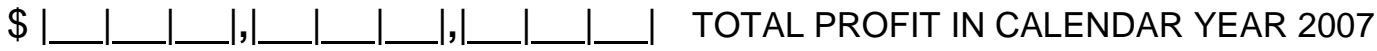

DON'T KNOW......................................................

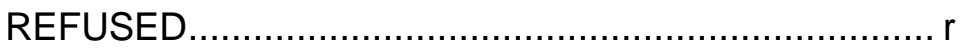


F25. IF DON'T KNOW OR REFUSED, PROBE WITH RANGES: Would you say it was ...

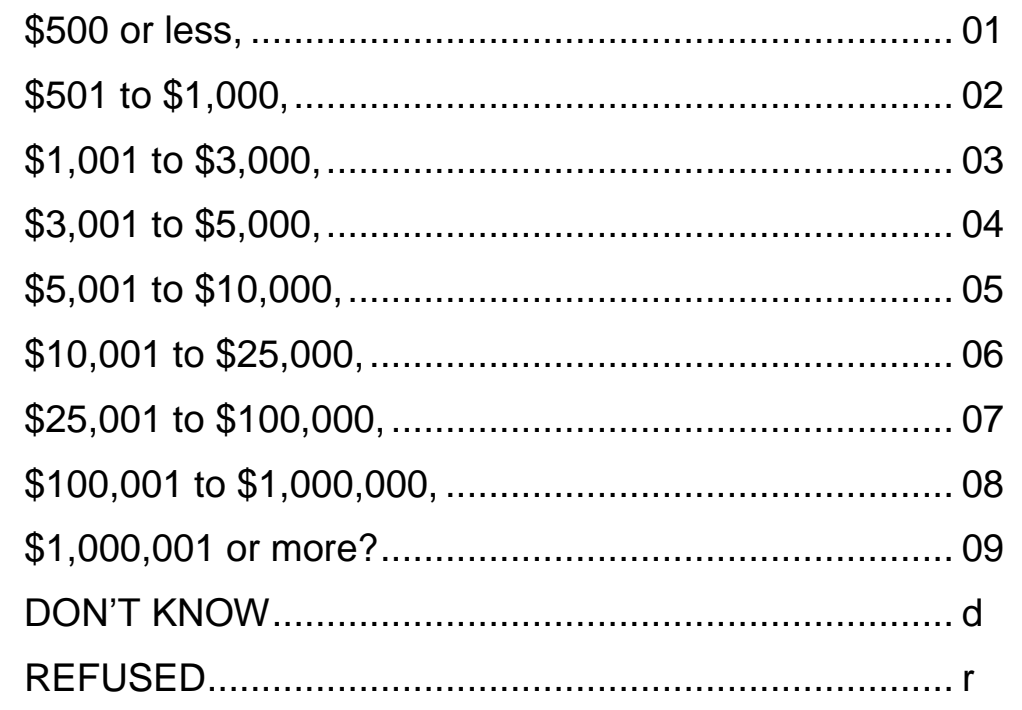

F26. ENTER LOSS AMOUNT

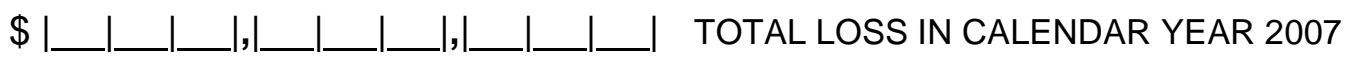

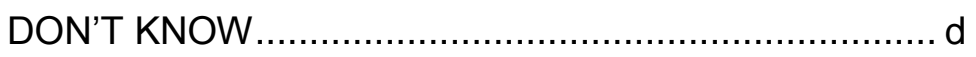

REFUSED .........................................................

F27. IF DON'T KNOW OR REFUSED, PROBE WITH RANGES: Would you say it was ...

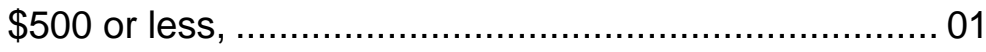

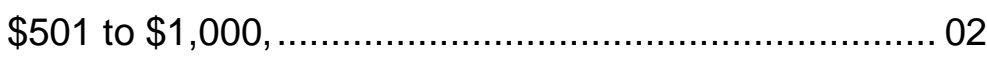

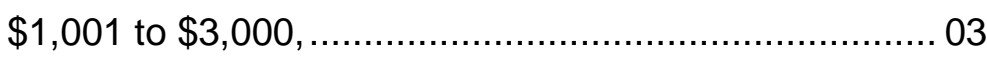

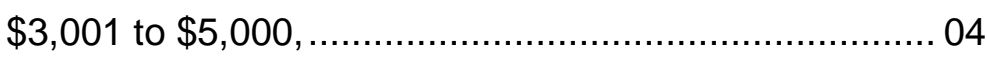

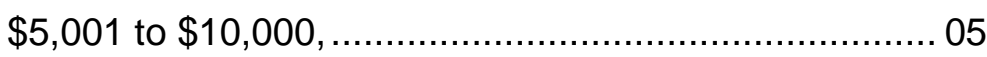

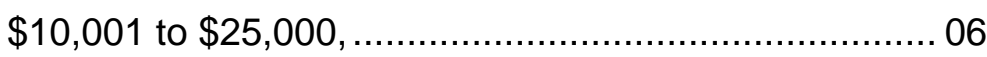

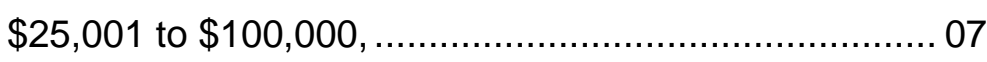

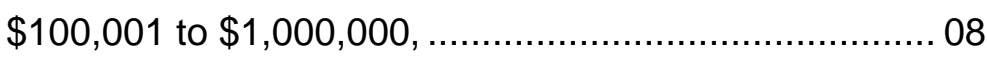

$\$ 1,000,001$ or more? ............................................ 09

DON'T KNOW .................................................. d

REFUSED.......................................................... 
F28. Assets are what the business owns. As of December 31, 2007, did [NAME BUSINESS]'s assets include [NAME ASSET FROM LIST]?

\begin{tabular}{|c|c|c|c|c|}
\hline & YES & NO & $\begin{array}{l}\text { DON'T } \\
\text { KNOW }\end{array}$ & REFUSED \\
\hline $\begin{array}{l}\text { a. Cash on hand in checking, savings, money } \\
\text { market accounts, certificates of deposit and other } \\
\text { time deposits }\end{array}$ & 01 & 00 & $d$ & r \\
\hline 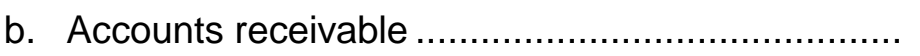 & 01 & 00 & $d$ & r \\
\hline 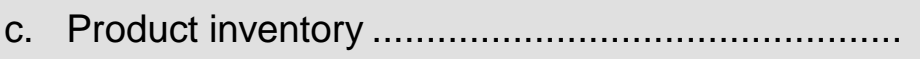 & 01 & 00 & $d$ & r \\
\hline 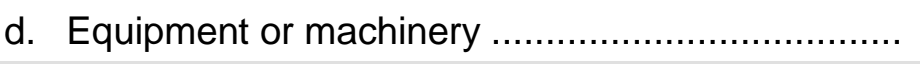 & 01 & 00 & $d$ & r \\
\hline e. Land, buildings, and other structures..................... & 01 & 00 & $d$ & r \\
\hline 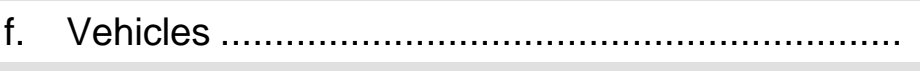 & 01 & 00 & d & r \\
\hline g. Any other business owned property (SPECIFY) ... & 01 & 00 & d & r \\
\hline h. Any other assets? (SPECIFY) & 01 & 00 & $d$ & r \\
\hline
\end{tabular}

F29. FOR EACH ASSET BUSINESS REPORTED, ASK:

As of December 31, 2007, what was the estimated value of the [NAME OF ASSET] owned by [NAME BUSINESS]?

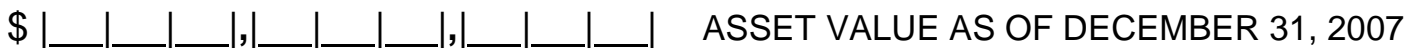

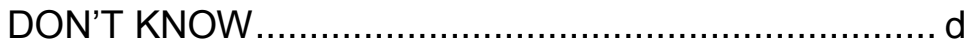

REFUSED...........................................................

IF DON'T KNOW OR REFUSED, PROBE WITH RANGES: Would you say it was . .

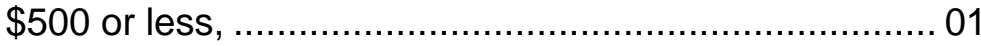

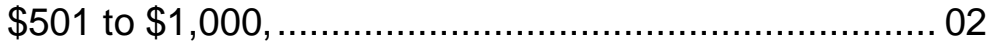

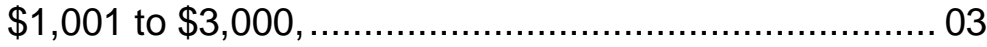

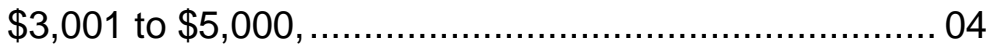

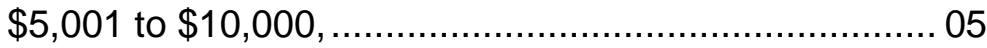

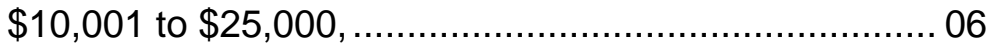

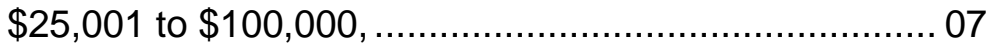

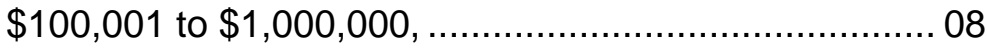

$\$ 1,000,001$ or more? ................................................. 09

DON'T KNOW .......................................................

REFUSED ........................................................... $\mathrm{r}$ 
F30. Liabilities are what the business owes. Other than the loans and the financial debt we've already talked about, did [NAME BUSINESS]'s liabilities as of December 31, 2007 include [NAME LIABILITY FROM LIST]?

\begin{tabular}{|c|c|c|c|c|}
\hline & YES & NO & $\begin{array}{l}\text { DON'T } \\
\text { KNOW }\end{array}$ & REFUSED \\
\hline 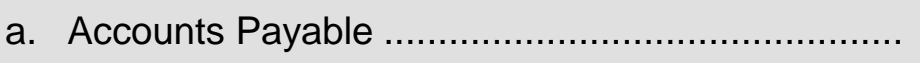 & 01 & 00 & $d$ & r \\
\hline b. Pension and post retirement benefits ................... & 01 & 00 & $d$ & r \\
\hline c. Any other liabilities? (SPECIFY) ..................... & 01 & 00 & $d$ & r \\
\hline
\end{tabular}

F31. FOR EACH LIABILITY BUSINESS HAS, ASK: As of December 31, 2007, what was the estimated value of [NAME BUSINESS]'s [NAME OF LIABILITY]?

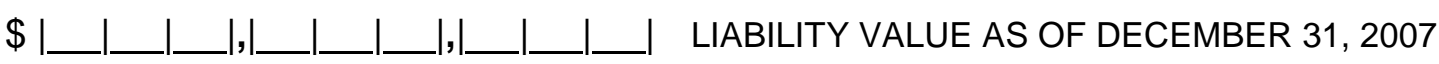

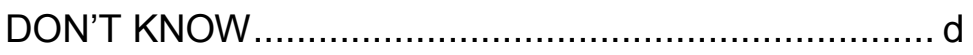

REFUSED..................................................... $\mathrm{r}$ 


\section{G. WORK BEHAVIORS AND DEMOGRAPHICS OF OWNER/OPERATOR(S)}

The last section contains questions for classification purposes only.

C4 LISTING OF OWNER/OPERATORS SHOULD BE ASKED THIS SERIES IN THE ORDER THEY APPEAR IN C4.

NO QUESTIONS WILL BE ASKED ABOUT OWNER/OPERATORS WHO HAVE LEFT THE BUSINESS.

FOR ALL SECOND FOLLOW-UP OWNER/OPERATORS IN C4, ASK BLOCK G1.

FOR ALL NEW OWNER/OPERATORS, ASK BLOCK G2.

QG9-G9b IS TO BE ASKED ONLY OF RESPONDENTS AND NOT ABOUT OTHER OWNER/OPERATORS.

\section{BLOCK G1}

G1a. (Are/ls) (you/[OWNER B-J]) also a paid employee at [NAME BUSINESS]?

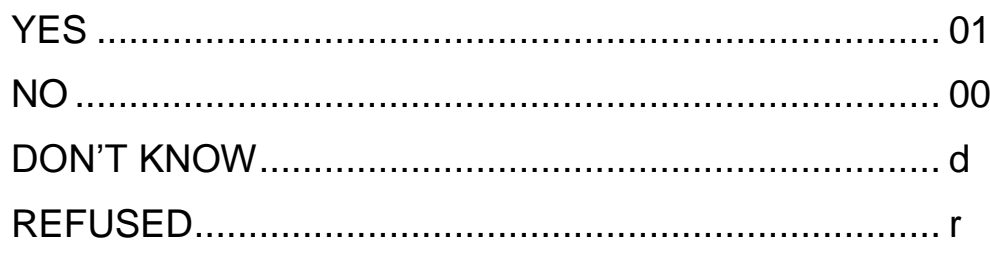

G1b. During the time [NAME BUSINESS] was in business during 2007, how many hours in an average week did (you/[OWNER B-J]) spend working at [NAME BUSINESS]?

I______ HOURS WORKED IN AVERAGE WEEK

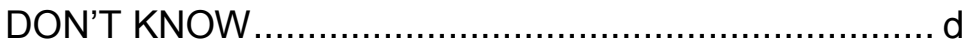

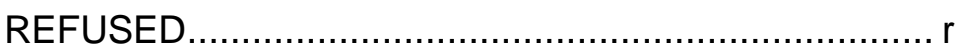

IF DON'T KNOW OR REFUSED PROBE: Would you say it was . . .

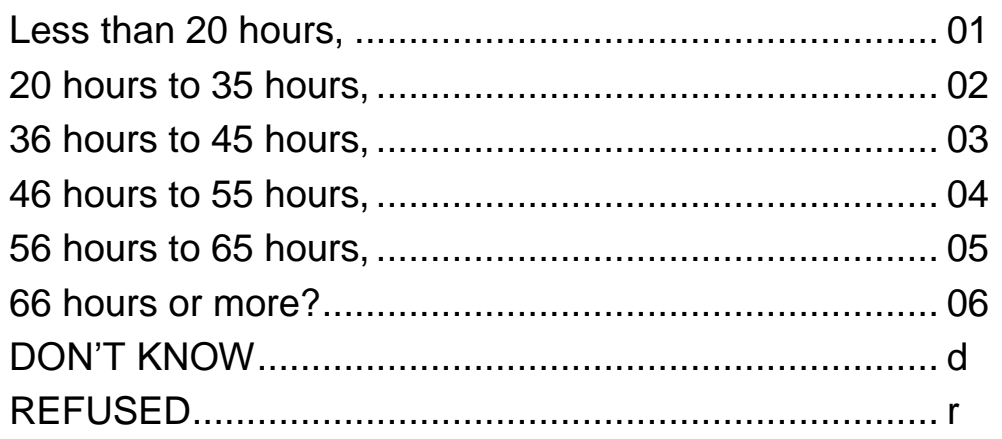


G9. What is the highest level of education (you/[OWNER B-J]) (have/has) completed so far? Would you say...

Less than 9th grade, 01

Some high school, but no diploma, 02

High school graduate (diploma or equivalent diploma [GED]), 03

Technical, trade or vocational degree, 04

Some college, but no degree, 05

Associate's degree, 06

Bachelor's degree, 07

Some graduate school but no degree, $08 \rightarrow$ GO TO G9b

Master's degree, or 09

Professional school or doctorate? 10

DON'T KNOW. d

REFUSED. $r$

G9a. What was the primary field of study for this degree?

DON'T KNOW. d REFUSED. $r$

G9b. What was the primary field of study for your bachelor's degree?

DON'T KNOW .......................................................

REFUSED......................................................... 
SECOND FOLLOW-UP OWNERS/OPERATORS: ANY DEMOGRAPHIC QUESTION G1dG10a NOT ANSWERED IN SECOND FOLLOW-UP WILL BE ASKED AGAIN. QUESTION G9-G9b IS TO BE ASKED ONLY OF RESPONDENTS AND NOT ABOUT OTHER OWNER/OPERATORS.

\section{ENDBLOCK G1-FOR ALL SECOND FOLLOW-UP OWNERS WITH COMPLETE DEMOGRAPHIC INFORMATION.}

BLOCK bSectionG2-for all NEW OWNERS

G1a. (Are/ls) (you/[OWNER B-J]) also a paid employee at [NAME BUSINESS]?

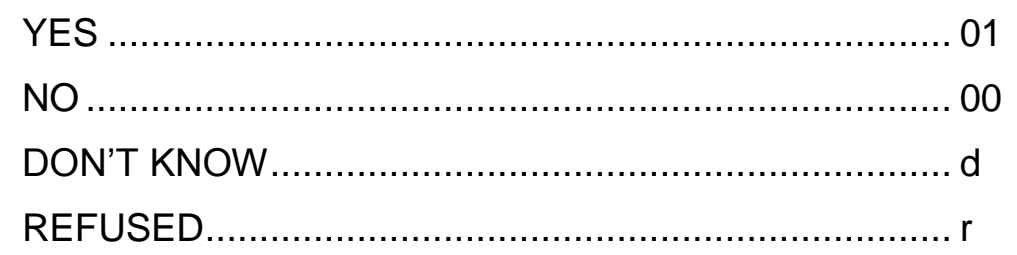

G1b. During the time [NAME BUSINESS] was in business during 2007, how many hours in an average week did (you [OWNER B-J] spend working at [NAME BUSINESS]?

|_____ I HOURS WORKED IN AVERAGE WEEK

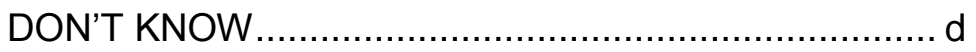

REFUSED........................................................... $\mathrm{r}$

G1b1. IF DON'T KNOW OR REFUSED, PROBE: Would you say it was . .

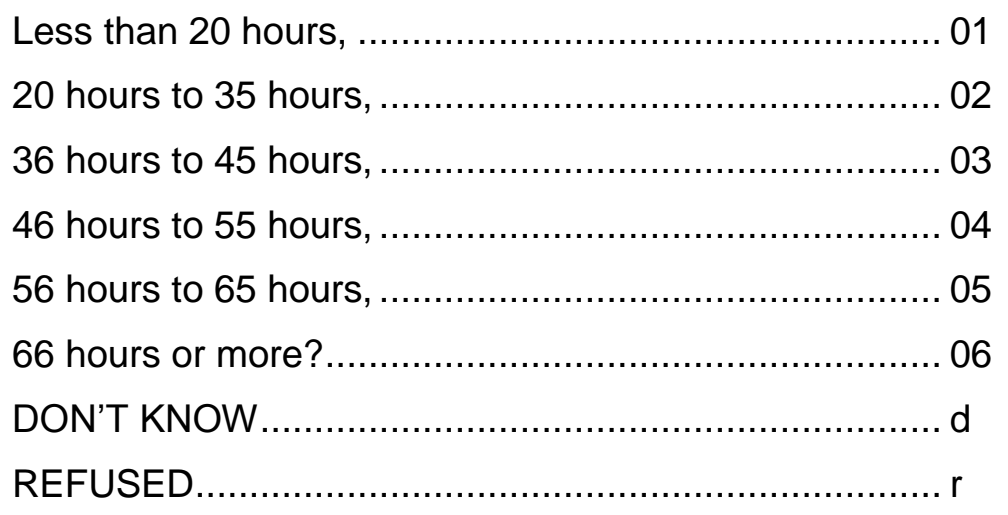


G2. How many years of work experience (have/has) (you/[OWNER B-J]) had in this industry-the one in which [NAME BUSINESS] competes?

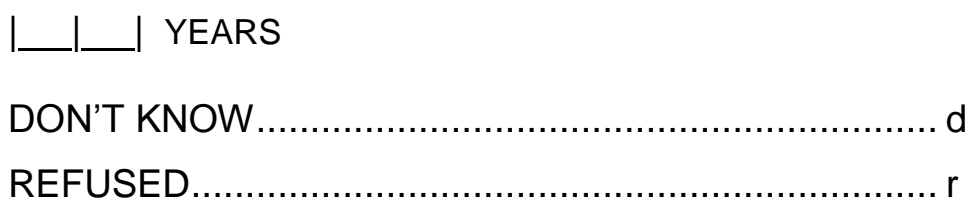

G3a. How many other new businesses (have/has) (you/[OWNER B-J]) started besides [NAME BUSINESS]?

L____ NUMBER OF BUSINESSES (ENTER “0” FOR NONE)

DON'T KNOW ..................................................... d

REFUSED........................................................... $\mathrm{r}$

\section{IF ZERO NEW BUSINESSES AT G3a, GO TO G4.}

G3b. (Was this/Were any of the) business(es) in the same industry as [NAME BUSINESS]?

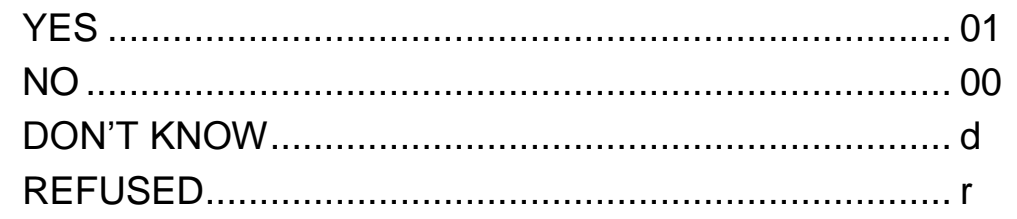

G4. How old will (you/[OWNER B-J]) be on (your/his/her) next birthday?

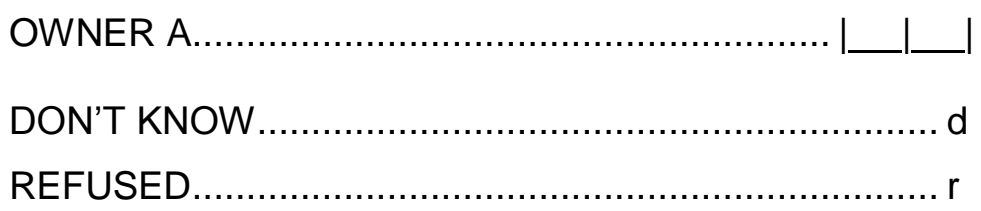

IF DON'T KNOW OR REFUSED, PROBE WITH RANGES: Would you say . .

18
25


IF G4 IS LESS THAN G2:

Perhaps I made a mistake in recording your answer. (Your/OWNER B-J)'s age is less than (Your/OWNER B-J)'s years of experience.

Now I have a few questions about race and ethnicity.

G5. (Are/ls) (you/[OWNER B-J]) of Hispanic or Latino origin?

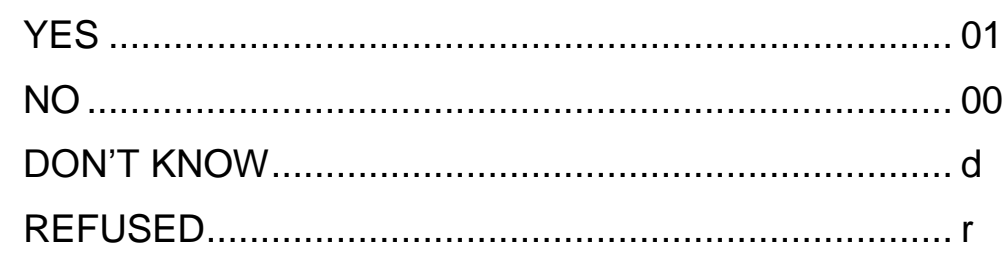

G6. I am going to read a list of race categories. Please choose one or more that best describes (your/[OWNER B-J])'s race. Are (you [OWNER B-J]) American Indian or Alaska Native, Native Hawaiian or other Pacific Islander, Asian, Black or African American, or White?

AMERICAN INDIAN OR ALASKA NATIVE 01

NATIVE HAWAIIAN OR OTHER

PACIFIC ISLANDER .................................................... 02

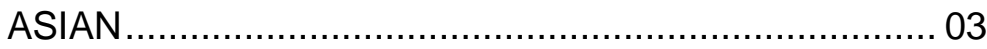

BLACK OR AFRICAN AMERICAN ................................ 04

WHITE

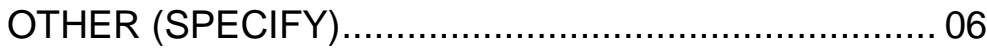

DON'T KNOW .........................................................

REFUSED.........................................................

G7. (Were/Was) (you/[OWNER B-J]) born in the United States?

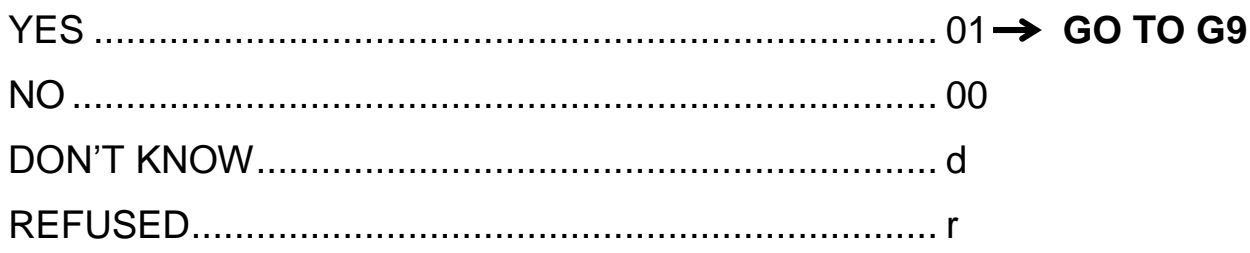


G8. (Are/ls) (you/[OWNER B-J]) a U.S. citizen?

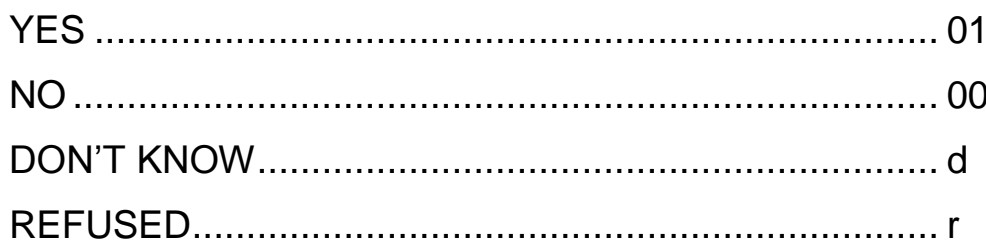

G9. What is the highest level of education (you/[OWNER B-J]) (have/has) completed so far? Would you say...

Less than 9th grade, .................................................. 01

Some high school, but no diploma, .............................. 02

High school graduate (diploma or equivalent diploma [GED]), 03

Technical, trade or vocational degree, ......................... 04

Some college, but no degree, 05

Associate's degree 06

Bachelor's degree, 07

Some graduate school but no degree, 08

Master's degree, or 09

Professional school or doctorate? 10

DON'T KNOW ......................................................

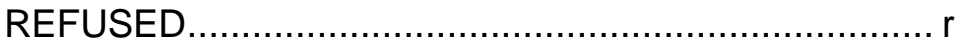

G9a. What was the primary field of study for this degree?

DON'T KNOW ................................................ d

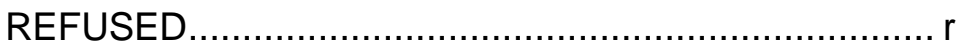

G9b. What was the primary field of study for your bachelor's degree?

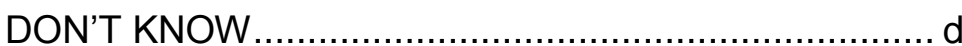

REFUSED .......................................................... 
BY OBSERVATION:

G10a. (Are/ls) (you/[OWNER B-J]) male or female?

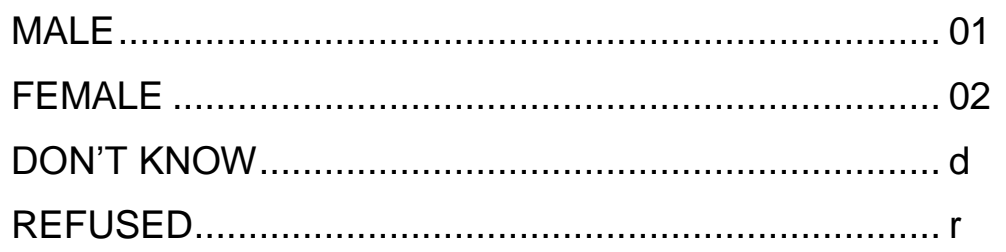

\section{ENDBLOCK bSectionG2}

SECTION G ARRAYED UP TO 10 TIMES, ONCE FOR EACH NEW OWNER. 
G11. IF EMAIL ADDRESS COLLECTED AT BASELINE, FIRST OR SECOND FOLLOWUP:

Can we confirm your email address?

INTERVIEWER: READ E-MAIL ADDRESS AND CORRECT AS NECESSARY. IF EMAIL ADDRESS FIELD BLANK FROM BASELINE, FIRST, AND SECOND FOLLOW-UP:

Can you give us an email address where you can be reached?

EMAIL: @

DON'T KNOW. d

REFUSED. $r$

G12. IF WEBSITE ADDRESS COLLECTED AT BASELINE, FIRST, OR SECOND FOLLOW-UP:

May we confirm your web site address as:

Web Address:

INTERVIEWER: CORRECT AS NECESSARY $\rightarrow$ GO TO G14

IF WEBSITE ADDRESS BLANK FROM BASELINE, FIRST, AND SECOND FOLLOW-UP:

Does [NAME BUSINESS] have its own website?

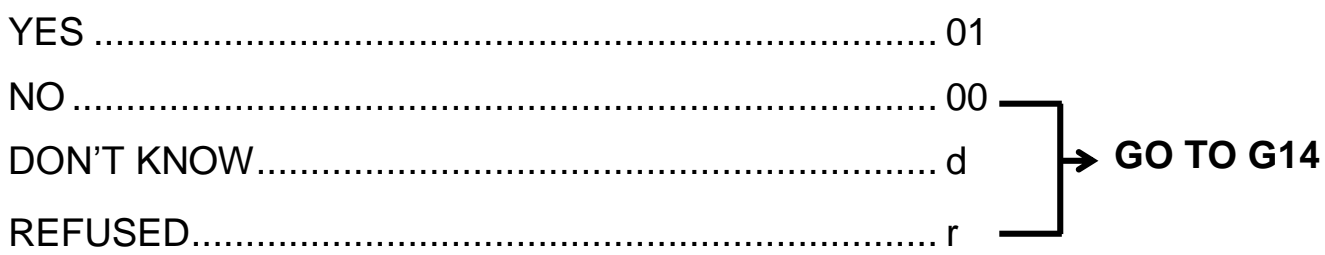

G13. Can you give me the web address?

WEB ADDRESS:

DON'T KNOW. d

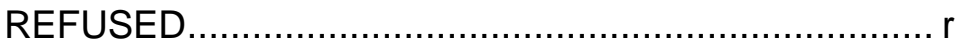


G14. Is the business likely to move to another location in the next 12 months?

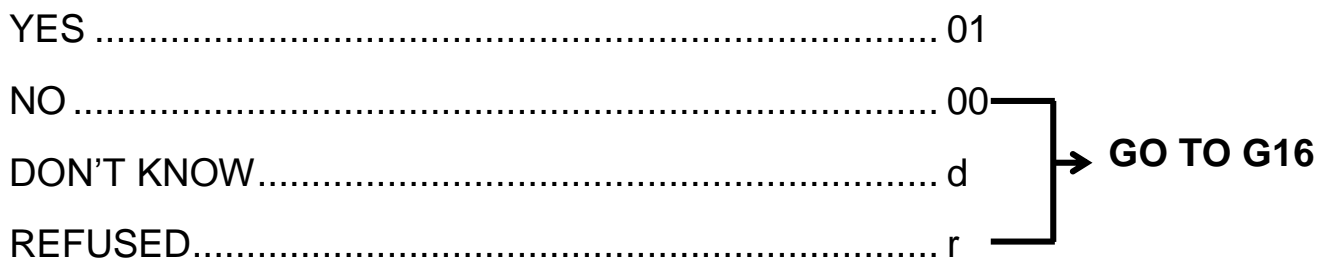

G15. What city and state is the business likely to move to?

CITY:

STATE:

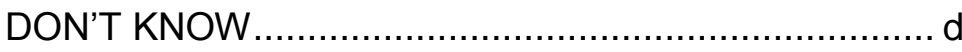

REFUSED..........................................................

G16. IF CONTACT INFORMATION COLLECTED AT BASELINE, FIRST, OR SECOND FOLLOW-UP:

Here is the information we have for a contact person. This information will be held in the strictest confidence, and will only be used if we cannot contact you or someone else associated with the business at the current business phone number or address.

INTERVIEWER: PLEASE ASK FOR ANY INFORMATION THAT IS NOT FILLED IN.

NAME:

ADDRESS:

CITY:

STATE:

PHONE:

EMAIL: $@$

DON'T KNOW ....................................................... d

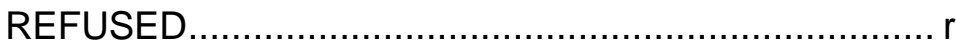




\section{IF CONTACT INFORMATION IS BLANK FROM BASELINE, FIRST, AND SECOND}

FOLLOW-UP:

In case we are unable to contact you, can you provide a name and contact information for a person besides yourself who would know how to reach you or someone else associated with [NAME BUSINESS]? All information collected will be held in the strictest confidence, and will only be used if we cannot contact you or someone else associated with the business at the current business phone number or address.

NAME:

ADDRESS:

CITY:

STATE:

PHONE:

EMAIL: @

DON'T KNOW d

REFUSED. $r$

THANK AND TERMINATE 

APPENDIX C

\section{RESPONDENT MATERIALS}





\section{Subject: Round 4 -- Kauffman Firm Survey}

\section{Dear [THIRD FOLLOW-UP RESPONDENT NAME]:}

Welcome to the 4th round of the Kauffman Firm Survey (KFS)! Sponsored by the Ewing Marion Kauffman Foundation, KFS is a groundbreaking study investigating how new businesses like yours develop and operate in their early years of existence. [BUSINESS NAME] is one of only 4,500 businesses participating in this, the largest longitudinal study of new businesses ever performed. Your continued participation is critical. Already, your input from previous rounds has helped provide important insights. Highlights include:

- Nearly $45 \%$ percent of businesses reported making a profit in their first year of operations, and about $17 \%$ had profits greater than $\$ 100,000$.

- One quarter of businesses had at least 2 employees.

- Most of the equity raised by businesses came from the owners themselves.

- $30 \%$ of businesses in the study were owned by women.

For additional findings from the first three rounds, check out: http://www.kauffman.org/kfs/

You can complete the 4th round of this important study online at www.kauffmansurvey.org using the following login ID and Password:

Login ID: «username»

Password: «password»

In appreciation, you will again receive $\$ 50$. All information you provide will be kept confidential, and no information will be released that can be linked to you or your business. If you have questions, please call Pat Jones toll free at 877-542-6725, or me directly at 609-7502018. You may also email the study team at KFS@mathematica-mpr.com.

Thank you in advance for your continuing participation.

Sincerely,

Betsy Santos

Survey Director

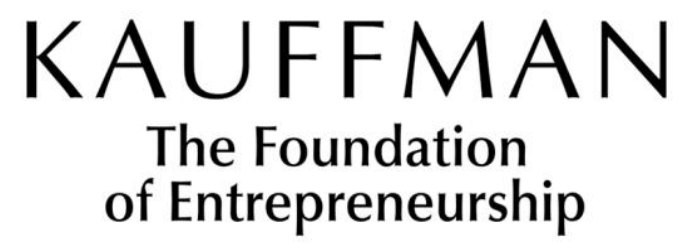





\section{ADVANCE LETTER}

Betsy Santos

Survey Director

June 6, 2008

«FirstName» «MiddleInitial» «LastName»

«CEO_Title»

«BusinessName»

«Address1»

«Address2»

«City», «State» «postalcode»

Dear «CEO_Prefix» «LastName»:

Welcome to the fourth round of the Kauffman Firm Survey (KFS)! Sponsored by the Ewing Marion Kauffman Foundation, KFS is a groundbreaking study investigating how new businesses like yours develop and operate in their early years of existence. «BusinessName» is one of only 4,500 businesses participating in this, the largest longitudinal study of new businesses ever performed. Already, your input from previous rounds has helped provide important insights. Highlights include:

- Nearly 45 percent of businesses reported making a profit in their first year of operations, and about 17 percent had profits greater than $\$ 100,000$.

- One-quarter of businesses had at least two employees.

- Most of the equity raised by businesses came from the owners themselves.

- Thirty percent of businesses in the study were owned by women.

For more findings from the first three rounds, check out: http://www.kauffman.org/kfs/.

We encourage you to complete the fourth round of this important study online at www.kauffmansurvey.org using the following secure login ID and Password:

$\begin{array}{ll}\text { Login ID: } & \text { «username» } \\ \text { Password: } & \text { «password» }\end{array}$

In appreciation, you will again receive $\$ 50$. All information you provide will be kept confidential, and Mathematica Policy Research, Inc. will not release any information that can be linked to you or your business. If you have questions, please call Pat Jones toll free at 877-542-6725, or me directly at 609-750-2018. You may also email the study team at KFS@ mathematica-mpr.com.

Thank you in advance for your continuing participation.

Sincerely,

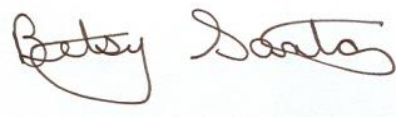





\title{
KAUFFMAN
}

The Foundation

of Entrepreneurship

\section{Frequently Asked Questions}

\begin{abstract}
What is the purpose of the Kauffman Firm Survey?
The Kauffman Firm Survey (KFS) is a research study sponsored by the Kauffman Foundation of Kansas City. The study's purpose is to learn about the challenges involved in owning and operating a new business.
\end{abstract}

Did our business already complete this survey?

Your business completed earlier rounds of this survey. At this time, we are asking about your business during calendar year 2007. Your input in this round is important. Since your business has been scientifically selected to participate, we cannot replace it.

\section{Why are you asking about Year $\mathbf{4}$ of my business?}

We are interested in following new businesses like yours from year to year as they continue to develop and operate. By studying businesses over the crucial early years of their growth and development, we can begin to understand what factors help businesses succeed in becoming established. No other study has examined as many new businesses in as much detail.

Will I be paid for participating?

You will receive $\$ 50$ again as a "thank you" for completing the interview.

What if my company is no longer in business or I have sold my business?

We want to know if you if your company is no longer in business or you have sold it. Take a few minutes to access the Web survey or call Pat Jones at 1-877-542-6725 to tell us what happened to your business.

\section{Will I get to see the results of the study?}

The Kauffman Foundation is committed to sharing information from this study. Included in this mailing are results from earlier rounds of the study. For more findings from the initial rounds of the study, visit www.kauffman.org. Results of this round will be posted as soon as it is completed.

Will the information I provide be kept confidential?

Yes. Information that you share will be kept private by the study investigators. Information provided will be used for research and statistical purposes only by the Kauffman Foundation, its contractors, and collaborating researchers for the purpose of analyzing data and preparing scientific reports and articles. Any information that is publicly released (such as statistical summaries) will appear in a form that does not personally identify your business or any individuals involved with the business. 


\title{
Will I be asked to make a donation to the Kauffman Foundation?
}

No. This study is solely a research study. At no time will you be asked to buy anything or contribute money to any foundation. Additionally, your name and your business name will not be sold or provided to anyone.

\section{What is the Kauffman Foundation?}

The Kauffman Foundation is a private foundation dedicated to studying and promoting entrepreneurship in the United States. For additional information about the Kauffman Foundation, please visit its web site: www.kauffman.org

\section{Who is Mathematica Policy Research?}

The Kauffman Foundation has hired Mathematica Policy Research, Inc. (MPR), an independent research firm, to conduct the study. MPR is an independent research firm based in Princeton, New Jersey known for its high-quality, objective research designed to support decision making on the nation's most pressing issues. For additional information about MPR, please visit the company's web site:

www.mathematica-mpr.com

\section{How can I contact you with further questions?}

If you have questions about this study, please call Pat Jones toll-free at 1-877-5426725 , or email the study team at KFS@mathematica-mpr.com. By mail, the study team can be contacted at:

\author{
Kauffman Firm Survey \\ Mathematica Policy Research, Inc. \\ P.O. Box 2393 \\ Princeton, NJ 08543-2393
}


Front

\section{KAUFFMAN}

The Foundation of Entrepreneurship

\section{We still need your help!}

Your business is one of only 4,500 businesses in the Kauffman Firm Survey. Your continued participation is vital to studying new business development.

If you haven't done so already, please complete the questionnaire at www.kauffmansurvey.org. You will receive \$50 as a "thank you."

If you have lost your login ID or password, or have questions, contact Pat Jones at 1-877-542-6725, or email KFS@mathematica-mpr.com.

\section{Back}

Kauffman Firm Survey (6091-440)

Mathematica Policy Research, Inc.

P.O. Box 2393

Princeton, NJ 08543-9809

\section{Return Service Requested}





\section{REFUSAL LETTER}

July 29, 2008

«FirstName» «Middlelnitial» «LastName»

«CEO_Title»

«BName»

«Address 1 »

«Address2»

«City», «State» «postalcode»

Dear «CEO_Prefix» «LastName»: [NOTE: USE «FirstName» IF «CEO_Prefix»IS MISSING]

We would like to thank you again for your past participating in the Kauffman Firm Survey, sponsored by the Ewing Marion Kauffman Foundation. Recently, we contacted you about participating in the fourth round of the study, but at that time you were unable to speak with us. I wanted to personally explain to you how important your continued cooperation in the survey is to the success of this critical study.

New businesses are vital to the economic future of the United States, and yet little is known about the challenges of running a business in the early years of development. Your continued participation in this, the largest longitudinal study of new businesses ever performed, will provide the Kauffman Foundation with a greater understanding of the challenges involved in owning and operating a new business. As such, your completion of the interview will contribute to the Foundation's mission of supporting entrepreneurship.

In appreciation of your time, you will receive $\$ 50$. Know that everything you report will be kept confidential, and no information will be released that can be linked to you or your business. If you have questions, please call Pat Jones toll free at 877-542-6725, or me directly at 609-750-2018. You may also email the study team at KFS@mathematica-mpr.com.

Sincerely,

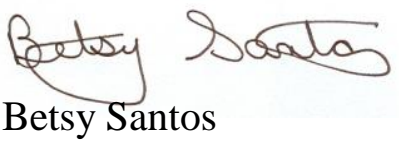

Survey Director 

APPENDIX D

KAUFFMAN FIRM SURVEY

THIRD FOLLOW-UP ANNOTATED QUESTIONNAIRE 

MPR Reference No.: 6091-470

MATHEMATICA

Policy Research, Inc.

Kauffman Firm Survey

Third Follow-Up

Annotated Questionnaire

April 6, 2009 



\section{A. INTRODUCTION}

INTRO: Hello, my name is . I'm calling on behalf of the Kauffman Foundation.

May I speak with (OWNER NAME/the owner or CEO of [NAME BUSINESS])?

OWNER NAME = Second Follow-Up Respondent for Section A.

\begin{tabular}{|c|c|}
\hline OWNER NAME —BAD TIME/CALL BACK ................. $02 \rightarrow$ & GO TO A2a \\
\hline 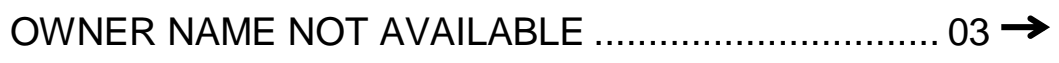 & GO TO Inform \\
\hline OWNER NAME NO LONGER WITH BUSINESS.......... $04 \rightarrow$ & $\begin{array}{l}\text { GO TO A1a } \\
\text { [then } A 4 w e b \\
\text { if } A 1 a=1 \text { ] }\end{array}$ \\
\hline USINESS NO LONGER IN OPERATION .................. $05 \rightarrow$ & GO TO A10 \\
\hline d & T \\
\hline
\end{tabular}

A1a. Your business has been participating in the Kauffman Firm Survey. Last year we asked you some questions about [NAME BUSINESS]'s operations in 2006. Now we'd like to ask about calendar year 2007.

We'd like to confirm that the name of the business is [NAME BUSINESS] and that [NAME BUSINESS] is still operating.

[NAME BUSINESS] IS THE CURRENT NAME

AND [NAME BUSINESS] IS STILL OPERATING......... 01

THE BUSINESS NAME IS INCORRECT .................. $02 \rightarrow$ GO TO A2Web

[NAME BUSINESS] IS OUT OF BUSINESS ............... $03 \rightarrow$ GO TO A10

A1b. We'd like to confirm that you are [OWNER NAME] and you are you are still an owner of [NAME BUSINESS]?

[OWNER NAME] IS THE RESPONDENT AND IS

STILL AN OWNER OF [NAME BUSINESS]

[OWNER NAME] IS THE RESPONDENT AND IS

STILL AN OWNER OF [NAME BUSINESS], BUT

CORRECT [OWNER NAME]'S NAME.

$02 \rightarrow$ GO TO A4aWeb

RESPONDENT IS NOT [OWNER NAME].

$03 \rightarrow$ GO TO A4Webz

THE RESPONDENT [OWNER NAME] IS NO

LONGER AN OWNER OF [NAME BUSINESS] $07 \rightarrow$ GO TO A5a Box 
A1c. We'd like to confirm that the title of your position is [TITLE]? Is that correct?

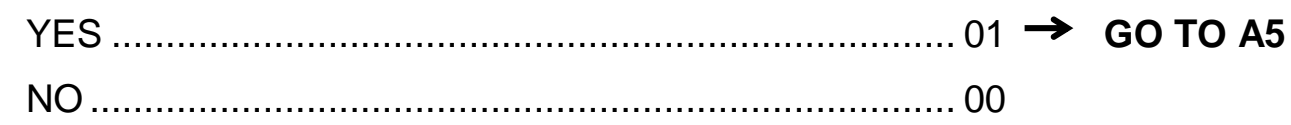

DON'T KNOW

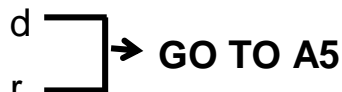

REFUSED. $r$

A1d. What is your job title?

INTERVIEWER: ENTER JOB TITLE.

UPDATE TITLE

\section{GO TO A5}

A2a. I'm sorry. When would be a better time to reach (you/[OWNER])?

INTERVIEWER: ENTER CALLBACK DATE AND TIME.

READ: Is this the best number to reach you?

INTERVIEWER: UPDATE CONTACT INFORMATION AS NEEDED.

Thank you very much. Good-bye.

\section{THANK AND TERMINATE}

A2Web. What is the correct business name?

INTERVIEWER: TYPE IN BUSINESS NAME.

A3Web. Is this a corrected spelling, a name change but the same business, or a different business?

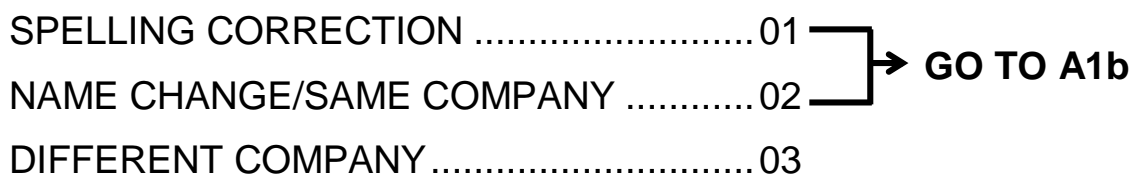


A3Webz. We are trying to find out what happened to [NAME BUSINESS]. Is [NAME BUSINESS] still in operation?

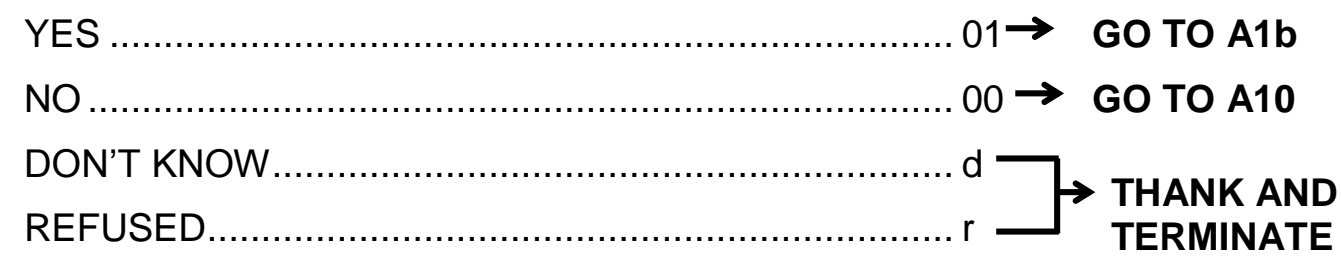

A4Webz Is [OWNER NAME] still an owner and actively involved in running [NAME BUSINESS]?

IF NEEDED: By actively involved, we mean providing regular assistance or advice with day-to-day operations of the business rather than providing only money or occasional operating assistance.

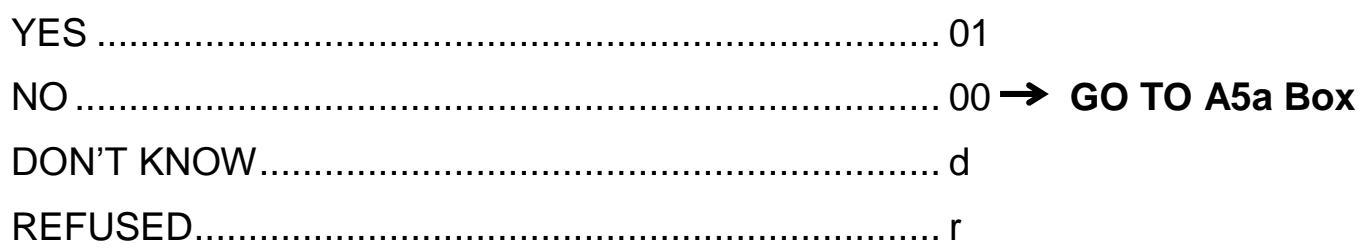

A4Webz1 Would [OWNER NAME] be available to do the study at another time?

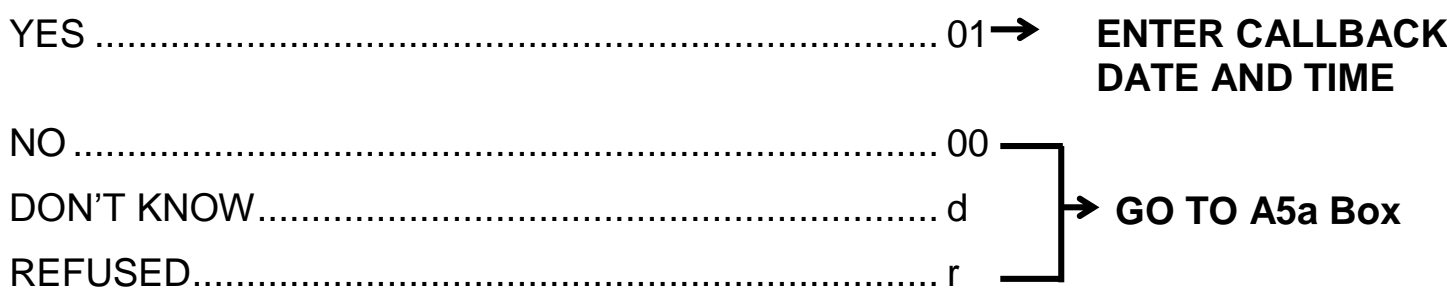

A4aWeb What is the correct spelling of your name?

NAME:

A5. Are you still actively involved in running [NAME BUSINESS]? By actively involved in running the business, we mean providing regular assistance or advice with day-to-day operations of the business rather than providing only money or occasional operating assistance.

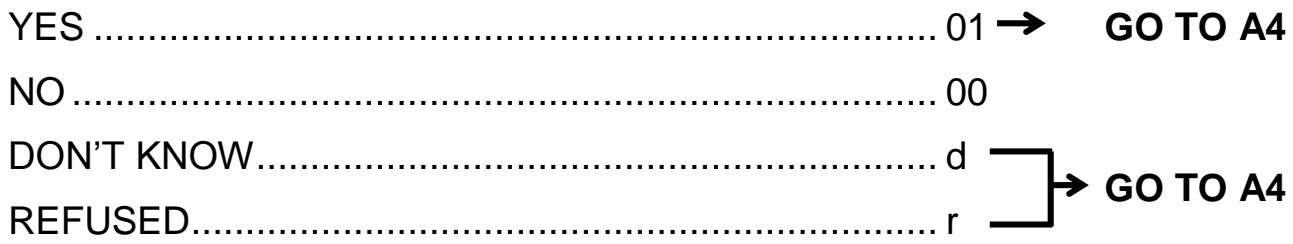

[A5_Actively_involved_3] 


\section{A5a BOX: \\ IF MORE THAN ONE OWNER-OPERATOR- FOUNDER FROM SECOND FOLLOW-UP, ASK A5a. ELSE, ASK A4Web.}

A5a. During the last interview with your business, we recorded other owners of [NAME BUSINESS]. Please tell me the person who is an owner of the business, is actively involved in running [NAME BUSINESS], and will answer this study.

By actively involved in running the business, we mean providing regular assistance or advice with day-to-day operations of the business rather than providing only money or occasional operating assistance.

READ THE OWNER NAMES BELOW. SELECT ONLY ONE.
NEW OWNER-OPERATOR WILL ANSWER $00 \rightarrow$ GO TO A5aweb1
[NAME OWNER] 2-9 $\rightarrow$ GO TO A7Title
NON-OWNER WILL ANSWER $11 \rightarrow$ GO TO A5aweb1
INTERVIEWER: CODE 11 ONLY WITH SUPERVISOR PERMISSION AND WRITE NOTE DOCUMENTING CIRCUMSTANCES

A4Web Who is currently an (OWNER/CEO) of [NAME BUSINESS]?

NAME:

A4Webz2 Are you (OWNER/CEO)?

YES 01

NO $00 \rightarrow$ GO TO Inform

A5new. And are you actively involved in running [NAME BUSINESS]? By actively involved in running the business, we mean providing regular assistance or advice with day-to-day operations of the business rather than providing only money or occasional operating assistance.

YES $01 \rightarrow$ GO TO A4new

NO 00

[A5New_Actively_involved_3] 
A7. Is there another owner of [NAME BUSINESS] who is actively involved in running [NAME BUSINESS], and can answer questions about the business?

PROBE: By actively involved in running the business, we mean providing regular assistance or advice with day-to-day operations of the business rather than providing only money or occasional operating assistance.

YES 01

NO $00 \rightarrow$ GO TO Stop5

A5aWeb1 Who is another owner of [NAME BUSINESS] who is actively involved in running [NAME BUSINESS], and can answer questions about the business?

ENTER FIRST NAME

ENTER LAST NAME

ENTER JOB TITLE

A4Webz2 Are you (OWNER/CEO)?

YES $01 \rightarrow$ GO TO A4new NO 00

Inform. Do you know a good time and date I can call to contact (OWNER/CEO)?

INTERVIEWER: ENTER CALLBACK DATE AND TIME.

\section{THANK AND TERMINATE}

Stop5. Thank you for your time.

\section{THANK AND TERMINATE}

A7Title. What is [OWNER NAME]'s title?

A4Webz2 Are you (OWNER NAME)?

YES $01 \rightarrow$ GO TO A4new

NO $\mathrm{OO} \rightarrow \mathrm{GO}$ TO Inform 
A4. You participated last year in the Kauffman Firm Survey. At that time, we asked some questions about [NAME BUSINESS] operations in 2006. Now we'd like to ask about the year 2007. Again, your answers will be completely confidential, and you will once again receive a $\$ 50$ payment as a token of our appreciation.

\section{GO TO A8}

A4new. Your business participated last year in the Kauffman Firm Study. At that time, we asked some questions about [NAME BUSINESS]'s operation in 2006. Now we'd like to ask about the year 2007. Again, your answers will be kept confidential, and you will receive a $\$ 50$ payment as a token of our appreciation.

A8. l'd like to confirm your business' mailing address. Is [NAME BUSINESS]'s mailing address (ADDRESS, CITY, STATE, ZIP)?

WEB: Our records indicate that the mailing address for [NAME BUSINESS] is (ADDRESS, CITY, STATE, ZIP). Is this correct?

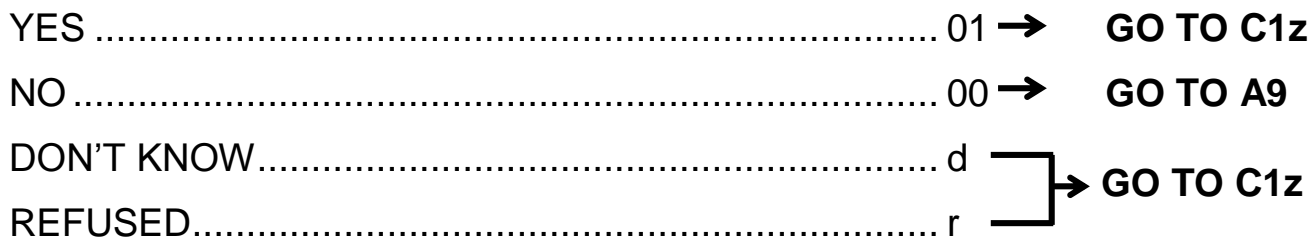

[A8_Addr_ver_3]

A9. What is [NAME BUSINESS]'s correct mailing address?

INTERVIEWER: UPDATE MAILING ADDRESS INFORMATION.

ADDRESS:

CITY:

STATE:

ZIP:

DON'T KNOW

d

REFUSED. 
A10. What is the main reason [NAME BUSINESS] is out of business? Has [NAME BUSINESS]. . .

Been s-old to another business, ................................ 01

Merged with another business, ................................. 02

Temporarily stopped operations, .............................. 03

Permanently stopped operations, or ......................... $04 \rightarrow$ GO TO A11

Something else? ...................................................... 05

DON'T KNOW ..................................................... d

REFUSED ....................................................... $\mathrm{r}$

[A10_Out_Of_Business_3]

[A10_Other_Specify_3]

\section{THANK AND TERMINATE}

A11. In what calendar year did [NAME BUSINESS] close?

YEAR $|\underline{2}| \underline{0}|\underline{0}|$

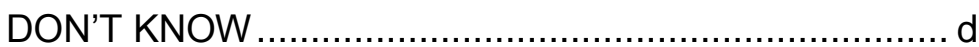

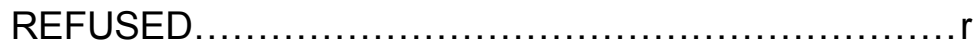

[A11_Year_Closed_3]

A11a. Did [NAME BUSINESS] file for bankruptcy?

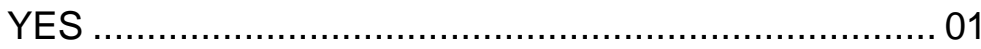

$\mathrm{NO}$................................................................... 00

DON'T KNOW.................................................. d

REFUSED ..................................................... $\mathrm{r}$

[A11a_Bankruptcy_3]

THANK AND TERMINATE 
NO SECTION B

Prepared by Mathematica Policy Research, Inc. 


\section{BUSINESS CHARACTERISTICS}

All of the following questions I'm going to ask are about [NAME BUSINESS]. Some of the questions will ask to confirm information about your business which you provided to us previously. As we go through the interview, please tell me if any of the information about your business is incorrect and needs to be updated.

C1z. Our records show that [NAME BUSINESS] had a legal status of

[tOWNERshipModel]. As of December 31, 2007, is that still the legal status of [NAME BUSINESS]?

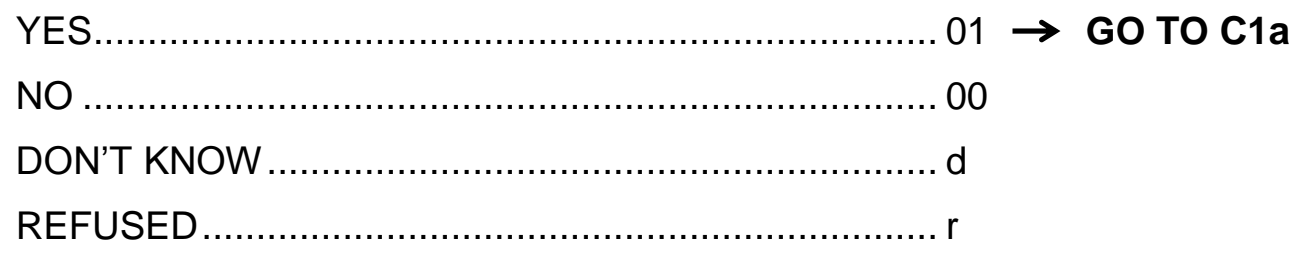

[C1z_Confirm_Legal_Status_3] 
C1z2. I'm going to read you a list of some different forms of legal status a business can have. As of December 31, 2007, which form of legal status did [NAME BUSINESS] have? Was it a ...

\section{READ LIST AND READ DESCRIPTIONS AS NEEDED:}

Sole Proprietorship: A type of business ownership in which a business is owned and managed by one individual and no subchapter S-corporation or C-corporation has been established.

Limited Liability Company: A cross between a corporation and a partnership, and offering some of the benefits of both. Similar to S-corporations, income produced by a limited liability company flows through to owners (known as "members") who pay their own taxes as individuals. Unlike S-corporations, however, limited liability companies are not subject to as many government restrictions.

Subchapter S-Corporation: Corporations in which all profits and losses are passed through to shareholders, just as they are passed through to partners in a partnership.

C-Corporation: Legal entities separate from their owners that may engage in business, make contracts, own property, pay taxes, and sue and be sued by others.

General Partnership: An association of two or more people who co-own a business for the purpose of making a profit and no subchapter S-corporation or C-corporation has been established.

Limited Partnership: A partnership in which one or more partners are general partners who manage the business and others are limited partners who invest in the business but forego any right to manage the company.

Sole Proprietorship, ......................................... 01

Limited Liability Company, .................................... 02

Subchapter S-Corporation, ..................................... 03

C-Corporation, ................................................. 04

General Partnership, ........................................ 05

Limited Partnership, or .......................................... 06

Something else? (SPECIFY) ................................. 07

[C1z2_Legal_Status_3]

[C1z2OtherSpecify_3]

DON'T KNOW .................................................. d

REFUSED ......................................................... 
C1a. Our records indicate the principal activity of the business was [D\&B NAICS CODE DESCRIPTION]. Was that still the principal activity of the business as of December $31,2007 ?$

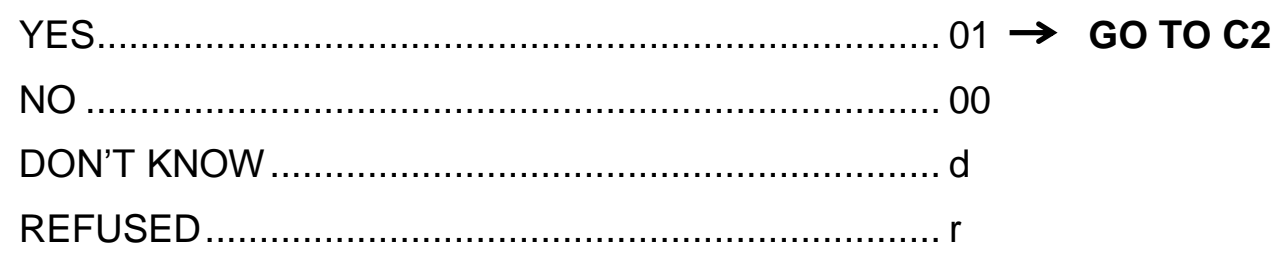

[C1a_NAICS_verification_3]

C1b. As of December 31, 2007, what was the principal activity of the business?

\section{IF SOLE PROPRIETORSHIP IN [tOWNERshipModel] [or C1z2], GO TO C5.}

C2. As of December 31, 2007, how many individuals or entities owned [NAME BUSINESS]? Please include all individuals or entities who owned shares in the business.
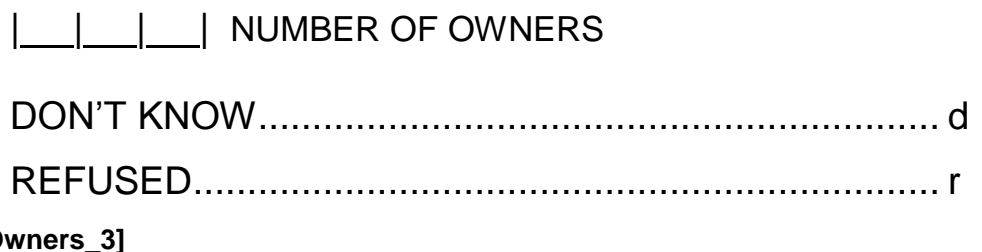

[C2_Owners_3]

C3. Of the [NUMBER OF OWNERS FROM C2] owners as of December 31, 2007, how many owners actively helped to run [NAME BUSINESS]? By helped to run the business we mean that they provided regular assistance or advice with day-to-day operations of the business, rather than providing only money or occasional operating assistance.

I_____ I NUMBER OF OWNER/OPERATORS

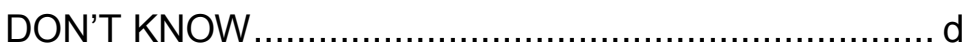

REFUSED.......................................................... $\mathrm{r}$

[C3a_Owner_Operators_3] 
IF ONE OWNER/OPERATOR REPORTED AT C3, GO TO C5. IF MORE THAN ONE OWNER/OPERATOR REPORTED AT C3, ASK:

C4. FOR EACH SECOND FOLLOW-UP OWNER/OPERATOR WHO IS NOT THE RESPONDENT, ASK:

Was [OWNER NAME] still an owner who actively helped run [NAME BUSINESS]—as of December 31, 2007?

YES 01

$\mathrm{NO}$ 00

YES BUT THE NAME IS MISSPELLED. 02

DON'T KNOW d

REFUSED. .. $r$

FOR ALL MISSPELLED NAMES, ASK:

How do you spell (your/his/her) name?

\section{INTERVIEWER: ENTER NAME}

\section{THEN ASK:}

How many other people, not previously listed, were owners actively helping to run [NAME BUSINESS] as of December 31, 2007.

\section{INTERVIEWER: PREVIOUSLY LISTED PEOPLE ARE STATED BELOW. NUMBER OF OWNERS STATED IN C3: [FILL FROM C3]}

I want to record with you the first and last names of these owners. These are the people who joined the business between the last time we talked to you and December 31, 2007. I'm going to be asking some questions about each of the owners who actively helped run [NAME BUSINESS]. Can you tell me the first and last name of the other owner(s) of $A B C$ Business?

\section{INTERVIEWER: $\quad$ ENTER FIRST AND LAST NAMES.}


C4Confirm. I have listed:

FIRST NAME

LAST NAME

OWNER A (RESPONDENT)

OWNER B

OWNER C

OWNER D

[C4_NumOwners_Confirm_3]

Are there any other owner-operators as of December 31, 2007 of [NAME BUSINESS] that I have not mentioned?

INTERVIEWER: CONFIRM SPELLING OF NAMES. TO CORRECT NAMES, ARROW BACK TO TABLE.

ADD ANOTHER NAME OR

CORRECT A MISSPELLING ..................................... 01

NO CHANGES ................................................... 02

\section{NOTE: UP TO 10 OWNER/OPERATOR/FOUNDERS WILL BE INCLUDED.}

C5. Not counting owner(s), on December 31, 2007, how many people worked for [NAME BUSINESS]? Please include all full- and part-time employees, but exclude contract workers who work for the business either full- or part-time but are not on the business' official payroll.

|_____ NUMBER OF EMPLOYEES ON DECEMBER 31, 2007

DON'T KNOW .....................................................

REFUSED........................................................

[C5_Num_Employees_3]

C5b. Was this change an increase, a decrease, or no change in the number of people who worked for [NAME BUSINESS] on December 31, 2007 compared to December 31, $2006 ?$

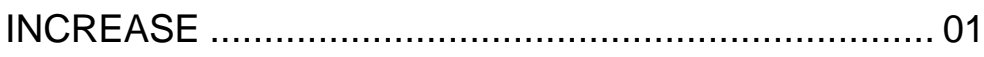

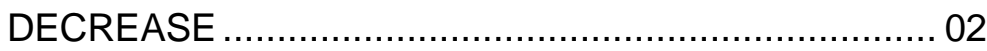

NO CHANGE ............................................... 03

DON'T KNOW ...................................................... d

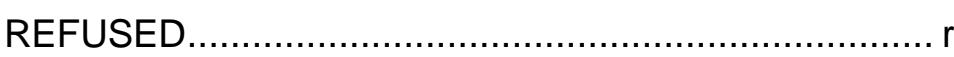

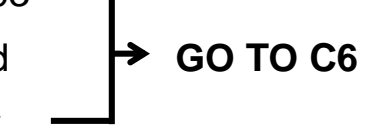

[C5b_Num_Employees_Change_3] 
C5c. And what was the (increase/decrease) in the number of people who worked for [NAME BUSINESS] on December 31, 2007 compared to December 31, 2006? Your best estimate is fine.

\section{I____ CHANGE IN NUMBER OF EMPLOYEES}

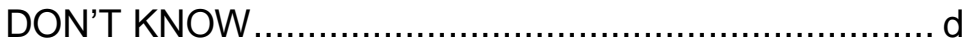

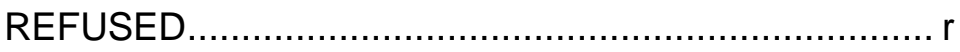

[C5c_Num_Employees_Change_Amt_3]

\section{IF BUSINESS REPORTED “0” EMPLOYEES AT C5, GO TO C8z.}

C6. And of those [NUMBER FROM C5], how many were full-time?

(IF NEEDED: Full-time is considered 35 hours or more per week)

|_____ NUMBER OF DECEMBER 31, 2007 FULL-TIME EMPLOYEES

DON'T KNOW ..................................................... d

REFUSED..........................................................

[C6_Num_FT_Employees_3]

C7. And how many were part-time? (IF NEEDED: Part-time is considered less than 35 hours per week)

|____ NUMBER OF DECEMBER 31, 2007 PART-TIME EMPLOYEES

DON'T KNOW .................................................... d

REFUSED .....................................................

[C7_Num_PT_Employees_3]

C8z. Our records show that the primary location where [NAME BUSINESS] operates is [tPrimaryLocation]. Is that correct?

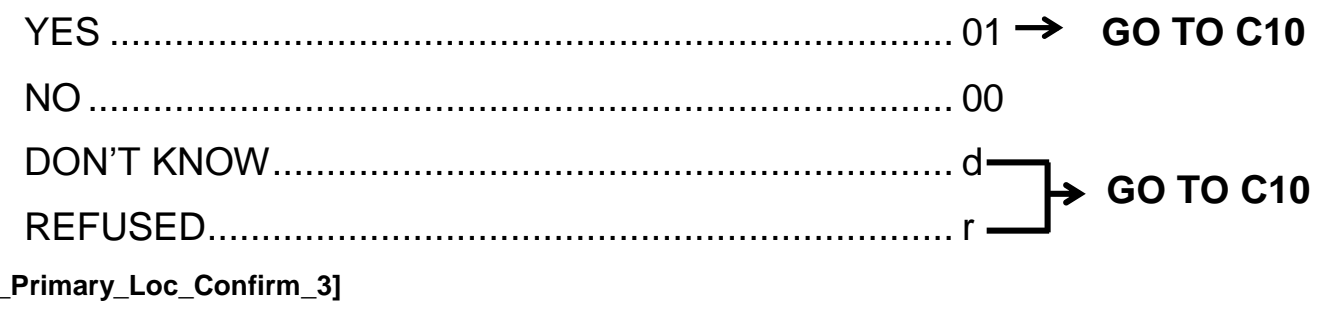

[C8z_Primary_Loc_Confirm_3] 
C8. How would you describe the primary location where [NAME BUSINESS] operates? Is it ...

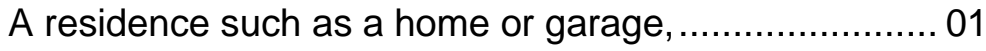

A rented or leased space, ...................................... 02

Space the business purchased, ............................... 03

A site where a client is located, or ............................... 04

Some other location? (SPECIFY) ........................... 05

DON'T KNOW.........................................................

REFUSED ........................................................ $\mathrm{r}$

[C8_Primary_Loc_3]

[C8_Primary_Loc_Specify_3]

C9. What was the main reason for the change of location?

Previous location too expensive ................................. 01

Needed more space due to growth of business ............ 02

Moved closer to customers ....................................... 03

Moved business and residence to new location ............ 04

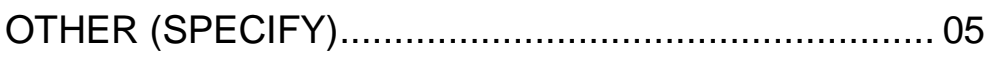

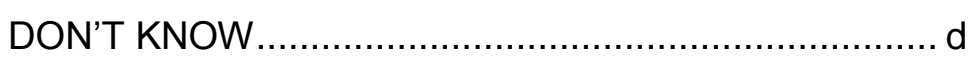

REFUSED........................................................ $r$

[C9_Loc_Change_Reason_3]

[C9OtherSpecify_3]

C10. As of December 31, 2007, did [NAME BUSINESS] operate in more than one location?

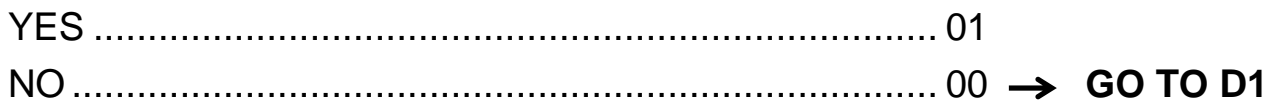

[C10_MoreLocations_3]

C11. And as of December 31, 2007, how many locations did [NAME BUSINESS] operate in?

I____ I NUMBER OF LOCATIONS AS OF DECEMBER 31, 2007

[C11_Num_Locations_3]

C11a. In what month and year did you open your second location?

Month

Year $|\underline{2}| 0|0|$

[C11a 2ndOpening Month 3]

[C11a_2ndOpening_Year_3] 


\section{STRATEGY AND INNOVATION}

D1. Does [NAME BUSINESS] provide (READ ITEM)?

\begin{tabular}{|l|l|l|l|}
\hline YES & NO & $\begin{array}{l}\text { DON'T } \\
\text { KNOW }\end{array}$ & REFUSED \\
\hline
\end{tabular}

a. A service

0100

d

r

[D1a_Provide_Service_3]

b. A product ...................................... $01 \quad 00 \quad d \quad r$

[D1b_Provide_Product_3]

D2. Businesses often have to compete with other businesses. A competitive advantage is something unique or distinctive a business provides that gives it an advantage compared to competitors. In calendar year 2007, did [NAME BUSINESS] have a competitive advantage over its competitors?

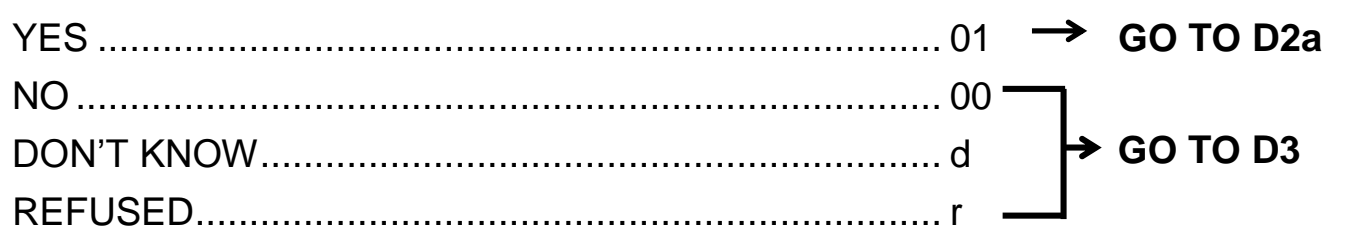

[D2_Comp_Advantage_3]

D2a. Was the competitive advantage [NAME BUSINESS] had in calendar year 2007 related in any way to [ITEM]?

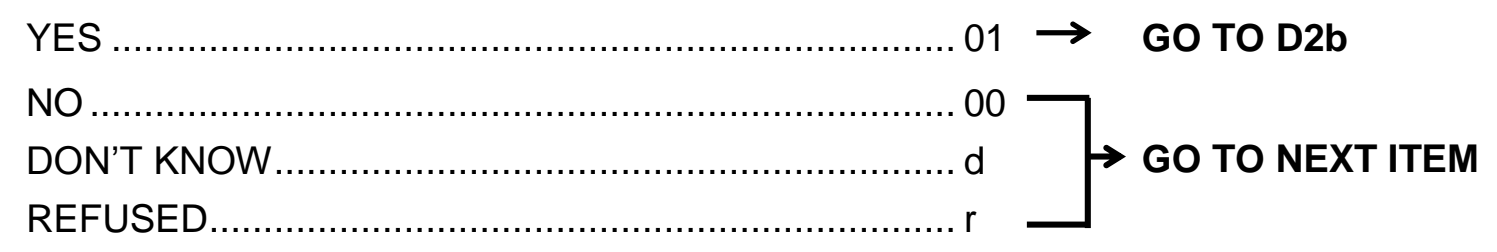


D2b. Do you consider this to have given [NAME BUSINESS] a major or a minor competitive advantage in calendar year 2007?

\section{REPEAT D2a-D2b FOR EACH ITEM.}

\begin{tabular}{|c|c|c|c|c|c|c|c|c|c|}
\hline \multirow[b]{2}{*}{ ITEMS } & \multicolumn{4}{|c|}{$\begin{array}{l}\text { D2a. Reason For } \\
\text { Competitive Advantage }\end{array}$} & & \multicolumn{4}{|c|}{$\begin{array}{l}\text { D2b. Strength of reason for } \\
\text { Competitive Advantage }\end{array}$} \\
\hline & YES & NO & $\begin{array}{l}\text { DON'T } \\
\text { KNOW }\end{array}$ & REFUSED & & $\begin{array}{l}\text { MAJOR } \\
\text { REASON }\end{array}$ & $\begin{array}{l}\text { MINOR } \\
\text { REASON }\end{array}$ & $\begin{array}{l}\text { DON'T } \\
\text { KNOW }\end{array}$ & REFUSED \\
\hline $\begin{array}{l}\text { a. teaming up with a college } \\
\text { or university? ................... } \\
\text { [D2a_CompAdv_Univ_Reason_3] } \\
\text { [D2b_CompAdv_Univ_Strength_3] }\end{array}$ & 01 & 00 & $d$ & $r$ & $\begin{array}{c}\text { IF } \\
\text { YES }\end{array}$ & 01 & 00 & $d$ & $r$ \\
\hline $\begin{array}{l}\text { b. teaming up with another } \\
\text { company? ...................... } \\
\text { [D2a_CompAdv_Comp_Reason_3] } \\
\text { [D2b_CompAdv_Comp_Strength_3] }\end{array}$ & 01 & 00 & $\mathrm{~d}$ & $r$ & $\begin{array}{c}\text { IF } \\
\text { YES }\end{array}$ & $\Rightarrow 01$ & 00 & $d$ & $r$ \\
\hline $\begin{array}{l}\text { c. teaming up with a } \\
\text { government lab or } \\
\text { research center? ............. } \\
\text { [D2a_CompAdv_GovLab_Reason_3] } \\
\text { [D2b_CompAdv_GovLab_Strength_3] }\end{array}$ & 01 & 00 & $d$ & $r$ & $\begin{array}{c}\text { IF } \\
\text { YES }\end{array}$ & $\Rightarrow 01$ & 00 & $d$ & $r$ \\
\hline $\begin{array}{l}\text { d. patents that [NAME } \\
\text { BUSINESS] owns, has } \\
\text { applied for, or licensed? .. } \\
\text { [D2a_CompAdv_Patents_Reason_3] } \\
\text { [D2b_CompAdv_Patents_Strength_3] }\end{array}$ & 01 & 00 & $d$ & $r$ & $\begin{array}{c}\text { IF } \\
\text { YES }\end{array}$ & $\Rightarrow 01$ & 00 & $d$ & $r$ \\
\hline
\end{tabular}


D3. Whether assigned by an owner or obtained in some other way, does [NAME BUSINESS] have any of the following? (READ LIST)

FOR EACH "YES," ASK: How many (READ ITEM) does [NAME BUSINESS] have?

\section{INTERVIEWERS IF NEEDED:}

Patent: A patent is a right given by the government to preclude others from making and selling an invention for 20 years from the date of application in return for disclosure of how the invention operates.

Copyright: The legal right granted to authors, composers, artists and publishers to protect their thoughts and ideas for exclusive publication, reproduction, sale and distribution of their works.

Trademark: Words, names, symbols or devices, or any combination of these used to identify the goods of a business and to distinguish these goods from the goods of others.

\begin{tabular}{|c|c|c|c|c|c|}
\hline & YES & NO & $\begin{array}{l}\text { DON'T } \\
\text { KNOW }\end{array}$ & REFUSED & $\begin{array}{l}\text { NUMBER BUSINESS } \\
\text { HAS }\end{array}$ \\
\hline $\begin{array}{l}\text { a. Patents ................. } \\
\text { [D3_a_Have_Patent_3] }\end{array}$ & 01 & 00 & $d$ & $r$ & [D3_a_Num_Patent_3] \\
\hline $\begin{array}{l}\text { b. Copyrights .............. } \\
\text { [D3_b_Have_Copyright_3] }\end{array}$ & 01 & 00 & $d$ & $r$ & [D3_b_Num_Copyright_3] \\
\hline $\begin{array}{l}\text { C. Trademarks ............ } \\
\text { [D3_c_Have_Trademark_3] ..... }\end{array}$ & 01 & 00 & $d$ & $r$ & [D3_c_Num_Trademark_3] \\
\hline
\end{tabular}

D4. "Licensing out" is licensing patents, copyrights, or trademarks owned by the business to other parties under a licensing agreement. In calendar year 2007, did [NAME BUSINESS] license out any (READ ITEM)?

a. Patents....

\begin{tabular}{|c|c|c|c|}
\hline YES & NO & $\begin{array}{c}\text { DON'T } \\
\text { KNOW }\end{array}$ & REFUSED \\
\hline
\end{tabular}

[D4_a_Lic_Out_Patent_3]

b. Copyrights

$01 \quad 00$

d

$r$

[D4_b_Lic_Out_Copyright_3]

C. Trademarks.

01

00

d

$r$

[D4_c_Lic_Out_Trademark_3] 
D5. "Licensing in" is acquiring the right to use intellectual property such as patents, copyrights, or trademarks created by someone outside the business through a licensing agreement. In calendar year 2007, did [NAME BUSINESS] license in any (READ ITEM)?

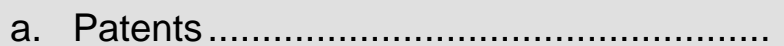

\begin{tabular}{|l|l|l|l|}
\hline YES & NO & DON'T & \\
KNOW & REFUSED \\
\hline
\end{tabular}

[D5_a_Lic_In_Patent_3]

b. Copyrights.

$01 \quad 00$

[D5_b_Lic_In_Copyright_3]

C. Trademarks

0100

d

r

[D5_c_Lic_In_Trademark_3]

D6. Did [NAME BUSINESS] have any customers or sales in calendar year 2007?

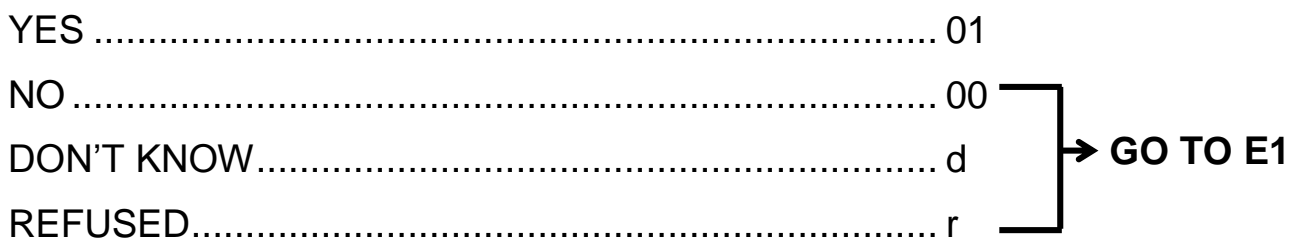

[D6_Have_Sales_3] 
D7. l'd like to learn more about the type of customers that [NAME BUSINESS] had during calendar year 2007. I am going to ask you to estimate the percent of the business' sales that were made to individuals, businesses, and government agencies. The total should equal $100 \%$.

a. During calendar year 2007, what percentage of the business' sales were to private individuals?

L_____ PERCENTAGE

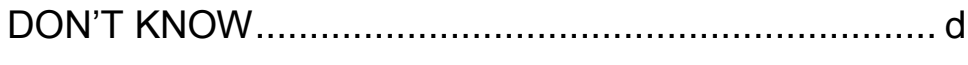

REFUSED ........................................................

[D7_Perc_Sales_Indiv_3]

b. What percentage of the business' sales were to other businesses?

[IF NEEDED: Please include sales to for-profit and not-for-profit business.]

l______ PERCENTAGE

DON'T KNOW ...................................................... d

REFUSED...........................................................

[D7_Perc_Sales_Bus_3]

c. What percentage of the business' sales were to government agencies?

I______ PERCENTAGE

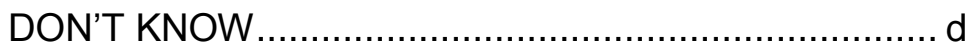

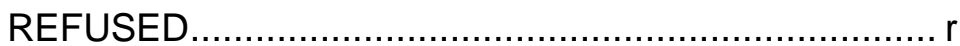

[D7_Perc_Sales_Govt_3]

D8. Now, I will read you a list of customer locations. When I am done reading, please select only one answer choice for your response. During calendar year 2007, where were most of [NAME BUSINESS]'s customers located? Would you say . . .

In neighborhoods local to the business, .......................... 01

In the same city or county, ............................................ 02

In the same region, such as in nearby counties

or states, .................................................................. 03

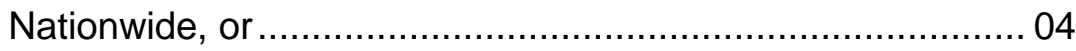

International? ...................................................... $05 \rightarrow$ GO TO D8b

DON'T KNOW ......................................................... d

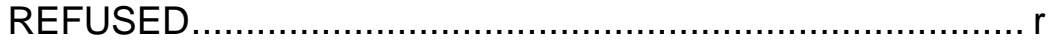

[D8_Customer_Locations_3] 
D8a. During calendar year 2007, were any of [NAME BUSINESS]'s sales made to individuals, businesses, or governments outside the United States?

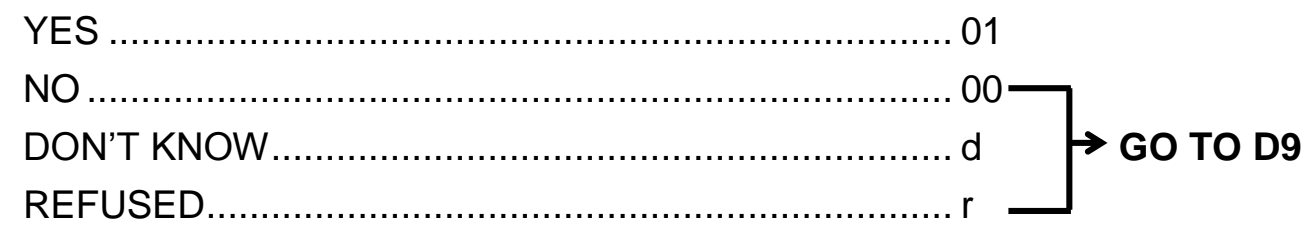

[D8a_International_Sales_3]

D8b. What percent of [NAME BUSINESS]'s total sales were to individuals, businesses, or governments outside of the United States? Would you say ...

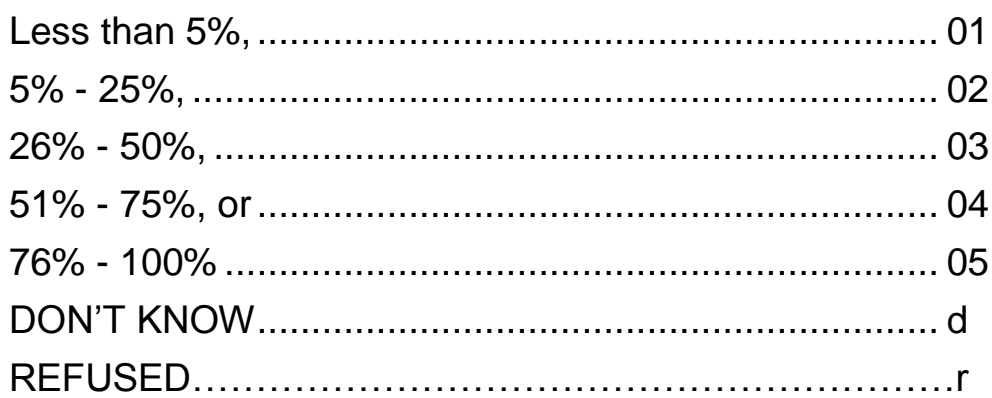

[D8b_Perc_International_Sales_3]

D9. During calendar year 2007, were any of [NAME BUSINESS]'s sales made to customers through the internet, such as through the business' website or an online retailer site?

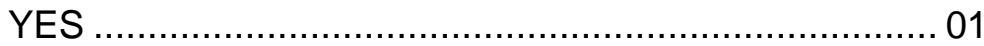

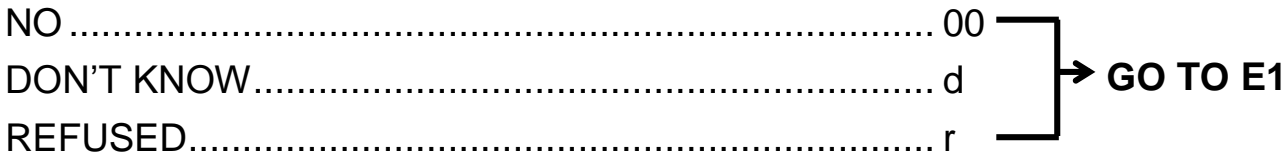

[D9_Internet_Sales_3]

D9a. What percent of [NAME BUSINESS]'s total sales were sales made to customers through the internet? Would you say ...

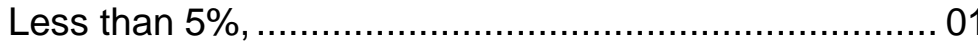

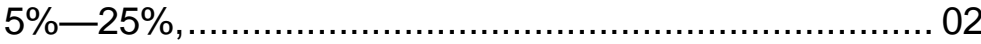

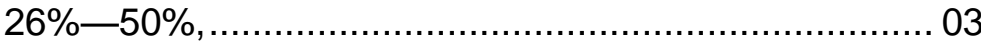

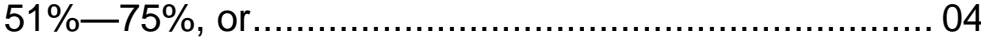

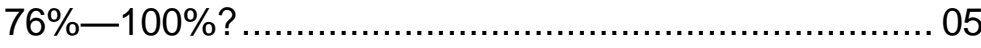

DON'T KNOW ........................................................ d

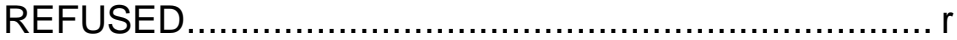

[D9a_Perc_Internet_Sales_3] 


\section{E. BUSINESS ORGANIZATION AND HR BENEFITS}

\section{IF ONE OWNER REPORTED AT C2 AND BUSINESS REPORTED “0” EMPLOYEES AT C5, GO TO F1.}

Next, l'd like to ask about how [NAME BUSINESS] is organized and about the benefits that are offered to employees.

E1. On December 31, 2007, how many employees or owners, if any, did [NAME BUSINESS] have who were primarily responsible for (READ ITEM)? Please include only full- and part-time employees, but not contract workers who work for the business but are not on the business' official payroll.

a. Human resources such as employee benefits, recruitment, or hiring

[E1_a_Num_Human_Res_3]

\begin{tabular}{|c|c|c|}
\hline $\begin{array}{c}\text { NUMBER } \\
\text { EMPLOYEES OR } \\
\text { OWNERS }\end{array}$ & $\begin{array}{c}\text { DON'T } \\
\text { KNOW }\end{array}$ & REFUSED \\
\hline
\end{tabular}

b. Sales or Marketing such as sales, market research, customer analysis, or promotional activities

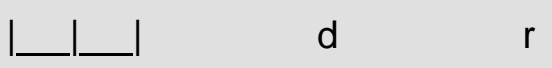

[E1_b_Num_Sales_3]

c. Executive administration functions such as strategic planning, competitive analysis, shareholder relations, or general management ....

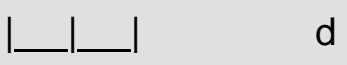

d $\quad r$ [E1_c_Num_Exec_Admin_3]

d. Research and development on new products or services

[E1_d_Num_ResDev_3]

e. Production or manufacturing such as producing materials or products, production planning, production control, quality control, or storage.......

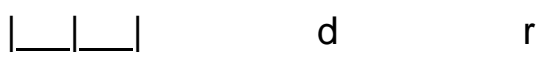

[E1_e_Num_Prod_Manu_3]

f. General administration such as office management, responding to maintenance requests, purchase supplies, or training employees in office procedures

[E1_fNum_Gen_Admin_3]

g. Financial administration such as accounting procedures, budgeting, financial analysis, or investment activities

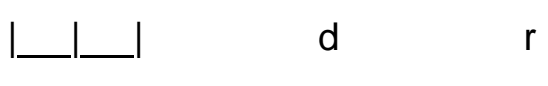

[E1_g_Num_Fin_Admin_3]

h. Does [NAME BUSINESS] have employees with any other key responsibilities? (SPECIFY).

[E1_h_Num_Other_3]

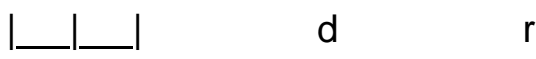

[E1_h_Other_Specify_3] 
E2a. As of December 31, 2007, did [NAME BUSINESS] offer full-time employees or owners (READ ITEM):

a. A health insurance plan either through the business or an association

\begin{tabular}{|l|l|l|l|} 
YES & NO & $\begin{array}{c}\text { DON'T } \\
\text { KNOW }\end{array}$ & REFUSED \\
\hline
\end{tabular}

[E2a_FT_Emp_HIth_Plan_3]

b. A retirement plan such as profit sharing, pension, including $401 \mathrm{~K}$, annuity, Keogh, etc.

[E2a_FT_Emp_Retire_Plan_3]

C. Stock options or other stock ownership. [E2a_FT_Emp_Stock_Own_3]

$01 \quad 00$

d

r

A bonus plan E2a_FT_Emp_Bonus_Plan_3]

e. Tuition reimbursement [E2a_FT_Emp_Tuit_Reim_3]

f. Paid vacation [E2a_FT_Emp_Paid_Vaca_3]

g. Paid sick days [E2a_FT_Emp_Paid_Sick_3]

$01 \quad 00$

d

$01 \quad 00 \quad 0$

d $\quad r$

$0100 \quad$ d $\quad r$

h. Alternative work schedules such as flex time or job sharing

0

00

d

$01 \quad 00$

d

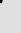
[E2a_FT_Emp_Flex_Time_3]

i. Any other benefits? (SPECIFY) [E2a_FT_Emp_Other_3]

0

00

d

$r$

$0100 \quad$ d $\quad r$

[E2a_Other_Specify_3] 
IF ZERO PART-TIME EMPLOYEES AT C7, GO TO F1.

E2b. As of December 31, 2007, did [NAME BUSINESS] offer part-time employees (READ ITEM):

\begin{tabular}{|l|l|l|l|}
\hline YES & NO & DON'T & \\
KNOW & REFUSED \\
\hline
\end{tabular}

a. A health insurance plan either through the business or an association

0100

d

$r$ [E2b_PT_Emp_Hlth_Plan_3]

b. A retirement plan such as profit sharing, pension, including $401 \mathrm{~K}$, annuity, Keogh, etc. [E2b_PT_Emp_Retire_Plan_3]

c. Stock options or other stock ownership. [E2b_PT_Emp_Stock_Own_3]

$0100 \quad d \quad r$

d. A bonus plan. [E2b_PT_Emp_Bonus_Plan_3]

e. Tuition reimbursement [E2b_PT_Emp_Tuit_Reim_3]

$01 \quad 00$

d

r

f. Paid vacation [E2b_PT_Emp_Paid_Vaca_3]

g. Paid sick days E2b_PT_Emp_Paid_Sick_3]

$01 \quad 00$

d $\quad r$

h. Alternative work schedules such as flex time or job sharing

$01 \quad 00$

d

$r$

[E2b_PT_Emp_Flex_Time_3]

i. Any other benefits? (SPECIFY) [E2b_PT_Emp_Other_3] 01

$01 \quad 00$

d $\quad r$

$0100 \quad$ d $\quad r$




\section{F. BUSINESS FINANCES}

F1. Now l'd like to ask about [NAME BUSINESS]'s financing. Businesses can get money from the savings or investments of the owner(s), money from spouses, family or other individuals, from companies, borrowing in an owner's name, venture funds, or by borrowing in the name of the business. Some of the funds must be paid back and other funds represent an equity stake or share of the business. We will ask some questions about what happened during calendar year 2007, some questions about what has happened since the business began, and other questions about balances as of December 31, 2007.

F1a. First, in calendar year 2007, did [you/OWNER B-J] put any of your own money into [NAME BUSINESS] in return for an ownership share of the business? Please do not include any money borrowed from others or from credit cards.

IF NEEDED: This would include all additional money invested by [you/OWNER B-J] in the business during calendar year 2007.

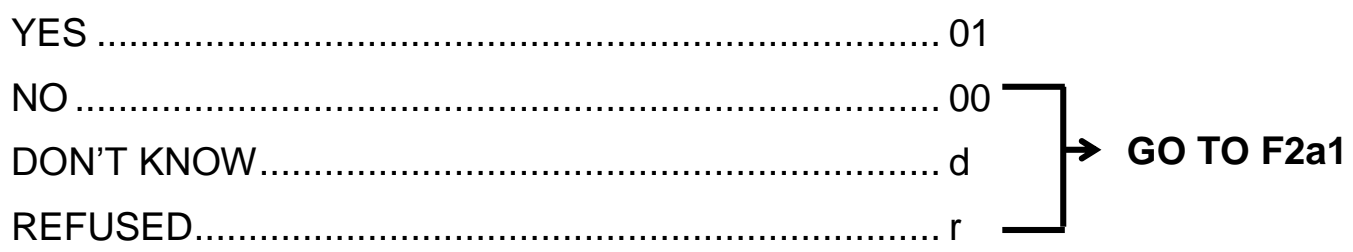

[F2_Owner_Eq_Invest_01_3] 
F2a. IF YES: How much of [your/her/his] own money did [you/she/he] put into the business during calendar year 2007?

IF NEEDED: Your best estimate is fine.

OWNER A $\$$

DON'T KNOW.

REFUSED.

[F2_Owner_Amt_Eq_Invest_01_3]

IF DON'T KNOW OR REFUSED, PROBE WITH RANGES: Would you say it was . .

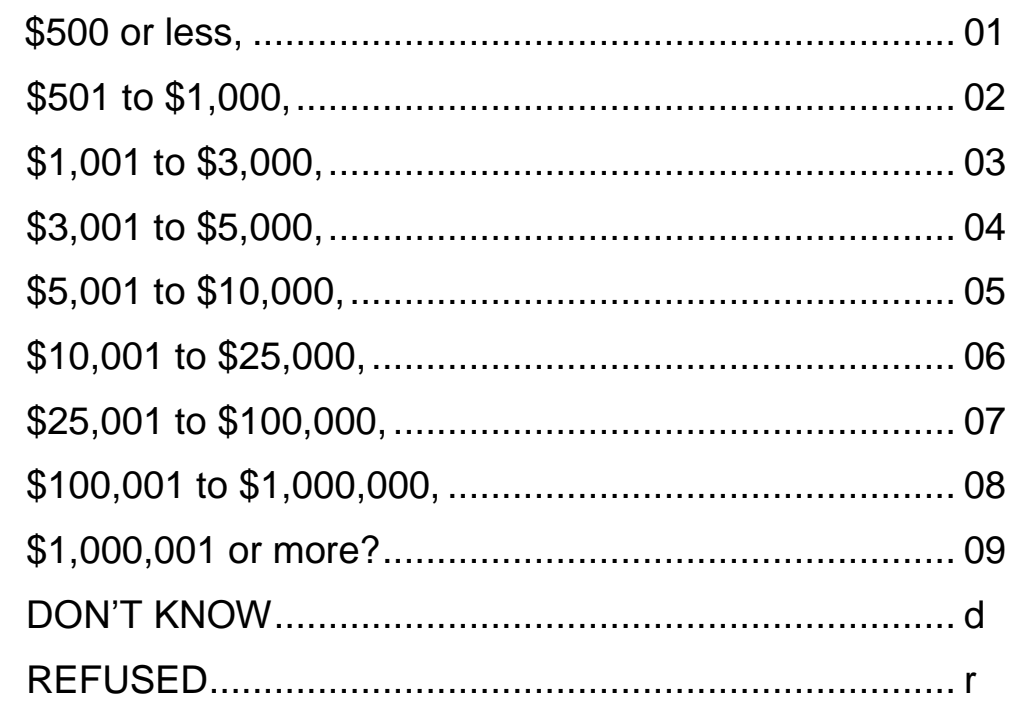

[F2_Ownr_Amt_EqInvest_Range_01_3] 
F2a1. Counting all years, how much of [your/OWNER B-J]'s own money did [you/she/he] put into [NAME BUSINESS] as of December 31, 2007?

IF NEEDED: This includes all money [you/she/he] invested in the business as of December 31, 2007.

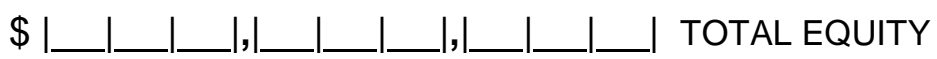

DON'T KNOW ........................................................

REFUSED..................................................... $\mathrm{r}$

[F2_Ownr_Amt_EqInvest_AlIYrs_01_3]

PROBE: IF DON'T KNOW OR REFUSED, PROBE WITH RANGES:

Would you say it was...

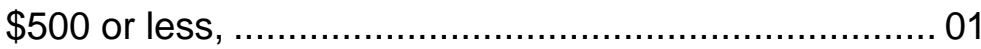

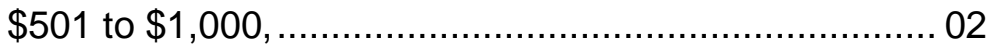

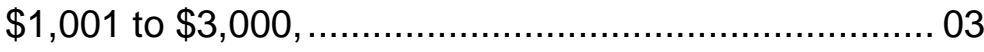

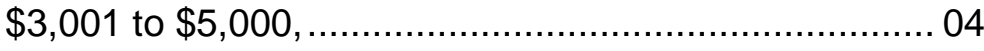

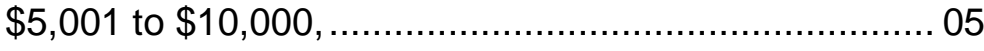

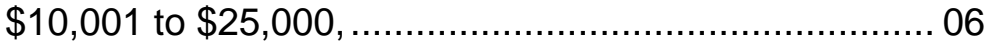

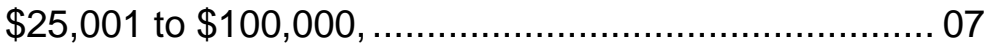

$\$ 100,001$ to $\$ 1,000,000, \ldots \ldots \ldots \ldots \ldots \ldots \ldots \ldots \ldots \ldots \ldots \ldots \ldots \ldots \ldots \ldots . . .08$

$\$ 1,000,001$ or more? .................................................. 09

DON'T KNOW ....................................................

REFUSED......................................................

[F2_Ownr_EqInvst_AllYrs_Range01_3]

IF F2a IS GREATER THAN F2a1:

I may have made a mistake. The amount invested in 2007 is greater than the amount invested in all years combined. Is there an error?

F2b. What percentage of the business did [you/OWNER B-J] own on December 31, 2007 ?

|____ PERCENTAGE OF BUSINESS

DON'T KNOW........................................................

REFUSED........................................................ $\mathrm{r}$

[F2_Owner_Perc_Own_01_3]

IF MORE THAN ONE OWNER/OPERATOR AT C4, ASK F1a-F2b FOR EACH OWNER/OPERATOR. OTHERWISE, GO TO F3. 
IF SOLE PROPRIETORSHIP AT QUESTION C1z OR C1z2, GO TO F6a.

F2 series asked of up to 10 owner-operators.

[F2_Owner_Eq_Invest_02_3]

[F2_Owner_Amt_Eq_Invest_02_3]

[F2_Ownr_Amt_Eqlnvest_Range_02 3]

[F2_Ownr_Amt_EqInvest_AllYrs_02_3]

[F2_Ownr_Eqlnvst_AllYrs_Range02_3]

[F2_Owner_Perc_Own_02_3]

[F2_Owner_Eq_Invest_03_3]

[F2_Owner_Amt_Eq_Invest_03_3]

[F2_Ownr_Amt_Eqlnvest_Range_03_3]

[F2_Ownr_Amt_EqInvest_AlIYrs_03_3]

[F2_Ownr_EqInvst_AllYrs_Range 03_3]

[F2 Owner_Perc Own 03_3]

[F2_Owner_Eq_Invest_04_3]

[F2 Owner Amt Eq Invest 04 3]

[F2_Ownr_Amt_Eqlnvest_Range_04_3]

[F2_Ownr_Amt_EqInvest_AllYrs_04_3]

[F2_Ownr_EqInvst_AllYrs_Range04_3]

[F2_Owner_Perc_Own_04_3]

[F2_Owner_Eq_Invest_05_3]

[F2_Owner_Amt_Eq_Invest_05_3]

[F2_Ownr_Amt_Eqlnvest_Range_05_3]

[F2_Ownr_Amt_EqInvest_AllYrs_05_3]

[F2_Ownr_EqInvst_AllYrs_Range05_3]

[F2_Owner_Perc_Own_05_3]

[F2_Owner_Eq_Invest_06_3]

[F2_Owner_Amt_Eq_Invest_06_3]

[F2_Ownr_Amt_Eqlnvest_Range_06_3]

[F2_Ownr_Amt_EqInvest_AlIYrs_06_3]

[F2_Ownr_EqInvst_AlIYrs_Range06_3]

[F2_Owner_Perc_Own_06_3]

[F2_Owner_Eq_Invest_07_3]

[F2_Owner_Amt_Eq_Invest_07_3]

[F2_Ownr_Amt EqqInvest Range_07_3]

[F2_Ownr_Amt_EqInvest_AllYrs_07_3]

[F2_Ownr_Eqlnvst_AllYrs Range 07_3]

[F2_Owner_Perc_Own_07_3]

[F2_Owner_Eq_Invest_08_3]

[F2_Owner_Amt_Eq_Invest_08_3]

[F2_Ownr_Amt_Eqlnvest_Range_08_3]

[F2_Ownr_Amt_EqInvest_AllYrs_08_3]

[F2_Ownr_Eqlnvst_AllYrs_Range08_3]

[F2_Owner_Perc_Own_08_3]

[F2_Owner_Eq_Invest_09_3]

[F2_Owner_Amt_Eq_Invest_09_3]

[F2_Ownr_Amt_Eqlnvest_Range_09_3]

[F2_Ownr_Amt_EqInvest_AllYrs_09_3]

[F2_Ownr_EqInvst_AllYrs_Range 09_3]

[F2_Owner_Perc_Own_09_3]

[F2_Owner_Eq_Invest_10_3]

[F2_Owner_Amt_Eq_Invest_10_3]

[F2_Ownr_Amt_Eqlnvest_Range_10_3]

[F2 Ownr Amt EqInvest AllYrs 10 3]

[F2_Ownr_Eqlnvst_AllYrs_Range10_3]

[F2_Owner_Perc_Own_10_3]

[F2_Owner_Amt_Eq_Invest_11_3]

[F2_Ownr_Amt_Eqlnvest_Range_11_3]

[F2_Ownr_Amt_EqInvest_AllYrs_11_3]

[F2_Ownr_EqInvst_AlIYrs_Range-11_3]

[F2_Owner_Perc_Own_11_3] 
F3. Equity investment is money received in return for some portion of ownership, and it is another way to fund business expenses. During calendar year 2007, did the business obtain equity financing from any of the following sources?

\begin{tabular}{|l|l|l|l|}
\hline YES & NO & DON'T & \\
KNOW & REFUSED \\
\hline
\end{tabular}

a. Spouses or life partners of owners of the business. This does not include spouses or life partners already named as owners.

[F3a_Eq_Invest_Spouse_3]

b. Parents, in-laws or children of owners of the business [F3b_Eq_Invest_Parents_3]

c. Individuals who are not spouses or life partners, parents, in-laws or children of the owners, excluding venture capitalists

$0100 \quad d \quad r$

[F3c_Eq_Invest_Angels_3]

d. Other companies [F3d_Eq_Invest_Companies_3]

$0100 \quad d \quad r$

$\begin{array}{llll}0 & 0 & d & r\end{array}$

Government agencies

[F3e_Eq_Invest_Govt_3]

f. Venture capitalists [F3f_Eq_Invest_Vent_Cap_3]

g. Any other sources? (SPECIFY) [F3g_Eq_Invest_Other_3]

01 00

d

$r$

[F3_Other_Specify_3] 
F4. FOR EACH EQUITY FINANCING OPTION REPORTED AS "YES” ABOVE, ASK:

In calendar year 2007, how much money did [NAME BUSINESS] receive from [EQUITY OPTION]?

$\$ 1$

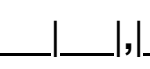

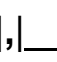

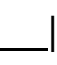

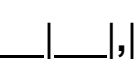

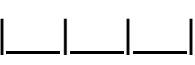

CALENDAR YEAR 2007 AMOUNT FROM EQUITY OPTION

DON'T KNOW d

REFUSED.

[F4_Eq_Amt_Spouse_3]

[F4_Eq_Amt_Parents_3]

[F4_Eq_Amt_Angels_3]

[F4_Eq_Amt_Companies_3]

[F4_Eq_Amt_Govt_3]

[F4_Eq_Amt_Vent_Cap_3]

[F4_Eq_Amt_Other_3]

IF DON'T KNOW OR REFUSED, PROBE WITH RANGES: Would you say it was . .

[F4a_Eq_Amt_Spouse_Ranges_3]

[F4a_Eq_Amt_Parents_Ranges_3]

[F4a_Eq_Amt_Angels_Ranges_3]

[F4a_Eq_Amt_Companies_Ranges_3]

[F4a_Eq_Amt_Govt_Ranges_3]

[F4a_Eq_Amt_Vent_Cap_Ranges_3]

[F4a_Eq_Amt_Other_Ranges_3] 
F4a. Counting all years, how much did [EQUITY OPTION] put into [NAME BUSINESS] as of December 31, 2007?

PROBE: This includes all money invested by [EQUITY OPTION] in all years.

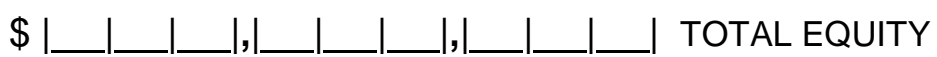

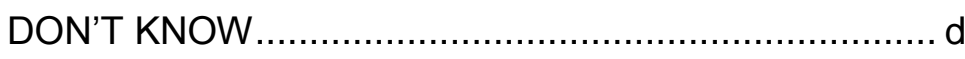

REFUSED ........................................................ $\mathrm{r}$

[F4 Eq_Amt_Spouse_AllYrs_3]

[F4_Eq_Amt_Parents_AllYrs_3]

[F4_Eq_Amt_Angels_AllYrs_3]

[F4_Eq_Amt_Companies_AllYrs_3]

[F4_Eq_Amt_Govt_AlIYrs_3]

[F4_Eq_Amt_Vent_Cap_AllYrs_3]

[F4_Eq_Amt_Other_AlIY'rs_3]

PROBE: IF DON'T KNOW OR REFUSED, PROBE WITH RANGES: Would you say it was...

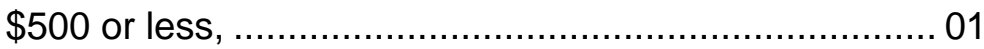

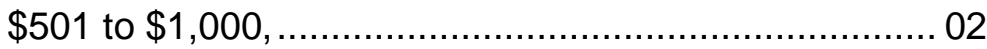

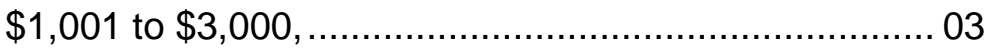

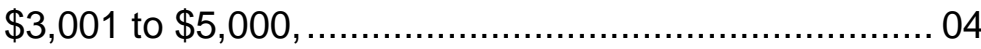

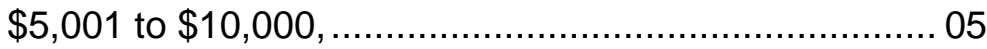

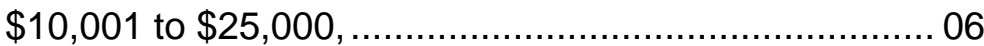

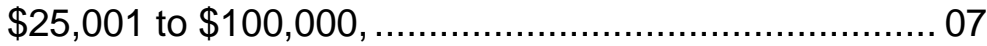

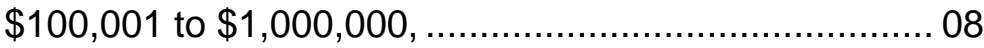

$\$ 1,000,001$ or more? .......................................................... 09

DON'T KNOW ...........................................................

REFUSED .........................................................

[F4_Eq_Amt_Spouse_AllYrs_Ranges_3]

[F4_Eq_Amt_Parents_AllYrs_Range_3]

[F4_Eq_Amt_Angels_AllYrs_Ranges_3]

[F4_Eq_Amt_Comp_AllYrs_Range_3]

[F4_Eq_Amt_Govt_AllYrs_Ranges_3]

[F4_Eq_Amt_VentCap_AlIYrs_Range_3]

[F4_Eq_Amt_Other_AlIYrs_Ranges_3]

\section{IF F4 IS GREATER THAN F4a:}

I may have made a mistake. The amount invested in 2007 is greater than the amount invested in all years combined. Is there an error? 
F5. FOR EACH EQUITY FINANCING OPTION REPORTED AS "YES” ABOVE, ASK: What was the total percentage of the business owned by the [EQUITY OPTION] who invested money in the business as of December 31, 2007?

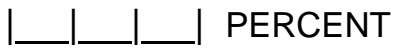

DON'T KNOW d

REFUSED. $r$

[F5 Perc_Owned Spouse 3]

[F5_Perc_Owned_Parents_3]

[F5_Perc_Owned_Angels_3]

[F5_Perc_Owned_Companies_3]

[F5 Perc_Owned Govt 3]

[F5_Perc_Owned_Vent_Cap_3]

[F5_Perc_Owned_Other_3]

INTERVIEWER CHECK BOX: CHECK ANSWER FROM F2b AND F5 FOR TOTAL PERCENTAGE OF BUSINESS ACCOUNTED FOR.

[F6Check_3]

IF TOTAL PERCENTAGE EQUALS $100 \%$, GO TO F6a

IF TOTAL EQUALS LESS OR MORE THAN 100\%

F6. So far, you've given me the following information on who owns [NAME BUSINESS]: [LIST EQUITY INVESTORS FROM F2b AND F5]. Can we review this list?

REVIEW LIST OF OWNERS AND PERCENTAGES WITH RESPONDENT. MAKE CHANGES AS NEEDED, ADDING NEW OWNERS AND/OR PERCENTAGES AS NECESSARY.

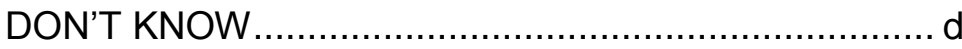

REFUSED.

[F6 perc owned owner 013]

[F6_perc_owned_owner_02_3]

[F6_perc_owned_owner_03_3]

[F6_perc_owned_owner_04_3]

[F6_perc_owned_owner_05_3]

[F6_perc_owned_owner_06_3]

[F6_perc_owned_owner_07_3]

[F6 perc owned owner 08 3]

[F6_perc_owned_owner_09_3]

[F6 perc owned owner 10 3]

[F6_perc_owned_owner_11_3]

[F6_perc_owned_owner_12_3]

[F6_perc_owned_owner_13_3] 
F6a. Have you (or other owners) withdrawn money from the business for personal use in calendar year 2007?

INTERVIEWER IF NEEDED: This does not include owner salaries.

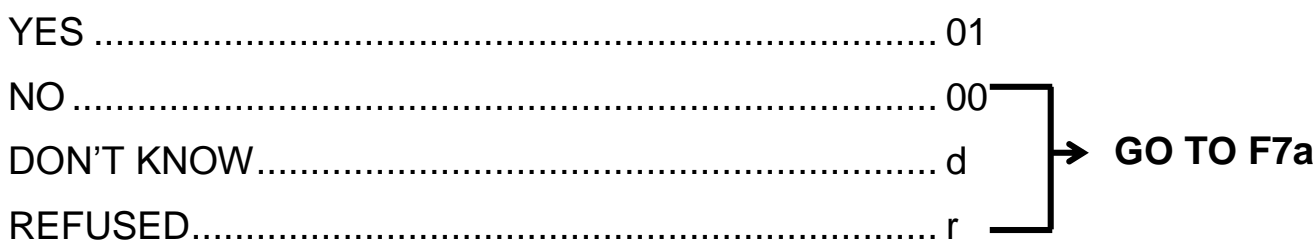

[F6a_Personal_Use_3]

F6b. IF YES: Thinking of calendar year 2007, how much money, if any, did you and other owners withdraw from the business for personal use? This includes any dividends paid.

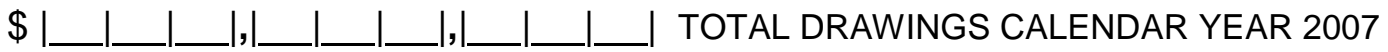

DON'T KNOW .................................................... d

REFUSED.......................................................... $r$

[F6b_Personal_Use_Amt_2007_3]

IF DON'T KNOW OR REFUSED, PROBE WITH RANGES: Would you say it was ...

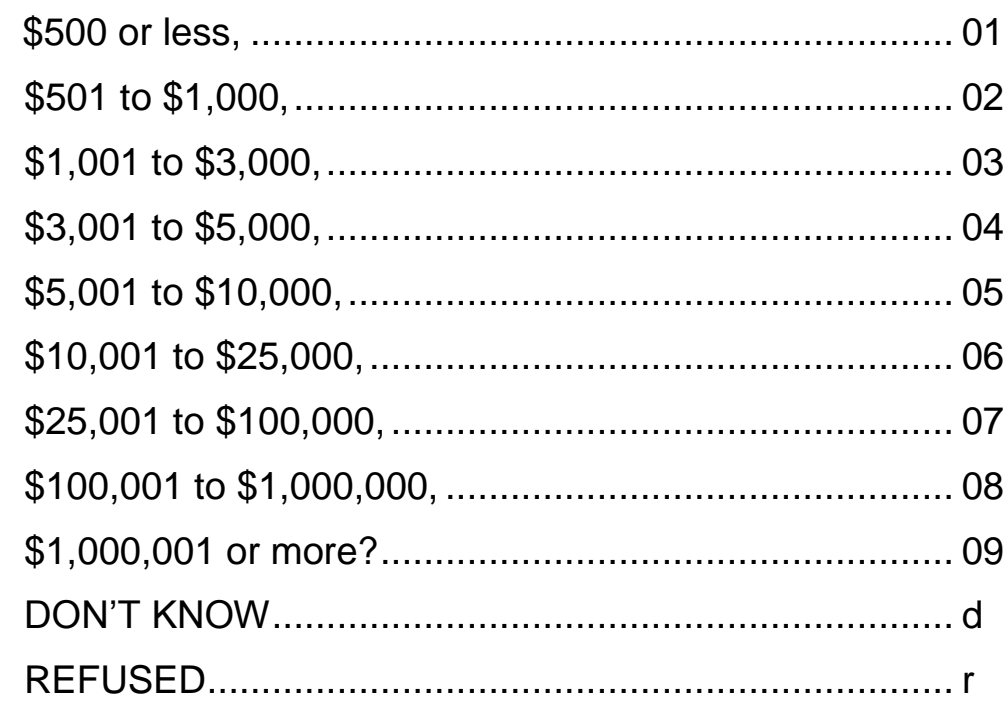

[F6b_PersonalUse_Amt_2007_Range_3] 
F7a. Another way to finance a business is debt financing. Debt is money borrowed that has to be paid back with or without interest.

We will be talking about categories of debt based on who is responsible for paying it back. For each category, l'll ask you about several sources of debt business owners or businesses can use to fund operations. We want to make sure that any businessrelated debt is reported in the right category, and is reported only once. I will identify each category and remind you when I change categories. Here is the first category.

I'm going to ask you about some different types of debt financing you may have borrowed in your name on behalf of [NAME BUSINESS]. For each, please tell me if you used this type at any time during calendar year 2007. Did you use [NAME FINANCING OPTION FROM LIST]?

F7b. IN BELOW LIST, FOR EACH DEBT FINANCING OPTION BUSINESS REPORTED, ASK: How many [NAME DEBT FINANCING OPTION] did you use to finance the operation of the business during calendar year 2007?

\begin{tabular}{|c|c|c|c|c|}
\hline ES & NO & DON'T & REFISED & NUMBER USED \\
\hline
\end{tabular}

a. Personal credit cards for business-related purposes [F7a_Pers_CredCard_3]

$0100 \quad d \quad r$

b. Personal loans from a bank or other financial institution, such as a mortgage or home equity loan used for the business.

$0100 \quad d \quad r$ [F7a_Pers_Loan_Bank_3]

[F7b_Pers_Loan_Bank_NumUsed_3]

c. Business or corporate credit cards issued in your name.

$0100 \quad d \quad r$ [F7a_Bus_CredCard_3]

d. Personal loans from any family or friends.

[F7a_Pers_Loan_Fam_3]

$0100 \quad d \quad r$

e. Personal loans from any other individuals not associated with the management of the business.......

$0100 \quad d \quad r$ [F7a_Pers_Loan_Other_3]

[F7b_Pers_Loan_Other_NumUsed_3]

f. Any other sources? (SPECIFY).. [F7a_Pers_Other_3]

$0100 \quad d$

[F7b_Bus_CredCard_NumUsed_3]

[F7b_Pers_CredCard_NumUsed_3] 
F8a. IF ANSWERED "YES" TO F7a ITEMS a, c, ASK: As of December 31, 2007, what was the maximum credit line on the [NAME DEBT FINANCING OPTION]?

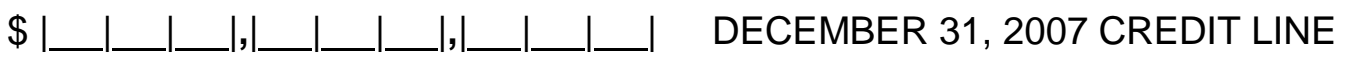

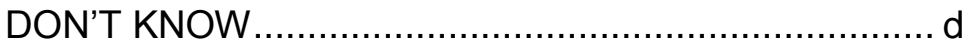

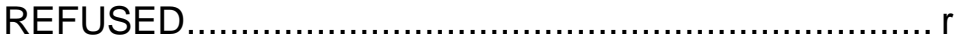

[F8a_Pers_CredCard_Line_3]

[F8a_Bus_CredCard_Line_3]

IF DON'T KNOW OR REFUSED, PROBE WITH RANGES: Would you say it was . .

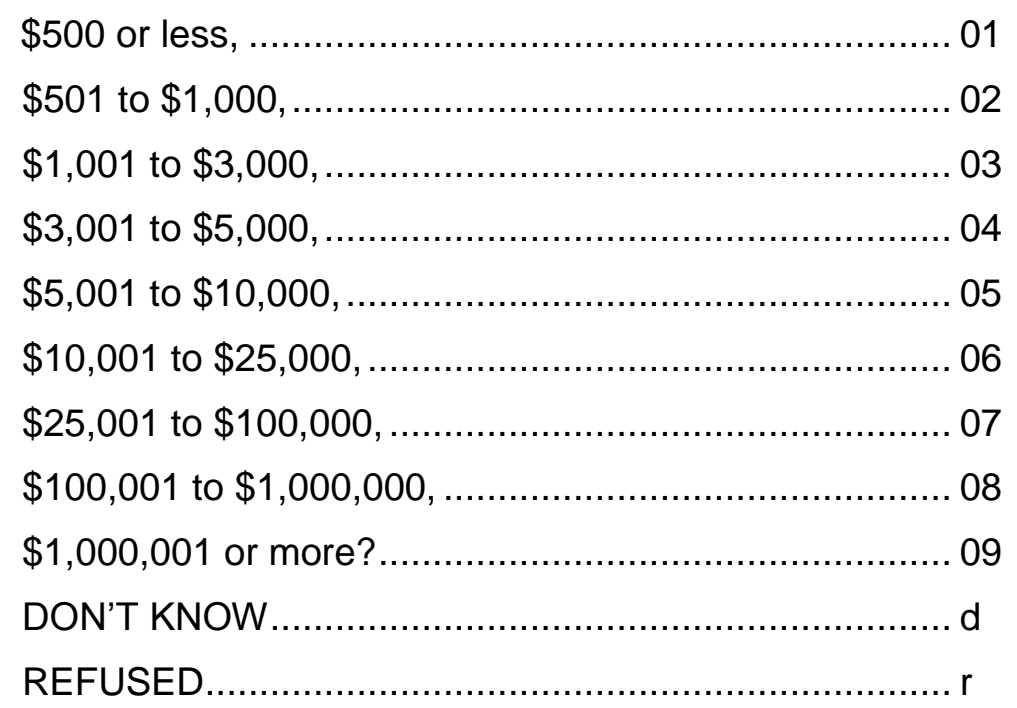

[F8a_Pers_CredCard_Line_Ranges_3]

[F8a_Bus_CredCard_Line_Ranges_3] 
F8b. IF ANSWERED "YES" TO F7a ITEMS a, c, ASK: As of December 31, 2007, what was the outstanding balance on the [NAME DEBT FINANCING OPTION]?

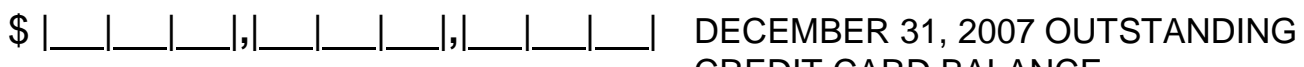
CREDIT CARD BALANCE

DON'T KNOW ......................................................... d

REFUSED..........................................................

[F8b_Pers_CredCard_Bal_3]

[F8b_Bus_CredCard_Bal_3]

IF DON'T KNOW OR REFUSED, PROBE WITH RANGES: Would you say it was . .

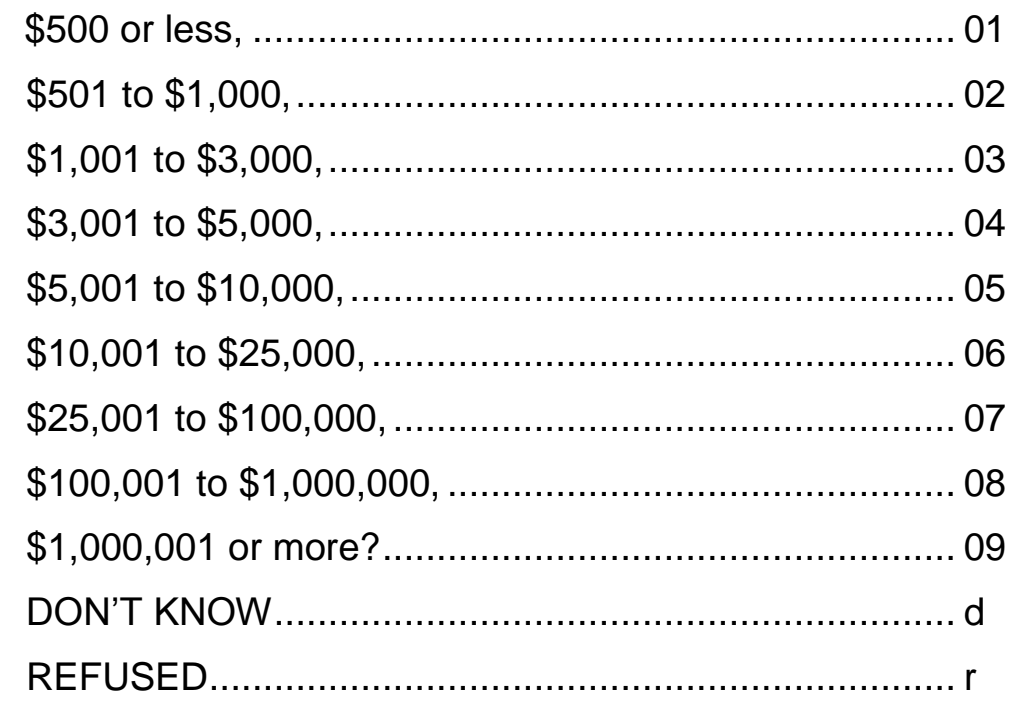

[F8b_Pers_CredCard_Bal_Ranges_3]

[F8b_Bus_CredCard_Bal_Ranges_3]

\section{IF F8b IS GREATER THAN F8a:}

Perhaps I made a mistake. The amount I recorded as the balance outstanding is greater than the amount reported as the maximum credit limit. 
F8c. IF ANSWERED “YES” TO F7a ITEMS b, d, e, f, ASK: In calendar year 2007, how much was obtained from the [NAME DEBT FINANCING OPTION]?

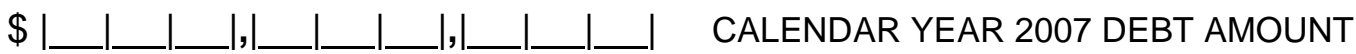

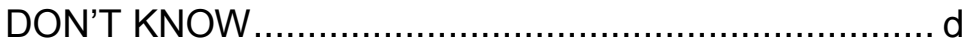

REFUSED .......................................................

[F8c_Pers_Loan_Bank_Amt_3]

[F8c_Pers_Loan_Fam_Amt_3]

[F8c_Pers_Loan_Other_Amt_3]

[F8c_Pers_Other_Amt_3]

IF DON'T KNOW OR REFUSED, PROBE WITH RANGES: Would you say it was . .

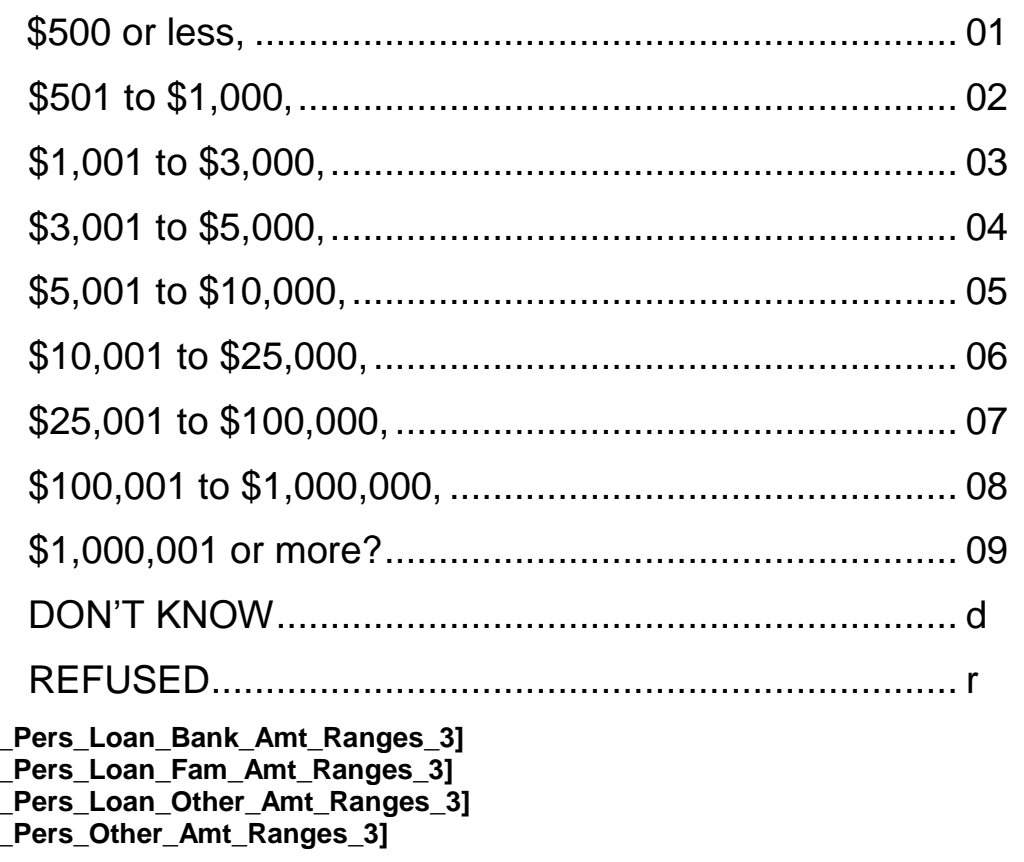


F8d. IF ANSWERED "YES" TO F7a ITEMS b, c, e, f, ASK: As of December 31, 2007, what was the estimated amount of the [NAME DEBT FINANCING OPTION] owed by you on behalf of [NAME BUSINESS]?

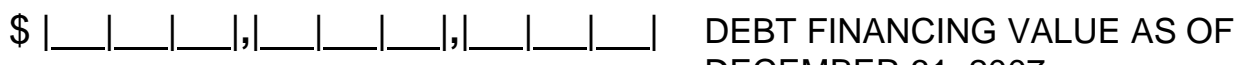
DECEMBER 31, 2007

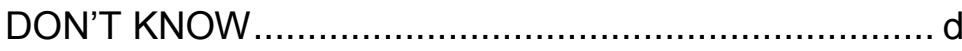

REFUSED .........................................................

[F8d_Pers_Loan_Bank_Owed_3]

[F8d_Pers_Loan_Fam_Owed_3]

[F8d_Pers_Loan_Other_Owed_3]

[F8d_Pers_Other_Owed_3]

IF DON'T KNOW OR REFUSED, PROBE WITH RANGES: Would you say it was . .

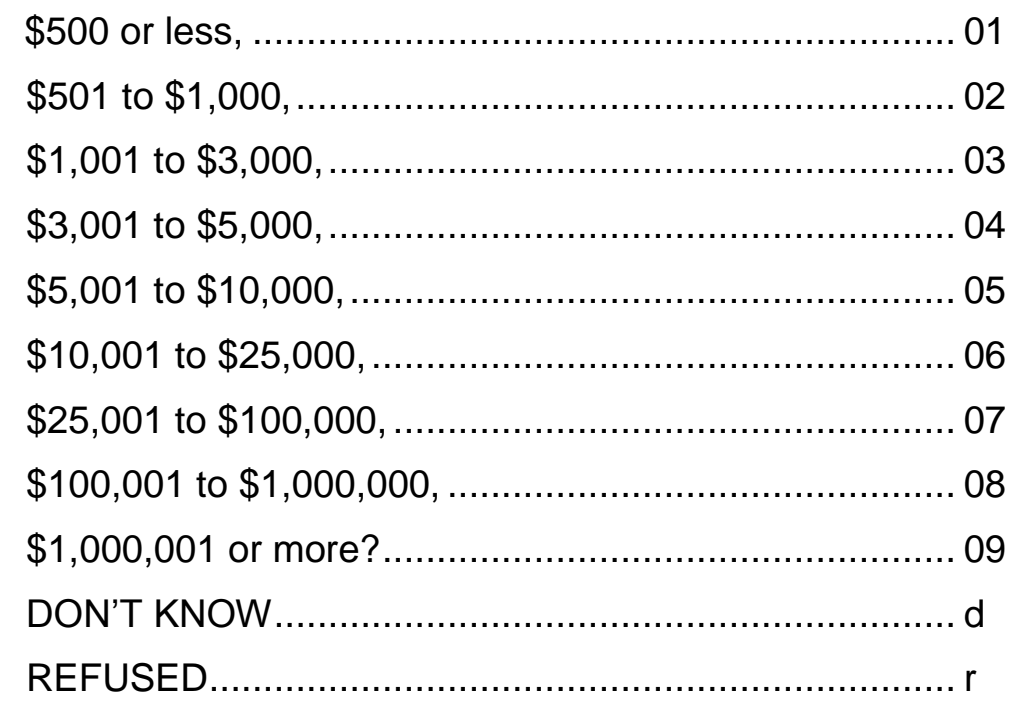

[F8d Pers Loan_Bank_Owed Ranges 3]

[F8d Pers Loan Fam Owed Ranges 3]

[F8d_PersLoan_Other_Owed_Range_3]

[F8d_Pers_Other_Owed_Ranges_3] 


\section{IF MORE THAN ONE OWNER/OPERATOR AT C4, ASK F9a. OTHERWISE, GO TO F11a.}

F9a. Here is the next debt category. I'm going to ask you about some different types of debt financing that other owners may have borrowed on behalf of [NAME BUSINESS]. This debt does not include amounts already reported in the previous section about your debt. For each, please tell me if other owners used this type at any time during calendar year 2007. Did other owners use [NAME DEBT FINANCING OPTION FROM LIST]?

F9b. IN BELOW LIST, FOR EACH DEBT FINANCING OPTION BUSINESS REPORTED, ASK: How many [NAME DEBT FINANCING OPTION] did other owners use to finance the operation of the business during calendar year 2007 ?

\begin{tabular}{|c|c|c|c|c|}
\hline YES & NO & $\begin{array}{l}\text { DON'T T } \\
\text { KNOW }\end{array}$ & REFUSED & NUMBER USED \\
\hline
\end{tabular}

a. Personal credit cards for business-related purposes.

$\begin{array}{llll}0 & 00 & d & r\end{array}$

[F9a_Pers_CredCard_3]

b. Personal loans from a bank or other financial institution, such as a mortgage or home equity loan used $0100 \quad d \quad r$ for the business

[F9a_Pers_Loan_Bank_3]

c. Business or corporate credit cards issued in the other owner's name(s)

0100

d

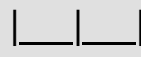

[F9a_Bus_CredCard_3]

d. Personal loans from any family or friends

0100

d

[F9a_Pers_Loan_Fam_3]

e. Personal loans from any other individuals not associated with the management of the business

$0100 \quad d$

[F9a_Pers_Loan_Other_3]

f. Any other sources? (SPECIFY) [F9a_Pers_Other_3]

$0100 \quad$ d $\quad r$

[F9b_Pers_CredCard_NumUsed_3]

[F9b_Pers_Loan_Bank_NumUsed_3]

[F9_Pers_Other_Specify_3] 
F10a. IF ANSWERED "YES" TO F9a ITEMS a, c, ASK: As of December 31, 2007, what was the maximum credit line on the [NAME DEBT FINANCING OPTION] of (one of) the other owner(s)?

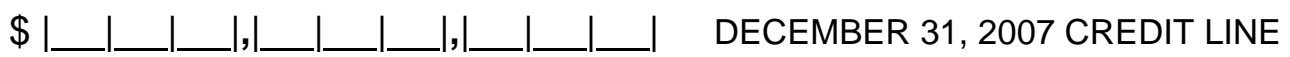

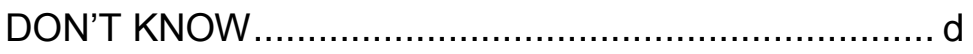

REFUSED .......................................................... $\mathrm{r}$

[F10a_Pers_CredCard_Line_3]

[F10a_Bus_CredCard_Line_3]

IF DON'T KNOW OR REFUSED, PROBE WITH RANGES: Would you say it was . .

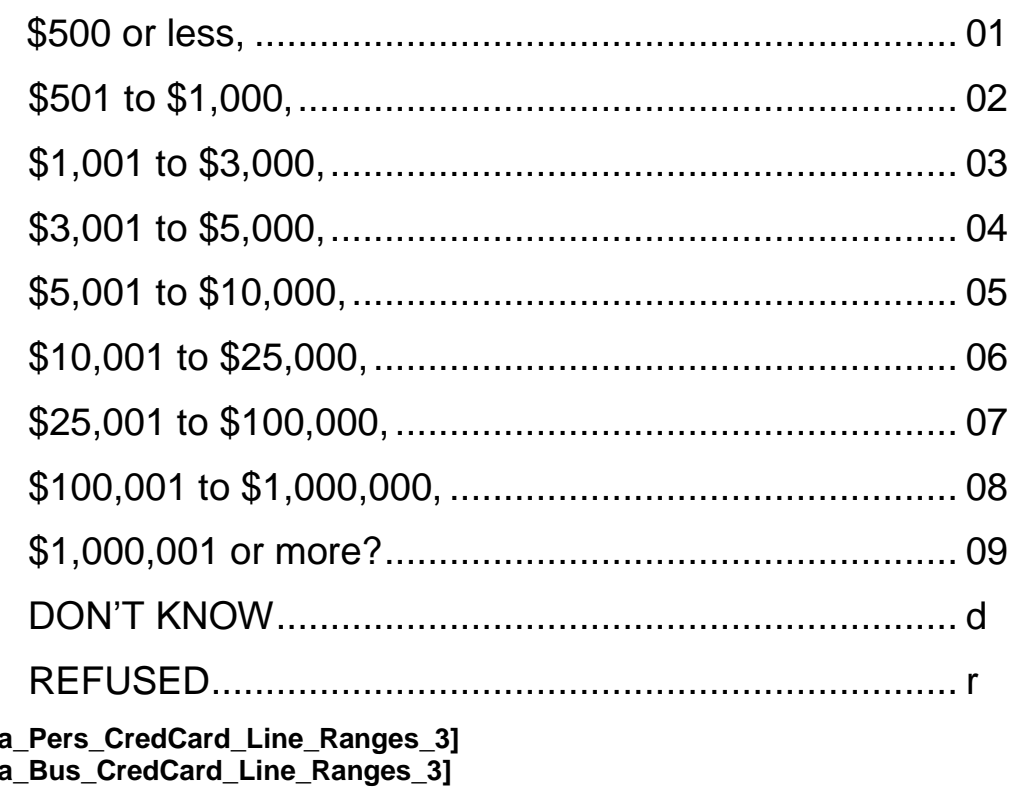


F10b. IF ANSWERED "YES" TO F9a ITEMS a, c, ASK: As of December 31, 2007, what was the outstanding balance on the [NAME DEBT FINANCING OPTION] used by (one of) the other owner(s)?

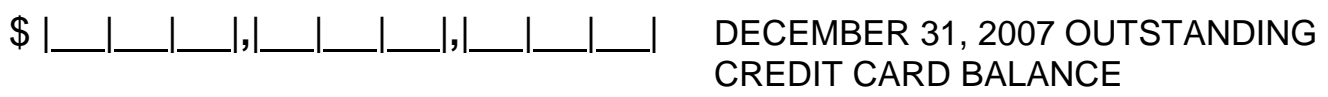

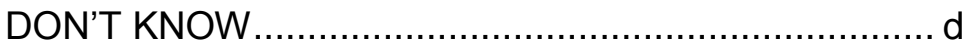

REFUSED ........................................................

[F10b_Pers_CredCard_Bal_3]

[F10b_Bus_CredCard_Bal_3]

IF DON'T KNOW OR REFUSED, PROBE WITH RANGES: Would you say it was . .

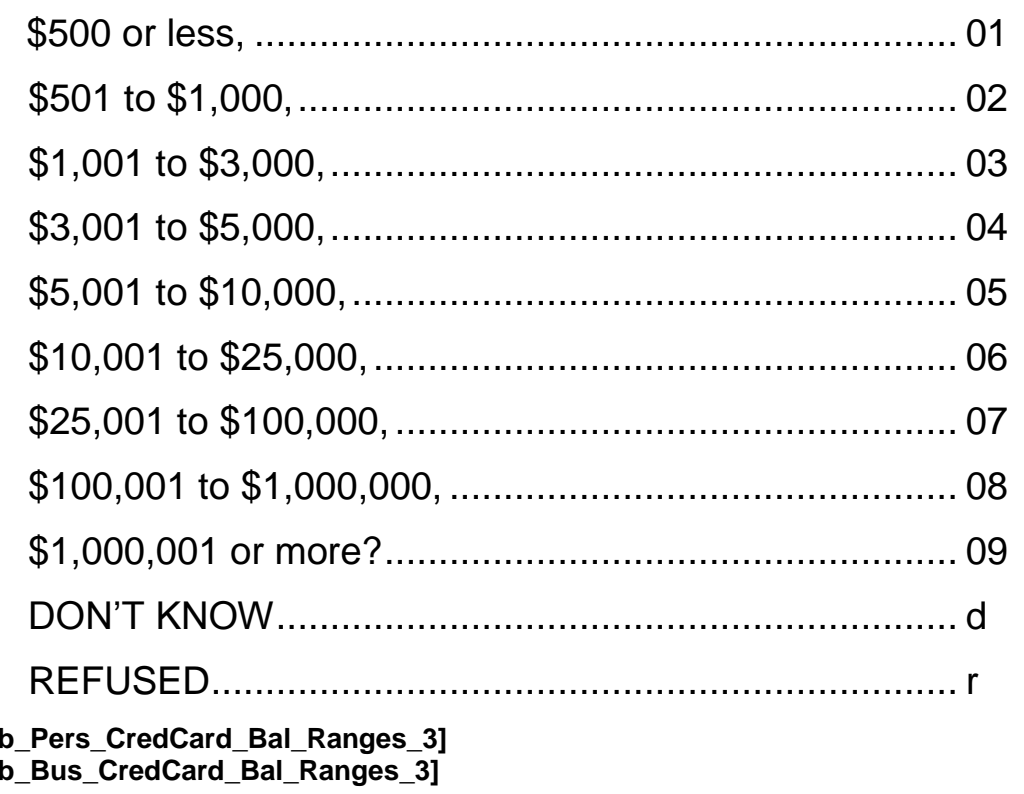

\section{IF F10b IS GREATER THAN F10a:}

Perhaps I made a mistake. The amount I recorded as the balance outstanding is greater than the amount reported as the maximum credit limit. 
F10c. IF ANSWERED "YES" TO F9a, ITEMS b, d, e, f, ASK: In calendar year 2007, how much was obtained from the [NAME DEBT FINANCING OPTION] other owners used?

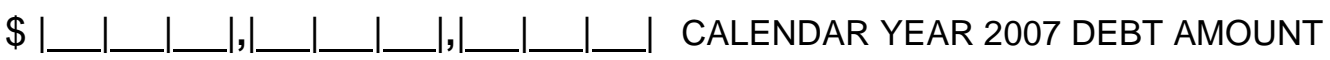

DON'T KNOW .......................................................

REFUSED......................................................... $\mathrm{r}$

[F10c_Pers_Loan_Bank_Amt_3]

[F10c_Pers_Loan_Fam_Amt_3]

[F10c_Pers_Loan_Other_Amt_3]

[F10c_Pers_Other_Amt_3]

IF DON'T KNOW OR REFUSED, PROBE WITH RANGES: Would you say it was . .

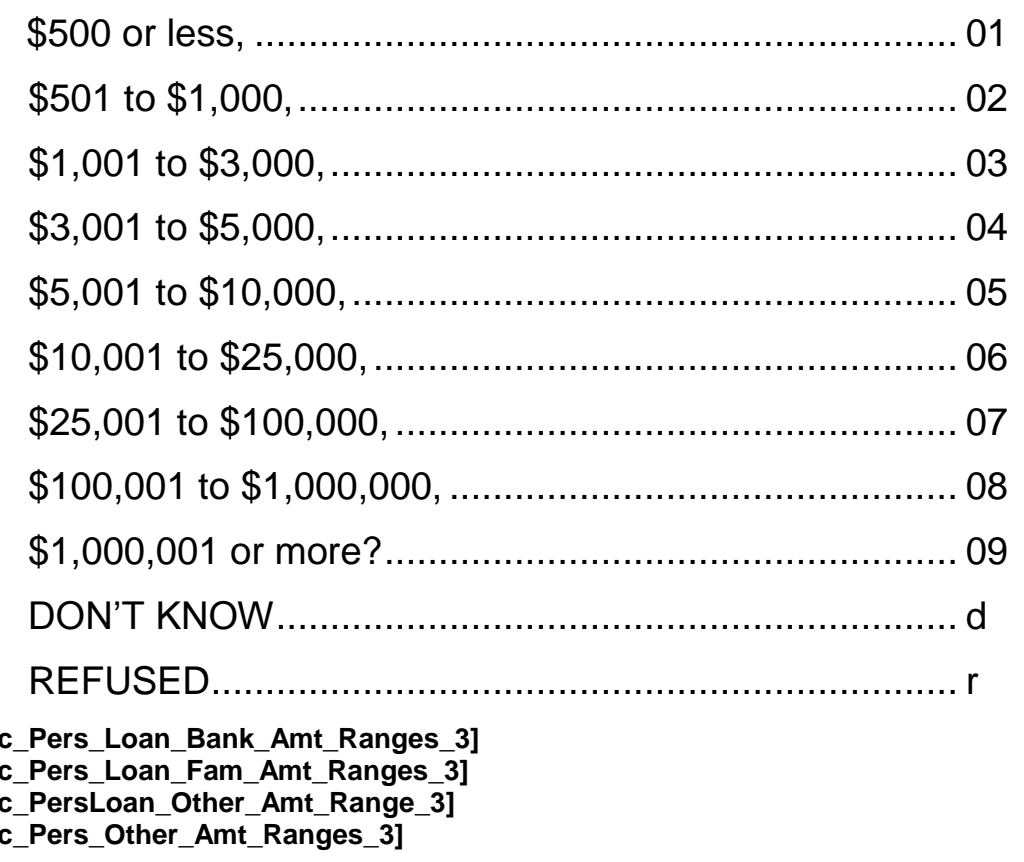


F10d. IF ANSWERED “YES” TO F9a ITEMS b, d, e, f, ASK: As of December 31, 2007, what was the estimated amount of the [NAME DEBT FINANCING OPTION] owed by other owners on behalf of [NAME BUSINESS]?

$\$$
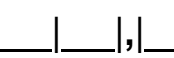
|

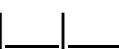

DEBT AMOUNT AS OF DECEMBER 31, 2007

DON'T KNOW d

REFUSED.

[F10d_Pers_Loan_Bank_Owed_3]

[F10d_Pers_Loan_Fam_Owed_3]

[F10d_Pers_Loan_Other_Owed_3]

[F10d_Pers_Other_Owed_3]

IF DON'T KNOW OR REFUSED, PROBE WITH RANGES: Would you say it was . .

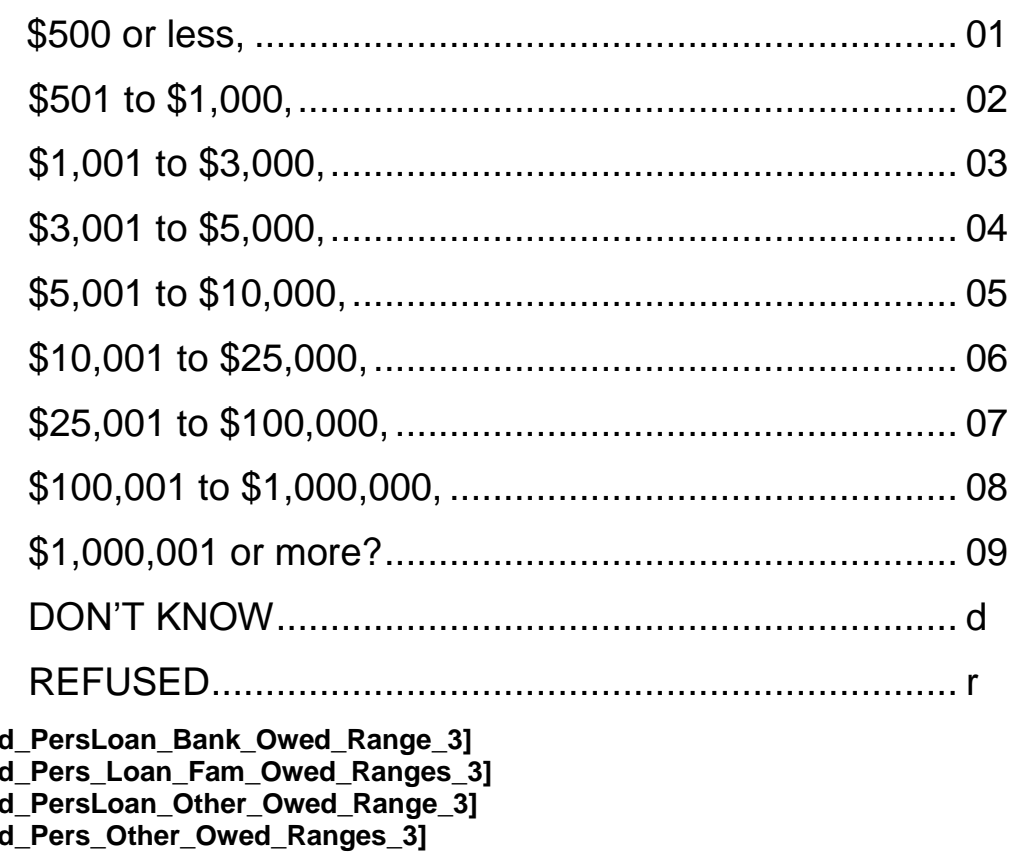


F11a. We are once again switching to another debt category. Now l'm going to ask you about some different types of debt financing that may have been obtained in the name of the business during calendar year 2007. This debt does not include amounts already reported in the previous sections about your debt or the debt of other owners. During calendar year 2007, did [NAME BUSINESS] use [NAME DEBT FINANCING OPTION FROM LIST]?

F11b. IN BELOW LIST, FOR EACH DEBT FINANCING OPTION BUSINESS REPORTED, ASK: How many [NAME DEBT FINANCING OPTION] did the business use to finance the operation or the business during calendar year 2007?

a. Business or corporate credit cards issued in the name of the business.

F11a_Bus_CredCard_3]

\begin{tabular}{|l|l|l|l|l|}
\hline YES & NO & $\begin{array}{l}\text { DON'T } \\
\text { KNOW }\end{array}$ & REFUSED & NUMBER USED \\
\hline
\end{tabular}

b. Business loans from a commercial bank.... [F11a_Bus_Loans_Bank_3]

$0100 \quad d \quad r$

$0100 \quad d \quad r$

[F11b_Bus_CredCard_NumUsed_3]

C. Business line of credit (READ IF NEEDED: a business line of credit is when a business has an agreement with a bank or other financial institution to borrow up to a certain $0100 \quad d \quad r$ [F11b_Bus_Loans_Bank_NumUsed_3] amount of funds)

[F11a_Bus_Cred_Line_3]

d. Business loans from a non-bank financial institution [F11a_Bus_Loans_Nonbank_3]

$0100 \quad d \quad r$

Business loans from any family or friends of the owners

$0100 \quad d \quad r$

[F11a_Bus_Loans_Fam_3]

f. Business loans from another owner of the business or a partner [F11a_Bus_Loans_Owner_3]

$0100 \quad d \quad r$

g. [IF HAVE EMPLOYEES AT C5] Loans to the business from employees that are not owners of the business

$0100 \quad d \quad r$

[F11a_Bus_Loans_Emp_3]

h. Loans from government agencies

[F11a_Bus_Loans_Govt_3]

$0100 \quad d \quad r$

i. Loans from other businesses. [F11a_Bus_Loans_Other_Bus_3]

$0100 \quad d \quad r$

[F11b_Bus_Loans_Nonbank_NumUsed_3]

[F11b_Bus_Cred_Line_NumUsed_3]

j. Business loans from any other individuals not associated with the management of the business

$0100 \quad d$ [F11b_Bus_Loans_Fam_NumUsed_3]

[F11a_Bus_Loans_Other_Ind_3]

k. Any other sources? (SPECIFY) [F11a_Bus_Other_3]

$0100 \quad d \quad r$ [F11b_Bus_Loans_Owner_NumUsed_3]

[F11_Bus_Other_Specify_3] 
F12a. IF ANSWERED "YES" TO F11a ITEMS a, c, ASK: As of December 31, 2007, what was the maximum credit line on the [NAME DEBT FINANCING OPTION]?

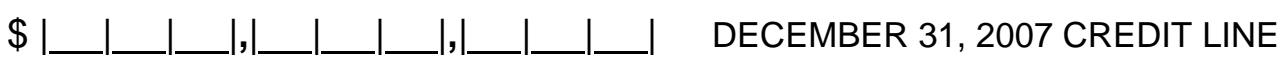

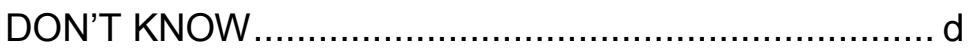

REFUSED ........................................................... $\mathrm{r}$

[F12a_Bus_CredCard_Line_3]

[F12a_Bus_Cred_Line_3]

IF DON'T KNOW OR REFUSED, PROBE WITH RANGES: Would you say it was . .

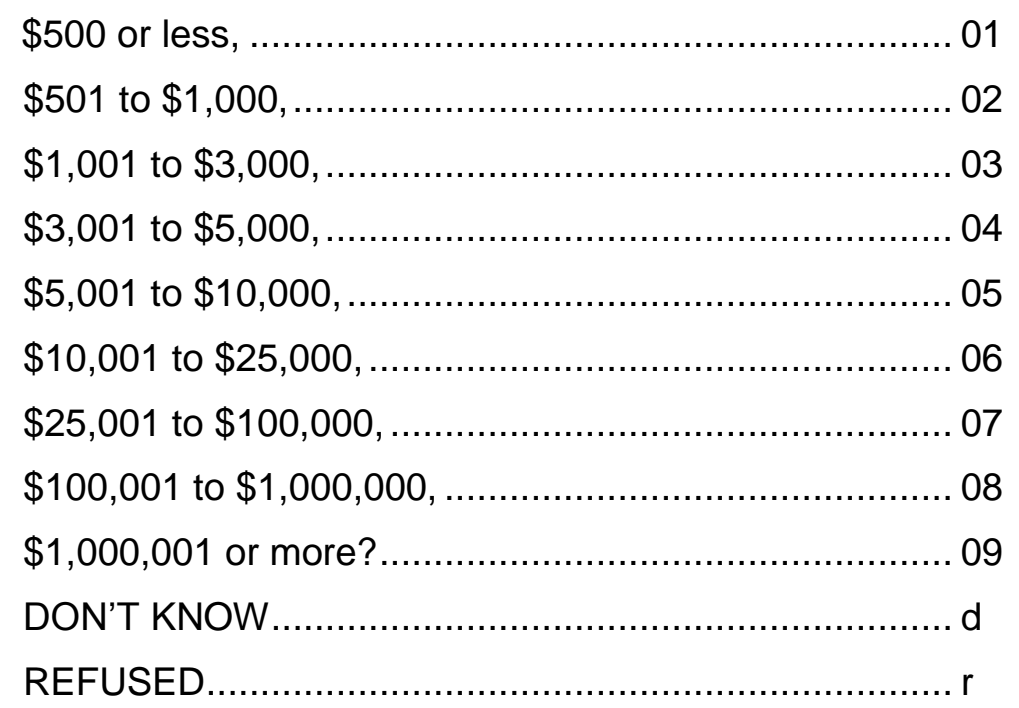

[F12a_Bus_CredCard_Line_Ranges_3]

[F12a_Bus_Cred_Line_Ranges_3] 
F12b. IF ANSWERED "YES" TO F11a ITEMS a, c, ASK: As of December 31, 2007, what was the outstanding balance on the [NAME DEBT FINANCING OPTION]?

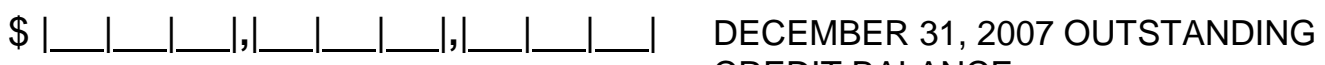
CREDIT BALANCE

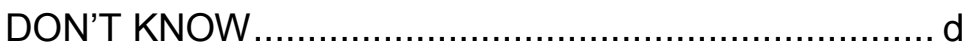

REFUSED ...................................................... $\mathrm{r}$

[F12b_Bus_CredCard_Bal 3]

[F12b_Bus_Cred_Line_Bal_3]

IF DON'T KNOW OR REFUSED, PROBE WITH RANGES: Would you say it was ...

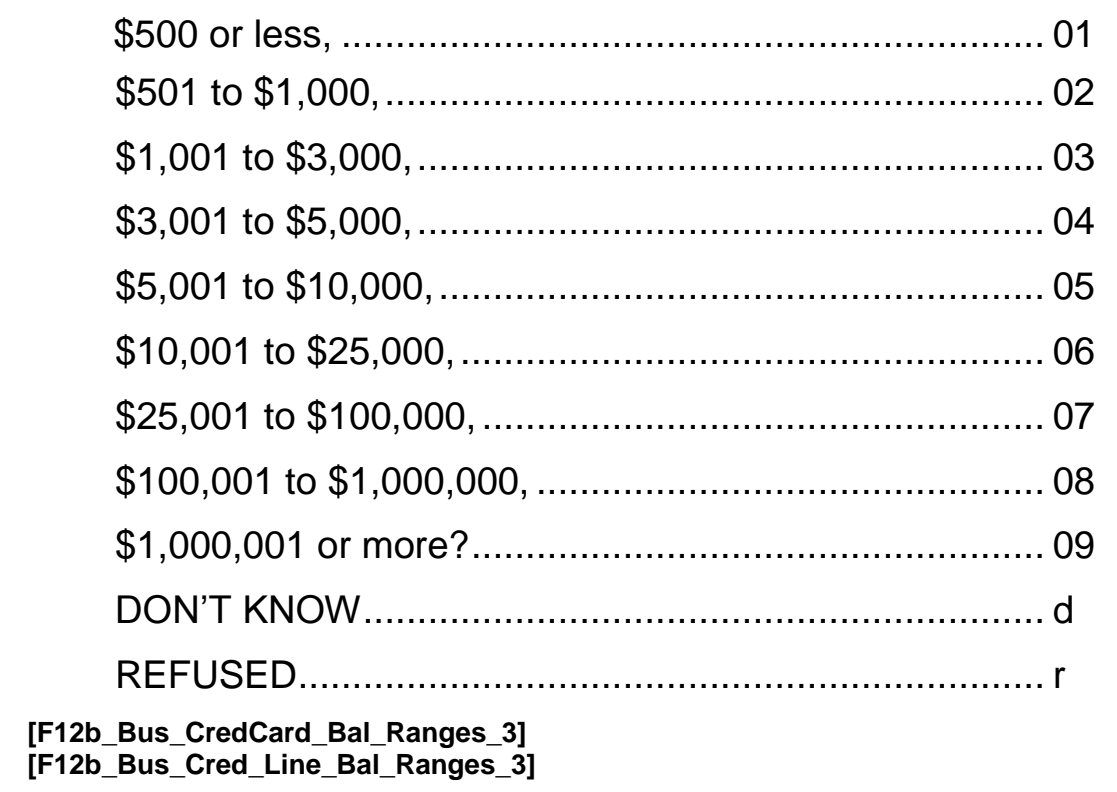

\section{IF F12a IS LESS THAN F12b:}

Perhaps I made a mistake. The amount I recorded as the balance outstanding is greater than the amount reported as the maximum credit limit. 
F12c. IF ANSWERED "YES" TO F11a ITEMS b, d-k, ASK: In calendar year 2007, how much was the amount obtained from [NAME DEBT FINANCING OPTION] used by [NAME BUSINESS]?

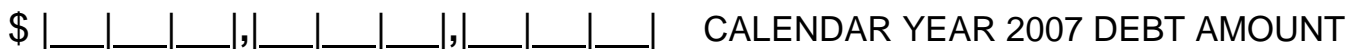

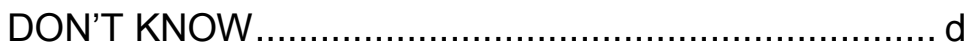

REFUSED ........................................................

[F12c_Bus_Loans_Bank_Amt_3]

[F12c_Bus_Loans_Nonbank_Amt_3]

[F12c_Bus_Loans_Fam_Amt_3]

[F12c_Bus_Loans_Owner_Amt_3]

[F12c Bus Loans Emp Amt 3]

[F12c_Bus_Loans_Govt_Amt_3]

[F12c Bus_Loans Bus_Amt 3]

[F12c_Bus_Loans_Other_Ind_Amt_3]

[F12c_Bus_Other_Amt_3]

IF DON'T KNOW OR REFUSED, PROBE WITH RANGES: Would you say it was . .

$\$ 500$ or less, ............................................................ 01

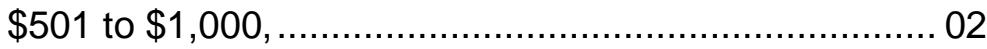

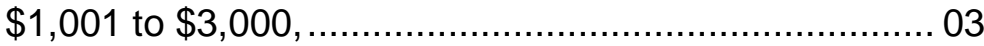

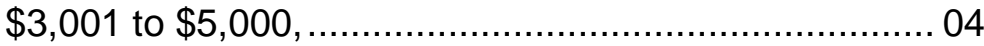

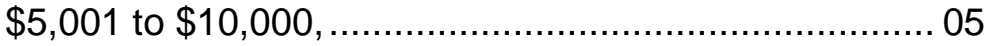

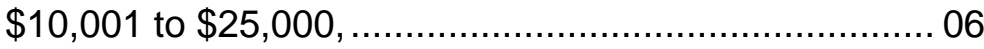

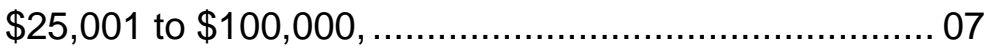

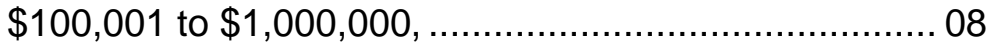

$\$ 1,000,001$ or more?.............................................. 09

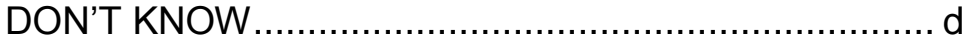

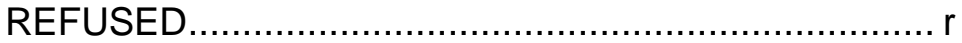

[F12c_Bus_Loans_Bank_Amt_Ranges_3]

[F12c_BusLoans_Nonbnk_Amt_Range_3]

[F12c_Bus_Loans_Fam_Amt_Ranges_3]

[F12c_BusLoans_Owner_Amt_Range_3]

[F12c_Bus_Loans_Emp_Amt_Ranges_3]

[F12c_Bus_Loans_Govt_Amt_Ranges_3]

[F12c_Bus Loans_Bus Amt Ranges 3]

[F12c_BusLoans_Other_Ind_Amt_Range_3]

[F12c_Bus_Other_Amt_Ranges_3] 
F12d. IF ANSWERED "YES" TO F11a ITEMS b, d-k, ASK: As of December 31, 2007, what was the estimated amount of the [NAME DEBT FINANCING OPTION] owed by [NAME BUSINESS]?

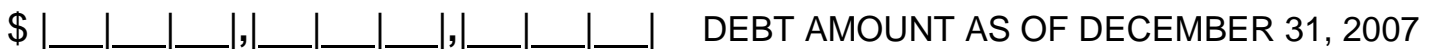

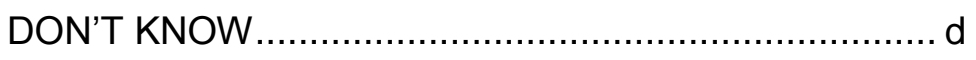

REFUSED .......................................................... $\mathrm{r}$

[F12d_Bus_Loans_Bank_Owed_3]

[F12d_Bus_Loans_Nonbank_Owed_3]

[F12d Bus Loans Fam Owed 3]

[F12d_Bus_Loans_Owner_Owed_3]

[F12d Bus Loans Emp Owed 3]

[F12d_Bus_Loans_Govt_Owed_3]

[F12d_Bus_Loans_Bus_Owed_3]

[F12d_Bus_Loans_Other_Ind_Owed_3]

[F12d_Bus_Other_Owed_3]

IF DON'T KNOW OR REFUSED, PROBE WITH RANGES: Would you say it was . .

$\$ 500$ or less, ........................................................ 01

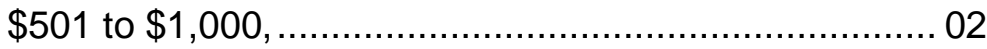

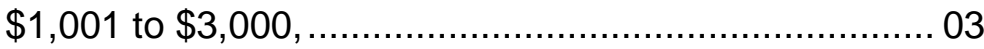

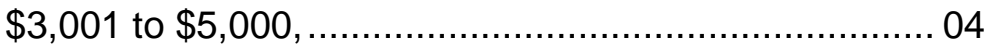

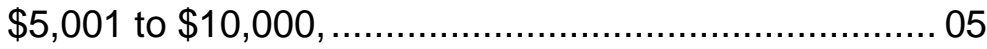

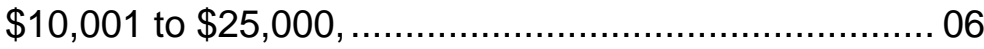

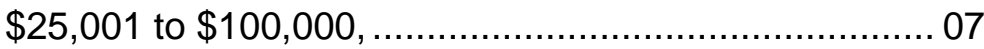

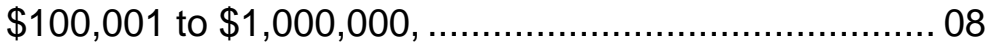

$\$ 1,000,001$ or more?................................................. 09

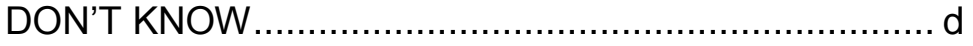

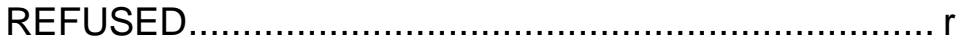

[F12d_BusLoans_Bank_Owed_Range_3]

[F12d_BusLoan_Nonbnk_Owed_Range_3]

[F12d_Bus_Loans_Fam_Owed_Ranges_3]

[F12d_BusLoans_Owner_Owed_Range_3]

[F12d_Bus_Loans_Emp_Owed_Ranges_3]

[F12d_BusLoans_Govt_Owed_Range_3]

[F12d_Bus_Loans_Bus_Owed_Ranges_3]

[F12d_BusLoan_Othrind_Owed_Range_3]

[F12d_Bus_Other_Owed_Ranges_3] 
F13. Trade financing is where a business has an arrangement with a supplier to make purchases on account. In calendar year 2007, did [NAME BUSINESS] make any purchases through trade financing?

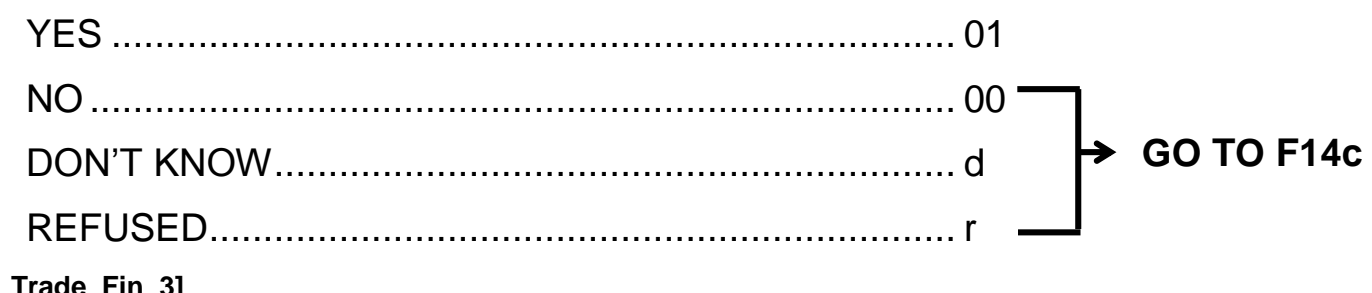

[F13_Trade_Fin_3]

F14a. In calendar year 2007, what was the amount of purchases made through trade financing?

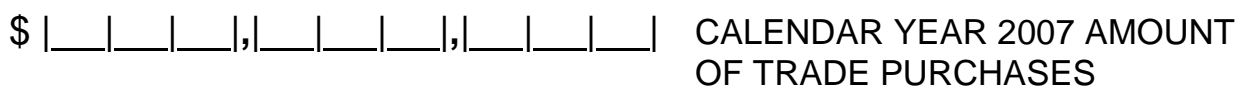

DON'T KNOW...........................................................

REFUSED .............................................................

[F14a_Trade_Fin_Amt_3]

F14b. IF DON'T KNOW OR REFUSED, PROBE WITH RANGES: Would you say it was ...

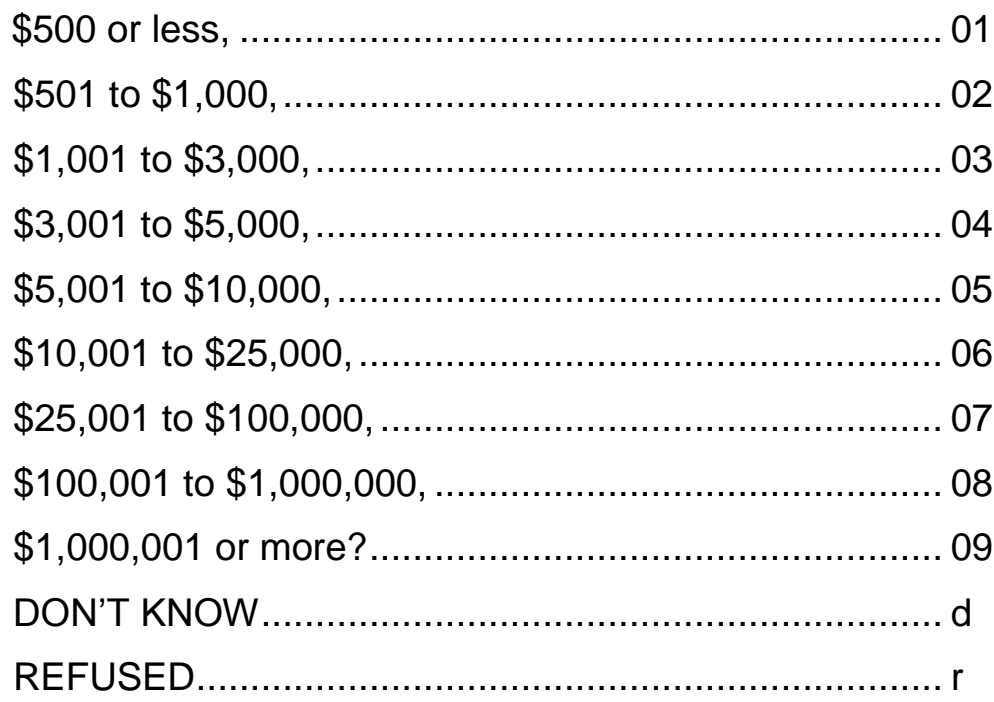

[F14b_Trade_Fin_Amt_Ranges_3] 
F14c. This next section is about applications for credit [NAME BUSINESS] made in calendar year 2007. In responding to these questions, include new as well as renewal applications for lines of credit and other types of loans. Do not include applications for credit cards, loans from owners, trade credit with suppliers, or loan applications that were withdrawn or are still pending.

F14d. Did [NAME BUSINESS] make any applications for new or renewed loans or lines of credit in calendar year 2007?

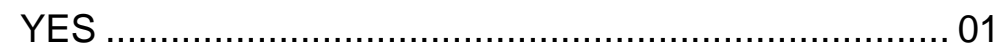

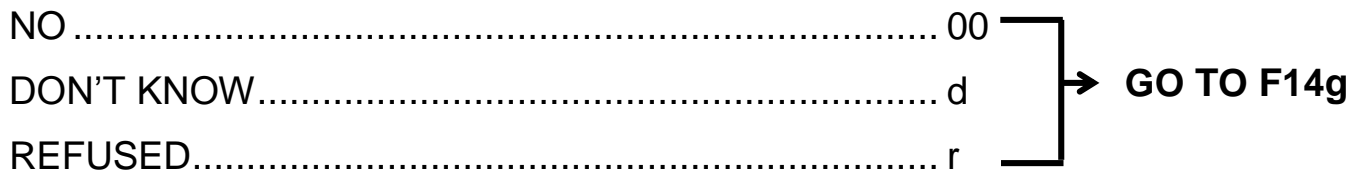

[F14d_New_Loans_3]

F14e. Were these applications always approved, sometimes approved and sometimes denied, or always denied?

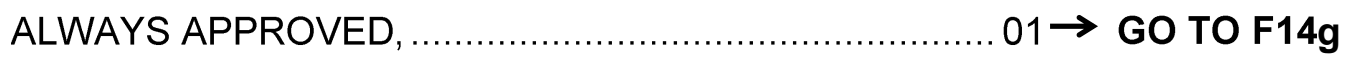

SOMETIMES APPROVED AND SOMETIMES DENIED, ... 02

ALWAYS DENIED, .......................................... 03

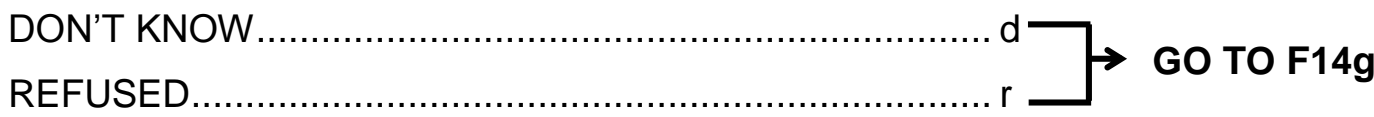

[F14e_Approved_Denied_3] 
F14f. Consider the most recent time [NAME BUSINESS]'s credit application was denied. Officially, was the application denied because of . . .

a. Insufficient collateral?.

\begin{tabular}{|l|l|l|l|}
\hline YES & NO & $\begin{array}{l}\text { DON'T } \\
\text { KNOW }\end{array}$ & REFUSED \\
\hline
\end{tabular}
[F14f_Insuff_Coll_3]

b. The loan requested was too large?

0100

d

$r$ [F14f_Loan_TooLarge_3]

C. Inadequate documentation provided? $01 \quad 00$ d [F14f_Inadeq_Doc_3]

d. Business credit history? 0100

d

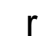
[F14f_Bus_Credit_Hist_3]

e. Personal credit history? $01 \quad 00$ d

$r$ [F14f_Pers_Credit_Hist_3]

f. Not being in business long enough? $01 \quad 00$

d [F14f_New_Bus_3]

g. Any other reason? (SPECIFY) $01 \quad 00$ d r [F14f_Other_3]

[F14f_OtherSpecify_3]

F14g. During calendar year 2007, was there any time when [NAME BUSINESS] needed credit, but did not apply because you or others associated with [NAME BUSINESS] thought the application would be denied?

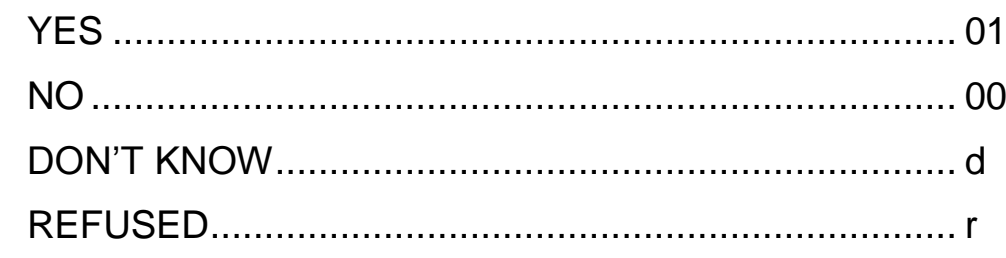

[F14g_DidNotApply_3] 
F15. In calendar year 2007, did [NAME BUSINESS] receive any revenue (money), from the sales of goods, services, or intellectual property? [IF SOLE PROPRIETORSHIP, ADD: This would be gross receipts reported on a Schedule $C$ or $C-E Z$ with your personal income tax return.]

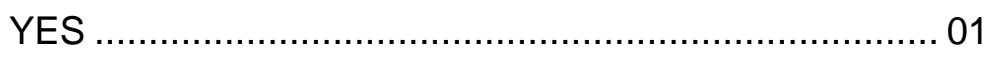

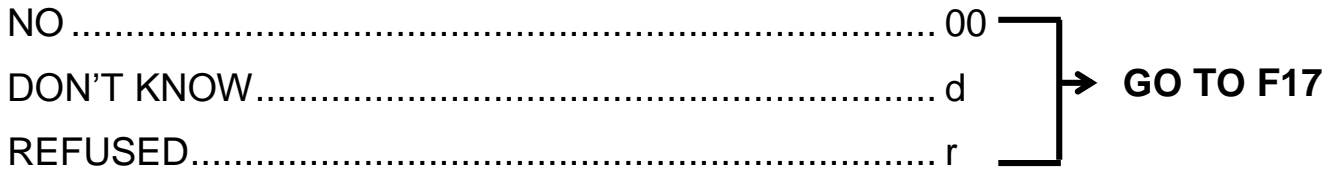

[F15_Revenue_2007_3]

IF F15 = 01 AND D6 = 00:

I may have made a mistake. Earlier in the interview, I recorded that [NAME BUSINESS] did not have any customers or sales in calendar year 2007. Is there an error?

F16. What was [NAME BUSINESS]'s total revenue for calendar year 2007? [IF SOLE PROPRIETORSHIP, ADD: This would be gross receipts reported on a Schedule $\mathrm{C}$ or C-EZ with your personal income tax return.]

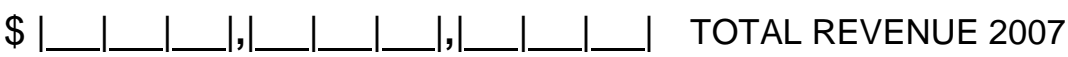

DON'T KNOW................................................... d

REFUSED................................................... $r$

[F16a_Rev_2007_Amt_3]

IF DON'T KNOW OR REFUSED, PROBE WITH RANGES: Would you say it was . .

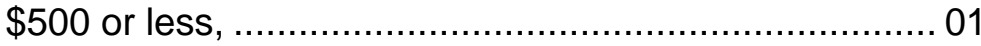

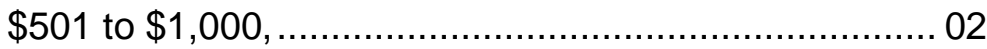

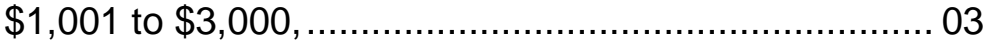

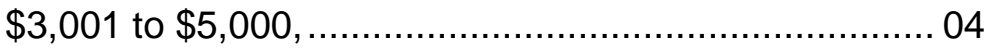

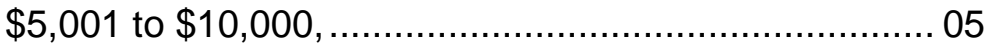

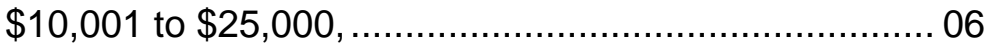

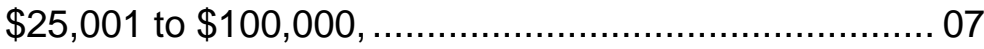

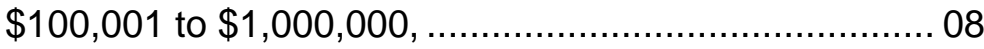

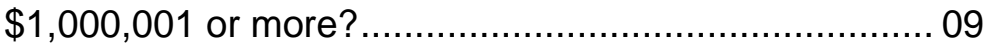

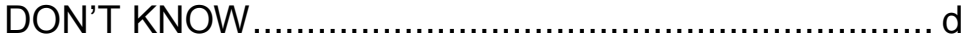

REFUSED.

[F16a_Rev_2007_Amt_Ranges_3] 
F16b. Was this an increase, a decrease, or no change in the amount of revenue for [NAME BUSINESS] in calendar year 2007 compared to $2006 ?$

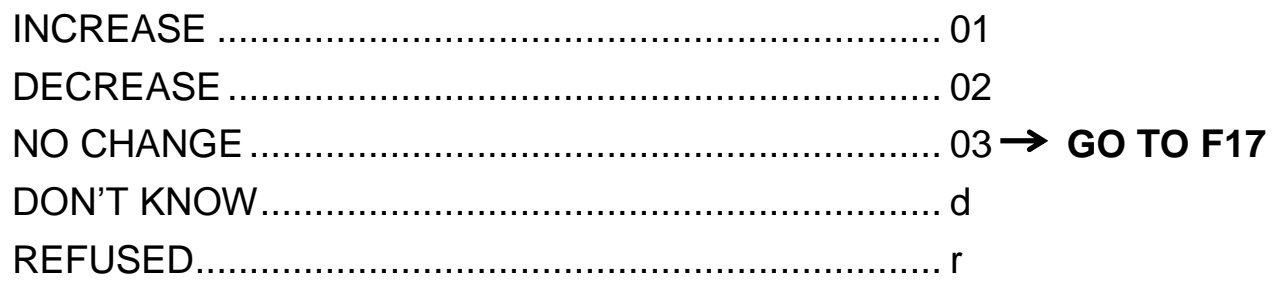

[F16b_Rev_2007_Change_3]

F16c. And what was the percentage change in revenue in calendar year 2007 compared 2006? Your best estimate is fine.

I_____ I \% CHANGE IN REVENUE

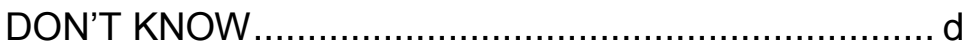

REFUSED ......................................................

[F16c_Perc_Change_3]

F17. Now l'm going to ask about the expenses the business paid. Expenses are the costs paid for the operation of the business, including wages, salaries, interest on loans, capital leases, materials, etc. How much, if any, did [NAME BUSINESS] pay in expenses during calendar year $2007 ?$

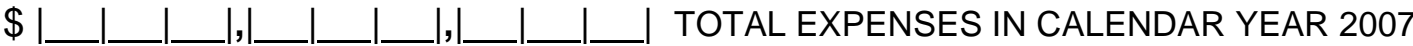

DON'T KNOW .......................................................

REFUSED ................................................... $\mathrm{r}$

[F17a_Total_Exp_2007_Amt_3]

IF DON'T KNOW OR REFUSED, PROBE WITH RANGES: Would you say it was ...

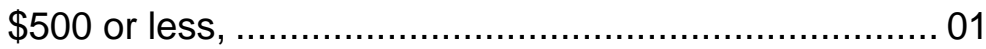

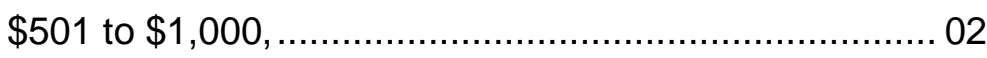

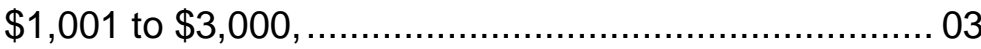

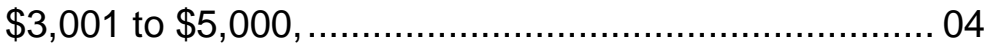

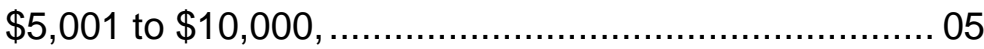

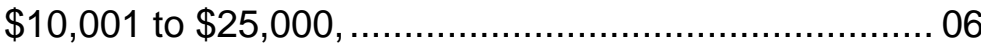

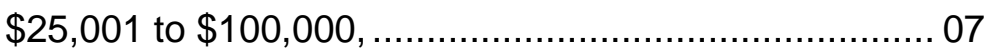

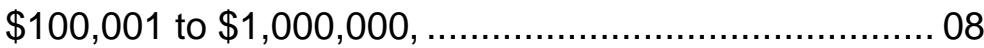

$\$ 1,000,001$ or more? ............................................... 09

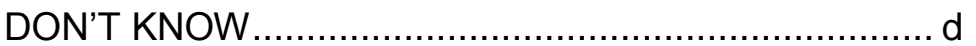

REFUSED

[F17a_Total_Exp_2007_Amt_Ranges_3] 
F17b. Was this an increase, a decrease, or no change in total expenses for [NAME BUSINESS] in calendar year 2007 compared to 2006?

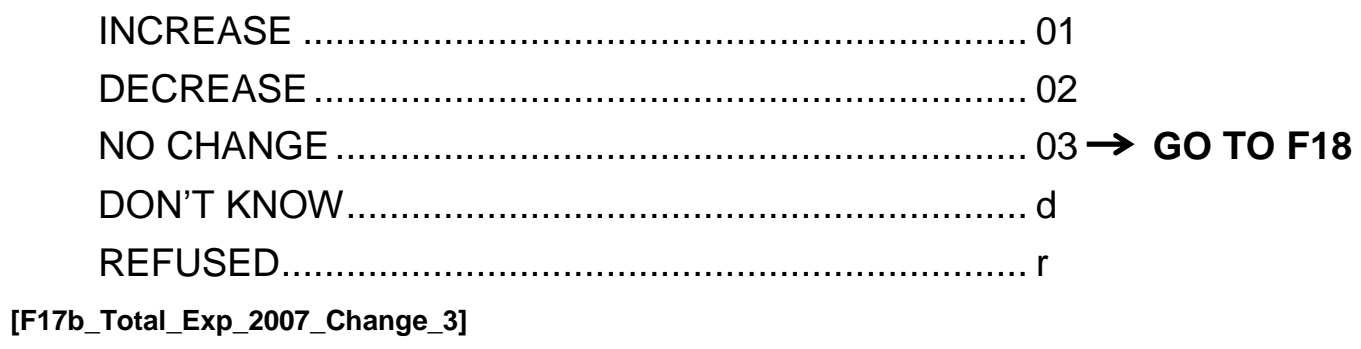

F17c. And what was the percentage change in total expenses in calendar year 2007 compared 2006? Your best estimate is fine.

$\left|\_\right| \_$__ $\%$ CHANGE IN EXPENSES

DON'T KNOW ..................................................... d

REFUSED .........................................................

[F17c_Perc_Change_3] 
F18. IF BUSINESS REPORTED “0” EMPLOYEES AT C5, GO TO F19.

How much, if any, did [NAME BUSINESS] pay in wages, salaries, and benefits to full-and part-time employees in calendar year 2007? Please do not include wages, salaries, and benefits to contract workers who work for the business but are not on the business' official payroll.

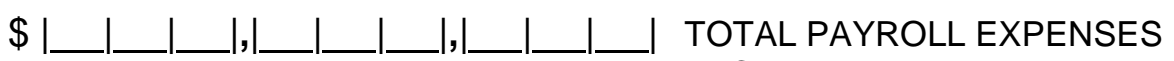
IN CALENDAR YEAR 2007

DON'T KNOW d

REFUSED. $r$

[F18a_Wage_Exp_2007_Amt_3]

IF DON'T KNOW OR REFUSED, PROBE WITH RANGES: Would you say it was ...

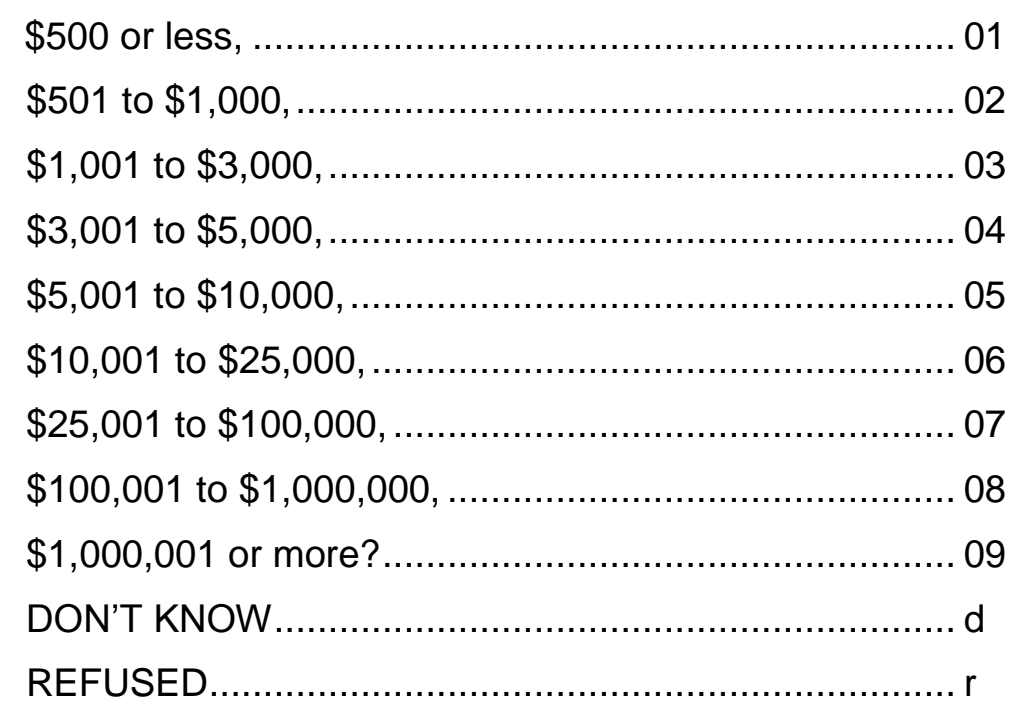

[F18b_Wage_Exp_2007_Amt_Ranges_3]

IF F18 > F17:

I may have made a mistake. I recorded that the business' wage expenses for 2007 were greater than its total expenses. Is there an error?

F19. Did [NAME BUSINESS] spend any money on research and development of new products and services during calendar year 2007 ?

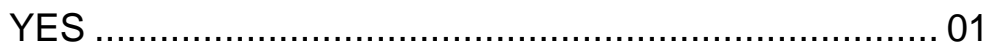

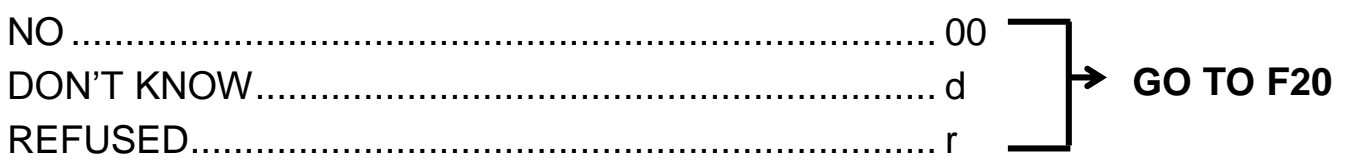

[F19_Res_Dev_3] 
F19a. Please estimate [NAME BUSINESS]'s total research and development expenses for calendar year 2007, including materials, equipment, space, salaries, wages, benefits, and consulting fees?

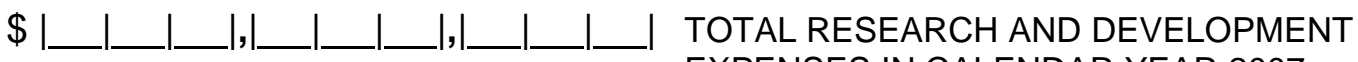
EXPENSES IN CALENDAR YEAR 2007

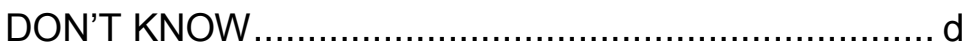

REFUSED .....................................................

[F19a_Res_Dev_Amt_2007_3]

IF DON'T KNOW OR REFUSED, PROBE WITH RANGES: Would you say it was . .

$\$ 500$ or less, ..................................................... 01

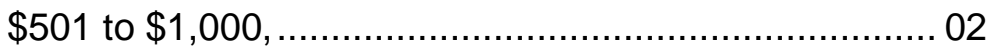

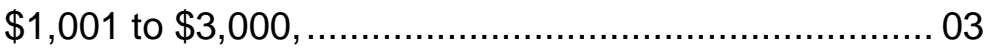

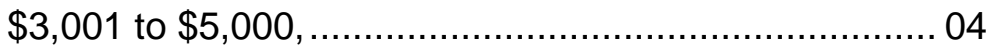

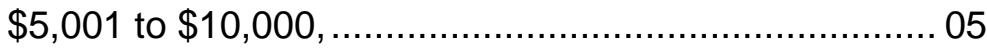

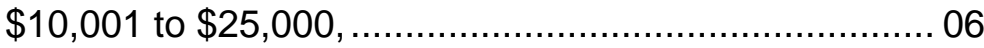

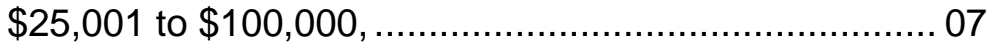

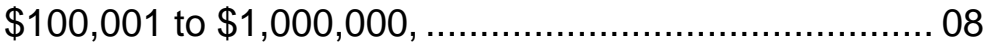

$\$ 1,000,001$ or more? ............................................... 09

DON'T KNOW .................................................... d

REFUSED ........................................................ $\mathrm{r}$

[F19b_Res_Dev_Amt_2007_Ranges_3]

IF F19a > F17:

I may have made a mistake. I recorded that the business' research and development expenses for 2007 were greater than its total expenses. Is there an error? 
F20. Did [NAME BUSINESS] spend any money on the purchase of new or used machinery or equipment during calendar year 2007?

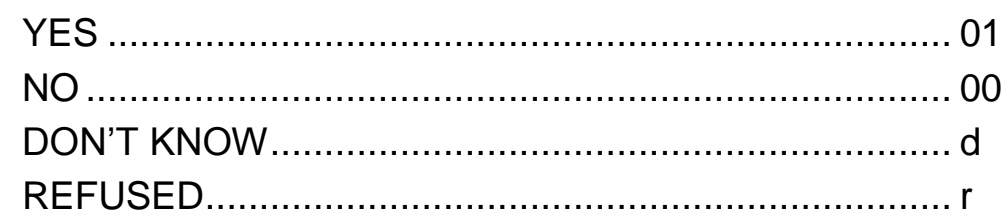

[F20_Mach_3]

F21. Did [NAME BUSINESS] spend any money on rental or lease payments for buildings or other structures during calendar year 2007 ?

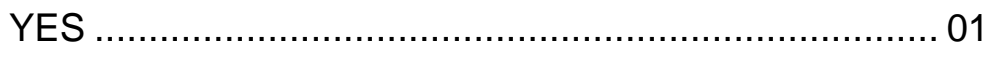

NO

DON'T KNOW......................................................

REFUSED.................................................. $\mathrm{r}$

[F21_Land_Rent_3]

F22. Did [NAME BUSINESS] spend any money on rental or lease payments for machinery or equipment during calendar year 2007 ?

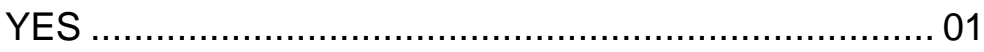

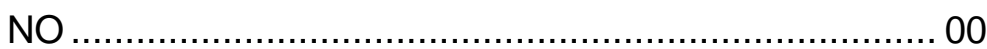

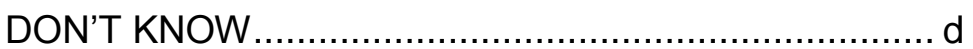

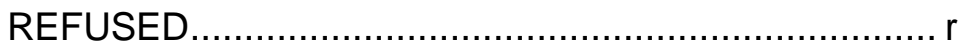

[F22_Mach_Rent_3]

F23. Did [NAME BUSINESS] have a profit or loss in calendar year 2007?

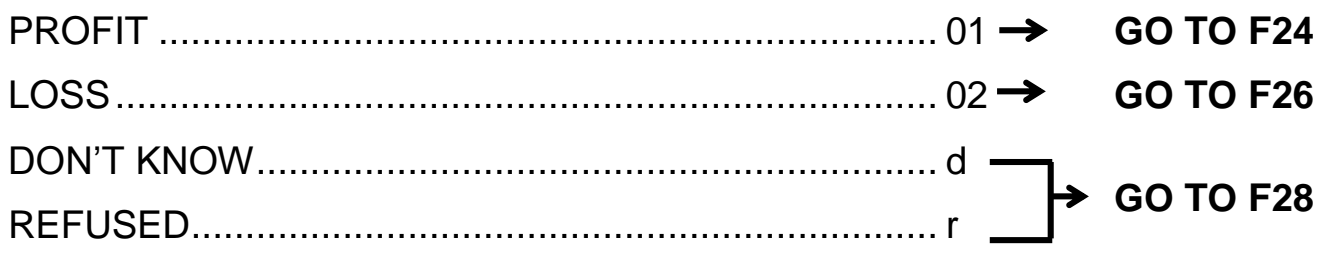

[F23_Profit_Or_Loss_3]

IF F23 = 01 AND F15 = 00:

I may have made a mistake. Earlier in the interview, I recorded that [NAME BUSINESS] did not have any revenue in calendar year 2007. Is there an error? 
F24. Profit is the business' income after all expenses and taxes have been deducted. What was [NAME BUSINESS]'s total profit for calendar year 2007?

\section{ENTER PROFIT AMOUNT}

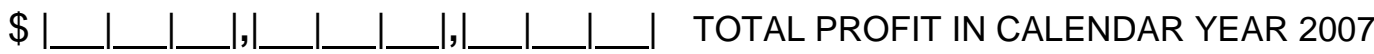

DON'T KNOW........................................................

REFUSED ....................................................

[F24_Profit_Amt_3]

F25. IF DON'T KNOW OR REFUSED, PROBE WITH RANGES: Would you say it was ...

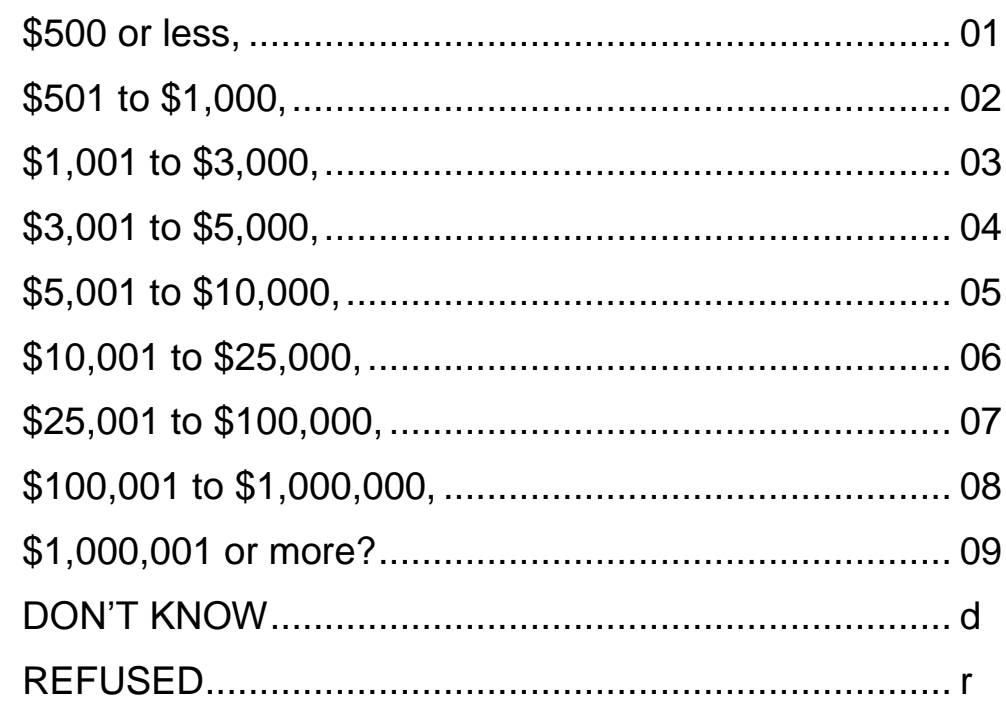

[F25_Profit_Amt_Ranges_3] 
F26. Loss is the business' negative income after all expenses and taxes have been deducted. What was [NAME BUSINESS]'s total loss for calendar year 2007?

\section{ENTER LOSS AMOUNT}

\$ $\mid$

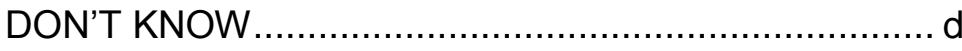

REFUSED .....................................................

[F26_Loss_Amt_3]

F27. IF DON'T KNOW OR REFUSED, PROBE WITH RANGES: Would you say it was ...

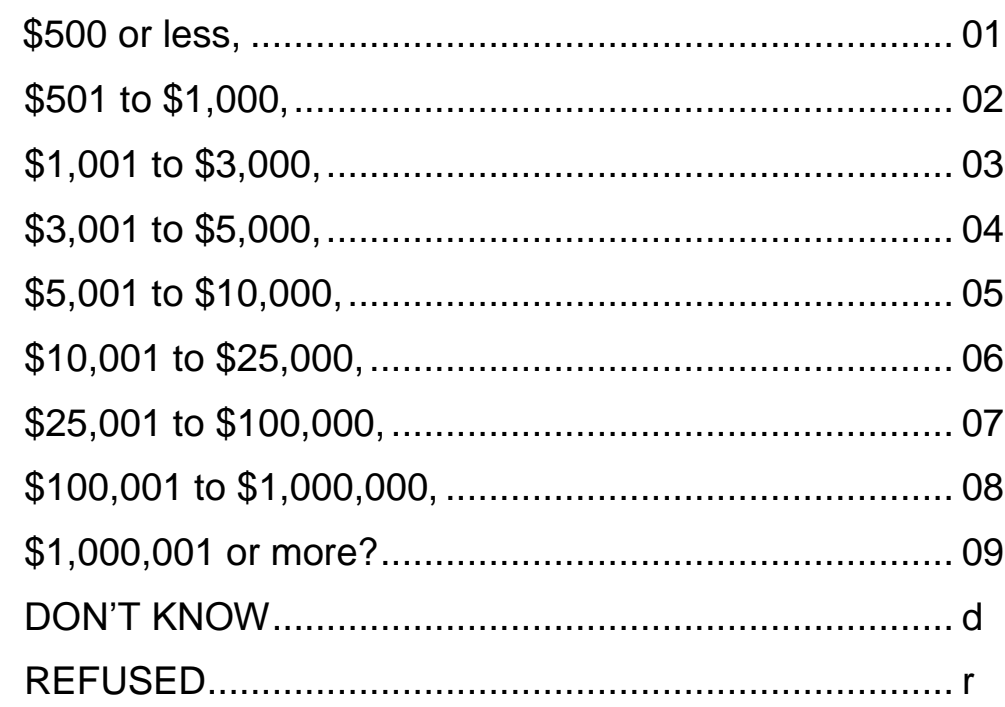

[F27_Loss_Amt_Ranges_3] 
F28. Assets are what the business owns. As of December 31, 2007, did [NAME BUSINESS]'s assets include [NAME ASSET FROM LIST]?

\begin{tabular}{|l|l|l|l}
\hline YES & NO & DON'T & \\
KNOW & REFUSED \\
\hline
\end{tabular}

a. Cash on hand in checking, savings, money market accounts, certificates of deposit and other time deposits.

$01 \quad 00$

d

r [F28a_Asset_Cash_3]

b. Accounts receivable [F28b_Asset_Acct_Rec_3]

$0100 \quad d \quad r$

C. Product inventory [F28c_Asset_Inv_3]

$01 \quad 00$

d

$r$

d. Equipment or machinery [F28d_Asset_Equip_3]

e. Land, buildings, and other structures... [F28e_Asset_LandBuild_3]

$01 \quad 00$

d

$r$

Vehicles

[F28f_Asset_Veh_3]

$01 \quad 00 \quad d$

$r$

g. Any other business owned property (SPECIFY) ... [F28g_Other_Bus_Prop_3]

$01 \quad 00 \quad d$

d $\quad r$

[F28_Other_Bus_Prop_Specify_3]

$01 \quad 00 \quad 0$

d

$r$

Any other assets? (SPECIFY)

[F28h_Other_Assets_3]

$01 \quad 00$

d

$r$

[F28_Other_Specify_3] 
F29. FOR EACH ASSET BUSINESS REPORTED, ASK:

As of December 31, 2007, what was the estimated value of the [NAME OF ASSET] owned by [NAME BUSINESS]?

$\$$
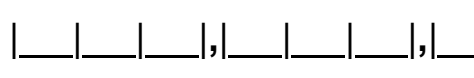

ASSET VALUE AS OF DECEMBER 31, 2007

DON'T KNOW

d

REFUSED.

[F29_AssetVal_Cash 3]

[F29_AssetVal_AcctRec_3]

[F29_AssetVal_Inv_3]

[F29_AssetVal_Equip_3]

[F29_AssetVal_LandBuild_3]

[F29_AssetVal_Veh_3]

[F29_AssetVal_OthBusProp_3]

[F29_AssetVal_Other_3]

IF DON'T KNOW OR REFUSED, PROBE WITH RANGES: Would you say it was ...

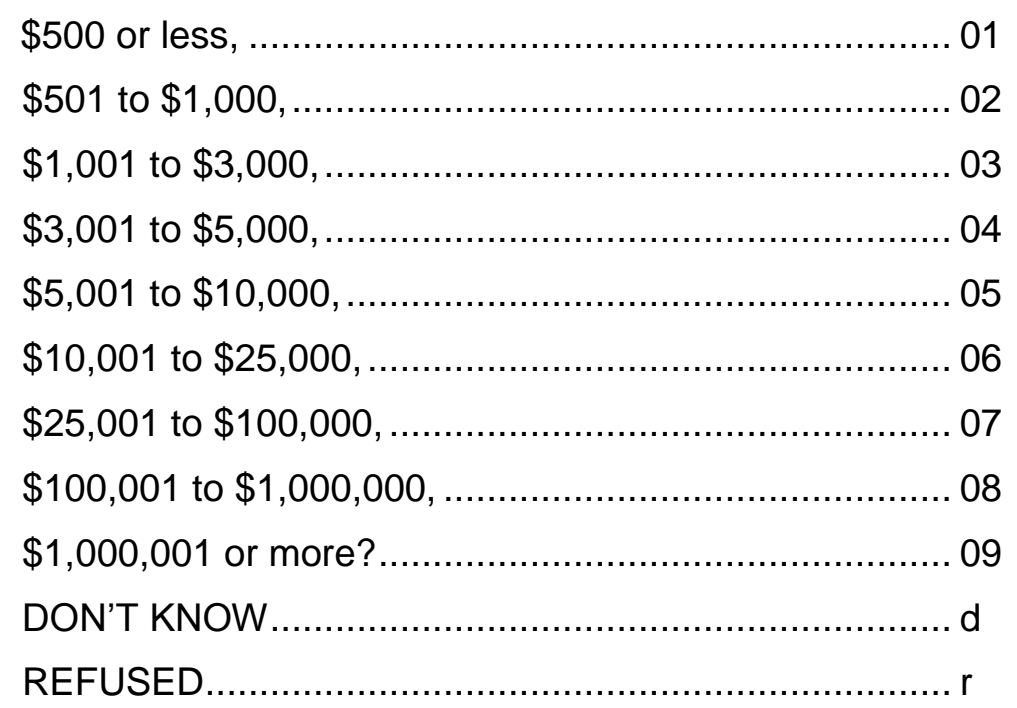

[F29_AssetVal_Cash_Ranges_3]

[F29_AssetVal_AcctRec_Ranges_3]

[F29_AssetVal_Inv_Ranges_3]

[F29_AssetVal_Equip_Ranges_3]

[F29_AssetVal_LandBuild_Ranges_3]

[F29_AssetVal_Veh_Ranges_3]

[F29_AssetVal_OthBusProp_Ranges_3]

[F29_AssetVal_Other_Ranges_3] 
F30. Liabilities are what the business owes. Other than the loans and the financial debt we've already talked about, did [NAME BUSINESS]'s liabilities as of December 31, 2007 include [NAME LIABILITY FROM LIST]?

\begin{tabular}{|l|l|l|l|}
\hline YES & NO & DON'T & \\
KNOW & REFUSED \\
\hline
\end{tabular}

a. Accounts Payable [F30a_Liab_AcctPay_3]

$0100 \quad d \quad r$

b. Pension and post retirement benefits [F30b_Liab_Pension_3]

c. Any other liabilities? (SPECIFY) [F30c_Liab_Other_3] [F30_Other_Specify_3]

F31. FOR EACH LIABILITY BUSINESS HAS, ASK: As of December 31, 2007, what was the estimated value of [NAME BUSINESS]'s [NAME OF LIABILITY]?

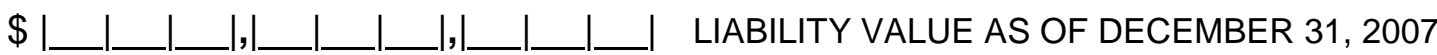

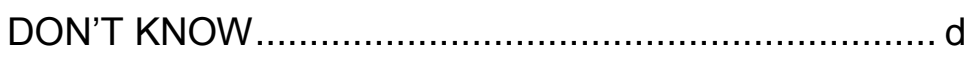

REFUSED ...........................................................

[F31_Value_AcctPay_3]

[F31_Value_Pension_3]

[F31_Value_Other_3]

IF DON'T KNOW OR REFUSED, PROBE WITH RANGES: Would you say it was ...

$\$ 500$ or less, ..................................................... 01

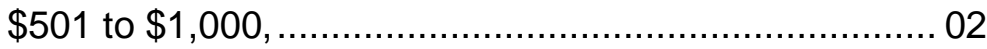

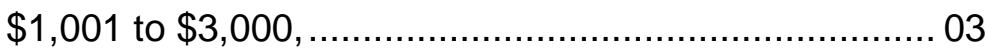

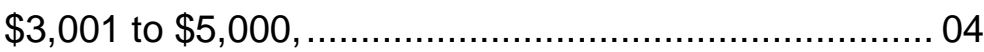

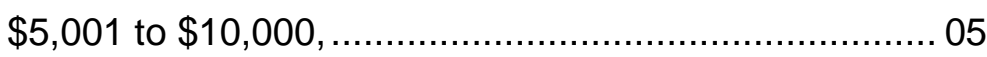

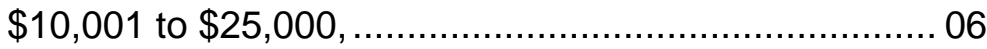

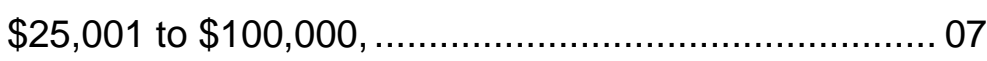

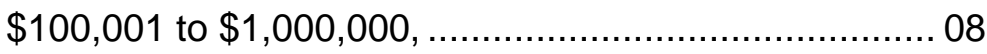

$\$ 1,000,001$ or more? ........................................... 09

DON'T KNOW ......................................................... d

REFUSED......................................................... $\mathrm{r}$

[F31_Value_AcctPay_Ranges_3]

[F31_Value_Pension_Ranges_3]

[F31_Value_Other_Ranges_3] 


\section{G. WORK BEHAVIORS AND DEMOGRAPHICS OF OWNER/OPERATOR(S)}

The last section contains questions for classification purposes only.

\section{C4 LISTING OF OWNER/OPERATORS SHOULD BE ASKED THIS SERIES IN THE ORDER THEY APPEAR IN C4.}

NO QUESTIONS WILL BE ASKED ABOUT OWNER/OPERATORS WHO HAVE LEFT THE BUSINESS.

FOR ALL SECOND FOLLOW-UP OWNER/OPERATORS IN C4, ASK BLOCK G1.

FOR ALL NEW OWNER/OPERATORS, ASK BLOCK G2.

QG9-G9b IS TO BE ASKED ONLY OF RESPONDENTS AND NOT ABOUT OTHER OWNER/OPERATORS.

\section{BLOCK G1}

G1a. (Are/ls) (you/[OWNER B-J]) also a paid employee at [NAME BUSINESS]?

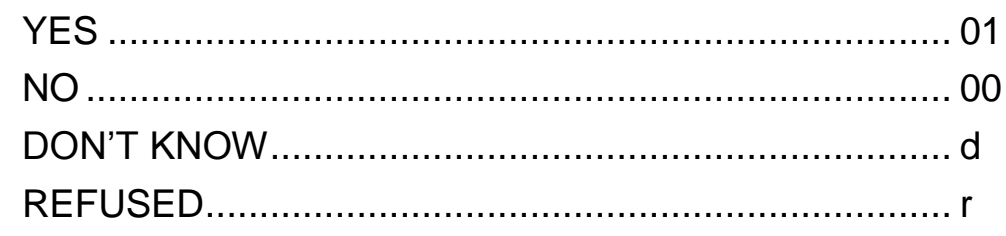

[G1a_Emp_Owner_01_3] THROUGH [G1a_Emp_Owner_11_3]

G1b. During the time [NAME BUSINESS] was in business during 2007, how many hours in an average week did (you/[OWNER B-J]) spend working at [NAME BUSINESS]?

I______ HOURS WORKED IN AVERAGE WEEK

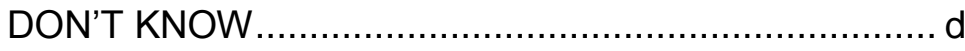

REFUSED........................................................

[G1b1_Hours_Owner_01_3] THROUGH [G1b1_Hours_Owner_11_3]

IF DON'T KNOW OR REFUSED PROBE: Would you say it was . . .

Less than 20 hours, ............................................. 01

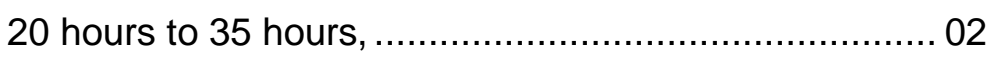

36 hours to 45 hours, ..................................... 03

46 hours to 55 hours, ..................................... 04

56 hours to 65 hours, .......................................... 05

66 hours or more?.............................................. 06

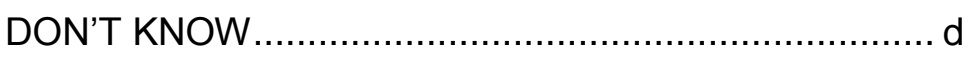

REFUSED.................................................... $\mathrm{r}$

[G1b2_Hours_Ranges_Owner_01_3] THROUGH [G1b2_Hours_Ranges_Owner_11_3] 
G9. What is the highest level of education (you/[OWNER B-J]) (have/has) completed so far? Would you say...

Less than 9th grade

01

Some high school, but no diploma,

02

High school graduate (diploma or equivalent diploma [GED]) 03

Technical, trade or vocational degree, 04

Some college, but no degree, 05

Associate's degree,

Bachelor's degree, 06

Some graduate school but no degree, 07

Master's degree, or .... $.08 \rightarrow$ GO TO G9b

Professional school or doctorate? 10

DON'T KNOW. d

REFUSED. $r$

[G9_Education_Owner_01_3] THROUGH [G9_Education_Owner_11_3]

G9a. What was the primary field of study for this degree?

DON'T KNOW d

REFUSED.

$r$

[G9_FieldOfStudy_Resp_3]

[G9_FieldOfStudy_Resp_2nd_3]

G9b. What was the primary field of study for your bachelor's degree?

DON'T KNOW d

REFUSED. .. r

[G9_FieldOfStudy_Resp_3]

[G9_FieldOfStudy_Resp_2nd_3] 
SECOND FOLLOW-UP OWNERS/OPERATORS: ANY DEMOGRAPHIC QUESTION G1dG10a NOT ANSWERED IN SECOND FOLLOW-UP WILL BE ASKED AGAIN. QUESTION G9-G9b IS TO BE ASKED ONLY OF RESPONDENTS AND NOT ABOUT OTHER OWNER/OPERATORS.

\section{ENDBLOCK G1-FOR ALL SECOND FOLLOW-UP OWNERS WITH COMPLETE DEMOGRAPHIC INFORMATION.}

\section{BLOCK bSectionG2-for all NEW OWNERS}

G1a. (Are/ls) (you/[OWNER B-J]) also a paid employee at [NAME BUSINESS]?

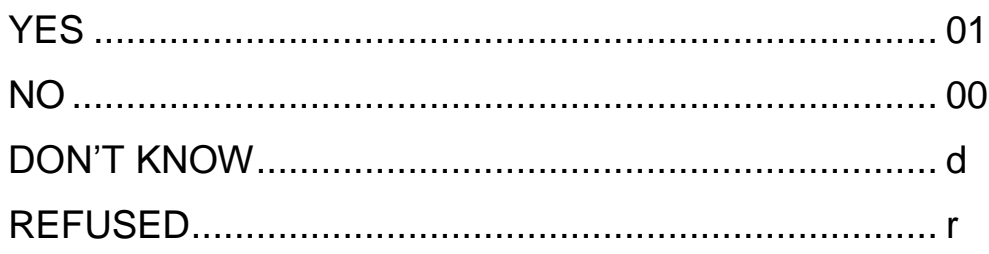

[G1a_Emp_Owner_01_3] THROUGH [G1a_Emp_Owner_11_3]

G1b. During the time [NAME BUSINESS] was in business during 2007, how many hours in an average week did (you [OWNER B-J] spend working at [NAME BUSINESS]?

L_____ HOURS WORKED IN AVERAGE WEEK

DON'T KNOW ....................................................... d

REFUSED ..................................................... $\mathrm{r}$

[G1b1_Hours_Owner_01_3] THROUGH [G1b1_Hours_Owner_11_3]

G1b1. IF DON'T KNOW OR REFUSED, PROBE: Would you say it was ...

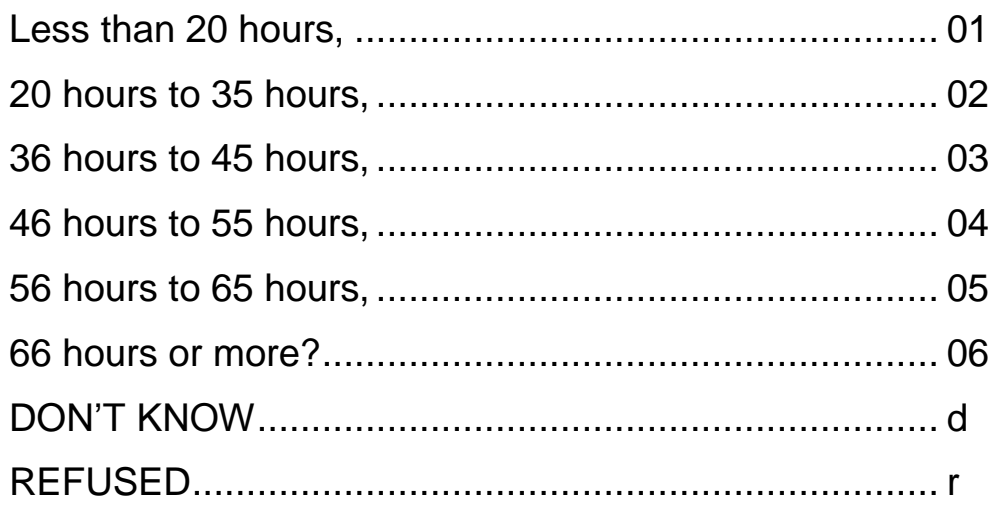

[G1b2_Hours_Ranges_Owner_01_3] THROUGH [G1b2_Hours_Ranges_Owner_11_3] 
G2. How many years of work experience (have/has) (you/[OWNER B-J]) had in this industry-the one in which [NAME BUSINESS] competes?
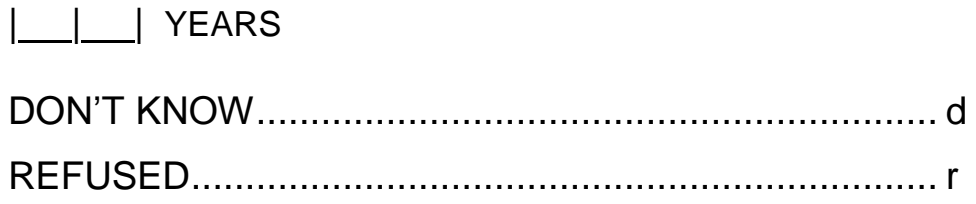

[G2_Work_Exp_Owner_01_3] THROUGH [G2_Work_Exp_Owner_11_3]

G3a. How many other new businesses (have/has) (you/[OWNER B-J]) started besides [NAME BUSINESS]?

L___ NUMBER OF BUSINESSES (ENTER “0” FOR NONE)

DON'T KNOW .................................................. d

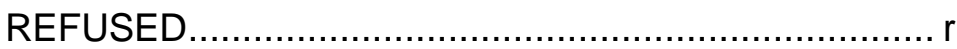

[G3a_Oth_Bus_Owner_01_3] THROUGH [G3a_Oth_Bus_Owner_11_3]

IF ZERO NEW BUSINESSES AT G3a, GO TO G4.

G3b. (Was this/Were any of the) business(es) in the same industry as [NAME BUSINESS]?

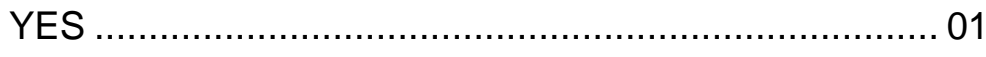

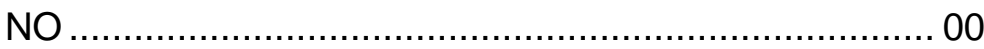

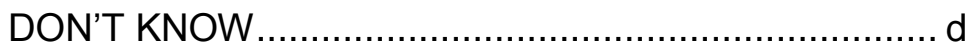

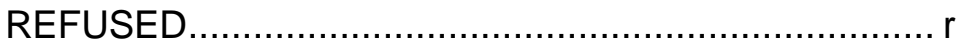

[G3b_Bus_Same_Ind_Owner_01_3] THROUGH [G3b_Bus_Same_Ind_Owner_11_3] 
G4. How old will (you/[OWNER B-J]) be on (your/his/her) next birthday?

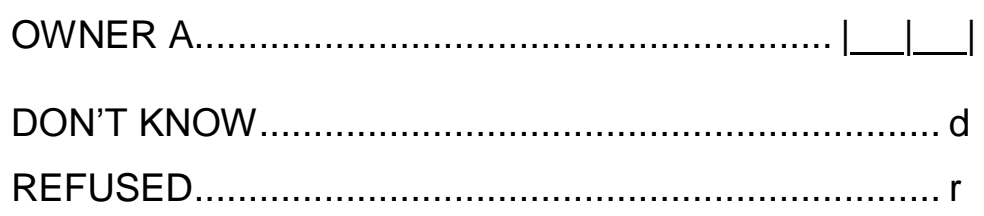

[G4_Age_Owner_01_3] THROUGH [G4_Age_Owner_11_3]

IF DON'T KNOW OR REFUSED, PROBE WITH RANGES: Would you say ...

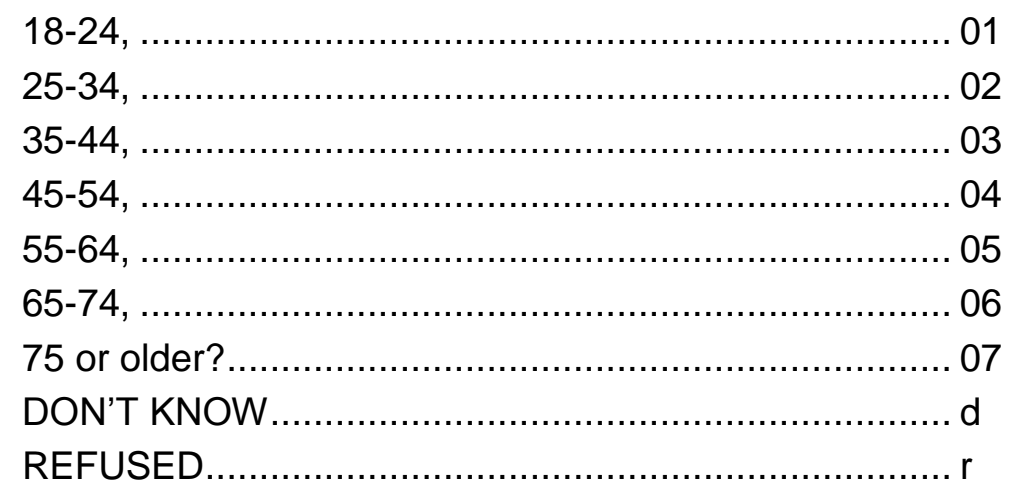

[G4a_Age_Ranges_Owner_01_3] THROUGH [G4a_Age_Ranges_Owner_11_3]

IF G4 IS LESS THAN G2:

Perhaps I made a mistake in recording your answer. (Your/OWNER B-J)'s age is less than (Your/OWNER B-J)'s years of experience.

Now I have a few questions about race and ethnicity.

G5. (Are/ls) (you/[OWNER B-J]) of Hispanic or Latino origin?

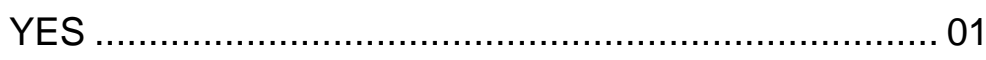

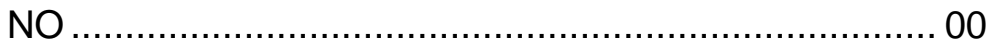

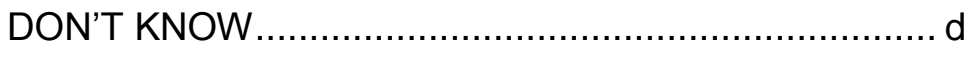

REFUSED .................................................... $\mathrm{r}$

[G5_Hisp_Origin_Owner_01_3] THROUGH [G5_Hisp_Origin_Owner_11_3] 
G6. I am going to read a list of race categories. Please choose one or more that best describes (your/[OWNER B-J])'s race. Are (you [OWNER B-J]) American Indian or Alaska Native, Native Hawaiian or other Pacific Islander, Asian, Black or African American, or White?

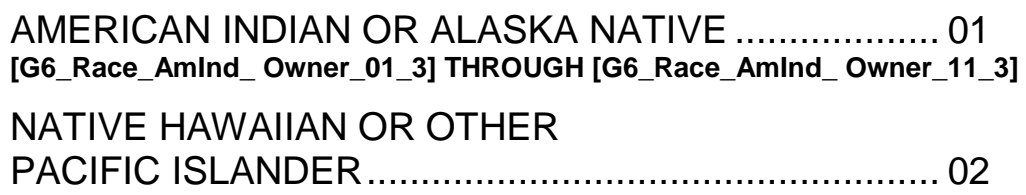

[G6_Race_Asian_Owner_01_3] THROUGH [G6_Race_Asian_Owner_11_3]

BLACK OR AFRICAN AMERICAN ........................... 04

[G6_Race_Black_Owner_01_3] THROUGH [G6_Race_Black_Owner_11_3]

WHITE

[G6_Race_White_Owner_01_3] THROUGH [G6_Race_White_Owner_11_3]

OTHER (SPECIFY) .......................................... 06

[G6_Race_Other_Owner_01_3] THROUGH [G6_Race_Other_Owner_11_3]

[G6_OtherSpecify_Owner_01_3] THROUGH [G6_OtherSpecify_Owner_11_3]

DON'T KNOW.

d

REFUSED. .. r

G7. (Were/Was) (you/[OWNER B-J]) born in the United States?

YES $01 \rightarrow$ GO TO G9

$\mathrm{NO}$ 00

DON'T KNOW. d

REFUSED.

[G7_Native_Born_Owner_01_3] THROUGH [G7_Native_Born_Owner_11_3]

G8. (Are/ls) (you/[OWNER B-J]) a U.S. citizen?

YES 01

NO 00

DON'T KNOW d

REFUSED. .. r

[G8_US_Cit_Owner_01_3] THROUGH [G8_US_Cit_Owner_11_3] 
G9. What is the highest level of education (you/[OWNER B-J]) (have/has) completed so far? Would you say...

Less than 9th grade, 01

Some high school, but no diploma, 02

High school graduate (diploma or equivalent diploma [GED]), 03

Technical, trade or vocational degree, 04

Some college, but no degree, 05

Associate's degree, .06

Bachelor's degree, 07

Some graduate school but no degree, .. 08

Master's degree, or .09

Professional school or doctorate? 10

DON'T KNOW. d

REFUSED.

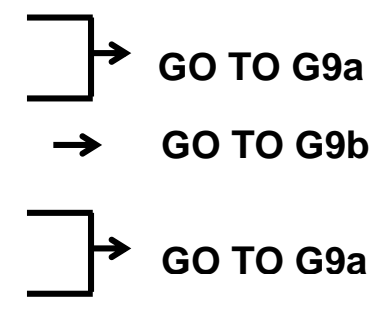

[G9_Education_Owner_01_3] THROUGH [G9_Education_Owner_11_3]

G9a. What was the primary field of study for this degree?

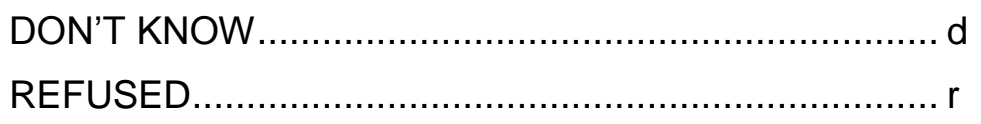

[G9_FieldOfStudy_Resp_3]

[G9_FieldOfStudy_Resp_2nd_3]

G9b. What was the primary field of study for your bachelor's degree?

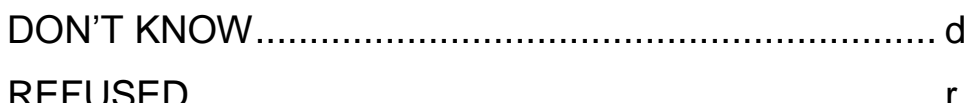

[G9_FieldOfStudy_Resp_3]

[G9_FieldOfStudy_Resp_2nd_3] 


\section{BY OBSERVATION:}

G10a. (Are/ls) (you/[OWNER B-J]) male or female?

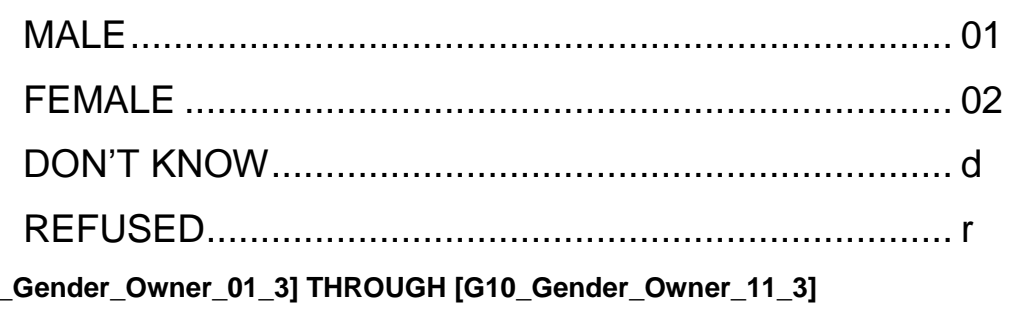

\section{ENDBLOCK bSectionG2}

SECTION G ARRAYED UP TO 10 TIMES, ONCE FOR EACH NEW OWNER.

G11. IF EMAIL ADDRESS COLLECTED AT BASELINE, FIRST OR SECOND FOLLOWUP:

Can we confirm your email address?

INTERVIEWER: READ E-MAIL ADDRESS AND CORRECT AS NECESSARY. IF EMAIL ADDRESS FIELD BLANK FROM BASELINE, FIRST, AND SECOND FOLLOW-UP:

Can you give us an email address where you can be reached?

EMAIL: @

DON'T KNOW d

REFUSED. . r 
G12. IF WEBSITE ADDRESS COLLECTED AT BASELINE, FIRST, OR SECOND FOLLOW-UP:

May we confirm your web site address as:

Web Address:

INTERVIEWER: CORRECT AS NECESSARY $\rightarrow$ GO TO G14

IF WEBSITE ADDRESS BLANK FROM BASELINE, FIRST, AND SECOND FOLLOW-UP:

Does [NAME BUSINESS] have its own website?

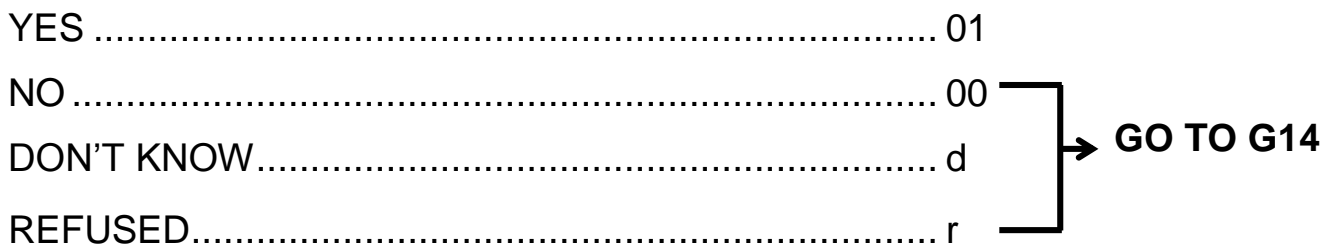

G13. Can you give me the web address?

WEB ADDRESS:

DON'T KNOW. d

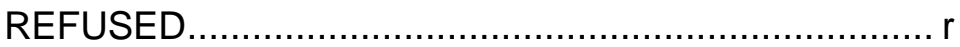

G14. Is the business likely to move to another location in the next 12 months?

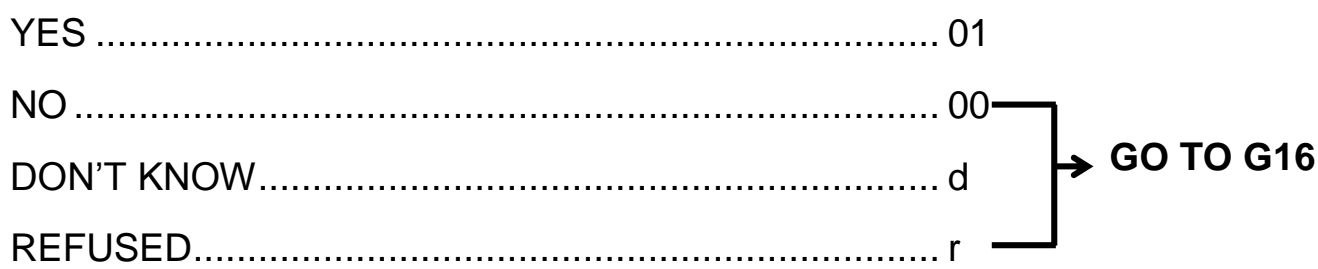

G15. What city and state is the business likely to move to?

CITY:

STATE:

DON'T KNOW d

REFUSED. $r$ 
G16. IF CONTACT INFORMATION COLLECTED AT BASELINE, FIRST, OR SECOND FOLLOW-UP:

Here is the information we have for a contact person. This information will be held in the strictest confidence, and will only be used if we cannot contact you or someone else associated with the business at the current business phone number or address.

INTERVIEWER: PLEASE ASK FOR ANY INFORMATION THAT IS NOT FILLED IN.

NAME:

ADDRESS:

CITY:

STATE:

PHONE:

EMAIL: @

DON'T KNOW.......................................................

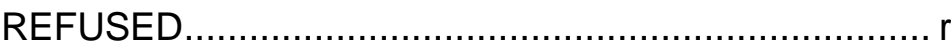

\section{IF CONTACT INFORMATION IS BLANK FROM BASELINE, FIRST, AND SECOND} FOLLOW-UP:

In case we are unable to contact you, can you provide a name and contact information for a person besides yourself who would know how to reach you or someone else associated with [NAME BUSINESS]? All information collected will be held in the strictest confidence, and will only be used if we cannot contact you or someone else associated with the business at the current business phone number or address.

NAME:

ADDRESS:

CITY:

STATE:

PHONE:

EMAIL: @

DON'T KNOW .................................................

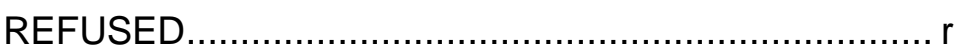

THANK AND TERMINATE 
APPENDIX E

DATA DOCUMENTATION MEMO 

TO: $\quad$ Alicia Robb and E. J. Reedy, Ewing Marion Kauffman Foundation

FROM: $\quad$ David DesRoches and Betsy Santos

DATE: $4 / 6 / 2009$

KFS - 137

SUBJECT: Kauffman Firm Survey (KFS) data documentation for longitudinal data file

This memo provides information about the longitudinal KFS data file, which includes data collected during the Baseline, First Follow-Up, Second Follow-Up, and Third Follow-Up Surveys. This includes information on how item non-response was handled within variables in the data file, as well as a description of variables not documented in the KFS questionnaire. It also documents variables used in constructing the survey weights and all constructed variables. Several of the variables included here were provided with the Dun \& Bradstreet (D\&B) listings of sampled businesses that may provide additional context during analysis. For variables derived directly from the KFS Baseline, First Follow-Up, Second Follow-Up, and Third Follow-Up questionnaires, the annotated versions of these questionnaires serve as the codebooks.

\section{NON-RESPONSE CLEANING STEPS}

All values for "Don't Know" and "Refusal” responses were recoded to blanks (“.”) in all variables.

\section{VARIABLE-SPECIFIC INFORMATION}

Variable names in the longitudinal dataset are similar between the Baseline, First Follow-Up, Second Follow-Up, and Third Follow-Up Surveys. With the exception of MPRID and the credit risk variables, all variables in the data file will have a suffix that corresponds to a round of data collection. Baseline variables contain an "_0" suffix, First Follow-Up variables contain an "_1" suffix, Second Follow-Up variables contain an "_2" suffix, and Third Follow-Up variables contain an "_3" suffix.

Unless indicated, the variables in this memo are listed without a suffix if the variable name is the same across all rounds. 
MEMO TO: Alicia Robb and E. J. Reedy, Ewing Marion Kauffman Foundation

FROM: David DesRoches and Betsy Santos

DATE: $\quad 4 / 6 / 2009$

PAGE: 2

\section{A. Weighting and non-response adjustment variables - Baseline}

VARIABLE

sampleinfo_samplestrata_0

RESP_0

SamplingWeight_0

WGT_INI_0

WGT_PLOCT_0

WGT_FINAL_0

LOCT_0

\section{DEFINITION}

The technology and gender ownership sampling strata MPR used to select the KFS sample.

$101=$ high tech, woman owned

102 = high tech, not woman owned

$201=$ medium tech, woman owned

202 = medium tech, not woman owned

$301=$ non tech, woman owned

$302=$ non tech, not woman owned

The response status of Baseline Survey cases.

$1=$ Complete

21 = Ineligible, out of business

$22=$ Ineligible, does not meet project requirements

3 = Refusal

4 = Unlocatable

Response Indicator - All completes and ineligibles are considered respondents under this measure.

$1=$ Respondent

$0=$ Non-respondent

Initial sampling weight when the sample was drawn

Weight after release adjustment

Weight after location model

Final Baseline weight after non-response model

Location indicator - Indicates whether business was located

1 = Located

$0=$ Unlocated 
MEMO TO: Alicia Robb and E. J. Reedy, Ewing Marion Kauffman Foundation

FROM: David DesRoches and Betsy Santos

DATE: $\quad 4 / 6 / 2009$

PAGE: $\quad 3$

B. Weighting and non-response adjustment variables - First, Second, and Third Follow-Up VARIABLE DEFINITION

Fstatus_1

The response status of First Follow-Up cases.

$1=$ Complete

21 = Ineligible, out of business

$22=$ Ineligible, does not meet project expectations

3 = Refusal

4 = Unlocatable

Resp_1

Response Indicator for First Follow-Up cases - All

completes and ineligibles are considered respondents under this measure.

$1=$ respondents

$0=$ non-respondents

Wgt_Final_1

Final weight after non-response model for First Follow-Up cases.

FSTATUS_f2_2

The response status of Second Follow-Up cases.

$1=$ Complete

21 = Ineligible, out of business

22 = Ineligible, does not meet project expectations

$3=$ Refusal

$4=$ Unlocatable

RESP_f2_2

Response Indicator for Second Follow-Up cases - All

completes and ineligibles are considered respondents under this measure.

$1=$ respondents

$0=$ non-respondents

Wgt_Final_F2_2

Second Follow-Up final weight - Cross-Sectional

Wgt_final_f12_long_2 Second Follow-Up final weight - Longitudinal 
MEMO TO: Alicia Robb and E. J. Reedy, Ewing Marion Kauffman Foundation

FROM: $\quad$ David DesRoches and Betsy Santos

DATE: $\quad 4 / 6 / 2009$

PAGE: $\quad 4$

B. Weighting and non-response adjustment variables - First, Second, and Third Follow-Up (Continued)

VARIABLE DEFINITION

Resp_f12_long_2

Indicates if there is a Second Follow-Up longitudinal weight

$1=$ Yes

$0=$ No

FSTATUS_f2_3

The response status of Third Follow-Up cases.

$1=$ Complete

21 = Ineligible, out of business

$22=$ Ineligible, does not meet project expectations

$3=$ Refusal

$4=$ Unlocatable

RESP_f3_3

Response Indicator for Third Follow-Up cases - All completes and ineligibles are considered respondents under this measure.

$1=$ respondents

$0=$ non-respondents

Wgt_Final_F3_3 Third Follow-Up final weight - Cross-Sectional

Wgt_final_f123_long_3 Third Follow-Up final weight - Longitudinal

Resp_f123_long_3 Indicates if there is a Third Follow-Up longitudinal weight

$1=$ Yes

$0=\mathrm{No}$ 
MEMO TO: Alicia Robb and E. J. Reedy, Ewing Marion Kauffman Foundation

FROM: David DesRoches and Betsy Santos

DATE: $\quad 4 / 6 / 2009$

PAGE: 5

C. Survey Management Variables (continued)

VARIABLE

DEFINITION

MPRID

Final_Status_Code_0
The identification number provided by MPR to each sampled business.

Final Disposition Code for sampled businesses in the Baseline Survey.

$10=$ Telephone Complete

$30=$ Web Complete

Final Disposition Code for sampled businesses in the First Follow-Up Survey.

$10=$ Telephone Complete

$30=$ Web Complete

$200=$ Refusal

$210=$ Refusal by gatekeeper

$220=$ Refusal by other

$330=$ Effort ended/Case retired

401 = Language Barrier (Spanish)

$431=$ Temporarily Stopped Operations During Field Period

$450=$ Business moved out of country

$463=$ No Longer in Business

$465=$ Started Previous to 2004 - The business was engaged in new business activity prior to calendar year 2004. New business activity is defined as applying for an EIN, submitting a Schedule C or C-EZ, paying state unemployment insurance taxes, or making FICA payments $590=$ Unlocatable 
MEMO TO: Alicia Robb and E. J. Reedy, Ewing Marion Kauffman Foundation

FROM: David DesRoches and Betsy Santos

DATE: $\quad 4 / 6 / 2009$

PAGE: 6

\section{Survey Management Variables (continued)}

VARIABLE

DEFINITION

Final_Status_Code_2

Final Disposition Code for sampled businesses in the Second Follow-Up Survey.

$10=$ CATI complete

$30=$ Web Complete

$200=$ Refusal by known respondent

$209=$ Adamant refusal by known respondent

$210=$ Refusal by gatekeeper

$220=$ Refusal by unknown person

$330=$ Effort ended/Case retired

$431=$ Temporarily Stopped Operations During Field Period

$463=$ No Longer in Business

$468=$ Duplicate case

$590=$ Unlocatable

Final_Status_Code_3

Final Disposition Code for sampled businesses in the Third Follow-Up Survey.

$10=$ CATI complete

$30=$ Web Complete

$200=$ Refusal by known respondent

$209=$ Adamant refusal by known respondent

$210=$ Refusal by gatekeeper

$220=$ Refusal by unknown person

$330=$ Effort ended/Case retired

$431=$ Temporarily Stopped Operations During Field Period

$450=$ Business moved out of country

$463=$ No Longer in Business

$590=$ Unlocatable

TotalCalls

Total number of calls made to interviews completed via Computer Assisted Telephone Interviewing (CATI).

SampleInfo_Wave_0

The sample wave number the sample business was included in during the Baseline Survey. 
MEMO TO: Alicia Robb and E. J. Reedy, Ewing Marion Kauffman Foundation

FROM: David DesRoches and Betsy Santos

DATE: $\quad 4 / 6 / 2009$

PAGE: $\quad 7$

\section{Survey Management Variables (continued)}

VARIABLE

SampleInfo_Strata_0

\section{DEFINITION}

The high-tech strata of businesses in the D\&B sample frame were defined by using the SIC codes of businesses listed below:

$1=$ High Tech

28 Chemicals and allied products

35 Industrial machinery and equipment

36 Electrical and electronic equipment

38 Instruments and related products

$2=$ Medium Tech

131 Crude Petroleum and natural gas operations

211 Cigarettes

229 Miscellaneous textile goods

261 Pulp mills

267 Miscellaneous converted paper products

291 Petroleum refining

299 Miscellaneous petroleum and coal products

335 Nonferrous rolling and drawing

348 Ordnance and accessories, not elsewhere classified

371 Motor vehicles and equipment

372 Aircraft and parts

376 Guided missiles, space vehicles, parts

379 Miscellaneous transportation equipment

737 Computer and data processing services

871 Engineering and architectural services

873 Research and testing services

874 Management and public relations

899 Services, not elsewhere classified

$3=$ Not High Tech

Includes all other industries not listed above. 
MEMO TO: Alicia Robb and E. J. Reedy, Ewing Marion Kauffman Foundation

FROM: David DesRoches and Betsy Santos

DATE: $\quad 4 / 6 / 2009$

PAGE: $\quad 8$

\section{Survey Management Variables (continued)}

VARIABLE

SampleInfo_Release_0

SampleInfo_Release_1

SampleInfo_Release_2

SampleInfo_Release_3

InterviewDate

TimeZone

\section{DEFINITION}

The Baseline Survey sample was released in six batches:

$1=1$ st release sent $07 / 29 / 05$

$2=2$ nd release sent $09 / 23 / 05$

$3=3$ rd release sent $11 / 4 / 05$

$4=4$ th release sent $12 / 1 / 05$

$5=5$ th release sent $01 / 11 / 06$

$6=6$ th release sent $02 / 28 / 06$

The First Follow-Up Survey sample was released in four batches:

$1=1$ st release sent $06 / 14 / 06$

$2=2$ nd release sent $07 / 6 / 06$

$3=3$ rd release sent $08 / 07 / 06$

$4=4$ th release sent $08 / 31 / 06$

The Second Follow-Up Survey sample was released in three batches:

$1=1$ st release sent $05 / 17 / 07$

$2=2$ nd release sent $05 / 31 / 07$

$3=3$ rd release sent $06 / 25 / 07$

The Third Follow-Up Survey sample was released in three batches:

$1=1$ st release sent $06 / 24 / 08$

$2=2$ nd release sent $07 / 09 / 08$

$3=3$ rd release sent $07 / 23 / 08$

The date the interview was completed.

The time zone the business is located in:

2 = Hawaiian/Aleutian Time Zone

$3=$ Alaska Time Zone

$4=$ Pacific Time Zone

$5=$ Mountain Time Zone

$6=$ Central Time Zone

7 = Eastern Time Zone 
MEMO TO: Alicia Robb and E. J. Reedy, Ewing Marion Kauffman Foundation

FROM: David DesRoches and Betsy Santos

DATE: $\quad 4 / 6 / 2009$

PAGE: $\quad 9$

\section{Variables provided with D\&B sampling frame}

These variables appear once in the longitudinal file, as they were included in the original D\&B listing and were not updated during the surveys.

VARIABLE

SampleInfo_Sex_0

SampleInfo_Sales_Volume_0

SampleInfo_Sales_Volume_ Code_0

SampleInfo_Employees_

Total_0

SampleInfo_Manufacturing Indica_0

SampleInfo_Legal_Status_0

\section{DEFINITION}

The gender variable for the business principal provided with the D\&B listing.

$1=$ Male

$2=$ Female

Sales volume provided by D\&B for the sampled business.

Code provided by D\&B that helps define the SampleInfo_Sales_Volume variable.

$0=$ SampleInfo_Sales_Volume contains a real value

1 = SampleInfo_Sales_Volume contains the low end of a real range

2 (with an all zero SampleInfo_Sales_Volume) = SampleInfo_Sales_Volume is unknown 2 (with a non-zero SampleInfo_Sales_Volume) $=$ SampleInfo_Sales_Volume is an estimate based on defined norms for this industry and size of business

Total employees provided by D\&B for the sampled business.

Code provided by D\&B indicating whether manufacturing operations occur at this location.

$0=$ Manufacturing is done here

$1=$ No manufacturing done here

Code provided by D\&B indicating the legal status of the establishment.

$000=$ not available

$003=$ corporation

$012=$ partnership of unknown type

$013=$ proprietorship type 
MEMO TO: Alicia Robb and E. J. Reedy, Ewing Marion Kauffman Foundation

FROM: David DesRoches and Betsy Santos

DATE: $\quad 4 / 6 / 2009$

PAGE: $\quad 10$

\section{Variables provided with D\&B sampling frame (continued)}

VARIABLE

SampleInfo_MajorIndustry_ Categ_0

SampleInfo_line_business_0

SampleInfo_SIC_1_0

SampleInfo_SIC_2_0

SampleInfo_SIC_3_0

SampleInfo_SIC_4_0

SampleInfo_SIC_5_0

SampleInfo_SIC_6_0

\section{DEFINITION}

Code provided by D\&B that denotes the major industry category under which a sampled business falls.

$1=$ agriculture

$2=\operatorname{mining}$

$3=$ construction

$4=$ manufacturing

$5=$ transportation, communications, utilities

$6=$ wholesale trade

$7=$ retail trade

$8=$ finance, insurance, real estate

$9=$ services

A brief description of the line of business provided by $D \& B$ for the sampled business based on the SIC code.

The first Standard Industrial Classification (SIC) code provided by D\&B for the sampled business. The SIC code taxonomy assigns a code to businesses and other organizations, classifying and subdividing the activity performed by the establishment at that location.

The second SIC code provided by D\&B for the sampled business.

The third SIC code provided by D\&B for the sampled business.

The fourth SIC code provided by D\&B for the sampled business.

The fifth SIC code provided by D\&B for the sampled business.

The sixth SIC code provided by D\&B for the sampled business. 
MEMO TO: Alicia Robb and E. J. Reedy, Ewing Marion Kauffman Foundation

FROM: David DesRoches and Betsy Santos

DATE: $\quad 4 / 6 / 2009$

PAGE: $\quad 11$

\section{Variables provided with D\&B sampling frame (continued)}

VARIABLE

Subsidiary_Indicator_0

SampleInfo_NAICS_Code_0

SampleInfo_NAICS_Desp_0
DEFINITION

Indicating if this business is a corporation that is more than 50 percent owned by another company according to D\&B:

$0=$ Non subsidiary

$3=$ Subsidiary

The NAICS code provided by D\&B for the sampled business. Refer to NAICS - North American Industry Classification System for additional documentation of this variable.

Descriptions of the NAICS code provided by D\&B for the sampled business. Refer to NAICS - North American Industry Classification System for additional documentation of this variable.

SampleInfo_Woman_owned_0 Code provided by D\&B indicating if the majority of the establishment is owned by a woman:

$\mathrm{Y}=$ Yes, woman owned

$\mathrm{N}=$ Not woman owned

SampleInfo_fips_msa_0
The Federal Information Processing System (FIPS) Metropolitan Statistical Area (MSA) code provided by D\&B for the sampled business. Refer to Current Lists of Metropolitan and Micropolitan Statistical Areas and Definitions for additional documentation of this variable. 
MEMO TO: Alicia Robb and E. J. Reedy, Ewing Marion Kauffman Foundation

FROM: David DesRoches and Betsy Santos

DATE: $\quad 4 / 6 / 2009$

PAGE: $\quad 12$

\section{E. Other Variables}

VARIABLE DEFINITION

TotalOwners

The total number of owners of the business, including owneroperators collected at question $\mathrm{C} 4$, and non-operating equity owners collected at question F3.

F6Check

NAICS_Code

State_final

Zip_Final

msa_final_3

Respondent_1

Respondent_2

Respondent_3

Owner_Active_01_1

Owner_Active_02_1

Owner_Active_03_1

Owner_Active_04_1

Owner_Active_05_1

Owner_Active_06_1

Owner_Active_07_1

Owner_Active_08_1

Owner_Active_09_1

Owner_Active_10_1
The total percentage of ownership accounted for prior to reconciliation. This includes the percentages collected among owner-operators at the question F2 series and among nonoperating equity owners at question F5.

Primary industry of the business confirmed or updated during the surveys. Refer to NAICS - North American Industry Classification System for additional documentation of this variable.

The state abbreviation for the sampled business.

The zip code for the sampled business.

Metropolitan Statistical Area, based on most recent zip code collected or confirmed from the panel businesses. Refer to Current Lists of Metropolitan and Micropolitan Statistical Areas and Definitions for additional documentation of this variable.

Owner who completed the First Follow-Up Survey

Owner who completed the Second Follow-Up Survey

Owner who completed the Third Follow-Up Survey

Active owner(s) 1-10 at time of First Follow-Up Survey 
MEMO TO: Alicia Robb and E. J. Reedy, Ewing Marion Kauffman Foundation

FROM: David DesRoches and Betsy Santos

DATE: $\quad 4 / 6 / 2009$

PAGE: 13

\section{E. Other Variables (continued)}

VARIABLE

Owner_Active_01_2

Owner_Active_02_2

Owner_Active_03_2

Owner_Active_04_2

Owner_Active_05_2

Owner_Active_06_2

Owner_Active_07_2

Owner_Active_08_2

Owner_Active_09_2

Owner_Active_10_2

Owner_Active_01_3

Owner_Active_02_3

Owner_Active_03_3

Owner_Active_04_3

Owner_Active_05_3

Owner_Active_06_3

Owner_Active_07_3

Owner_Active_08_3

Owner_Active_09_3

Owner_Active_10_3

Owner_Active_11_3

G9_FieldOfStudy_Resp_2nd_3 Second majors collected during the Third Follow-Up Survey and coded to a six-digit CIP code. Refer to CIP -

Classification of Instructional Programs for additional documentation of this variable.

G9_FieldOfStudy_CIP_Desc_3 Descriptions of the CIP code assigned to the field of study collected from respondents. Refer to CIP - Classification of Instructional Programs for additional documentation of this variable.

G9_FieldOfStudy2nd_ CIP_Desc_3
Descriptions of the CIP code assigned to the second field of study collected from respondents. Refer to CIP -

Classification of Instructional Programs for additional documentation of this variable. 
MEMO TO: Alicia Robb and E. J. Reedy, Ewing Marion Kauffman Foundation

FROM: $\quad$ David DesRoches and Betsy Santos

DATE: $\quad 4 / 6 / 2009$

PAGE: $\quad 14$

\section{E. Other Variables (continued)}

credrisk04

credrisk05

credrisk06

credrisk07

credrisk08
Credit risk variables categorized as shown below:

\begin{tabular}{ccc}
\hline $\begin{array}{c}\text { Credit Score } \\
\text { Risk Class }\end{array}$ & $\begin{array}{c}\text { Credit Score } \\
\text { Percentile }\end{array}$ & $\begin{array}{c}\text { Commercial } \\
\text { Credit Score }\end{array}$ \\
\hline 1 & $91-100$ & $536-670$ \\
2 & $71-90$ & $493-535$ \\
3 & $31-70$ & $423-492$ \\
4 & $11-30$ & $376-422$ \\
5 & $1-10$ & $101-375$ \\
\hline
\end{tabular}


MEMO TO: Alicia Robb and E. J. Reedy, Ewing Marion Kauffman Foundation

FROM: David DesRoches and Betsy Santos

DATE: $\quad 4 / 6 / 2009$

PAGE: $\quad 15$

\section{CONSTRUCTED VARIABLES}

The data file includes constructed variables for ease of analysis. These fall into several categories, each of which is explained below. Variables using Baseline data are denoted by a "_0" suffix, First Follow-Up variables with the "_1" suffix. Similarly, variables using Second FollowUp data have a "_2" suffix and Third Follow-Up data have a "_3” suffix.

\section{A. Total Intellectual Property Variables}

These variables create a total number of patents, copyrights, or trademarks the businesses possessed at the time of each interview. For each type of intellectual property, the variables were constructed using data from the following questions:

- “Indicator" questions, such as Question D3a (“Does the business have any patents?”)

- "Exact value" measures, such as Question D3b ("How many patents does the business have?")

The construction was specified by the rules provided in the table below.

Intellectual Property Variable Specifications

\begin{tabular}{lc}
\hline Condition & Value of Constructed Variable \\
\hline "Indicator" variable $=0$ & 0 \\
"Exact value" variable $>0$ & Value of "Exact value" variable \\
"Indicator" variable $=$ BLANK & BLANK \\
"Indicator" variable $=1$ and "Continuous" variable = BLANK & BLANK \\
\hline
\end{tabular}

The following variables were created using these specifications:

Total_Patents

Total_Copyrights

Total_Trademarks 
MEMO TO: Alicia Robb and E. J. Reedy, Ewing Marion Kauffman Foundation

FROM: David DesRoches and Betsy Santos

DATE: $\quad 4 / 6 / 2009$

PAGE: $\quad 16$

\section{B. Amount Variables}

These variables were constructed for the specific types of equity, debt, revenue, assets, and liabilities the businesses possessed at the time of each interview. For each type, variables were constructed using data from the following survey questions:

- "Indicator" questions, such as Question F1 ("First, in calendar year 2004, did you put any of your own money into the business in return for an ownership share of the business?")

- "Exact value" measures such as Question F2a ("How much of your own money did you put into the business during calendar year 2004?”)

- "Range" questions asked of respondents who could or would not provide an exact figure

The construction was specified by the rules provided in the table below.

Amount Variable Specifications

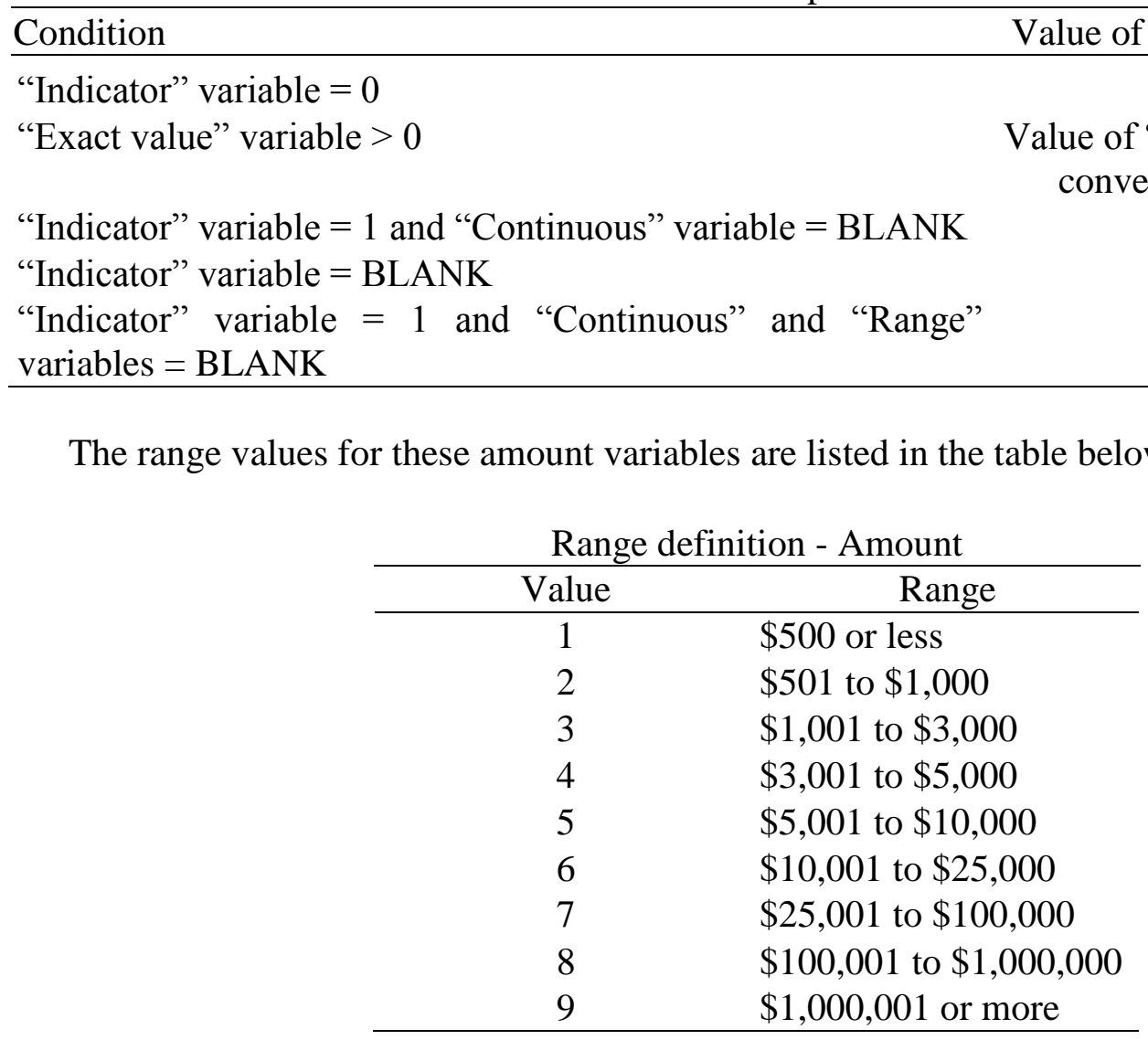

0

uariable 0 converted to range value Range value BLANK BLANK 
MEMO TO: Alicia Robb and E. J. Reedy, Ewing Marion Kauffman Foundation

FROM: David DesRoches and Betsy Santos

DATE: $\quad 4 / 6 / 2009$

PAGE: $\quad 17$

\section{B. Amount Variables (continued)}

This process was used to construct the following variables:

Tot_Equity_Owner_1_R

Tot_Equity_Owner_2_R

Tot_Equity_Owner_3_R

Tot_Equity_Owner_4_R

Tot_Equity_Owner_5_R

Tot_Equity_Owner_6_R

Tot_Equity_Owner_7_R

Tot_Equity_Owner_8_R

Tot_Equity_Owner_9_R

Tot_Equity_Owner_10_R

Tot_Equity_Spouse_R

Tot_Equity_Parents_R

Tot_Equity_Angels_R

Tot_Equity_Companies_R

Tot_Equity_Govt_R

Tot_Equity_Vent_Cap_R

Tot_Equity_Other_R

Tot_Pers_CredCard_Line_Resp_R

Tot_Pers_CredCard_Bal_Resp_R

Tot_Pers_Loan_Bank_Resp_R

Tot_Bus_CredCard_Line_Resp_R

Tot_Bus_CredCard_Bal_Resp_R

Tot_Pers_Loan_Fam_Resp_R

Tot_Pers_Loan_Other_Resp_R

Tot_Pers_Other_Resp_R

Tot_Pers_CredCard_Line_Othrs_R

Tot_Pers_CredCard_Bal_Others_R

Tot_Pers_Loan_Bank_Others_R

Tot_Bus_CredCard_Line_Others_R

Tot_Bus_CredCard_Bal_Others_R

Tot_PersLoan_Fam_OtherOwners_R

Tot_Pers_Loan_Other_Owners_R

Tot_Pers_Other_Other_Owners_R

Tot_CredCard_Line_Bus_R

Tot_CredCard_Bal_Bus_R

Tot_Loan_Bank_Bus_R

Tot_Cred_Line_Bus_Line_R

Tot_Cred_Line_Bus_Bal_R

Tot_Loan_NonBank_Bus_R 
MEMO TO: Alicia Robb and E. J. Reedy, Ewing Marion Kauffman Foundation

FROM: David DesRoches and Betsy Santos

DATE: $\quad 4 / 6 / 2009$

PAGE: $\quad 18$

\section{B. Amount Variables (continued)}

Tot_Loan_Fam_Bus_R

Tot_Loan_Owner_Bus_R

Tot_Loan_Emp_Bus_R

Tot_Loan_Govt_Bus_R

Tot_Loan_Other_Bus_R

Tot_Loan_Other_Ind_R

Tot_Bus_Debt_Other_R

Tot_Trade_Finan_R

Tot_Asset_Cash_R

Tot_Asset_Acct_Rec_R

Tot_Asset_Inv_R

Tot_Asset_Equip_R

Tot_Asset_LandBuild_R

Tot_Asset_Veh_R

Tot_Asset_Other_Bus_Prop_R

Tot_Asset_Other_R

Tot_Liab_Acct_Pay_R

Tot_Liab_Pension_R

Tot_Liab_Other_R

Tot_Revenue_R

Tot_Loss_R

Tot_Profit_R

The following constructed variables are specific to the First, Second, and Third Follow-Up Surveys. The First Follow-Up variables with the "_1" suffix are shown below. The Second Follow-Up and Third Follow-Up variables are denoted by a "_2" suffix and "_3" suffix (respectively) instead of the "_1" suffix.

Tot_Equity_AllYrs_Owner_01_R_1

Tot_Equity_AllYrs_Owner_02_R_1

Tot_Equity_AllYrs_Owner_03_R_1

Tot_Equity_AllYrs_Owner_04_R_1

Tot_Equity_AllYrs_Owner_05_R_1

Tot_Equity_AllYrs_Owner_06_R_1

Tot_Equity_AllYrs_Owner_07_R_1

Tot_Equity_AllYrs_Owner_08_R_1

Tot_Equity_AllYrs_Owner_09_R_1

Tot_Equity_AllYrs_Owner_10_R_1

Tot_Equity_Spouse_AllYrs_R_1

Tot_Equity_Parents_AllYrs_R_1 
MEMO TO: Alicia Robb and E. J. Reedy, Ewing Marion Kauffman Foundation

FROM: David DesRoches and Betsy Santos

DATE: $\quad$ 4/6/2009

PAGE: $\quad 19$

\section{B. Amount Variables (continued)}

Tot_Equity_Angels_AllYrs_R_1

Tot_Equity_Comp_AllYrs_R_1

Tot_Equity_Govt_AllYrs_R_1

Tot_Equity_Vent_Cap_AllYrs_R_1

Tot_Equity_Other_AllYrs_R_1

Tot_Pers_Loan_Bank_Owed_Resp_R_1

Tot_Pers_Loan_Fam_Owed_Resp_R_1

Tot_PersLoan_Other_Owed_Resp_R_1

Tot_Pers_Other_Owed_Resp_R_1

Tot_PersLoan_Bank_Owed_Othrs_R_1

Tot_PersLoan_Fam_Owed_Othrs_R_1

Tot_PersLoan_Othr_Owed_Othrs_R_1

Tot_Pers_Other_Owed_Others_R_1

Tot_Bus_Loans_Bank_Owed_R_1

Tot_Bus_Loans_Nonbank_Owed_R_1

Tot_Bus_Loans_Fam_Owed_R_1

Tot_Bus_Loans_Owner_Owed_R_1

Tot_Bus_Loans_Emp_Owed_R_1

Tot_Bus_Loans_Govt_Owed_R_1

Tot_Bus_Loans_OtherBus_Owed_R_1

Tot_Bus_Loans_OtherInd_Owed_R_1

Tot_Bus_Loans_Other_Owed_R_1

The constructed variables below were named according to the reference year mentioned in the indicator question and therefore differ across the rounds. Data about business funds being withdrawn for personal use were not collected during the Baseline Survey. The First FollowUp Survey collected data about the incidence and level of this activity occurring in calendar years 2004 and 2005, the Second Follow-Up Survey collected data about 2006 and Third Follow-Up about 2007.

Tot_Personal_Use_2004_R_1

Tot_Personal_Use_2005_R_1

Tot_Personal_Use_2006_R_2

Tot_Personal_Use_2007_R_3

The following constructed variables are specific to the Third Follow-Up Survey only.

Tot_Res_Dev_R_3

Tot_Equity_AllYrs_Owner_11_R_3 
MEMO TO: Alicia Robb and E. J. Reedy, Ewing Marion Kauffman Foundation

FROM: David DesRoches and Betsy Santos

DATE: $\quad 4 / 6 / 2009$

PAGE: $\quad 20$

\section{Expense Variables}

The variables created for total expenses, wage expenses, and total profit or loss are similar to those detailed in Section III.B above, but at these questions there was no "Indicator" question. The variables were constructed using data from the following types of survey questions:

- "Exact value" measures such as Question F17 ("How much, if any, did the business pay in expenses during calendar year 2007?"),

- "Range" questions asked of respondents who could or would not provide an exact figure at the "Exact value" variable.

The construction was specified by the rules provided in the table below using the series of equity questions as an example.

Amount Variable Specifications

\begin{tabular}{lc}
\hline \multicolumn{1}{c}{ Condition } & Value of Constructed Variable \\
\hline "Exact value" variable $=0$ & 0 \\
"Exact value" variable $>0$ & Value of "Exact value" variable converted \\
& to range value \\
"Exact value" variable $=$ BLANK & Range value \\
"Exact value" and "Range" variables = BLANK & BLANK \\
\hline
\end{tabular}

These variables used the same amount range values as those described above in III.B. The following variables were created using these specifications:

Tot_Expenses_R

Tot_Wages_R 
MEMO TO: Alicia Robb and E. J. Reedy, Ewing Marion Kauffman Foundation

FROM: $\quad$ David DesRoches and Betsy Santos

DATE: $\quad 4 / 6 / 2009$

PAGE: $\quad 21$

\section{Total Amount Variables}

These variables create total amounts of equity, debt, revenue, assets, and liabilities the businesses reported at each interview, combining the values reported for each individual type. For example, the variable "Tot_Equity_Owner_Operators_R" sums all values in the owner-operator variables (Tot_Equity_Owner_1_R through Tot_Equity_Owner_10_R, Tot_Equity_Owner_11_R_3), which is then translated into the amount range values described above in III.B and III.C. The variables created in this way are listed below along with the component variables.

Total Amount Variables

\begin{tabular}{|c|c|}
\hline Variable Name & Variables used to create \\
\hline Tot_Equity_Owner_Operators_R & $\begin{array}{l}\text { Tot_Equity_Owner_1_R, Tot_Equity_Owner_2_R, } \\
\text { Tot_Equity_Owner_3_R, Tot_Equity_Owner_4_R, } \\
\text { Tot_Equity_Owner_5_R, Tot_Equity_Owner_6_R, } \\
\text { Tot_Equity_Owner_7_R, Tot_Equity_Owner_8_R, } \\
\text { Tot_Equity_Owner_9_R, Tot_Equity_Owner_10_R } \\
\text { Tot_Equity_Owner_11_R_3* }\end{array}$ \\
\hline Tot_Equity_OwnerOper_AllYrs_R_1** & $\begin{array}{l}\text { Tot_Equity_AllYrs_Owner_01_R_1, Tot_Equity_AllYrs_Owner_02_R_1 } \\
\text { Tot_Equity_AllYrs_Owner_03_R_1, Tot_Equity_AllYrs_Owner_04_R_1 } \\
\text { Tot_Equity_AllYrs_Owner_05_R_1, Tot_Equity_AllYrs_Owner_06_R_1 } \\
\text { Tot_Equity_AllYrs_Owner_07_R_1, Tot_Equity_AllYrs_Owner_08_R_1 } \\
\text { Tot_Equity_AllYrs_Owner_09_R_1, Tot_Equity_AllYrs_Owner_10_R_1 } \\
\text { Tot_Equity_AllYrs_Owner_11_R_3* }\end{array}$ \\
\hline Tot_Equity_NonOwnerOperators_R & $\begin{array}{l}\text { Tot_Equity_Spouse_R, Tot_Equity_Parents_R, } \\
\text { Tot_Equity_Angels_R, Tot_Equity_Companies_R, } \\
\text { Tot_Equity_Govt_R, Tot_Equity_Vent_Cap_R, } \\
\text { Tot_Equity_Other_R }\end{array}$ \\
\hline Tot_Equity_NonOwnerOp_AllYrs_R_1** & $\begin{array}{l}\text { Tot_Equity_Spouse_AllYrs_R_1, Tot_Equity_Parents_AllYrs_R_1 } \\
\text { Tot_Equity_Angels_AllYrs_R_1, Tot_Equity_Comp_AllYrs_R_1 } \\
\text { Tot_Equity_Govt_AllYrs_R_1, Tot_Equity_Vent_Cap_AllYrs_R_1 } \\
\text { Tot_Equity_Other_AllYrs_R_1 }\end{array}$ \\
\hline Tot_Equity_R & $\begin{array}{l}\text { Tot_Equity_Owner_Operators_R, } \\
\text { Tot_Equity_NonOwnerOperators_R }\end{array}$ \\
\hline Tot_Pers_Debt_Resp_R & $\begin{array}{l}\text { Tot_Pers_CredCard_Bal_R, Tot_Pers_Loan_Resp_R, } \\
\text { Tot_Bus_CredCard_Bal_Resp_R, Tot_Pers_Loan_Fam_Resp_R, } \\
\text { Tot_Pers_Loan_Other_Resp_R, Tot_Pers_Other_Resp_R }\end{array}$ \\
\hline
\end{tabular}

* Third Follow-Up data only.

** First, Second, and Third Follow-Up Up data only. Variable shown for First Follow-Up. Second and Third Follow-Up variables will have a “_2” and "_3" suffix respectively. 
MEMO TO: Alicia Robb and E. J. Reedy, Ewing Marion Kauffman Foundation

FROM: $\quad$ David DesRoches and Betsy Santos

DATE: $\quad 4 / 6 / 2009$

PAGE: 22

\section{Total Amount Variables (continued)}

Total Amount Variables

\begin{tabular}{|c|c|}
\hline Variable Name & Variables used to create \\
\hline Tot_Pers_Debt_Owed_Resp_R_1** & $\begin{array}{l}\text { Tot_Pers_CredCard_Bal_Resp_R } \\
\text { Tot_Bus_CredCard_Bal_Resp_R } \\
\text { Tot_Pers_Loan_Bank_Owed_Resp_R_1 } \\
\text { Tot_Pers_Loan_Fam_Owed_Resp_R_1 } \\
\text { Tot_PersLoan_Other_Owed_Resp_R_1 } \\
\text { Tot_Pers_Other_Owed_Resp_R_1 }\end{array}$ \\
\hline Tot_Pers_Debt_Other_Owners_R & $\begin{array}{l}\text { Tot_Pers_CredCard_Bal_Others_R, Tot_Pers_Loan_Bank_Others_R, } \\
\text { Tot_Bus_CredCard_Bal_Others_R, } \\
\text { Tot_PersLoan_Fam_OtherOwners_R, } \\
\text { Tot_Pers_Loan_Other_Owners_R, } \\
\text { Tot_Pers_Other_Other_Owners_R }\end{array}$ \\
\hline Tot_Pers_Debt_Owed_OthrOwnrs_R_1** & $\begin{array}{l}\text { Tot_Pers_CredCard_Bal_Others_R_1 } \\
\text { Tot_Bus_CredCard_Bal_Others_R_1 } \\
\text { Tot_PersLoan_Bank_Owed_Othrs_R_1 } \\
\text { Tot_PersLoan_Fam_Owed_Othrs_R_1 } \\
\text { Tot_PersLoan_Othr_Owed_Othrs_R_1 } \\
\text { Tot_Pers_Other_Owed_Others_R_1 }\end{array}$ \\
\hline Tot_Debt_Owner_Operators_R & Tot_Pers_Debt_Resp_R, Tot_Debt_Other_Owners_R \\
\hline Tot_Debt_Bus_R & $\begin{array}{l}\text { Tot_CredCard_Bal_Bus_R, Tot_Loan_Bank_Bus_R, } \\
\text { Tot_Cred_Line_Bus_Bal_R, Tot_Loan_NonBank_Bus_R, } \\
\text { Tot_Loan_Fam_Bus_R, Tot_Loan_Owner_Bus_R, } \\
\text { Tot_Loan_Emp_Bus_R, Tot_Loan_Govt_Bus_R, } \\
\text { Tot_Loan_Other_Bus_R, Tot_Loan_Other_Ind_R, } \\
\text { Tot_Bus_Debt_Other_R }\end{array}$ \\
\hline Tot_Bus_Debt_Owed_R_1** & $\begin{array}{l}\text { Tot_Bus_Loans_Bank_Owed_R_1 } \\
\text { Tot_Bus_Loans_Nonbank_Owed_R_1 } \\
\text { Tot_Bus_Loans_Fam_Owed_R_1 } \\
\text { Tot_Bus_Loans_Owner_Owed_R_1 } \\
\text { Tot_Bus_Loans_Emp_Owed_R_1 } \\
\text { Tot_Bus_Loans_Govt_Owed_R_1 } \\
\text { Tot_Bus_Loans_OtherBus_Owed_R_1 } \\
\text { Tot_Bus_Loans_OtherInd_Owed_R_1 } \\
\text { Tot_Bus_Loans_Other_Owed_R_1 }\end{array}$ \\
\hline Tot_Debt_R & Tot_Debt_Owner_Operators_R, Tot_Debt_Bus_R \\
\hline Tot_Assets_R & $\begin{array}{l}\text { Tot_Asset_Cash_R, Tot_Asset_Acct_Rec_R, Tot_Asset_Inv_R, } \\
\text { Tot_Asset_Equip_R, Tot_Asset_LandBuild_R, Tot_Asset_Veh_R, } \\
\text { Tot_Asset_Other_Bus_Prop_R, Tot_Asset_Other_R }\end{array}$ \\
\hline Tot_Liab_R & Tot_Liab_Acct_Pay_R, Tot_Liab_Pension_R, Tot_Liab_Other_R \\
\hline
\end{tabular}
** First, Second, and Third Follow-Up Up data only. Variables shown for First Follow-Up. Second and Third Follow-Up variables will have a “_2” and "_3" suffix respectively. 
MEMO TO: Alicia Robb and E. J. Reedy, Ewing Marion Kauffman Foundation

FROM: $\quad$ David DesRoches and Betsy Santos

DATE: $\quad 4 / 6 / 2009$

PAGE: $\quad 23$

\section{E. Variables constructed using the "Quarter" range}

These variables were constructed for questions (in the Baseline Survey only) collecting the month in 2004 businesses first paid unemployment insurance or FICA taxes. The components of the constructed variables include:

- Exact values such as Question B9 ("For what month in 2004 were the first unemployment taxes paid"),

- "Range" questions asked of respondents who could or would not provide an exact figure value - the response choices were "The 1st quarter of 2004 (January to March)," "The 2nd quarter of 2004 (April to June)," etc.

\begin{tabular}{cc}
\multicolumn{2}{c}{ Range definition - Quarter } \\
\hline Value & Range (months) \\
\hline 1 & $1-3$ \\
2 & $4-6$ \\
3 & $7-9$ \\
4 & $10-12$ \\
\hline
\end{tabular}

This process was used to construct the following variables:

UI_Month_R

FICA_Month_R 
MEMO TO: Alicia Robb and E. J. Reedy, Ewing Marion Kauffman Foundation

FROM: $\quad$ David DesRoches and Betsy Santos

DATE: $\quad 4 / 6 / 2009$

PAGE: $\quad 24$

\section{F. Variables constructed using the "Hours" range}

These variables were constructed for the question collecting the average number of hours per week owner-operators worked at the business. The components of the constructed variables include:

- Exact values collected at Question G1b ("During the time [NAME BUSINESS] was in business during 2004, how many hours in an average week did (you/[owner B-J]) spend working at [NAME BUSINESS]?”)

- "Range" questions asked of respondents who could or would not provide an exact value. The range definitions are provided below.

\begin{tabular}{cc}
\multicolumn{2}{c}{ Range definition - Hours } \\
\hline Value & Range \\
\hline 1 & $1-19$ \\
2 & $20-35$ \\
3 & $36-45$ \\
4 & $46-55$ \\
5 & $56-65$ \\
6 & $66+$ \\
\hline
\end{tabular}

This process was used to construct the following variables:

Total_Hours_Owner_01_R

Total_Hours_Owner_02_R

Total_Hours_Owner_03_R

Total_Hours_Owner_04_R

Total_Hours_Owner_05_R

Total_Hours_Owner_06_R

Total_Hours_Owner_07_R

Total_Hours_Owner_08_R

Total_Hours_Owner_09_R

Total_Hours_Owner_10_R

Total_Hours_Owner_11_R_3*

* Third Follow-Up data only. 
MEMO TO: Alicia Robb and E. J. Reedy, Ewing Marion Kauffman Foundation

FROM: $\quad$ David DesRoches and Betsy Santos

DATE: $\quad 4 / 6 / 2009$

PAGE: 25

\section{G. Variables constructed using the "Age" range}

These variables were constructed for the question collecting the ages of owner-operators of the business. The components of the constructed variables include:

- Exact values collected at Question G4 ("How old will (you/[OWNER B-J]) be on (your/his/her) next birthday?")

- "Range" questions asked of respondents who could or would not provide an exact value. The range definitions are provided below.

\begin{tabular}{cc}
\multicolumn{2}{c}{ Range definition - Age } \\
\hline Value & Range \\
\hline 1 & $18-24$ \\
2 & $25-34$ \\
3 & $35-44$ \\
4 & $45-54$ \\
5 & $55-64$ \\
6 & $65-74$ \\
7 & $75+$ \\
\hline
\end{tabular}

This process was used to construct the following variables:

Age_Owner_01_R

Age_Owner_02_R

Age_Owner_03_R

Age_Owner_04_R

Age_Owner_05_R

Age_Owner_06_R

Age_Owner_07_R

Age_Owner_08_R

Age_Owner_09_R

Age_Owner_10_R

Age_Owner_11_R_3*

* Third Follow-Up data only. 